OECD Education Working Papers No. 130

\section{How teachers teach and students learn:}

Successful strategies for school
Alfonso Echazarra, Daniel Salinas, Ildefonso Méndez, Vanessa Denis, Giannina Rech 
Organisation de Coopération et de Développement Économiques

Organisation for Economic Co-operation and Development

17-Mar-2016

DIRECTORATE FOR EDUCATION AND SKILLS

English text only

HOW TEACHERS TEACH AND STUDENTS LEARN: SUCCESSFUL STRATEGIES FOR SCHOOL

OECD Education Working Paper No. 130

By Alfonso Echazarra, Daniel Salinas, Ildefonso Méndez, Vanessa Denis and Giannina Rech

This working paper has been authorised by Andreas Schleicher, Director of the Directorate for Education and Skills, OECD.

Alfonso Echazarra, Directorate for Education and Skills, OECD

(Alfonso.ECHAZARRA@ @ecd.org)

\section{JT03392165}

Complete document available on OLIS in its original format

This document and any map included herein are without prejudice to the status of or sovereignty over any territory, to the delimitation of international frontiers and boundaries and to the name of any territory, city or area. 


\section{OECD EDUCATION WORKING PAPERS SERIES}

OECD Working Papers should not be reported as representing the official views of the OECD or of its member countries. The opinions expressed and arguments employed herein are those of the author(s).

Working Papers describe preliminary results or research in progress by the author(s) and are published to stimulate discussion on a broad range of issues on which the OECD works. Comments on Working Papers are welcome, and may be sent to the Directorate for Education and Skills, OECD, 2 rue André-Pascal, 75775 Paris Cedex 16, France.

This document and any map included herein are without prejudice to the status of or sovereignty over any territory, to the delimitation of international frontiers and boundaries and to the name of any territory, city or area.

The statistical data for Israel are supplied by and under the responsibility of the relevant Israeli authorities. The use of such data by the OECD is without prejudice to the status of the Golan Heights, East Jerusalem and Israeli settlements in the West Bank under the terms of international law.

You can copy, download or print OECD content for your own use, and you can include excerpts from OECD publications, databases and multimedia products in your own documents, presentations, blogs, websites and teaching materials, provided that suitable acknowledgement of OECD as source and copyright owner is given. All requests for public or commercial use and translation rights should be submitted to rights@oecd.org.

Comment on the series is welcome, and should be sent to edu.contact@oecd.org.

This working paper has been authorised by Andreas Schleicher, Director of the Directorate for Education and Skills, OECD.

www.oecd.org/edu/workingpapers

Copyright $\odot$ OECD 2016 


\section{ACKNOWLEDGEMENTS}

The authors would like to thank Andreas Schleicher, Montserrat Gomendio, Yuri Belfali, Miyako Ikeda, Pablo Fraser, Noémie Le Donné, Mario Piacentini, Francesco Avvisati, Pablo Zoido, and the representatives of Australia, France, Japan, Peru, Singapore, Sweden and the European Commission for valuable feedback on earlier drafts of this paper.

This paper was prepared by Alfonso Echazarra, Daniel Salinas, Vanessa Denis and Giannina Rech from the OECD Directorate for Education and Skills, and Ildefonso Méndez from the University of Murcia, and edited by Marilyn Achiron. Statistical, editorial and administrative support was provided by Hélène Guillou, Claire Chetcuti, Judit Pàl and Camilla Lorentzen. 


\begin{abstract}
This paper examines how particular teaching and learning strategies are related to student performance on specific PISA test questions, particularly mathematics questions. The report compares teacher-directed instruction and memorisation learning strategies, at the traditional ends of the teaching and learning spectrums, and student-oriented instruction and elaboration learning strategies, at the opposite ends. Other teaching strategies, such as formative assessment and cognitive activation, and learning approaches, such as control strategies, are also analysed. Our analyses suggest that to perform at the top, students cannot rely on memory alone; they need to approach mathematics strategically and creatively to succeed in the most complex problems. There is also some evidence that most teaching strategies have a role to play in the classroom. To varying degrees, students need to learn from teachers, be informed about their progress and work independently and collaboratively; above all, they need to be constantly challenged.
\end{abstract}

\title{
RÉSUMÉ
}

Ce document examine le lien entre certaines stratégies d'enseignement et d'apprentissage, et la performance des élèves dans certains items de l'évaluation PISA, en particulier en mathématiques. Il compare d'un côté (traditionnel), les stratégies d'instruction dirigée par l'enseignant et d'apprentissage par mémorisation, et de l'autre (à l'autre extrémité du spectre), les stratégies d'instruction centrée sur l'élève et d'apprentissage par élaboration. D'autres stratégies d'enseignement, telles que l'évaluation formative et l'activation cognitive, et approches de l'apprentissage, telles que les stratégies de contrôle, sont également examinées. Nos analyses semblent indiquer que pour être parmi les plus performants, les élèves ne peuvent pas compter uniquement sur leurs capacités de mémorisation ; pour réussir à résoudre les problèmes les plus complexes, ils doivent avoir une approche stratégique et créative des mathématiques. En outre, certains résultats indiquent que la plupart des stratégies d'enseignement ont un rôle à jouer en classe. À des degrés divers, les élèves doivent apprendre de leurs enseignants, être informés de leurs progrès et travailler seuls ou en groupe ; mais avant tout, ils doivent se sentir stimulés en permanence. 


\section{TABLE OF CONTENTS}

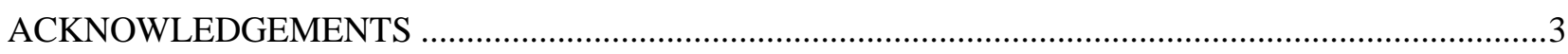

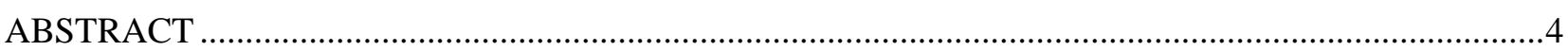

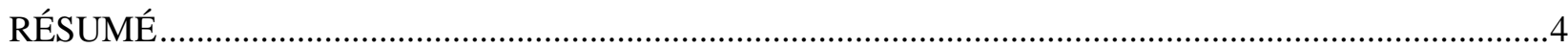

CHAPTER 1. TEACHING, LEARNING AND TRANSFORMING CLASSROOMS …...........................7

Definitions and relevance of teaching and learning strategies .........................................................11

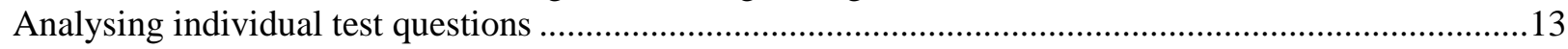

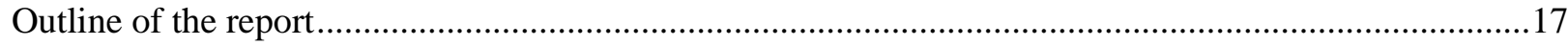

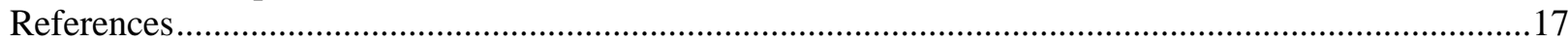

CHAPTER 2. UNDERSTANDING PISA MATHEMATICS ITEMS .....................................................19

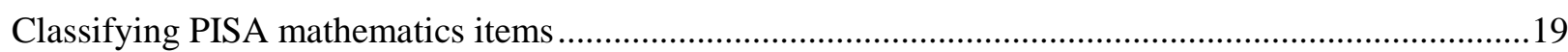

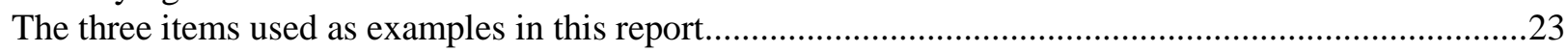

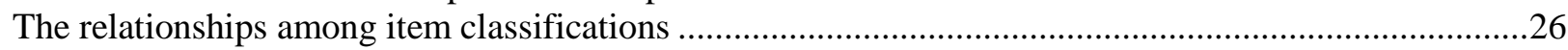

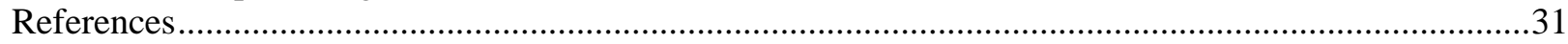

CHAPTER 3. TEACHING STRATEGIES AND BELIEFS, AND STUDENT PERFORMANCE.............32

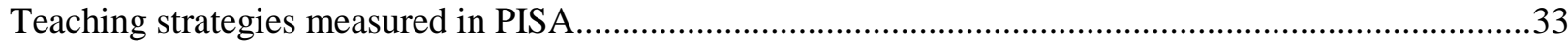

The use of teaching strategies in PISA-participating countries and economies ......................................37

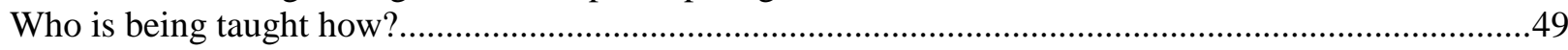

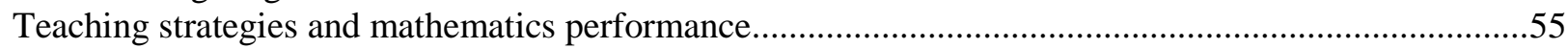

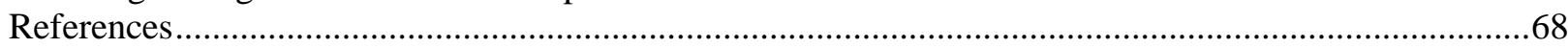

CHAPTER 4. LEARNING WITH UNDERSTANDING: APPROACHES TO MATHEMATICS

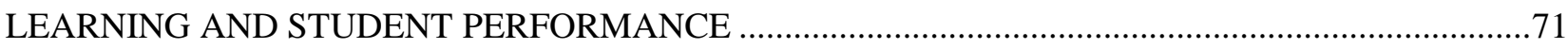

What we know about the effectiveness of learning strategies ................................................................72

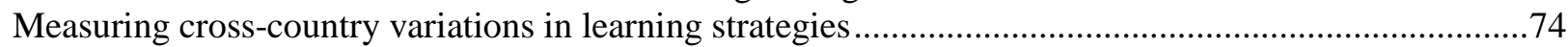

Creating profiles of students who use memorisation, elaboration and control strategies .........................78

The use of learning strategies and success in solving PISA mathematics problems ...............................83

Learning strategies and success rates across all PISA mathematics items ..............................................86

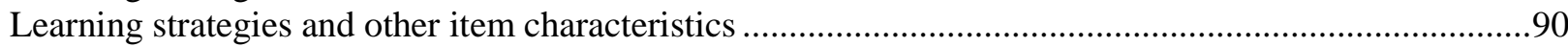

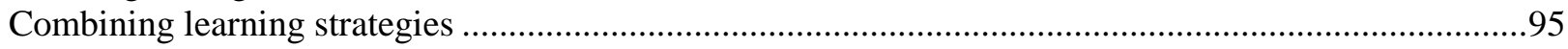

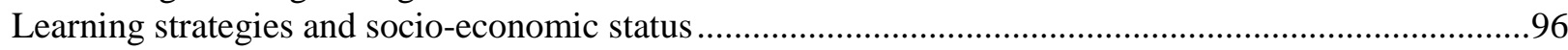

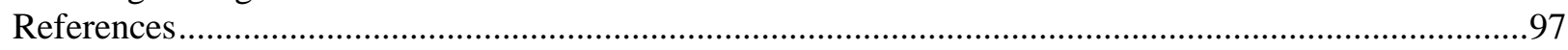

CHAPTER 5. WHAT WE HAVE LEARNED: SUMMARY OF FINDINGS .........................................101

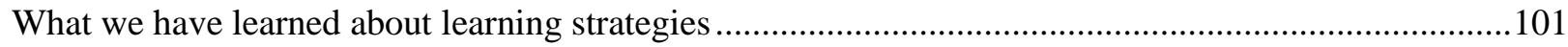

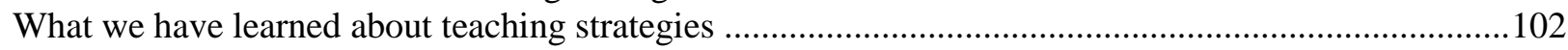

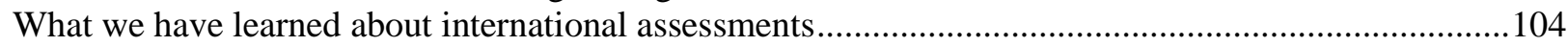

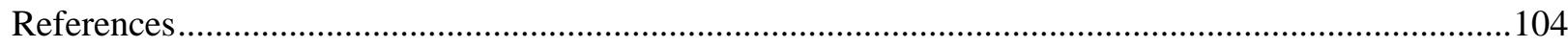

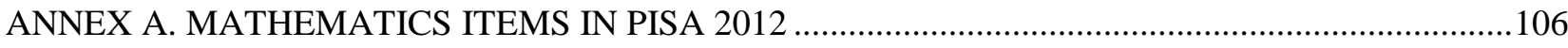

ANNEX B. EXPLAINING CROSS-SUBJECT ANALYSIS WITH STUDENT FIXED-EFFECTS ........110 


\section{Boxes}

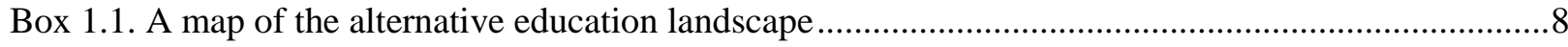

Box 1.2. Teaching and learning strategies for excellence in Singapore ….............................................11

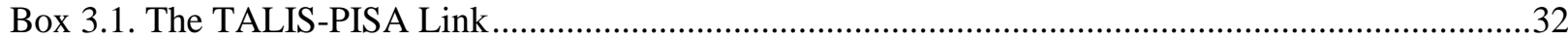

Box 3.2. How PISA and TALIS measure teaching strategies and beliefs .............................................35

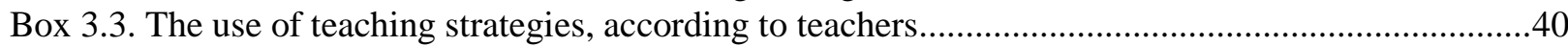

Box 3.4. Understanding logistic regression and interpreting odds ratio ..............................................60

Box 3.5. Self-reported teaching strategies and beliefs in TALIS 2013, and student performance in

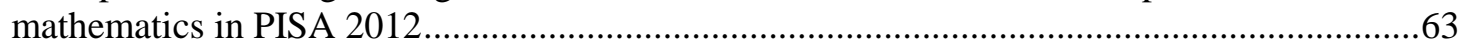

Box 3.6. A cross-subject analysis of teaching strategies and beliefs, and student performance using

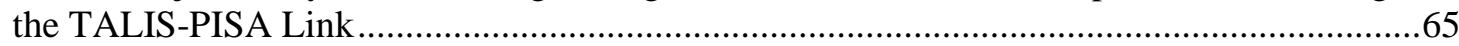

Box 4.1. Learning strategies in the PISA student questionnaire ........................................................... 


\section{CHAPTER 1. TEACHING, LEARNING AND TRANSFORMING CLASSROOMS}

The world is changing in fundamental ways. The Internet is connecting people around the world as never before; faster and cheaper transport is making it easier for people and goods to move around; increasing migration is giving rise to more diverse societies; and populations in OECD countries are ageing, creating pressures on labour productivity. These social, demographic and economic transformations are changing the demand for skills: routine cognitive and craft skills are losing ground to interpersonal, information-processing and other higher-order skills (OECD, 2013a). At the same time, many jobs, particularly low-skilled ones, are at risk of becoming computerised in the near future (Frey and Osborne, 2013).

More than ever before, living and working in the 21st century requires the "four Cs" - creativity, critical thinking, communication and collaboration - but also digital literacy, proactivity, adaptability and open-mindedness. The question is whether schools today can foster these creative and social skills so that students are adequately equipped to meet these challenges. Many believe schools have changed too little since the 19th century to prepare students for the 21 st.

The traditional classroom is often depicted as four walls where the teacher and textbooks are the only providers of information and students are passive sponges, absorbing what they read and are told, memorising the facts, rules and procedures from a fragmented curriculum. The modern classroom, in contrast, is presented as an open space where the teacher provides opportunities to discover, using a taskbased approach, an interdisciplinary curriculum that is relevant to the real world.

Given these stereotypical perceptions, this report examines how particular teaching and learning strategies - most of which can be placed along a traditional-modern scale (Figure 1.1) - are related to student performance on specific PISA (Programme for International Student Assessment) test questions, particularly mathematics questions. The report compares teacher-directed instruction and memorisation learning strategies, at the traditional ends of the teaching and learning spectrums, and student-oriented instruction and elaboration learning strategies, at the opposite ends. While the report recognises that a global shift towards less-traditional approaches to both teaching and learning is taking place - with sporadic pushback from supporters of back-to-basics education - the report does not endorse any particular teaching or learning approach.

Figure 1.1. Classifying teaching and learning strategies along a traditional-modern scale

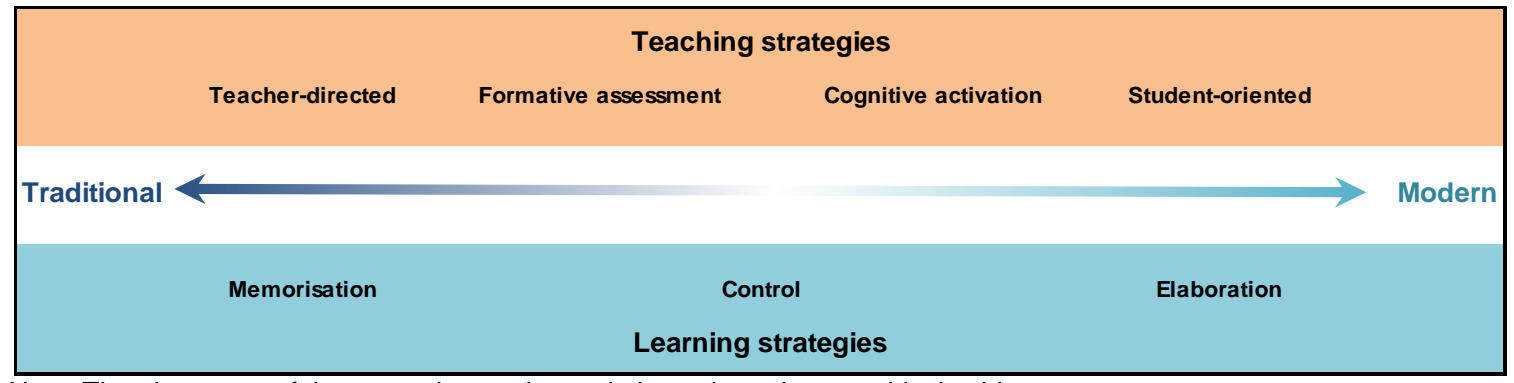

Note: The placement of the strategies on the scale is not based on empirical evidence.

Efforts to transform teaching so that it embraces student-centred instruction and inquiry- and taskbased learning are ubiquitous. "Museum schools", Colombian Escuelas Nuevas, the Partnership for 21st Century Learning (P21) in the United States, the Agastya International Foundation in India, the Singaporean mottos "Thinking Schools, Learning Nation" and "Teach Less, Learn More" or the Japanese Ikiru-chikara are only a few examples. Many other education-reform movements and reformers have 
preceded them, starting as early as the 19th century, or even before, with reformers such as John Dewey in the United States, Reggio and Montessori Schools in Italy, and La Institución Libre de Enseñanza in Spain (see Box 1.1 for a general classification of alternative models). So far, all have failed to transform mainstream education profoundly, even if many of the instructional and learning strategies they developed have influenced how learning happens in schools across the world and have blurred the boundaries between "mainstream" and "alternative" education (OECD, 2008).

\section{Box 1.1. A map of the alternative education landscape}

\section{The transmission model}

Conventional or traditional education refers to the dominant or mainstream approach to education. Knowledge is seen as an established, objective, authoritative body of facts outside of students' experiences and preferences, and the role of the educator is to transmit this knowledge, along with accompanying academic skills and attitudes. The transmission model denotes a one-way process. According to an understanding of education as a transmission of knowledge, instruction is "delivered" and classrooms are "managed" as efficiently as possible. The teacher is backed by a system of demands, inducements, punishments, measuring devices and packaging of knowledge, including testing, grades, standards, curriculum units, textbooks, psychological and medical labels, detention slips and much more. Many critics have complained about this model's narrow vision of the learning process and its effects on students' motivation and sense of self. Yet, in many education settings, some degree of transmission is appropriate and even necessary.

\section{Social constructivist models}

In constructivist models of education, learning is a social endeavour, requiring meaningful interaction among people within an environment that deliberately encourages collaboration, inquiry and creative problem solving. For educators holding this view, knowledge is neither entirely objective nor entirely subjective; rather, it is dynamically constructed through the relationship between people and their social and physical environment. Social constructivism has often been called "child-centred" education because it strives to respect human capacities and tendencies as they naturally unfold, and engages students fully in their learning. This understanding embraces ideas that John Dewey and his followers, and developmental psychologists, such as Jean Piaget and Lev Vygotsky, expressed early in the 20th century. Perhaps the most complete and explicit examples of this orientation are the Reggio schools with their emphasis on young children's innate creative abilities and the importance of developing a collaborative and supportive learning community.

\section{Freedom-based learning}

Some proponents of education alternatives have insisted that the learner's freedom and autonomy should be limited as little as possible - if at all. They believe that learning always starts with the individual's needs, goals and desires, and not with any supposed body of knowledge or societal demands. For these alternative educators, the ideal education embraces the exact opposite of transmission: it centres on a learner's entirely self-motivated exploration of whatever the world has to offer that seems relevant to the learner's own life. This full-bodied individualism has a long and colourful history in education, including Leo Tolstoy, Francisco Ferrer, Ivan Illich, John Holt, among its supporters, and the "modern school", "free school" and "unschooling" movements.

\section{Spiritual developmentalism}

Spiritual developmentalism encompasses education models based on specific ideas about the unfolding of the human soul through each stage of development. The educators who practise these models insist that there is a spiritual dimension to human existence and carefully prescribe what sorts of teaching and learning experiences are appropriate and beneficial at each level of development. These types of education alternatives are "child-centred" in a paradoxical way. The learning environment is generally highly structured, with specially trained, self-disciplined and caring teachers who have an active and authoritative role. Yet the structure provided is intended to meet the authentic (if often unconscious) developmental needs of the growing child. The two best-known proponents of this approach are the Montessori and Waldorf schools, which are firmly rooted in observations and beliefs about the developmental cycles of children and young adults. 


\section{Critical pedagogy}

Some educators believe that the main purpose of education is not to transmit knowledge and preserve social traditions but to transform society by helping students develop a perceptive and inquisitive consciousness of the conditions of their culture. They argue that, in a world suffering from excessive violence and exploitation, racism and class division, and the devastating effects of globalisation and corporate expansion, teachers and parents cannot afford to regard the acquisition of knowledge and academic skills from a morally neutral, disengaged perspective, as they often do. In the 1970s, after the publication of Pedagogy of the Oppressed by the radical Brazilian educator Paulo Freire, the term "critical pedagogy" came to be used to describe a deliberate effort to educate for social responsibility.

\section{Integral or holistic education}

A holistic educator recognises that all five of the other orientations on the educational map have value: they all have something important to say about the nature of the human being and the process of learning. From a holistic perspective, however, each one of them contains only a partial truth, because human existence and the world in which humans function are so enormously complex and dynamic that they cannot be fully grasped by any one ideology. A holistic educator attempts to balance freedom and structure, individuality and social responsibility, spiritual wisdom and spontaneity, in order to respond to each learning situation in its immediate presence. Every particular learner, in a particular setting, in a particular culture, at a particular point in history should be addressed in that moment, and not according to a fixed model meant to apply to all individuals in all learning situations.

Reference: Adapted from the article "A map of the alternative education landscape" by Ron Miller (2008), published by The Alternative Education Resource Organization (AERO).

Figure 1.2. Traditional and modern mathematics teaching and learning

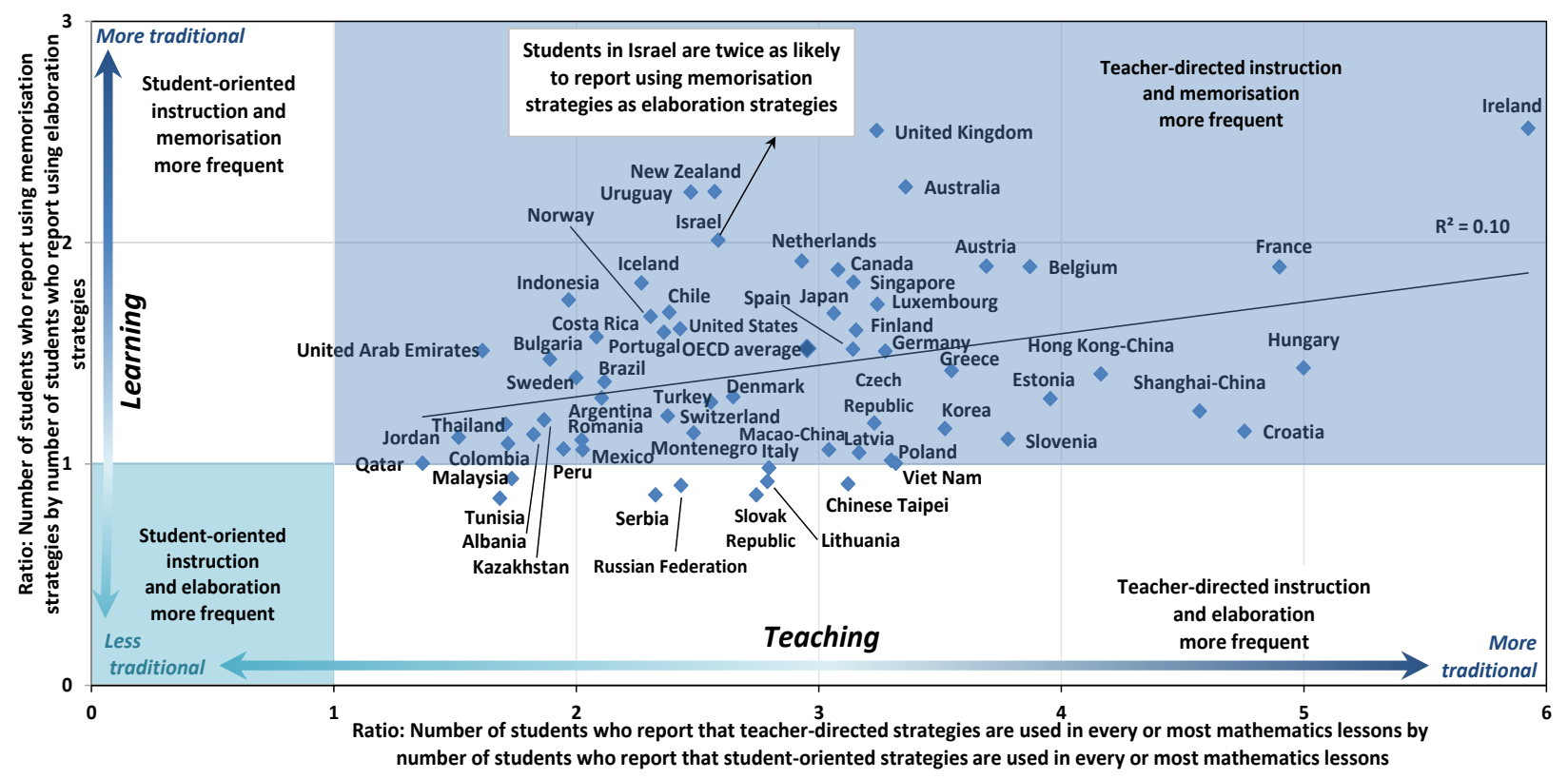

Notes: The ratio memorisation/elaboration is calculated using the average of the four questions on learning strategies.

The ratio teacher-directed/student-oriented is calculated using the average of the five questions on teacher-directed instruction and the four questions on student-oriented instruction.

Source: OECD, PISA 2012 Database.

Evidence from PISA shows that, at least for mathematics, teaching and learning strategies that are usually labelled as traditional still predominate in most participating countries and economies (Figure 1.2). ${ }^{1}$ In all education systems, students more frequently reported that their teachers use teacher-directed instruction rather than student-oriented practices; and in almost every country/economy, students reported 
that they use memorisation more than learning strategies that involve making connections and seeking alternative ways of finding solutions. In Ireland, for instance, students were six times more likely to report being exposed to teacher-directed than student-oriented instructional practices in their mathematics lessons. In Australia, Ireland, New Zealand, the United Kingdom and Uruguay, students were more than twice as likely to report that they use memorisation strategies as to report that they use elaboration strategies. Interestingly enough, teacher-directed instruction and students' self-reported use of memorisation strategies are only weakly linked at the country level.

One reason why a more constructivist approach to education is less frequently adopted could be that there is still no clear evidence that this would necessarily improve student outcomes. Brewer and Goldhaber (1997), for instance, cast doubt on the beneficial effects of having students work in small groups or solve problems on their own; and Schwerdt and Wuppermann (2011) show that students who are more frequently exposed to lecture-style presentations performed better in the Trends in International Mathematics and Science Study (TIMSS). In their analysis of 15 interventions on teaching mathematics to low-performing students, Baker, Gersten and Lee (2002) found that there was little evidence that contextualised approaches - teachers as facilitators, using real-world examples, discussing alternative solutions - were beneficial for these students. Only when students had been explicitly taught the foundations of mathematics did low performers appear to perform well in authentic problem solving (Bottge and Hasselbring, 1993). Hattie (2009) finds that many of the pillars of the constructivist approach, such as the idea that students should construct meaning "through discussion, reflection and the sharing of ideas with other learners with minimal corrective intervention", are against "the successful recipe for teaching and learning" that is developed in his synthesis of 800 meta-analyses (a statistical technique for summarising the findings from independent studies) of the influences on student achievement. In his model of "visible learning", Hattie calls for striking a balance between teacher- and student-centred approaches, and also between surface and deep knowledge. A similar idea is proposed by Pask (1976) when he refers to "versatile learners". Drilling, memorisation and surface learning have a role to play in education, if only as a first step before moving into more advanced, deeper and creative learning. A good balance between traditional and modern, teacher- and student-centred teaching, and deep, surface and strategic learning can be found in the way mathematics is taught and learned in Singapore (Box 1.2).

So far, PISA has also produced little evidence that supports the use of "modern" teaching and learning strategies. In the OECD report Mathematics Teaching and Learning Strategies in PISA (OECD, 2010), the within-country correlations of elaboration strategies with student achievement were small; the main influence on mathematics scores was the disciplinary climate in the classroom, an essential element of back-to-basics education. Meanwhile, the hopes - and resources - invested in information and communications technologies (ICT) to transform the education landscape have so far been disappointing. According to the OECD report Computers, Students and Learning: Making the Connection (2015), there have been "no appreciable improvements in student achievement in reading, mathematics or science in the countries that had invested heavily in ICT for education" and the world of opportunities that have opened up with ICTs "have yet to be fully realised and exploited".

This report will try to clarify how four approaches to teaching - teacher-directed, student orientation, formative assessment and cognitive activation - and three approaches to learning mathematics memorisation, control and elaboration strategies - are related to student performance across individual PISA items. Since most of the questions on teaching and learning in the student questionnaire refer explicitly to mathematics, the subject assessed in detail in PISA 2012, mathematics will be the main focus of this report. Even though there may be references to many of the other elements that make up a school lesson - the quality of teaching (pedagogical and content knowledge, beliefs, enthusiasm), disciplinary climate, teacher-student and peer relations, time spent on learning, physical infrastructure, availability of ICT - it is beyond the scope of this report to provide an in-depth analysis of their relationship to student outcomes. 


\section{Box 1.2. Teaching and learning strategies for excellence in Singapore}

The focus of the Singapore mathematics curriculum is to develop students' ability to apply mathematics to solve problems. The teaching and learning of mathematics pays attention to the development of concepts, skills, processes, attitudes and metacognition.

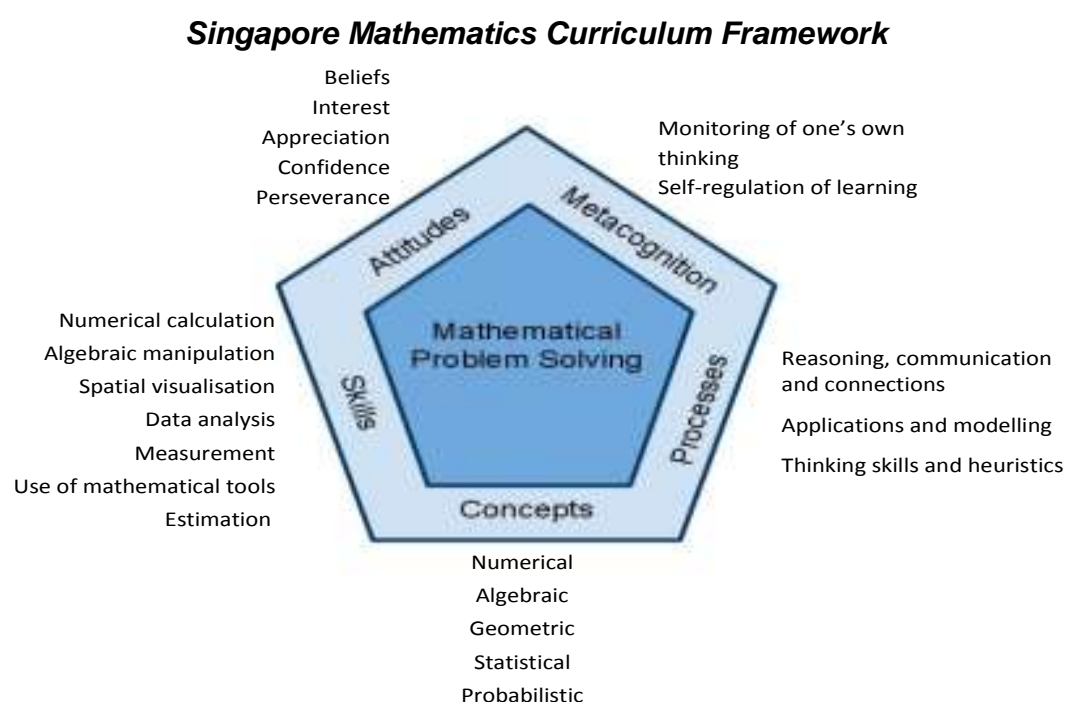

Three fundamental pedagogical approaches form the spine that supports most of the mathematics instruction in the classrooms. They are direct instruction, inquiry-based and activity-based learning.

Teachers typically provide a context for the value of various mathematical concepts, explain the concepts, demonstrate problem-solving approaches, and facilitate activities in class. Technology tools such as graphing software, dynamic geometry software, and spreadsheets are used where appropriate to help students understand concepts, visualise relationships and carry out investigations. Teachers also use various assessment practices to provide students feedback so that they can improve their learning.

Students are exposed to a wide range of problems in the learning of mathematics. Routine problems help students achieve fluency. Non-routine problems give students opportunities to think strategically and creatively. Contextual problems require students to formulate mathematically, apply the relevant mathematics and interpret the mathematical solution in context. In this way, students learn to apply mathematics to solve problems, appreciate the value of mathematics and develop important skills that will support their future learning and ability to deal with new problems.

Reference: Ministry of Education, Singapore.

\section{Definitions and relevance of teaching and learning strategies}

"Teaching strategies" refer to a broad range of processes, from the organisation of classrooms and resources to the moment-by-moment activities teachers engage in to facilitate learning (OECD, 2010). Other definitions include "everything teachers do or should do in order to help their learners learn" (Hatch and Brown, 2000) or "the aggregate of actions, methods and strategies employed by an instructor to enact a piece of curriculum" (Brogt, 2009).

"Learning strategies" are defined as the "conscious thoughts and actions that learners take to complete learning tasks" (Chamot, 2004). Other ways of defining learning strategies include the "cognitive and metacognitive processes employed by students as they attempt to learn something new" (OECD, 2010), the 
behaviours and thoughts "intended to influence the learner's encoding process" (Weinstein and Mayer, 1983), or to acquire, store, retrieve and use information (Dansereau, 1985).

How teachers teach and learners learn has a strong influence on student outcomes. In Hattie (2009), several interventions related to teaching and learning, such as providing formative evaluation and feedback, reciprocal teaching and metacognitive strategies, have a significant impact on student performance (Figure 1.3). In Wang, Haertel and Walberg (1993), such interventions are second in importance to the learning process - and thus in their potential to influence student outcomes - only after a student's home circumstances (OECD, 2010).

\section{Figure 1.3. The top $\mathbf{3 0}$ educational interventions on student achievement} Based on the book Visible Learning (2009)

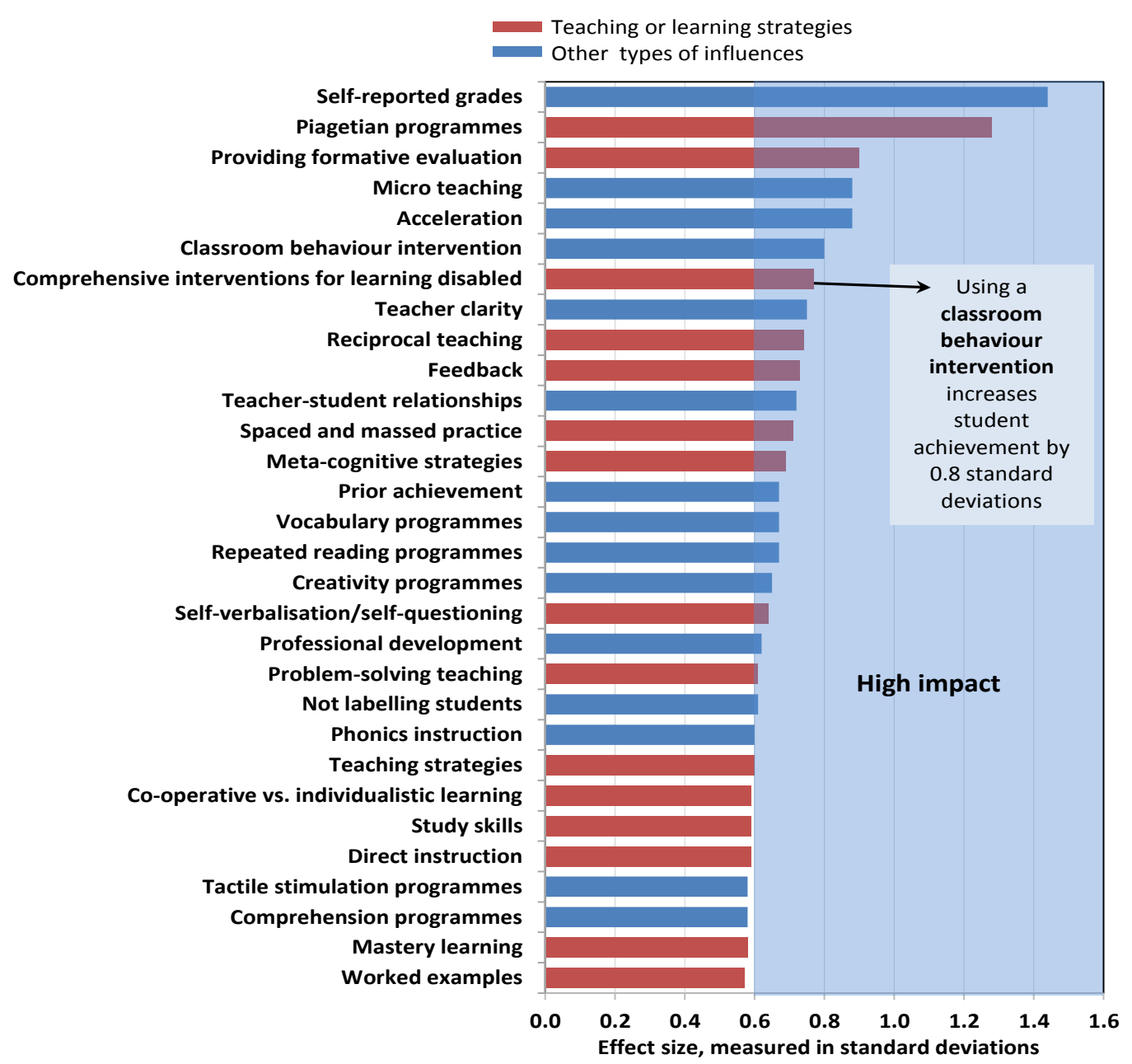

Notes: An effect size measures the magnitude of the impact of an (educational) intervention.

Only the top 30 of the 138 influences analysed in Hattie (2009) are shown.

The educational interventions are ranked in descending order of their effect size.

Source: Hattie (2009).

In the Teaching and Learning toolkit built by the Education Endowment Foundation, an independent grant-making charity dedicated to breaking the link between family income and educational achievement, metacognition and self-regulation appear, together with feedback, as the best value-for-money interventions for disadvantaged students. Other interventions directly related to the learning process, such 
as mastery learning, learning styles, individualised instruction and collaborative learning, also provide good value for money.

In Slavin and Lake's (2008) effort to identify effective programmes for elementary mathematics, the most significant positive effects were found among teacher practices and classroom management. According to this study, to improve mathematics at the elementary level, educators should focus on how mathematics is taught, rather than on what is being taught and with which technology. Similar findings are reported by Kroesbergen and Van Luit (2003) in their meta-analysis of mathematics interventions for children with special education needs. In Marzano's meta-analysis of instructional practices covering different grades, student abilities and duration (1998), the effect sizes of the interventions were found to be fairly strong, with metacognition emerging as the "engine of learning".

\section{Analysing individual test questions}

In general, every item in PISA is treated as a partial expression of a more general goal or idea, like mathematical literacy (OECD, 2013b). However, questions can also be analysed separately, either in groups or individually, to obtain more fine-grained information. The PISA 2012 initial report revealed cross-country differences in student performance in the process and content subscales. The results were intriguing (Figure 1.4). For instance, some countries and economies were particularly strong when mathematics items mainly assessed students' ability to formulate situations mathematically (Hong Kong-China, Japan, Kazakhstan and Shanghai-China), employ mathematical concepts, facts, procedures and reasoning (Viet Nam), or interpret, apply and evaluate mathematical outcomes (Colombia, Costa Rica, France, Greece, Italy, New Zealand and Spain).

Figure 1.4. Performance across process subscales

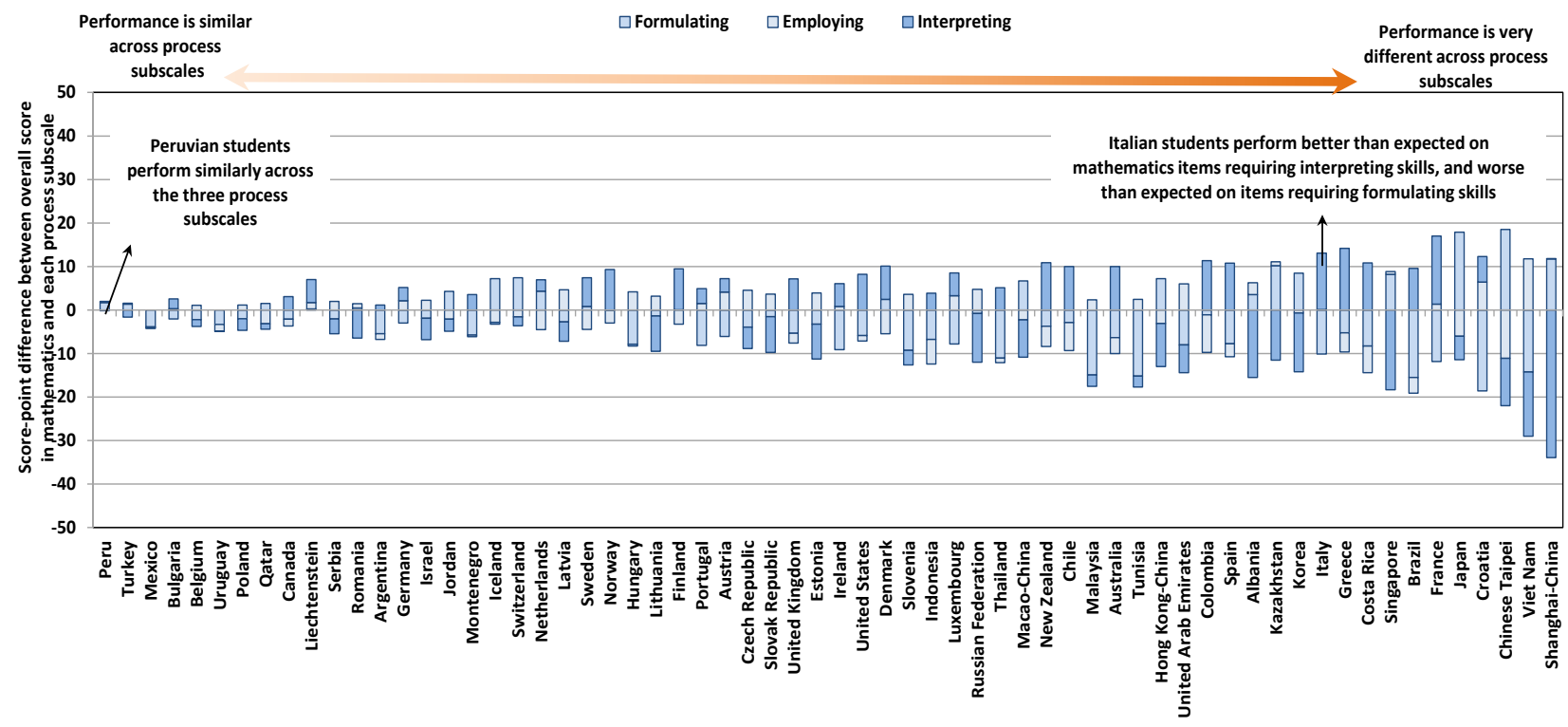

Countries and economies are ranked in ascending order of the absolute overall differences in performance across process subscales.

Source: OECD, PISA 2012 Database.

Relative performance also changed considerably across content areas in mathematics (Figure 1.5). Students in the top-performing Asian education systems, for example, did particularly well in items relating to space and shape as did students in Albania, Kazakhstan, Malaysia, the Russian Federation and 
Switzerland. Meanwhile, in some countries, such as Argentina, Hungary, Mexico and Uruguay, students performed similarly across the four content areas.

Figure 1.5. Performance across content subscales

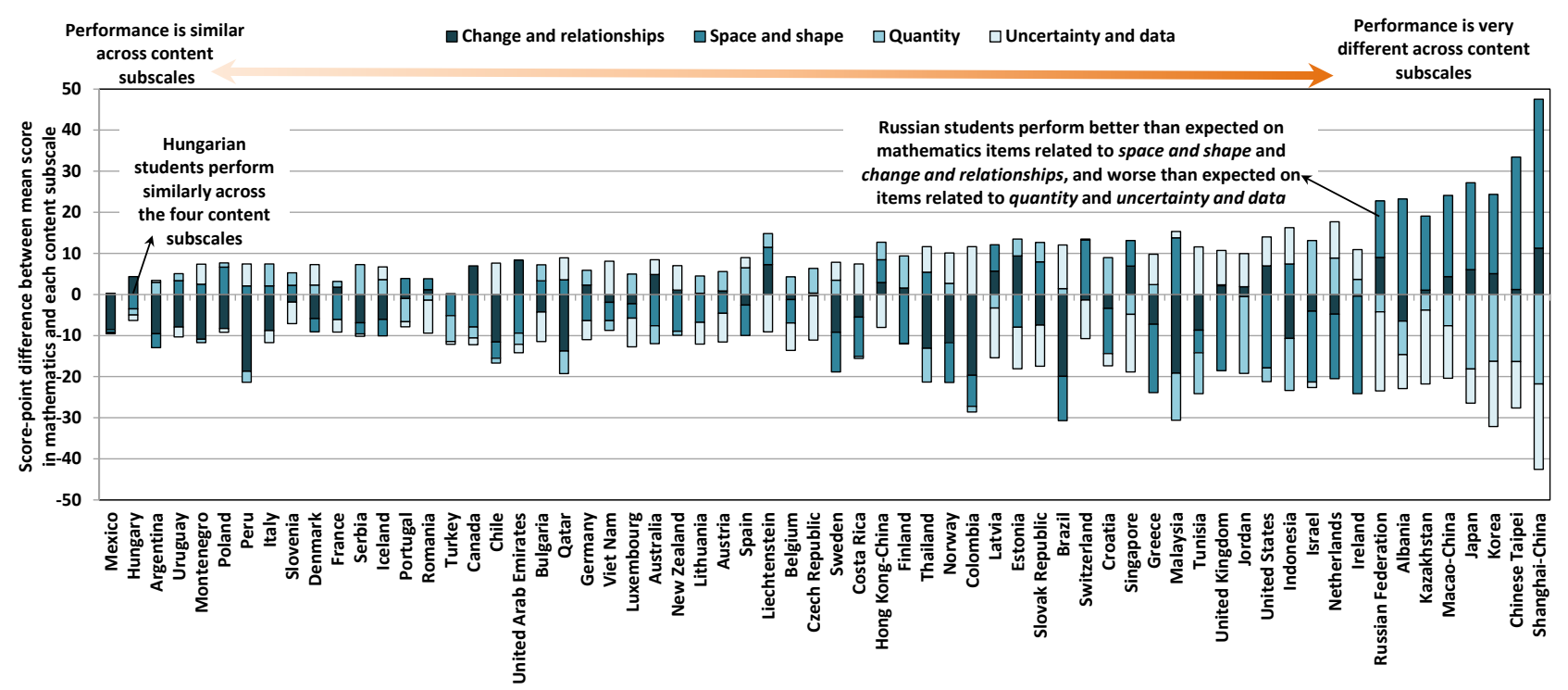

Countries and economies are ranked in ascending order of the absolute overall differences in performance across content subscales.

Source: OECD, PISA 2012 Database.

The relative performance of PISA-participating countries and economies changed even across the difficulty of mathematics items (Figures 1.6a and 1.6b), at least when the overall success rate (across the 59 mathematics items common to every education system) is compared to the performance in the easiest and most difficult items. For instance, students in some education systems, such as Costa Rica, Croatia, Finland and Mexico, performed relatively better on the easiest items, while students in other countries and economies, like Kazakhstan, Switzerland and Chinese Taipei, did so in the most difficult items.

Previous PISA reports have analysed how student, school or system-level factors are associated with overall student performance. By contrast, this report focuses on students' performance on individual items, which means that the explained or predicted variable will usually have two possible values (no credit or full credit), associations are measured using logistic regression, and results are presented as probabilities or odds ratios (see Box 3.4). ${ }^{2}$ In later chapters, it will become clear that the item-level analyses provide an innovative and complementary perspective to that of the earlier OECD report, Mathematics Teaching and Learning Strategies in PISA (OECD, 2010). Other differences include using PISA 2012 data, using information on teaching strategies collected from both students and teachers, through the TALIS (OECD Teaching and Learning International Survey)-PISA link, and making a greater effort to identify causal effects through a student fixed-effects approach.

However, even if some analyses in this report try to identify causal effects, for instance those accounting for relevant variables or using student fixed effects, the analyses are mainly correlational and the findings should be interpreted accordingly. In addition, the relationships between teaching and learning strategies and student outcomes should be interpreted cautiously for several reasons: these strategies are not directly observed; students in PISA were asked about the instructional practices used by their current teachers only; the TALIS-PISA Study links students and teachers at the school level (not at the classroom level); the TALIS 2013 survey was conducted later than the PISA 2012 cycle in northern hemisphere 
countries; and in some education systems, like Japan, students have only been in the same schools for a short time (sometimes less than a year).

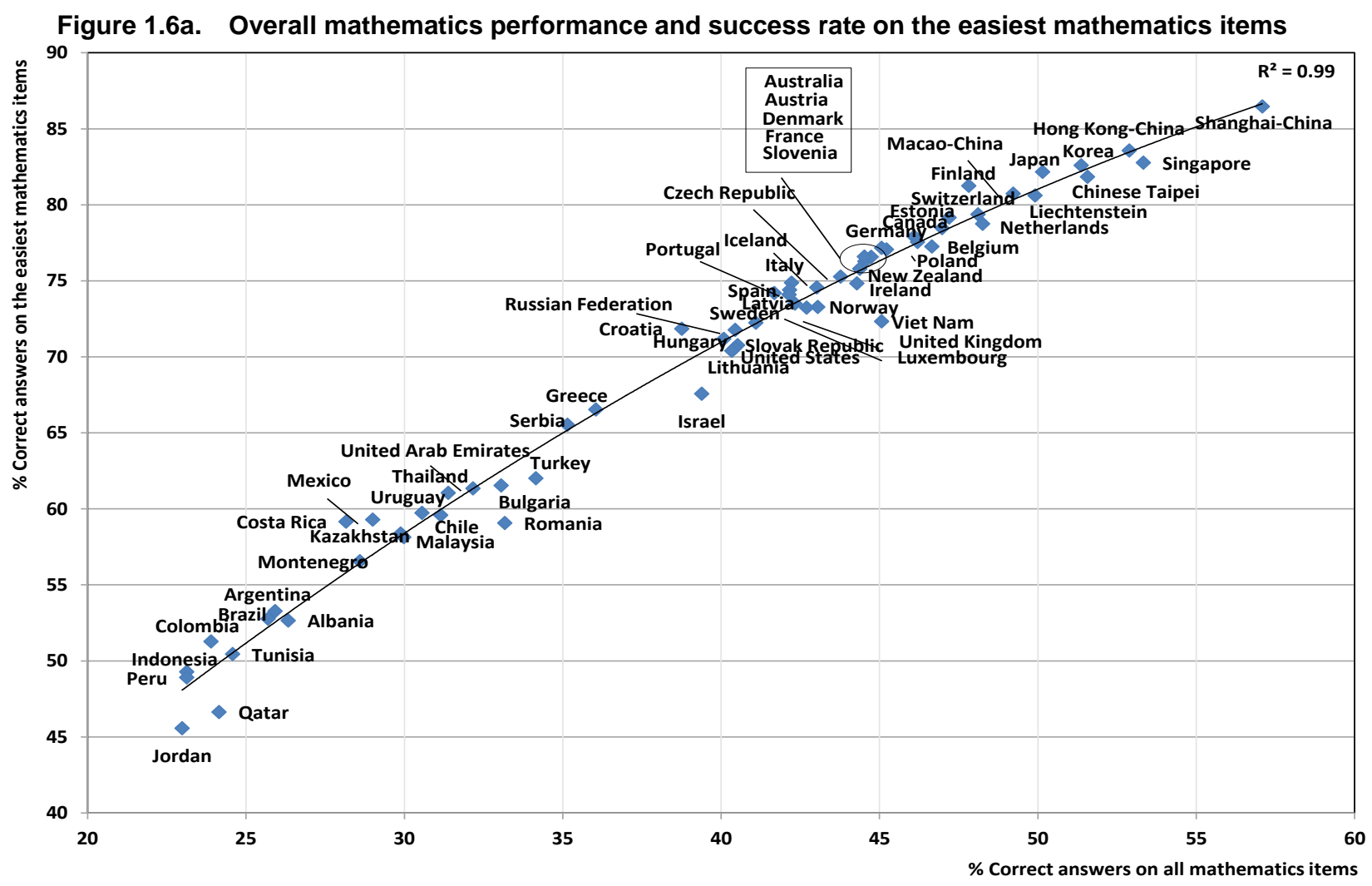

Source: OECD, PISA 2012 Database.

However, even if some analyses in this report try to identify causal effects, for instance those accounting for relevant variables or using student fixed effects, the analyses are mainly correlational and the findings should be interpreted accordingly. In addition, the relationships between teaching and learning strategies and student outcomes should be interpreted cautiously for several reasons: these strategies are not directly observed; students in PISA were asked about the instructional practices used by their current teachers only and in some education systems, like Japan, students have been in the same school for a short period of time (sometimes less than a year); the TALIS-PISA Study links students and teachers at the school level (not at the classroom level); the TALIS 2013 survey was conducted later than the PISA 2012 cycle in northern hemisphere countries.

It is important that a shared "teaching culture" exists within schools - teachers in the same school should approach teaching in a similar way - to give credibility to the findings about teaching strategies, particularly in education systems with larger schools. To a certain extent, the findings in Figure 1.7 suggest that a shared teaching culture might exist since students are more likely to be exposed to similar teaching strategies when they come from the same school than when they do not. Between 5\% and $13 \%$ of the variation in the teaching practices reported by students is explained by schools, a percentage that is particularly high for student-oriented teaching practices. These percentages compare to less than $2 \%$ of variation explained by schools when the same students are asked about their learning strategies. 
Figure 1.6b. Overall mathematics performance and success rate on the most difficult mathematics items

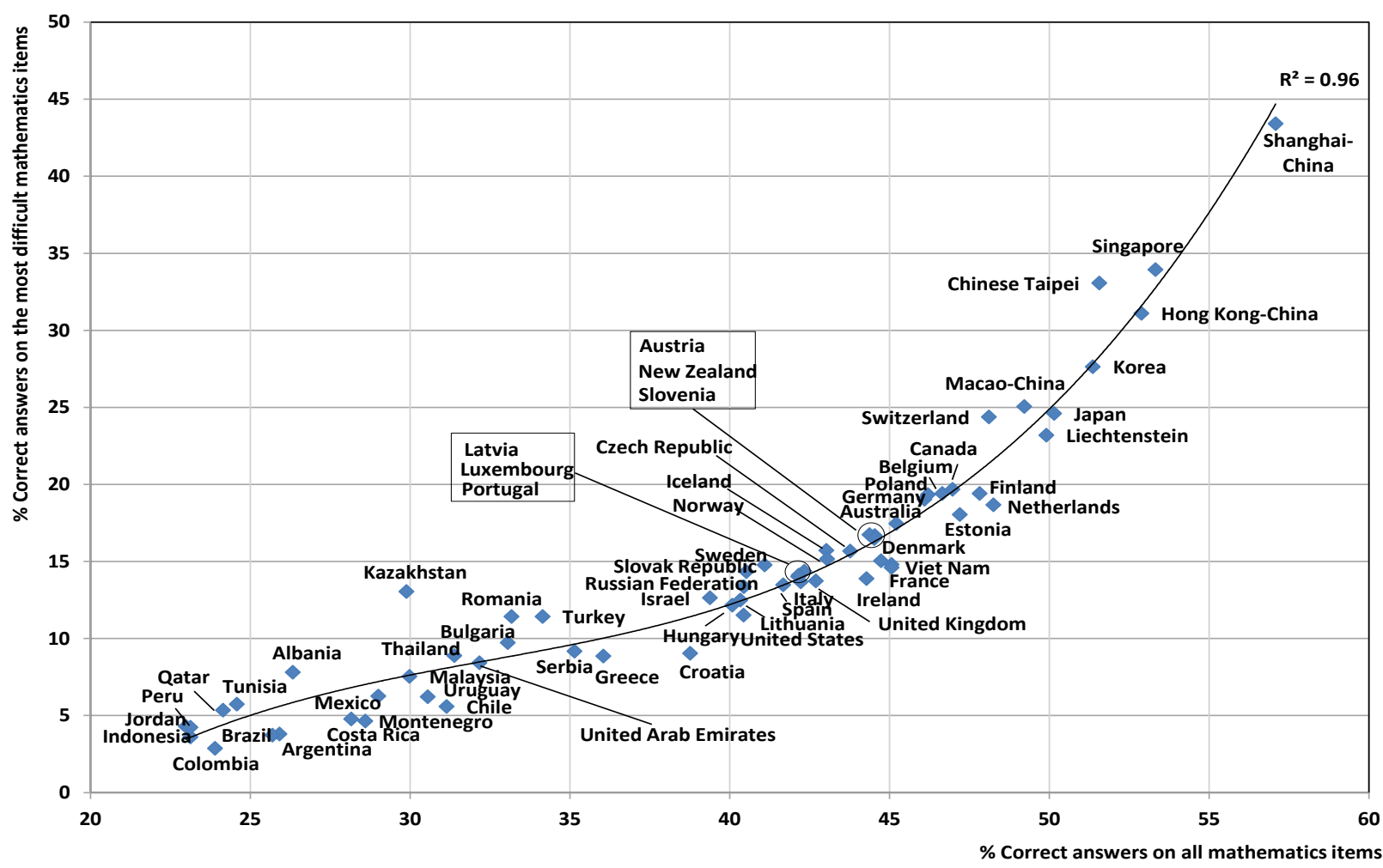

Source: OECD, PISA 2012 Database.

Figure 1.7. Between-school variation of learning and teaching strategies

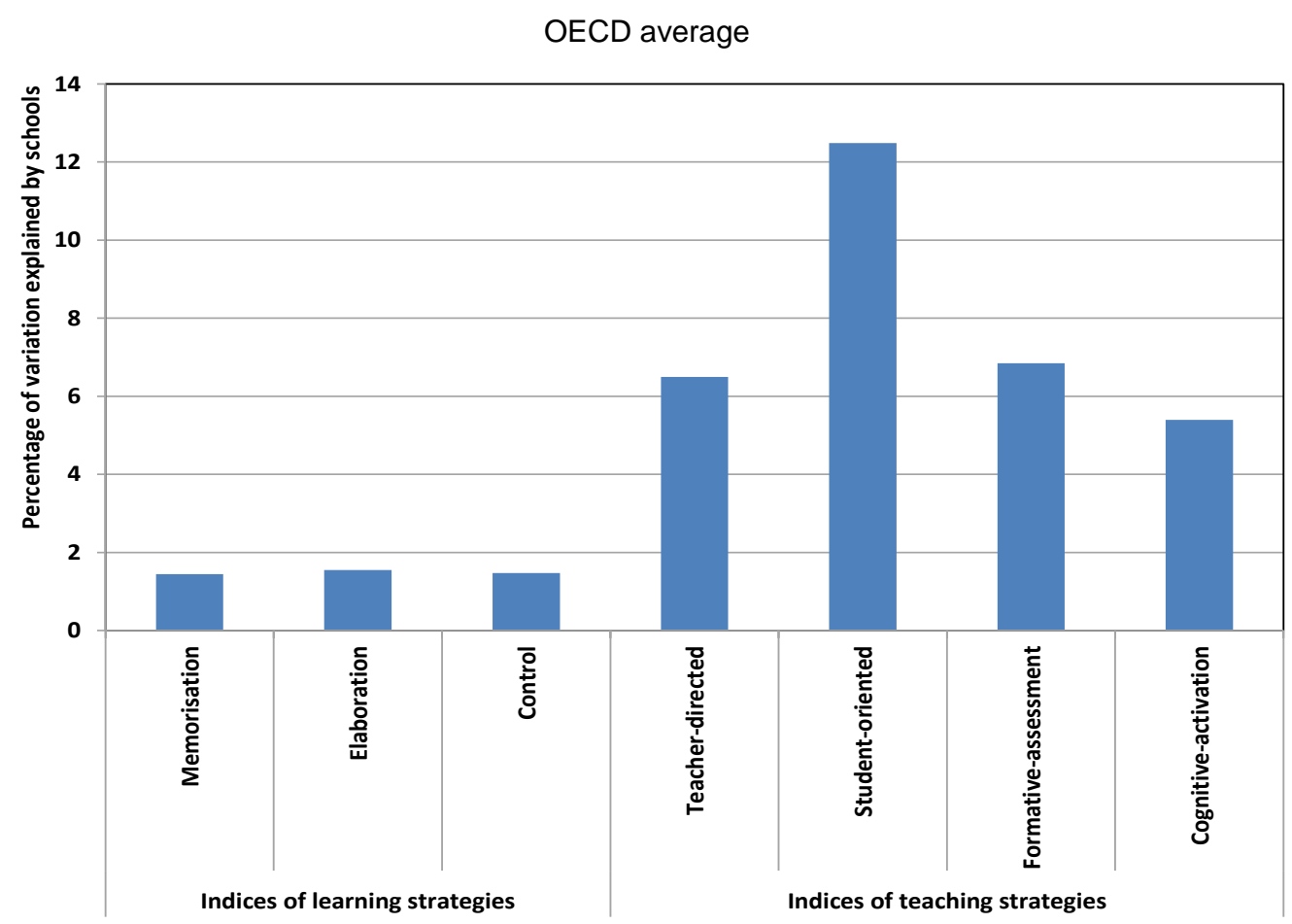

Note: The data of this figure are based on students' self-reports.

Source: OECD, PISA 2012 Database. 


\section{Outline of the report}

Chapter 2, Understanding PISA mathematics items, explains how PISA classifies items and how these classifications are inter-related. It presents three examples of mathematics items that have been made public. Chapter 3, Teaching strategies and beliefs, and student performance, analyses how students' views of the instructional practices used by their mathematics teachers are related to student and school factors, particularly to student performance on individual test questions. It also looks at the relationship between instructional practices, as viewed by teachers themselves, and student outcomes using information from PISA 2012 and the 2013 TALIS survey. In addition to correlational evidence, the chapter presents a methodological approach (regression models with student fixed effects) that accounts for unobservable student characteristics. Chapter 4, Learning with understanding: Approaches to mathematics learning and student performance, explains which students are using memorisation, elaboration and control strategies when learning mathematics and how these strategies are related to their performance on individual mathematics items. The concluding chapter, What we have learned: summary of the findings, describes the main results in the report.

\section{References}

Baker, S., R. Gersten and D. Lee (2002), "A Synthesis of Empirical Research on Teaching Mathematics to Low-Achieving Students”, The Elementary School Journal, pp. 51-73.

Bottge, B., and T. Hasselbring (1993), "A Comparison of Two Approaches for Teaching Complex, Authentic Mathematics Problems to Adolescents in Remedial Math Classes", Exceptional Children, Vol. 59/6, pp. 556-566.

Brogt, E. (2009), Pedagogical and Curricular thinking of professional astronomers teaching the Hertzsprung-Russell diagram in introductory astronomy courses for non-science majors, ProQuest.

Chamot, A. (2004), "Issues in Language Learning Strategy Research and Teaching", Electronic Journal of Foreign Language Teaching, Vol. 1/1, pp. 14-26.

Dansereau, D. (1985), “Learning Strategy Research”, in J. Segal, S. Chipman and R. Glaser (eds.), Thinking and learning skills, Lawrence Erlbaum Associates, Mahwah, New Jersey.

Frey, C., and M. Osborne (2013), "The Future of Employment: How Susceptible Are Jobs to Computerisation", Oxford Martin School Study, Oxford.

Goldhaber, D., and D. Brewer (1997), "Why Don't Schools and Teachers Seem to Matter? Assessing the Impact of Unobservables on Educational Productivity", Journal of Human Resources, pp. 505-523.

Hatch, E, and C. Brown, (2000), Vocabulary, Semantics, and Language Education, Cambridge University Press, Cambridge.

Hattie, J. (2009), Visible Learning: A Synthesis of over 800 Meta-analysis Relating to Achievement, Routledge, London.

Kroesbergen, E, and J. Van Luit (2003), "Mathematics Interventions for Children with Special Educational Needs a Meta-Analysis", Remedial and Special Education, Vol. 24/2, pp. 97-114.

Marzano, R. (1998), A Theory-Based Meta-Analysis of Research on Instruction, Mid-continent Regional Educational Laboratory, Denver. 
OECD (2015), Students, Computers and Learning: Making the Connection, OECD Publishing, Paris, http://dx.doi.org/10.1787/9789264239555-en.

OECD (2013a), OECD Skills Outlook 2013: First Results from the Survey of Adult Skills, OECD Publishing, Paris, http://dx.doi.org/10.1787/9789264204256-en.

OECD (2013b), PISA 2012 Assessment and Analytical Framework: Mathematics, Reading, Science, Problem Solving and Financial Literacy, OECD Publishing, Paris. http://dx.doi.org/10.1787/9789264190511-en.

OECD (2010), Mathematics Teaching and Learning Strategies in PISA, OECD Publishing, Paris, http://dx.doi.org/10.1787/9789264039520-en.

OECD (2008), Innovating to Learn, Learning to Innovate, OECD Publishing, Paris, http://dx.doi.org/10.1787/9789264047983-en.

Pask, G. (1976), "Styles and Strategies of Learning", British Journal of Educational Psychology, Vol. 46/2, pp. 128-148.

Schwerdt, G., and A. Wuppermann (2011), "Is Traditional Teaching Really all that Bad? A within-Student Between-Subject Approach", Economics of Education Review, Vol. 30/2, pp. 365-379.

Slavin, R, and C. Lake (2008), "Effective Programs in Elementary Mathematics: A Best-Evidence Synthesis”, Review of Educational Research, Vol. 78/3, pp. 427-515.

Wang, M., G. Haertel, and H. Walberg (1993), “Toward a Knowledge Base for School Learning”, Review of Educational Research, Vol. 63/3, pp. 249-294.

Weinstein, C., and R. Mayer (1983), "The Teaching of Learning Strategies”, Innovation Abstracts, Vol. 5/32.

Notes:

${ }^{1}$ Readers should be aware of the inherent limitations of any information collected through questionnaires. In particular, the indices of teaching and learning strategies are constructed using a limited set of questions from the PISA student or TALIS teacher questionnaires, which are affected by traditional problems of survey data collection, such as social desirability, cross-cultural bias or faulty memory.

${ }^{2}$ In this report, item responses with "partial credit" are transformed into "no credit" so that the dependent variable is always dichotomous/binary. 
EDU/WKP(2016)4

\section{CHAPTER 2. UNDERSTANDING PISA MATHEMATICS ITEMS}

Mathematical literacy is defined as the ability of students to analyse, reason and communicate ideas effectively as they formulate, employ and interpret mathematical problems in a variety of contexts (OECD, 2013a). Measuring a broad concept like mathematical literacy using a standardised test like PISA requires an equally wide variety of test questions. These questions have to be asked using different formats, be located in various contexts, and be related to several content areas. They also need to cover the full modelling cycle - formulate, employ and interpret - and the range of mathematics skills of a typical 15-year-old.

To ensure that PISA mathematics items are diverse enough, and accurately reflect the students' abilities defined in the assessment framework (OECD, 2013a), PISA classifies them by their response format, the mathematical process involved, the content of the problem, the context in which the item is set, and actual difficulty. Classifying items not only enhances the psychometric adequacy of the test and helps to describe what mathematical literacy means in practice, it is also useful for analysing student performance at the item level.

The analysis of PISA mathematics subscales already shows that some countries perform much better in certain areas of mathematics (Figures 1.4 and 1.5). For instance, students from the top-performing education systems performed relatively better when items required more formulating than interpreting skills, and when items were related to change and relationships and space and shape content rather than quantity and uncertainty and data content. An analysis of the conspicuous items - those that indicate particular strengths or weaknesses among students - reveal that students from the United States did better in change and relationships and uncertainty and data items than in test questions classified as both formulate and space and shape (OECD, 2013b). The same analysis also shows students struggling on problems that require transforming a real-life situation into a mathematics problem or working with $\pi$.

This chapter provides some technical background to this report. It briefly explains how PISA mathematics problems were classified in the 2012 assessment. It then describes, in detail, three mathematics items that were made public: an easy item, "Charts Q1"; an item of intermediate difficulty, "Sailing ships Q1"; and a difficult item, "Revolving door Q2". The chapter then discusses how the five ways of classifying items overlap.

\section{Classifying PISA mathematics items}

In accordance with the PISA 2012 Assessment and Analytical Framework (OECD, 2013), the mathematics assessment aims to measure the overarching idea of mathematical literacy among 15-year-old students. PISA classifies items in five ways to ensure a balanced assessment of mathematical literacy: by the item's empirical difficulty, the type of response format, the process involved, the content area of the problem, and the context in which the item is situated (Figure 2.1). ${ }^{1}$ PISA items usually involve multiple processes, contents and contexts, so it is necessary to make judgements about the main demand on students in order to allocate items to just one of the categories. For a full list of mathematics items in the PISA 2012 assessment and their characteristics, please see the Annex. 
Figure 2.1. Categories of items constructed for the PISA 2012 mathematics assessment

\begin{tabular}{|c|c|c|c|c|}
\hline Process categories & Content categories & Context categories & Response categories & Empirical difficulty \\
\hline \multirow{2}{*}{$\begin{array}{c}\text { Formulating situations } \\
\text { mathematically }\end{array}$} & Quantity & Personal & $\begin{array}{c}\text { Multiple choice: } \\
\text { Simple and complex }\end{array}$ & 317 points \\
\cline { 2 - 4 } & Uncertainty and data & Societal & Easy items \\
\cline { 2 - 3 } $\begin{array}{c}\text { Employing mathematical } \\
\text { concepts, facts, } \\
\text { procedures, and reasoning }\end{array}$ & Change and relationships & Occupational & $\begin{array}{c}\text { Constructed response: } \\
\text { Manual, expert and auto- } \\
\text { coded }\end{array}$ & Difficult items \\
\cline { 2 - 3 } $\begin{array}{c}\text { Interpreting, applying and } \\
\text { evaluating mathematical } \\
\text { outcomes }\end{array}$ & Space and shape & Scientific & & \\
\cline { 2 - 3 }
\end{tabular}

Source: Based on OECD (2013a).

\section{Difficulty}

First and foremost, PISA items are ranked according to their level of difficulty. Even though PISA designs items that are suitable for the least and most able 15-year-old students, the actual difficulty of the items is calculated only after the students take the test. The level of empirical difficulty of all items is calculated using a scaling approach known as Item Response Theory (OECD, 2014), which estimates the difficulty of items and students' score on the test simultaneously. Simply put, the lower the percentage of students who give the correct answer, the more difficult the item.

\section{Figure 2.2. Distribution of mathematics items on the PISA scale}

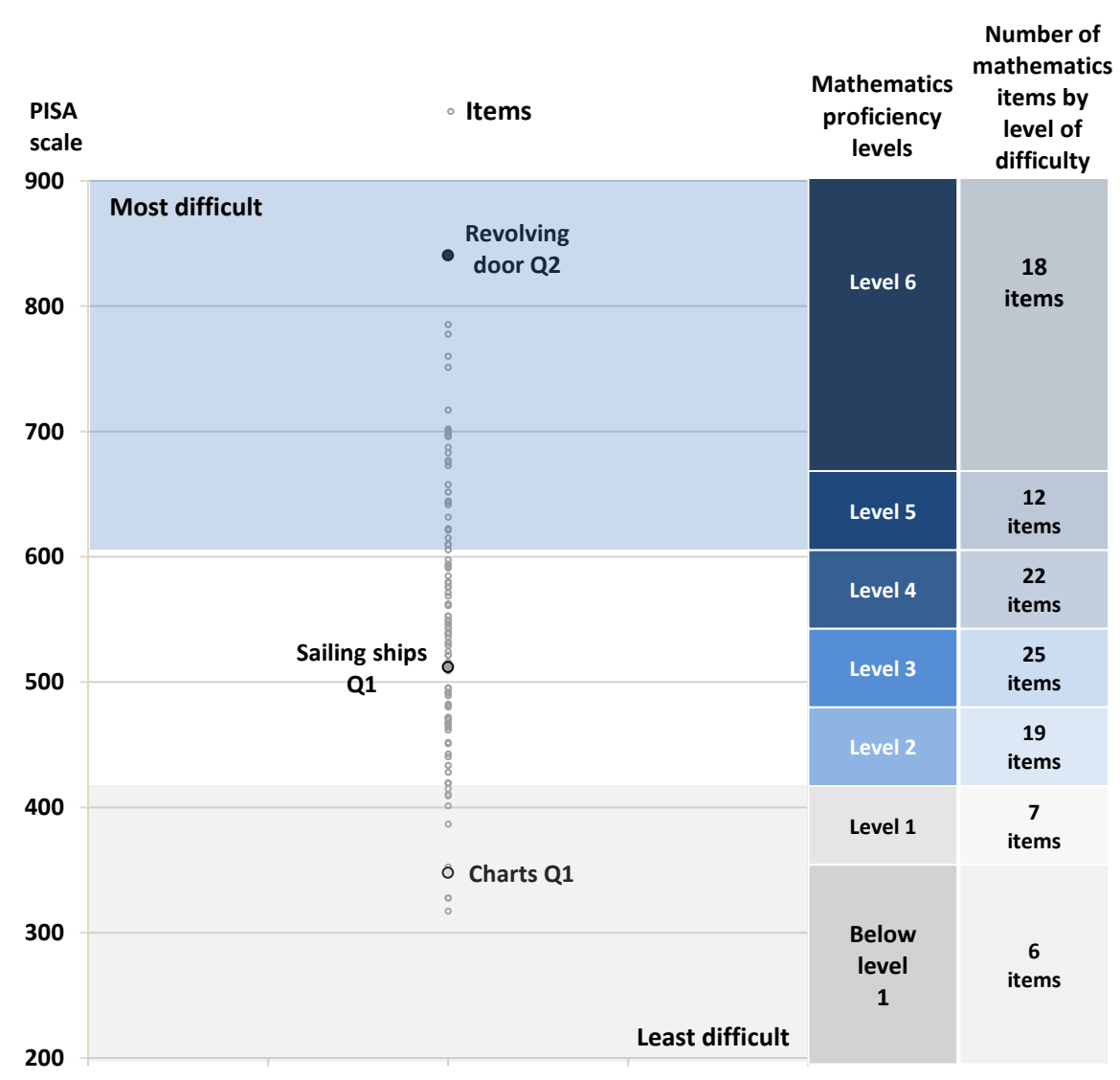

Note: This chart shows the PISA score distribution of each mathematics item assessed in PISA 2012. Charts Q1 sits at 348 score points (below Level 1), Sailing ships Q1 sits at 512 score points (Level 3), and Revolving door Q2 sits at 840 score points (above Level 6).

Source: OECD, PISA 2012 Database. 
For example, students with a score of 348 points have a $62 \%$ probability (this probability was chosen by the PISA consortium as part of the scoring design) of solving "Charts Q1", which $87 \%$ of students answering it correctly and sits at 348 points on the PISA scale of difficulty. "Sailing ships Q1", which 59\% of students answered correctly, sits at 512 points on the scale; and "Revolving door Q2", which only 3\% of students answered correctly, sits at 840 points on the PISA scale of difficulty. The average difficulty of the 109 items was 544 points on the PISA scale. The distribution of all mathematics items along the PISA scale shows that most of them are located in the intermediate level of difficulty (more than $60 \%$ of them are between Levels 2 and 4 on the mathematical proficiency scale), 12\% are below the baseline level of proficiency, and 28\% are located at the highest levels of proficiency, Level 5 or 6 (Figure 2.2). ${ }^{2}$

Not every country administered the same set of mathematics items: all participating countries administered 59 common items; 16 countries opted for an easy booklet, with 25 mathematics items whose average difficulty was 527 points, to better measure the skills of students at the lower end of the ability spectrum; and the remaining 48 education systems opted for the standard booklet, with 25 mathematics items with an average difficulty of 554 points. ${ }^{3}$

\section{Response format}

PISA mathematics items were presented using five response types. The main distinction is between selected-response questions, commonly known as multiple choice, and constructed response or open-ended questions. Selected-response items include simple multiple choice and complex multiple choice, in which students must select correct answers from several choices offered. Items using these response types can be objectively scored and are easy to automate/analyse, but they allow for guessing and designing them to test higher-order skills, such as creativity and critical thinking, can be challenging and labour intensive (Halpern, 2003; Ku, 2009).

The opposite is true for questions that require students to construct their own responses (Ennis, 1993). They include items whose response can be scored routinely (constructed response [manual]), such as a single number or a simple phrase, computer-based items, whose response can be captured and processed automatically (constructed response [auto-coded]), and others that require an expert to score (constructed response [expert]), such as items that ask students to provide an explanation or those requiring a long calculation.

Acknowledging that each response type has its strengths and shortcomings (Bridgeman and Moran, 1996), and that the best strategy is to combine response formats (Ku, 2009), the PISA mathematics assessment combines a variety of formats: 32 simple multiple-choice responses, 13 complex multiplechoice responses, 30 constructed response (manual), 3 constructed response (auto-coded) and 31 constructed response (expert).

\section{Processes of the modelling cycle}

When solving PISA tasks, students go through the mathematics modelling cycle, or some parts of it. The action begins with a "problem in context" that students need to transform into a "mathematics problem" (mathematising). This might require identifying the mathematics relevant to the problem, formulating the situation mathematically, and/or making assumptions to simplify the situation.

The student then uses mathematical concepts, facts, procedures and reasoning to obtain the "mathematical results". This stage usually involves mathematical manipulation, transformation and computation. The "mathematical results" then need to be interpreted in terms of the original problem to obtain the "results in context" (contextualising). At this stage, the problem-solver must interpret, apply and evaluate mathematical outcomes in the real world. 
These three stages are formally named as: formulate situations mathematically; employ mathematical concepts, facts, procedures and reasoning; and interpret, apply and evaluate mathematical outcomes. Students are often required to move back and forth between the stages of the modelling cycle, though not all PISA tasks necessarily engage students in every stage. In PISA 2012, mathematics items were classified according to the dominant processes as follows: 50 items were classified as employ, 32 were classified as formulate, and 27 were classified as interpret.

Each of these three processes draws on fundamental mathematical abilities to varying degrees: communication; mathematising; representation; reasoning and argument; devising strategies for solving problems; using symbolic, formal and technical language and operations; and using mathematical tools. These cognitive abilities, which can be learned, are described in detail in the PISA 2012 Assessment and Analytical Framework (OECD, 2013a).

\section{Content areas}

PISA mathematics items cover four areas of content that correspond to the mathematics most 15-year-olds have been exposed to and are familiar with. The content category quantity incorporates the quantification of attributes of objects, relationships, situations and entities in the world. It involves understanding measurements, counts, magnitudes, units, indicators, relative size, and numerical trends and patterns. Items in this category require the use of number sense, multiple representations of numbers, mental calculation and estimations, and students must be able to assess the soundness of results.

The content category uncertainty and data covers two closely related issues: how to identify and summarise the messages that are present in data sets, and how to evaluate the influence of the variability that is inherent in many real processes. Uncertainty is part of scientific predictions, poll results, weather forecasts and economic models; variation occurs in manufacturing processes, test scores and survey findings; and chance is part of many recreational activities that individuals enjoy. Probability and statistics, taught as part of mathematics, address these issues.

Change and relationships focuses on the multitude of relationships that exist among objects, circumstances and time. Greater aptitude in this content category involves understanding fundamental types of change and recognising when change occurs so that suitable mathematical models can be used to describe and predict change.

The content category space and shape encompasses a wide range of phenomena: patterns, properties of objects, positions and orientations, representations of objects, decoding and encoding of visual information, navigation, and dynamic interaction with real shapes and their representations. Geometry is essential to space and shape, but the category extends beyond traditional geometry into content, meaning and method, drawing on elements of other areas of mathematics, such as spatial visualisation, measurement and algebra.

The four content categories are represented by a similar number of items: 28 quantity items, 25 uncertainty and data items, 29 change and relationship items, and 27 space and shape items.

\section{Mathematics problems in context}

The four context categories used in PISA identify the broad areas of life in which the problems may arise: personal, which is related to individuals' and families' daily lives; societal, which is related to the community - local, national or global - in which students live; occupational, which is related to the world of work; and scientific, which is related to the use of mathematics in science and technology. These four categories are represented by the following number of items: 21 items were set in a personal context, 36 in a societal context, 24 in an occupational context, and 28 in a scientific context. 
The three items used as examples in this report

\section{CHARTS}

In January, the new CDs of the bands 4U2Rock and The Kicking Kangaroos were released. In February, the CDs of the bands No One's Darling and The Metalfolkies followed. The following graph shows the sales of the bands' CDs from January to June.

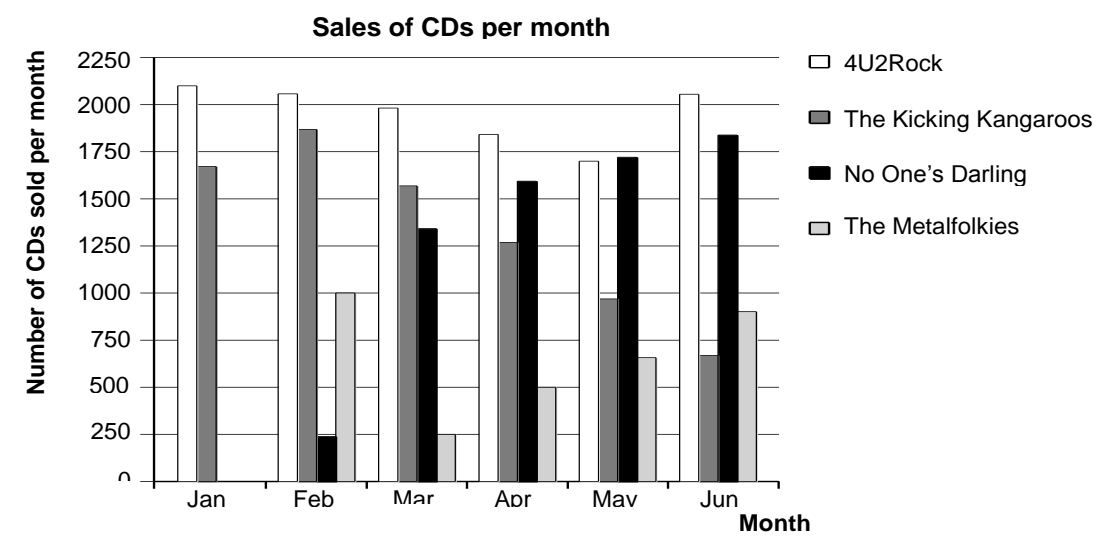

Question 1 (PM918Q01)

How many CDs did the band The Metalfolkies sell in April?
A. 250
B. 500
C. 1000
D. 1270

\section{Characteristics}

Description: Read a bar chart

Mathematical content area: Uncertainty and data

Context: Societal

Process: Interpret

Question format: Simple multiple choice

Difficulty: 347.7 (Below Level 1)

Full Credit: B. 500

Comment: Charts Q1, with a difficulty of 347.7 , is below Level 1 on the mathematics proficiency scale, being one of the easiest tasks in the PISA 2012 item pool. It requires the student to find the bars for April, select the correct bar for The Metafolkies, and read the height of the bar to obtain the required response selections B (500). No scale reading or interpolation is required. 
Ninety-five percent of world trade is moved by sea, by roughly 50000 tankers, bulk carriers and container ships. Most of these ships use diesel fuel.

Engineers are planning to develop wind power support for ships. Their proposal is to attach kite sails to ships and use the wind's power to help reduce diesel consumption and the fuel's impact on the environment.

Translation Note: "ㅇ by skysails": Do not adapt skysails as this is a registered label.

\section{Question 1 (PM923Q01)}

One advantage of using a kite sail is that it flies at a height of $150 \mathrm{~m}$. There, the wind speed is approximately $25 \%$ higher than down on the deck of the ship. At what approximate speed does the wind blow into a kite sail when a wind speed of $24 \mathrm{~km} / \mathrm{h}$ is measured on the deck of the ship?
A. $6 \mathrm{~km} / \mathrm{h}$
B. $18 \mathrm{~km} / \mathrm{h}$
C. $25 \mathrm{~km} / \mathrm{h}$
D. $30 \mathrm{~km} / \mathrm{h}$
E. $49 \mathrm{~km} / \mathrm{h}$

\section{Characteristics}

Description: Apply calculation of percentage within a given real world situation

Mathematical content area: Quantity

Context: Scientific

Process: Employ

Question format: Simple multiple choice

Difficulty: 511.7 (Level 3)

\section{Full Credit: D. $30 \mathrm{~km} / \mathrm{h}$}

Comment: Sailing ships Q1, with a difficulty of 511.7, is at Level 3. It is classified in the employing process and can be solved by simple use of percentages, provided students can separate the relevant information $(24 \mathrm{~km} / \mathrm{h}$ and $25 \%$ higher) from irrelevant pieces of information (150 metres of height). The solution can be found either indirectly by calculating first how much the speed increases at a height of 150 $\mathrm{m}$ compared to the deck of the ship (24 km/h $* 25 / 100)$, and then add the increase to the speed on the deck of the ship $(24 \mathrm{~km} / \mathrm{h}+6 \mathrm{~km} / \mathrm{h})$ or directly by multiplying the speed on the deck of the ship by 1.25 . 
A revolving door includes three wings which rotate within a circular-shaped space. The inside diameter of this space is 2 metres ( 200 centimetres). The three door wings divide the space into three equal sectors. The plan below shows the door wings in three different positions viewed from the top.

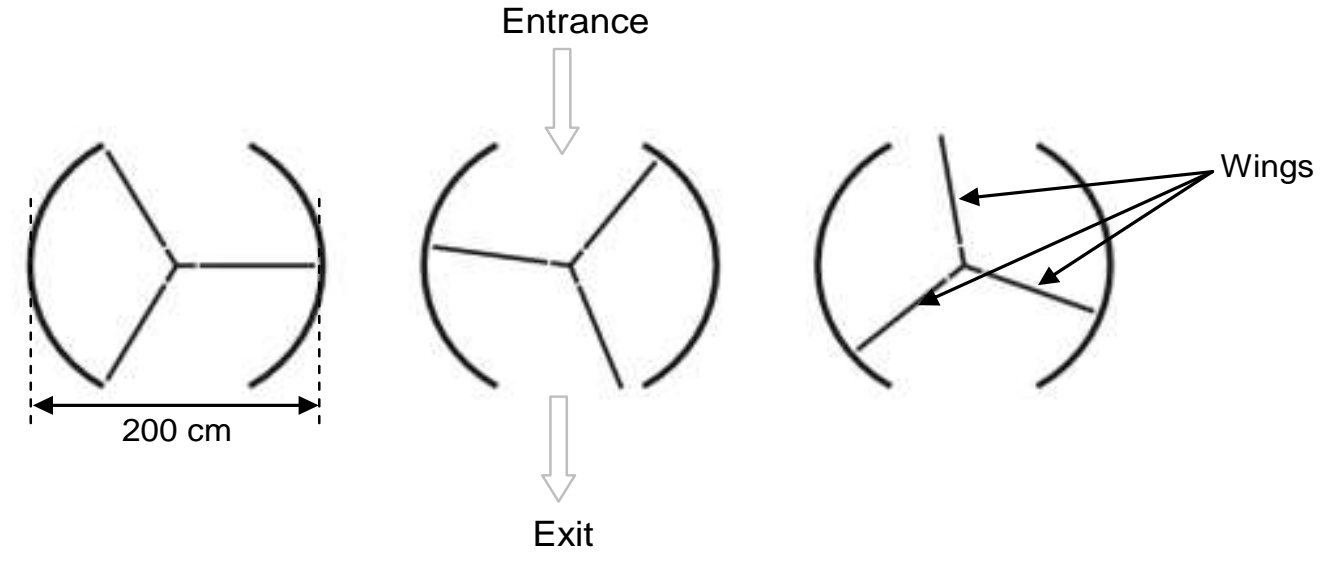

Question 2 (PM995Q02-019)

The two door openings (the dotted arcs in the diagram) are the same size. If these openings are too wide the revolving wings cannot provide a sealed space and air could then flow freely between the entrance and the exit, causing unwanted heat loss or gain. This is shown in the diagram opposite. What is the maximum arc length in centimetres $(\mathrm{cm})$ that each door opening can have, so that air never flows freely between the entrance and the exit?

Maximum arc length: $\mathrm{cm}$

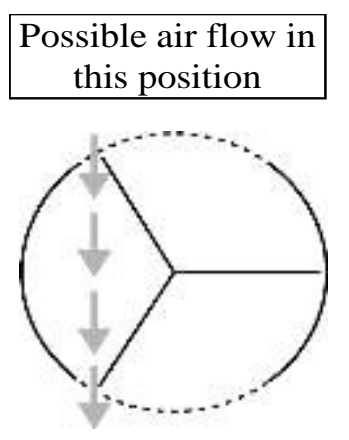

\section{Characteristics}

Description: Interpret a geometrical model of a real life situation to calculate the length of an arc

Mathematical content area: Space and shape

Context: Scientific

Process: Formulate

Question format: Constructed response expert

Difficulty: 840.3 (Level 6)

Full Credit: Answers in the range from 103 to 105. [Accept answers calculated as 1/6th of the circumference $\left(\frac{100 \pi}{3}\right)$. Also accept an answer of 100 only if it is clear that this response resulted from using $\pi=3$. Note: Answer of 100 without supporting working could be obtained by a simple guess that it is the same as the radius (length of a single wing).]

Comment: Question 2 was the most challenging question in the survey, lying towards the upper end of Level 6. It addresses the main purpose of revolving doors, which is to provide an airlock between inside and outside the building and it requires substantial geometric reasoning, which places it in the space and shape content category. The complexity of coding such a multi-step response in so many countries led to 
this item being assessed only as full credit or no credit. For full credit, the complex geometrical reasoning showing that the maximum door opening is one sixth of the circumference needed to be followed by an accurate calculation in centimetres. The item is classified in the formulating process, and it draws very heavily on the mathematisation fundamental mathematical capability, because the real situation has to be carefully analysed and this analysis needs to be translated into geometric terms and back again at multiple points to the contextual situation of the door. As the diagram supplied in the question shows, air will pass from the outside to the inside, or vice versa, if the wall between the front and back openings is shorter than the circumference subtended by one sector. Since the sectors each subtend one third of the circumference, and there are two walls, together the walls must close at least two thirds of the circumference, leaving no more than one third for the two openings. Arguing from symmetry of front and back, each opening cannot be more than one sixth of the circumference. There is further geometric reasoning required to check that the airlock is indeed maintained if this opening length is used. The question therefore draws very heavily on the reasoning and argument fundamental mathematical capability.

\section{The relationships among item classifications}

Mathematics items in each category of the process, content and context classifications represent a range of difficulty and demands on students' abilities in mathematics (OECD, 2013a).Together with a balanced distribution of items among categories, this guarantees that the results can be reported through the various subscales. However, despite these ranges of difficulties, this section shows that the categories in each of the classifications differ in their average difficulty, particularly within the format and process classifications. A final analysis illustrates how the context in which the mathematics items were set relates to the response type employed.

Figure 2.3. Response format and difficulty of PISA mathematics items

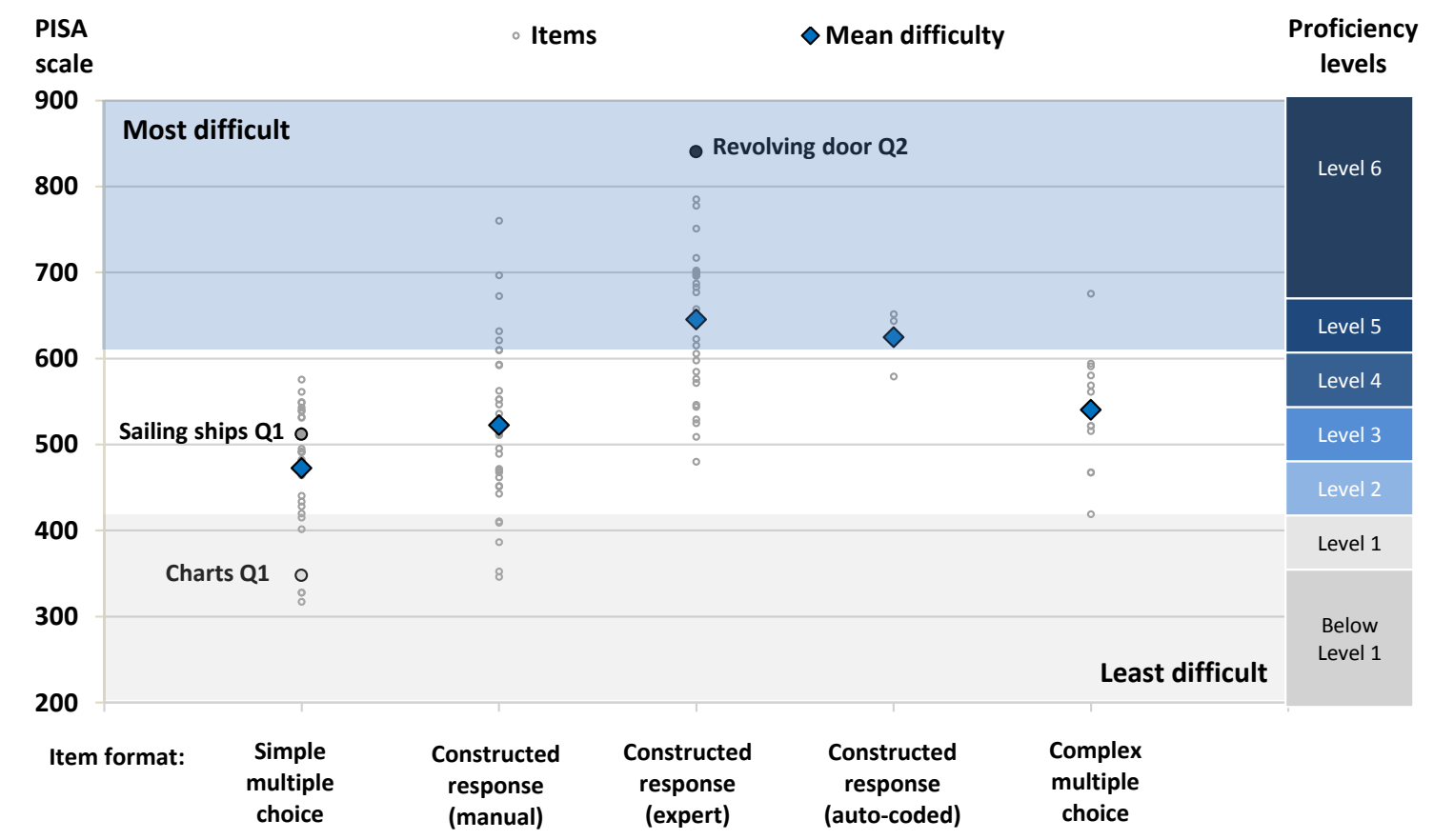

Source: OECD, PISA 2012 Database. 


\section{Response-format type and difficulty}

The difficulty varies considerably across and within the five different response formats used in PISA mathematics problems (Figure 2.3). With an average difficulty of 473 points, simple multiple-choice questions are located mainly at the lower levels of the proficiency scale. The items "Charts Q1" and "Sailing ships Q1" belong to this category. Constructed response (manual) and complex multiple choice responses are used in somewhat more difficult items - 522 points and 540 points, respectively. Items requiring a constructed response (expert), in which students often need to carry out long calculations and provide explanations, are the most difficult, located well above 600 points on the PISA scale. The item "Revolving door Q2" belongs to this category.

\section{Processes of the mathematics modelling cycle and difficulty}

The three processes of the mathematics modelling cycle - formulate, employ and interpret - require different skills. Formulate, certainly the most creative part of the modelling cycle and less amenable to linear learning, is also the most challenging process for students. Items classified as formulate, which include "Revolving door Q2", have an average difficulty of 607 points (Figure 2.4). Interpret, the other process that involves making connections between mathematics and the real world (but in the opposite direction to formulate), is located at the lower end of the PISA scale, at 478 points. Items classified as employ, which call on students' ability to work on a mathematically formulated problem, are welldistributed across the PISA scale, covering all proficiency levels.

Figure 2.4. The processes of the modelling cycle and difficulty of PISA mathematics items

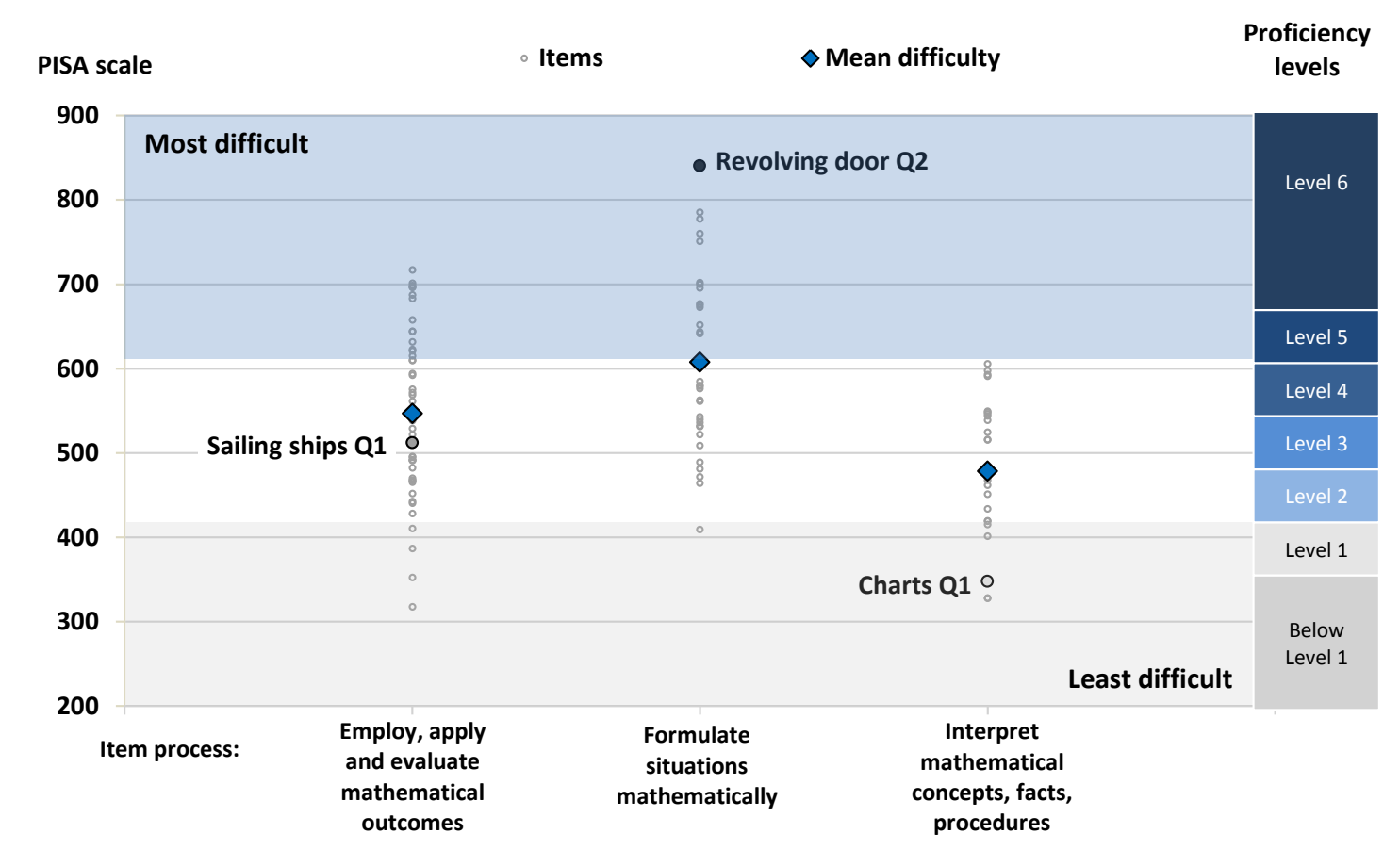

Source: OECD, PISA 2012 Database.

\section{Mathematics content areas and difficulty}

There are no obvious reasons why test questions related to the four mathematics content areas quantity, change and relationship, space and shape and uncertainty and data - should be more or less difficult. Yet items classified as space and shape tend to be more challenging probably because, in addition 
to requiring logical mathematical intelligence, they demand considerable spatial intelligence to solve (Gardner, 1983).

The most difficult items fall mainly in the change and relationships and space and shape content areas, with mean difficulty of 579 points and 594 points, respectively (Figure 2.5). Items classified as quantity (average difficulty of 500 points, which corresponds to proficiency Level 3) and uncertainty and data (average difficulty of 514 points, also Level 3) include most of the easy items (Level 1 or below) and only a few that require the highest level of proficiency to solve.

Figure 2.5. Mathematical content areas and difficulty of PISA mathematics items

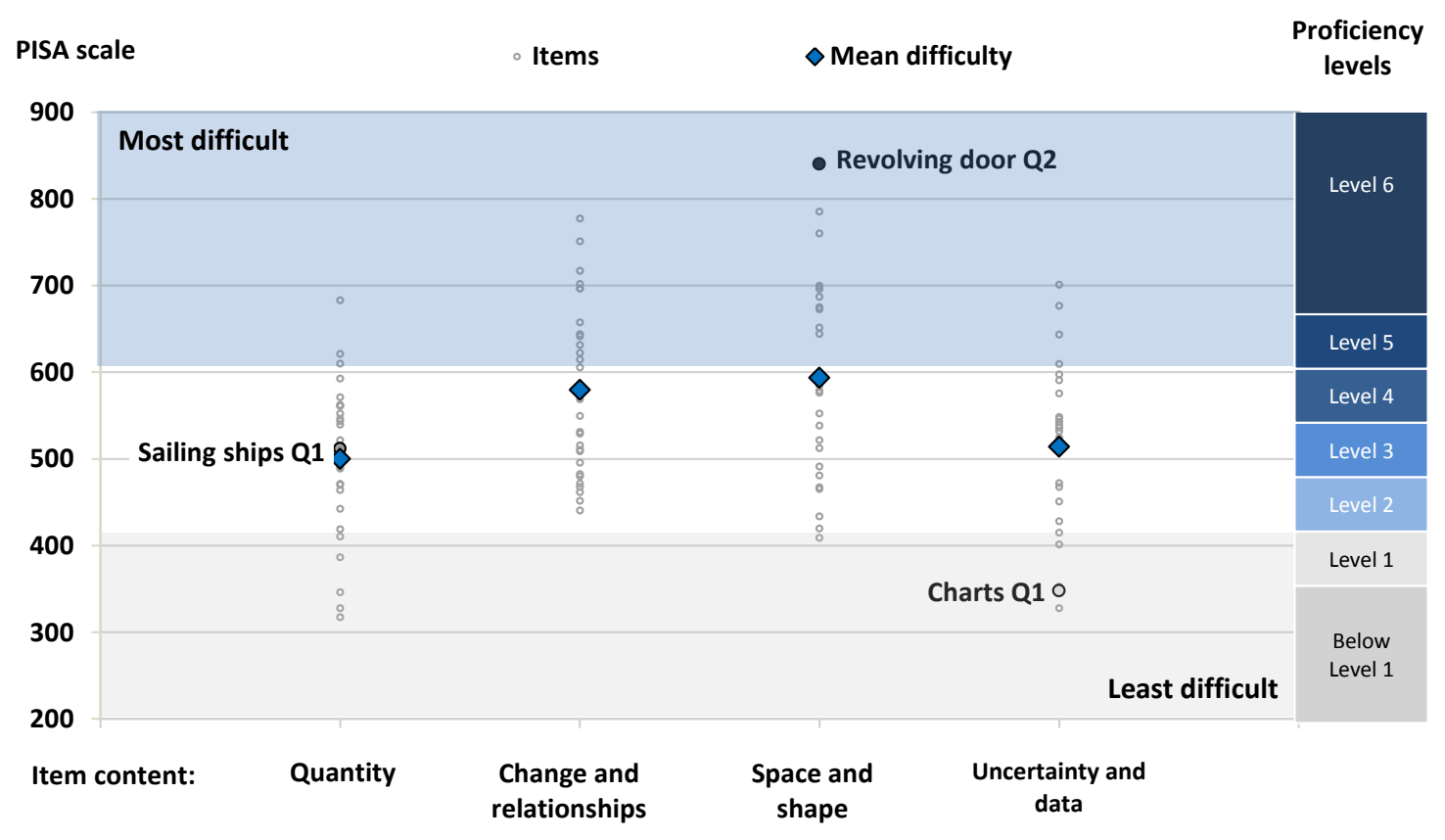

Source: OECD, PISA 2012 Database.

\section{Mathematics contexts}

Items situated in the four different contexts - personal, occupational, scientific and societal - share a similar level of difficulty (Figure 2.6). The items set in a scientific context, which include both "Sailing ships Q1" and "Revolving door Q2", are the most difficult (583 points), followed closely by items set in occupational contexts (565 points). Items classified as personal and societal are comparatively easier, with average difficulties of 526 points and 518 points, respectively.

To determine which of the classifications - response-format type, process, content or context - is the most strongly associated with an item's difficulty, a regression analysis was conducted including all of these characteristics (Figure 2.7). The results of the analysis shows that the response format and process classifications are the two most strongly related to item difficulty. After accounting for other item characteristics, those items that require a constructed response (expert) are 150 points more difficult on the PISA scale than those offering a simple multiple-choice response. Meanwhile, test questions classified as related to formulate and employ processes are also associated with item difficulty: they are 94 points and 57 points, respectively, more difficult than items requiring students to interpret, apply and evaluate mathematical outcomes. 
Figure 2.6. Contexts and difficulty of PISA mathematics items

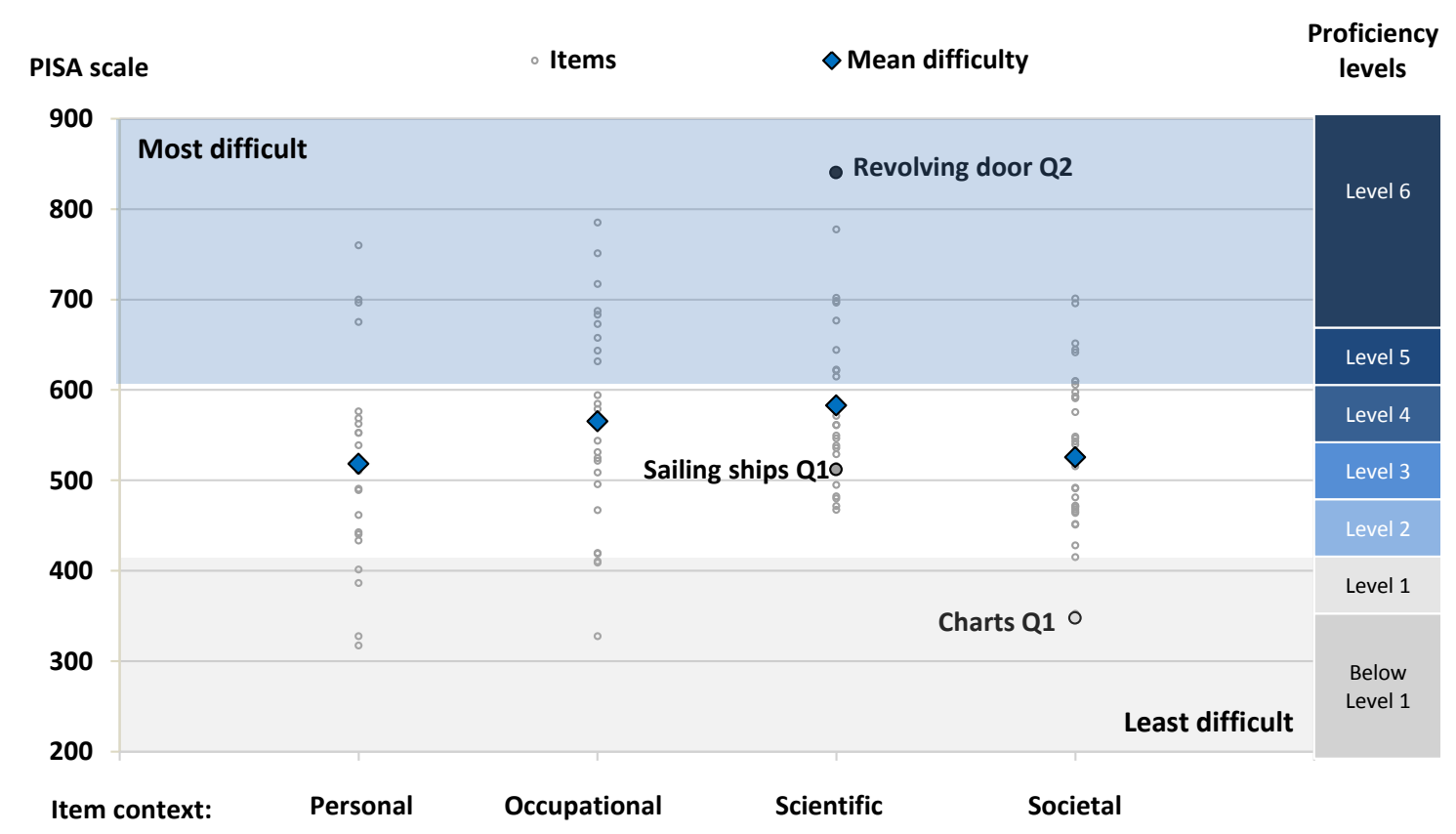

Source: OECD, PISA 2012 Database.

Figure 2.7. Association between item characteristics and difficulty

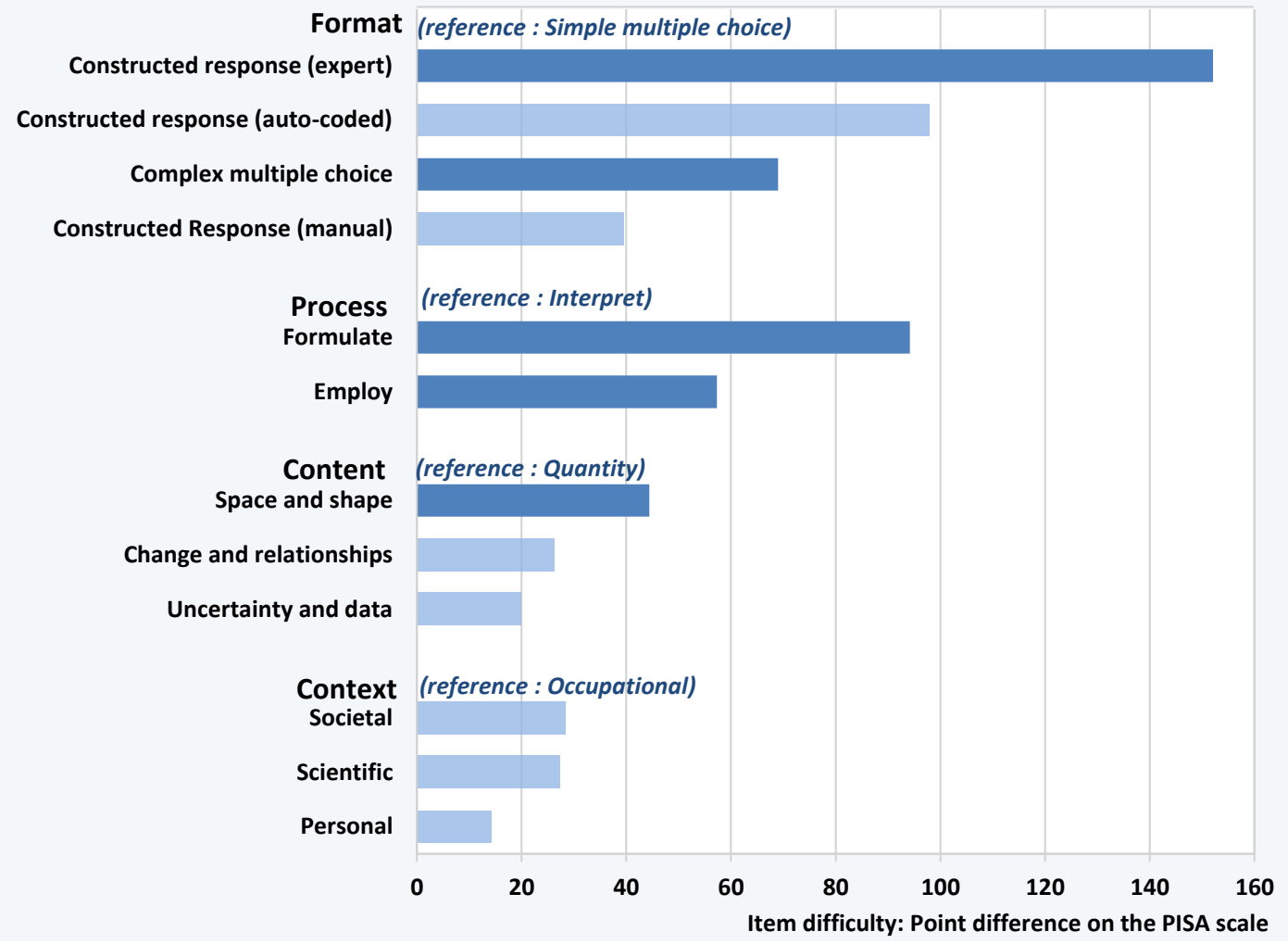

Significant coefficients are marked in a darker tone. The R-Square of the linear regression model is 0.55 . Source: OECD, PISA 2012 Database. 
By contrast, content area and context are not as strongly linked to item difficulty. In the content classification, only items classified as space and shape are significantly more difficult - by 44 points on the PISA scale - than items belonging to the quantity content area. The context in which the mathematics problem is set has no association with the problem's level of difficulty. The small difference in difficulty that is observed in Figure 2.6 is mainly explained by the fact that problems situated in certain contexts are more likely to use different response formats (Figure 2.8). For example, the greater difficulty of items set in scientific and occupational contexts is explained by the fact that many of these problems require openended responses; the relatively easy items set in the societal context more frequently require simple multiple-choice responses. These results also show that not only are PISA classifications related to item difficulty, but they overlap considerably among themselves too.

Figure 2.8. The overlapping of context and response format

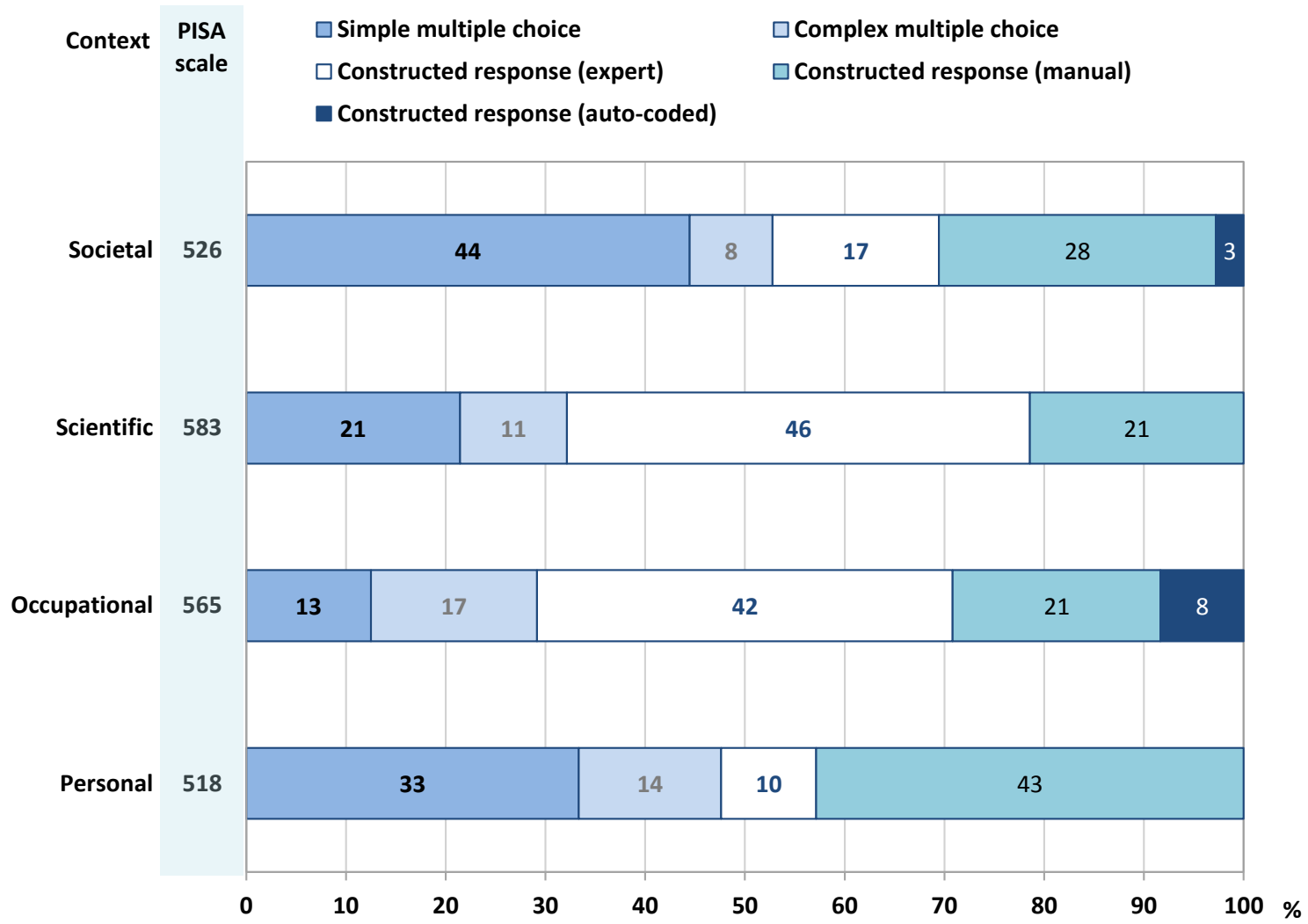

Note: Items set in the "scientific" context are the most difficult. Some $46 \%$ of these items are constructed response (expert) type. Items set in the "personal" context are the least difficult. Only $10 \%$ of these items are constructed response (expert) type.

Source: OECD, PISA 2012 Database.

These findings have several implications. For designing mathematics tests, they show that questions need to use different response formats, cover the full modelling cycle, and include all content areas that are appropriate for 15-year-olds in order to measure the full range of students' abilities. The strong association between open-ended questions and item difficulty, for example, suggests that these questions are crucial in order to measure what top performers know, understand and can do as problem solvers.

For this report, whose main goal is to identify those teaching and learning strategies that work best for individual mathematics items, the overlapping of PISA classifications means that is not always necessary to carry out the analyses and present the results for all five classifications. In Chapter 3, for instance, the relationship between teaching practices and success in solving individual mathematics problems are examined only as related to the difficulty of the items. 


\section{References}

Bridgeman, B., and R. Moran (1996), "Success in College for Students with Discrepancies Between Performance on Multiple Choice and Essay Tests", Journal of Educational Psychology, Vol. 88/2, pp. 333-340.

Ennis, R. (1993), “Critical Thinking Assessment”, Theory into Practice, Vol. 32/3, pp. 179-186.

Gardner, H. (1983), Multiple Intelligences: The Theory in Practice, Basic Books, New York.

Halpern, D. (2003), "The "how" and "why" of critical thinking assessment", in D. Fasko (Ed.), Critical Thinking and Reasoning: Current Research, Theory and Practice, Hampton Press, Cresskill, NJ.

Ku, K. (2009), “Assessing Students’ Critical Thinking Performance: Urging for Measurements Using Multi-Response Format", Thinking Skills and Creativity, Vol. 4/1, pp. 70-76.

OECD (2014), PISA 2012 Technical Report, PISA, OECD Publishing, Paris.

OECD (2013a), PISA 2012 Assessment and Analytical Framework: Mathematics, Reading, Science, Problem Solving and Financial Literacy, OECD Publishing, Paris, http://dx.doi.org/10.1787/9789264190511-en.

OECD (2013b), Lessons from PISA 2012 for the United States, Strong Performers and Successful Reformers in Education, OECD Publishing, Paris, http://dx.doi.org/10.1787/9789264207585-en.

Notes:

1 The mathematics items could also be administered in a paper-based or a computer-based format, but this classification only applies to half of the PISA-participating countries and economies that participated in the computer-based assessment.

2 The range of difficulty of the tasks in the PISA 2012 mathematics assessment was represented by six levels of mathematical proficiency. The levels range from the lowest, Level 1, to the highest, Level 6. Students with proficiency within the range of Level 1 are likely to be able to complete Level 1 tasks, but are unlikely to be able to complete tasks at higher levels. Students with scores in the range of Level 6 are likely to be able to complete tasks located at that level, as well as all the other PISA mathematics tasks. Information on the mathematical skills, knowledge and understanding required at each level of the mathematical literacy scale, the average proportion of students at each of these proficiency levels across OECD countries, and the range of scores that each level covers can be found in PISA 2012 Results: What Students Know and Can Do, PISA, OECD Publishing, http://dx.doi.org/10.1787/9789264201118-en.

${ }^{3}$ Regardless of which additional booklet was completed by students, the 59 items common to all education systems guarantee that students' performance can be placed on a continuous scale with Item Response Theory (IRT). 


\section{CHAPTER 3. TEACHING STRATEGIES AND BELIEFS, AND STUDENT PERFORMANCE}

Students' learning and motivation to learn are directly influenced by their teachers. While the atmosphere at school may promote or undermine student achievement, teaching practices in the classroom have an even stronger impact (Wang et al., 1993; Wayne and Youngs 2003; Hattie, 2009; Hanushek and Woessmann 2011). Today's students need teachers who are confident in their own knowledge and skills, challenging and innovative in their teaching practices, and who can reach all types of learners (OECD, 2015).

But what is high-quality teaching? Evidence suggests that there is no single "best" way of teaching for every learner, subject and context (OECD, 2013). Teachers can be effective using a variety of teaching techniques, tailoring them to the students and contexts in question. For example, teaching complex mathematical skills, such as linking mathematics concepts to students' daily lives, might require different instructional strategies than those used to solve basic mathematics problems (Schoenfeld, 1987, 1992).

This chapter looks at teaching strategies, and their relation to student achievement, based on PISA 2012 results and on evidence provided by students who responded to the student questionnaire that was distributed with the assessment. The chapter starts by reviewing the way teaching strategies are conceptualised and measured in PISA. It then identifies the most frequently used teaching strategies across PISA-participating countries and economies. It concludes by examining the relationship between these strategies and students' mean scores in mathematics, in general, and students' success in solving easy, intermediate or difficult mathematics problems, in particular.

The findings are complemented by analysing the relationship between teaching practices, as reported by teachers in the 2013 OECD Teaching and Learning International Survey (TALIS) (Box 3.1), and student performance in the PISA tests. Measuring teaching practices from the perspective of both teachers and students is important because the two groups might have different perceptions of what happens in the classroom (Kunter and Baumert, 2006; Kunter et al., 2008).

\section{Box 3.1. The TALIS-PISA Link}

Eight countries that participated in the 2013 Teaching and Learning International Survey (TALIS) opted to survey teachers in schools that also participated in the PISA 2012 cycle. The TALIS-PISA Link examines the relationships between the information reported by teachers and principals in the TALIS survey with the information reported by students, principals and parents in PISA, and with the performance of those students in the PISA assessments. TALIS provides insight into teachers' backgrounds, beliefs and practices through data collected from teachers and their school principals. More information about the TALIS 2013 study can be found in the initial report and supporting documentation (OECD, 2014a; 2014b).

The design of the TALIS-PISA Link:

- International target population: Teachers in schools that participated in PISA 2012.

- Representative samples of schools and teachers within schools with a target sample size of 150 schools per country, 1 school principal and 20 teachers in each school, including all eligible mathematics teachers.

- Target response rates: $75 \%$ of the sampled schools, together with a $75 \%$ response rate from all sampled teachers in the country. A school is considered to have responded if $50 \%$ of sampled teachers responded.

- TALIS questionnaires for teachers and school principals, with a special, additional questionnaire for mathematics teachers, were available on paper and on line.

- Survey windows:

- For TALIS 2013: September-December 2012 for countries in the southern hemisphere and February-June 2013 for countries in the northern hemisphere countries.

- For PISA 2012: Usually March-May 2012 for countries/economies in the northern hemisphere and May-August 2012 for countries in the southern hemisphere.

- Participating countries: Australia, Finland, Latvia, Mexico, Portugal, Romania, Singapore and Spain. 
Teachers and school principals were given the TALIS teacher and principal questionnaires, which require between 45 and 60 minutes to complete. Teachers answered questions about the teaching practices they used in their first class after 11 a.m. on the previous Tuesday. Sampled mathematics teachers were also given an additional short questionnaire asking them about the mathematics classes they teach. Mathematics teachers were asked in more detail about the teaching practices they used in this particular class and their beliefs about teaching and learning mathematics. Further details about the sample for all target populations and about the TALIS questionnaires can be found in the TALIS 2013 Technical Report (OECD, 2014b).

Since schools, rather than classrooms, are the basis of the association between students and teachers in the TALIS-PISA Link study, any information about individual students can only be linked to the TALIS survey by aggregating teachers' responses at the school level.

\section{References}

OECD (2014a), TALIS 2013 Results: An International Perspective on Teaching and Learning, OECD Publishing, Paris, http://dx.doi.org/10.1787/9789264196261-en.

OECD (2014b), TALIS 2013 Technical Report, OECD, Paris, http://www.oecd.org/edu/school/TALIStechnical-report-2013.pdf.

Results in this chapter must be interpreted cautiously. PISA and TALIS data on teaching strategies do not come from direct observations of classrooms, but from students' and teachers' reports. Furthermore, the information collected in both surveys is cross-sectional and therefore any causal interpretations of the findings should be downplayed or considered inaccurate. Even if some analyses account for a range of contextual characteristics, other relevant characteristics about students, teachers and schools remain unobserved, which means that the analyses are correlational in nature and the findings should be interpreted accordingly. Reverse causality is of particular concern here, because teaching strategies can influence student performance as much as students' abilities, or teachers' expectations of those abilities, can lead teachers to adopt particular types of instructional practices. Additional caution is needed when interpreting the results from the TALIS-PISA Link study because it considers students in relation to their school, not to their individual teachers, and the TALIS 2013 survey was conducted later than the PISA 2012 assessments in countries in the northern hemisphere.

\section{Teaching strategies measured in PISA}

In its Analytical Framework (OECD, 2013), PISA defines the three dimensions of good teaching as: clear, well-structured classroom management; supportive, student-oriented classroom climate; and cognitive activation with challenging content (Klieme et al, 2009; Baumert et al, 2010; Lipowsky et al, 2009; Kunter et al 2008).

Teachers have a wide array of instructional strategies at their disposal. Some of these can be classified as "traditional" (a.k.a. "vertical") or "modern" (a.k.a. "horizontal") methods (Bietenbeck, 2014; Schwerdt et al, 2001; Schoenfeld, 1987, 1992; Stein 2008). A teacher using traditional methods of instruction will aim to provide a well-structured, clear and informative lecture on a given topic. Traditional instruction is typically directed by the teacher, who decides what students have to learn, plans the lessons in advance and delivers the content. This can involve starting the class by briefly summarising the previous lesson and clearly establishing the goals for the current lesson. Students would be expected to remain silent and take notes, or could be requested to participate, by answering teachers' questions or by posing their own questions to the teacher. Teachers can pose questions to students as a way to make sure that they understand the material, and to invite students to present their thinking or reasoning at some length. 
As in other teaching strategies, much of the effectiveness of teacher-directed practices depends upon how these practices are used in the classroom. Whereas good-quality, well-structured and dynamic lessons can be both inspiring and challenging for students, teacher-directed instruction risks leaving students in a passive and disengaged role, and performing monotonous tasks. Previous analysis based on data from the OECD Teaching and Learning International Survey (TALIS) suggest that these strategies are associated with greater classroom discipline, as perceived by teachers (OECD, 2009). PISA measures the frequency of this kind of teaching strategy through the index of teacher-directed instruction (see Box 3.2).

Student-centred teaching methods, on the other hand, aim to give students a more active role in classroom processes (Deboer, 2002; Felder and Brent, 1996). Having students work in small groups to come up with joint solutions to problems or tasks, assigning projects or homework that require at least one week to complete, giving students a role in planning classroom activities and topics, and/or assigning different tasks to students based on the speed with which they learn, are all examples of student-oriented teaching practices. These kinds of practices might allow for more informal exchanges between teachers and students, and among students themselves (e.g. co-operative learning), compared with the more formal relationships engendered by traditional top-down approaches. Previous analysis based on teachers' reports suggest that student-oriented strategies are less commonly used by mathematics and science teachers compared with teachers of other subjects (OECD, 2009). PISA measures the frequency of this kind of teaching strategy through the index of student-oriented instruction.

In order to foster conceptual understanding and students' motivation to learn, teachers have to use content and stimuli that are challenging for students and demand the use of higher-order skills (Brown, 1994; Klieme, Pauli and Reusser, 2009). The literature on mathematics education in particular emphasises the effectiveness of challenging, cognitive-activation methods of instruction to develop mathematics skills (Baumert et al, 2010; Blum and Leiss, 2007). These strategies include asking students to solve mathematics problems that require them to think for an extended time, for which there is no immediately obvious solution or that can be solved in several different ways, or by using alternative routes and procedures. Challenging instructional practices may also include having students reflect on and share with their peers the process through which they solved mathematics problems covered in class or assigned as homework, which is a way that students can learn from their mistakes. They may also include requiring students to apply what they have learned to new contexts. PISA measures the frequency of these kinds of teaching strategies through the index of cognitive-activation instruction.

PISA considers one additional teaching strategy, namely, the extent to which teachers give feedback to their students on their progress in mathematics. Research has linked offering informative and encouraging feedback to better student performance (Hattie and Timperley, 2007; Black and William, 1998). This strategy includes conducting formative assessments to inform students of their strengths and weaknesses in mathematics, how well they are doing in mathematics class, what is expected of them in assignments, quizzes and tests, and suggesting actions that students can take to become better at mathematics. PISA measures the frequency of these kinds of teaching strategies through the index of formative-assessment instruction.

In this chapter, the teacher strategies described above are distinguished from those related to classroom management and disciplinary climate. Of course, teachers need classroom management skills to create a positive, orderly atmosphere that fosters respect between the teacher(s) and students. But a positive classroom climate is a pre-condition for quality instruction and learning, rather than an instructional strategy in the sense used here. It does not, in itself, constitute or guarantee high-quality instruction; rather, it allows teachers to use most of their time on teaching instead of on controlling disruptive behaviour (Creemers and Kyriakides, 2008; Harris and Chrispeels, 2006; Hopkins, 2005; Scheerens and Bosker 1997). 
A similar distinction is used in Carroll's classic model for school learning, where time actually spent on learning is defined as "opportunity to learn" and instructional practices as "quality of teaching" (Carroll, 1963, 1989). Thus, the empirical analyses in this chapter focus on instructional practices that are directly related to the pedagogies of teaching; the classroom and disciplinary climate will be analysed as the context in which the instructional practices take place.

\section{Box 3.2. How PISA and TALIS measure teaching strategies and beliefs}

Four indices measuring teaching strategies and beliefs are considered in this chapter: the index of teacherdirected instruction, the index of formative-assessment instruction, the index of student-oriented instruction, and the index of cognitive-activation instruction/beliefs. PISA 2012 collected data for these indices through the student questionnaire using the following questions and items:

How often do these things happen in your mathematics lessons?

Items considered in the index of teacher-directed instruction (PISA)

- The teacher sets clear goals for our learning.

- The teacher asks me or my classmates to present our thinking or reasoning at some length.

- The teacher asks questions to check whether we have understood what was taught.

- At the beginning of a lesson, the teacher presents a short summary of the previous lesson.

- The teacher tells us what we have to learn.

\section{Items considered in the index of student-oriented instruction (PISA)}

- The teacher gives different work to classmates who have difficulties learning and/or to those who can advance faster.

- The teacher assigns projects that require at least one week to complete.

- The teacher has us work in small groups to come up with joint solutions to a problem or task.

- The teacher asks us to help plan classroom activities or topics.

\section{Items considered in the index of formative-assessment instruction (PISA)}

- The teacher tells me about how well I am doing in my mathematics class.

- The teacher gives me feedback on my strengths and weaknesses in mathematics.

- The teacher tells us what is expected of us when we get a test, quiz or assignment.

- The teacher tells me what I need to do to become better in mathematics.

Thinking about the mathematics teacher who taught your last mathematics class: How often does each of the following happen?

\section{Items considered in the index of cognitive-activation instruction (PISA)}

- The teacher asks questions that make us reflect on the problem.

- The teacher gives problems that require us to think for an extended time.

- The teacher asks us to decide on our own procedures for solving complex problems.

- The teacher presents problems for which there is no immediately obvious method of solution.

- The teacher presents problems in different contexts so that students know whether they have understood the concepts.

- The teacher helps us to learn from mistakes we have made.

- The teacher asks us to explain how we have solved a problem.

- The teacher presents problems that require students to apply what they have learned to new contexts.

- The teacher gives problems that can be solved in several different ways.

Responses available to students were: "Every lesson", "Most lessons", "Some lessons", and "Never or hardly ever" for questions used in the indices of teacher-directed, student-oriented and formative-assessment instruction. 
For the index of cognitive-activation instruction, available responses were: "Always or almost always", "Often", "Sometimes" and "Never or rarely". When answering these questions, students could give positive responses to as many of these teaching practices as they considered correct (no restriction on the number of possible responses).

PISA indices are standardised to have a value of zero, which corresponds to the OECD average student, and a standard deviation of 1 , meaning that about two-thirds of the OECD student population are located between the values of -1 and 1 on the indices. Positive scores indicate that students responded more positively than the average OECD student (for more information, see OECD, 2015).

Each student has a value for each one of these indices; therefore, students in the same school and in the same classroom could have different values in each one of these indices. Differences in student-reported instructional indices could reflect the true heterogeneity of teaching practices (e.g. some teachers use a wider variety of strategies than others), or they could be due to differences in students' perceptions about their teachers or in students' response styles. Previous studies have shown that response biases, such as social desirability, acquiescence and extreme response, are more common in countries with low GDP than in more affluent countries and, within countries, more common among individuals of lower socio-economic status and less education (Buckley, 2009; Bempechat, Jimenez and Boulay, 2002).

TALIS 2013 and PISA 2012 did not use identical lists of instructional practices. The following questions and items were used in TALIS to collect information on teaching strategies and beliefs:

(1) How often does each of the following happen in the <target class $>$ throughout the school year?

(2) How often do you use the following methods of assessing student learning in the <target class>?

(3) We would like to ask about your personal beliefs on teaching and learning. Please indicate how strongly you agree or disagree with each of the following statements.

\section{Items considered in the index of teacher-directed instruction (TALIS)}

- (1) I present a summary of recently learned content.

- (1) I let students practice similar tasks until I know that every student has understood the subject matter.

Items considered in the index of student-oriented instruction (TALIS)

- (1) Students work in small groups to come up with a joint solution to a problem or task.

- (1) I give different work to the students who have difficulties learning and/or to those who can advance faster

- (1) Students work on projects that require at least one week to complete.

\section{Items considered in the index of formative-assessment instruction (TALIS)}

- (1) Check my students' exercise books or homework.

- (2) I provide written feedback on student work in addition to a mark.

- (2) I observe students when working on particular tasks and provide immediate feedback.

\section{Items considered in the index of cognitive activation beliefs (TALIS)}

- (3) My role as a teacher is to facilitate students' own inquiry.

- (3) Students learn best by finding solutions to problems on their own.

- (3) Students should be allowed to think of solutions to practical problems themselves before the teacher shows them how they are solved.

-(3) Thinking and reasoning processes are more important than specific curriculum content.

Responses available to teachers in questions (1) and (2) were: "Never or almost never", "Occasionally", "Frequently", and "In all or nearly all lessons". In question (3) on teaching and learning beliefs, the responses available to teachers were: "Strongly disagree", "Disagree", "Agree", and "Strongly agree".

The indices are standardised to have a value of zero, which corresponds to the average teacher across the eight countries participating in the TALIS-PISA Link, and a standard deviation of 1 , meaning that about two-thirds of the teacher population in these countries are located between the values of -1 and 1 on the indices. Positive scores indicate that teachers responded more positively than the average teacher in these countries. 


\section{References}

Bempechat, J., N.V. Jimenez and B.A. Boulay (2002), "Cultural-cognitive issues in academic achievement: New directions for crossnational research", in A.C. Porter and A. Gamoran (eds.), Methodological Advances in Cross-National Surveys of Educational Achievement, National Academic Press, Washington, D.C.

Buckley, J. (2009), "Cross-national response styles in international educational assessments: Evidence from PISA 2006”, Department of Humanities and Social Sciences in the Professions, Steinhardt School of Culture, Education, and Human Development, New York University, New York.

Kunter, M., Y.-M. Tsai, U. Klusmann, M. Brunner, S. Krauss and J. Baumert (2008), "Students' and Mathematics Teachers' Perception of Teacher Enthusiasm and Instruction”, Learning and Instruction, Vol. 18, pp. 468-482.

OECD (2015), PISA 2012 Technical Report, PISA, OECD Publishing, Paris.

\section{The use of teaching strategies in PISA-participating countries and economies}

Figures 3.1a, b, c and d show the average share of students in all countries and economies that participated in PISA 2012 who reported that their mathematics teacher uses the instructional practices included in each of the four instructional indices considered in this chapter.

Figure 3.1a. Teaching strategies in PISA: Teacher-directed instructional practices Percentage of students who responded "in every lesson or most lessons"

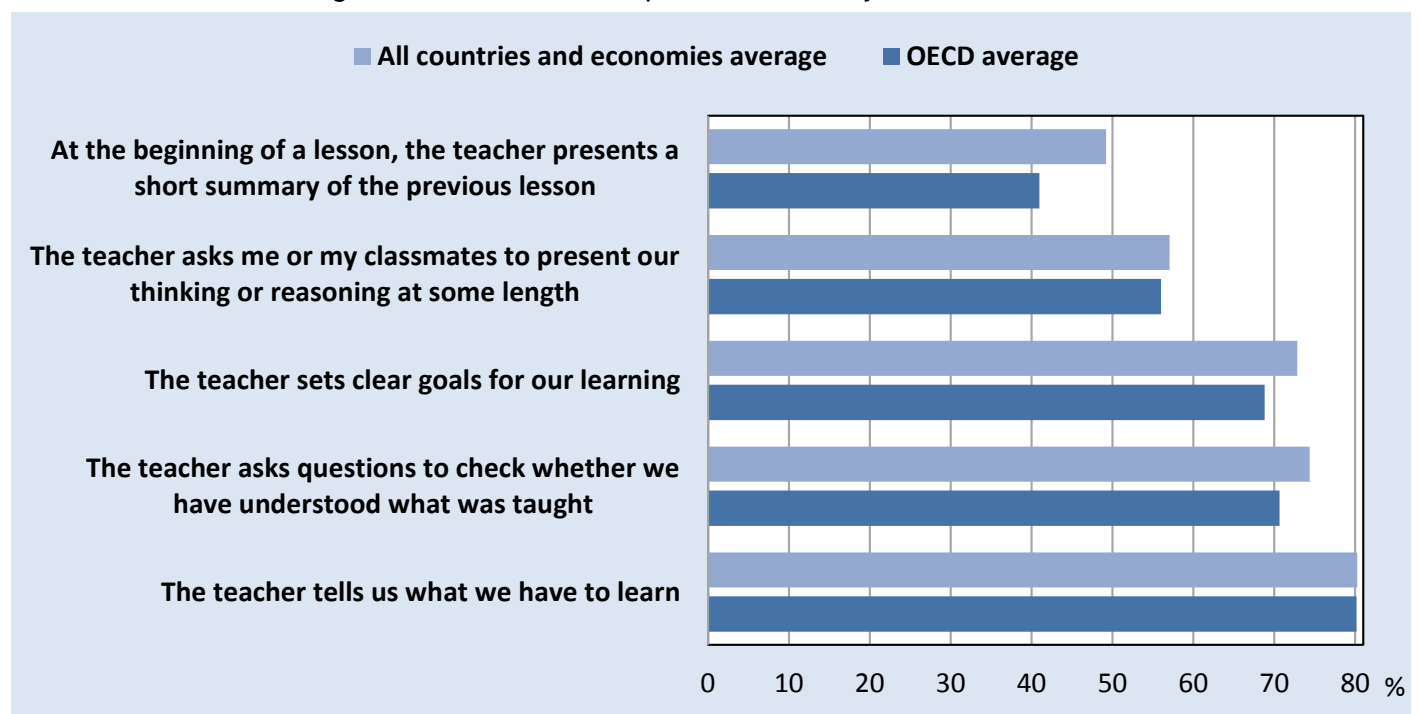

Source: OECD, PISA 2012 Database.

According to students' reports, the "traditional" teacher-directed methods of instruction were among the most frequently used. On average across OECD countries, eight out of ten students (80\%) reported having a mathematics teacher who tells them what they have to learn in every or most lessons; only in Spain and Uruguay was this share smaller than $70 \%$ (66\% in both cases). Similarly, about seven out of ten OECD students reported having a mathematics teacher who asks questions to check whether students understood the material $(71 \%)$ or who set clear goals for student learning (69\%). Out of all teacher-directed instructional practices, the least commonly used, according to students' reports, is presenting a short summary of the previous lesson at the beginning of the current lesson. Some $40 \%$ of students in OECD countries reported that their teachers did this.

Cognitive-activation strategies were also among the most frequently used, particularly asking students to explain how they solved a problem. On average across OECD countries, $70 \%$ of students reported that 
their teachers ask them to do this. The proportions range from more than $80 \%$ of students in Albania, Germany, Liechtenstein, the Russian Federation and the United Kingdom, to only $44 \%$ of students in Japan.

Figure 3.1b. Teaching strategies in PISA: Cognitive-activation instructional practices Percentage of students who responded "in every lesson or most lessons"

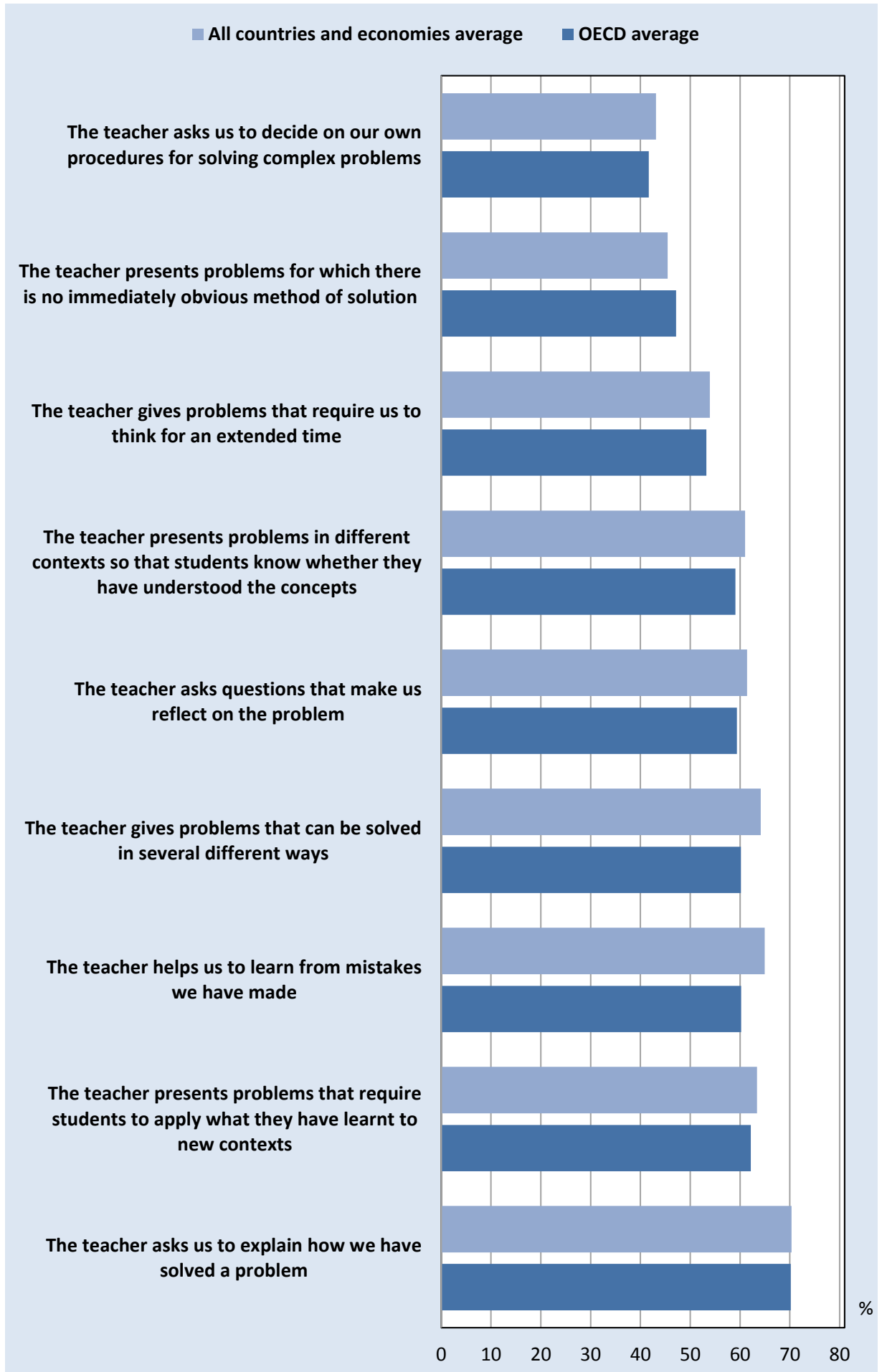

Source: OECD, PISA 2012 Database. 
Figure 3.1c. Teaching strategies in PISA: Student-oriented instructional practices

Percentage of students who responded "in every lesson or most lessons"

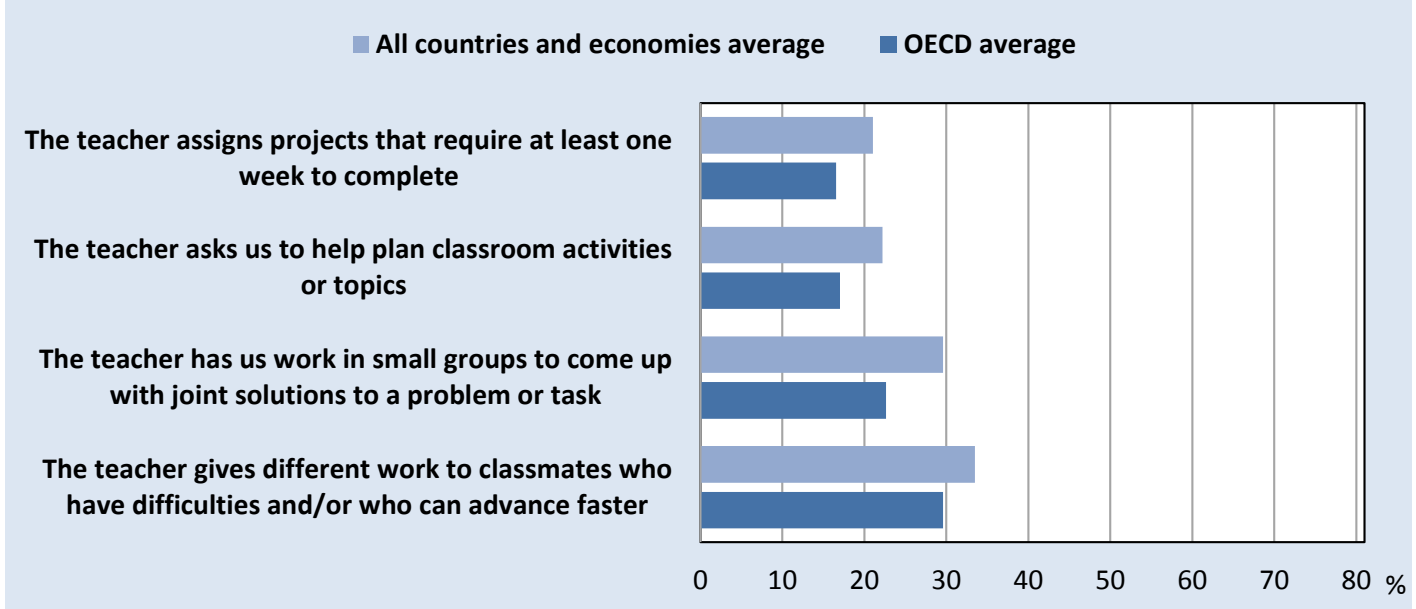

Source: OECD, PISA 2012 Database.

Figure 3.1d. Teaching strategies in PISA: Formative-assessment instructional practices

Percentage of students who responded "in every lesson or most lessons"

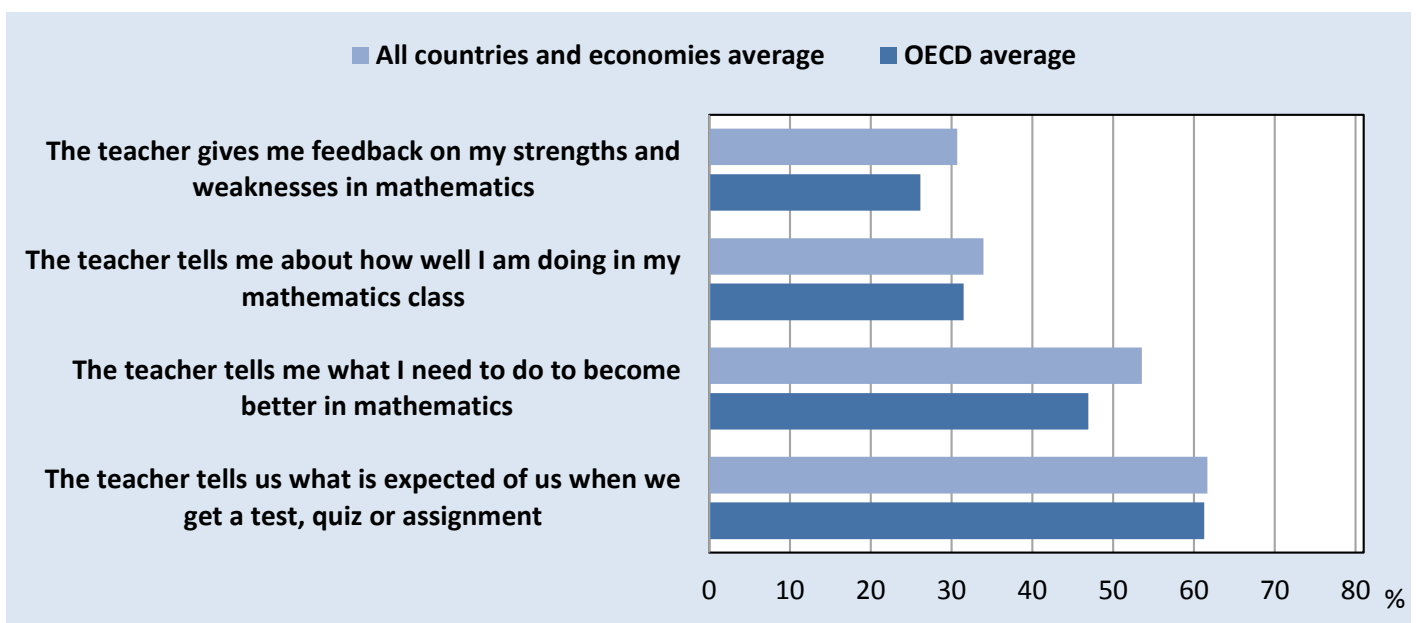

Source: OECD, PISA 2012 Database.

More than one in two students across OECD and partner countries/economies also reported that their teachers use other cognitive-activation strategies, such as asking students to explain how they solved a problem, asking students to apply what they have learned to new contexts, helping students to learn from mistakes, giving students problems that can be solved in several different ways, asking questions that make students reflect on how to solve a problem, presenting problems in different contexts so that students know whether they have understood the concepts, and giving students problems that require them to think for an extended time.

Student-oriented instructional practices, such as having students work in small groups, conducting projects that require at least one week to complete, or asking students to help plan classroom activities, were the least frequently used, on average across all participating countries and economies. The most 
common of these strategies was giving different work to students based on the speed with which they learned. Fewer than one in three students in OECD countries reported that their teachers did this.

Formative-assessment techniques were also not very frequently used in mathematics classes, with the exception of telling students what is expected of them for tests, quizzes and assignments. Around $60 \%$ of students reported that their teachers did this in all countries/economies.

\section{Box 3.3. The use of teaching strategies, according to teachers}

Teacher-directed instructional practices are the most frequently reported by teachers in the eight countries participating in the TALIS-PISA Link study, and they are also those whose frequency varies the least across countries (Figure 3.2). On average across the eight countries, about three out of four teachers reported presenting a summary of recently learned content or letting students practice similar tasks until they have understood the subject matter.

By contrast, student-oriented strategies are relatively uncommon. Among the three instructional practices mentioned in the TALIS survey, the least frequently used is having students work on projects that require at least one week to complete. On average, $30 \%$ of mathematics teachers reported that they use that practice frequently or in all, or nearly all, their lessons. This contrasts with the more than $40 \%$ of mathematics teachers who frequently or in all, or nearly all, their lessons have students work in small groups and/or assign different work to students with different capacities. The largest discrepancies in teaching practices among the eight countries included the TALIS-PISA Link study are generally found with respect to student-oriented practices. For example, whereas across the eight countries $46 \%$ of teachers said they have students work in small groups frequently or in all, or nearly all, lessons, as many as $75 \%$ of teachers in Mexico and only $31 \%$ of teachers in Singapore reported so.

Figure 3.2. Teaching strategies in TALIS-PISA Link countries

Percentage of teachers who responded "frequently" or "in all or nearly all lessons"

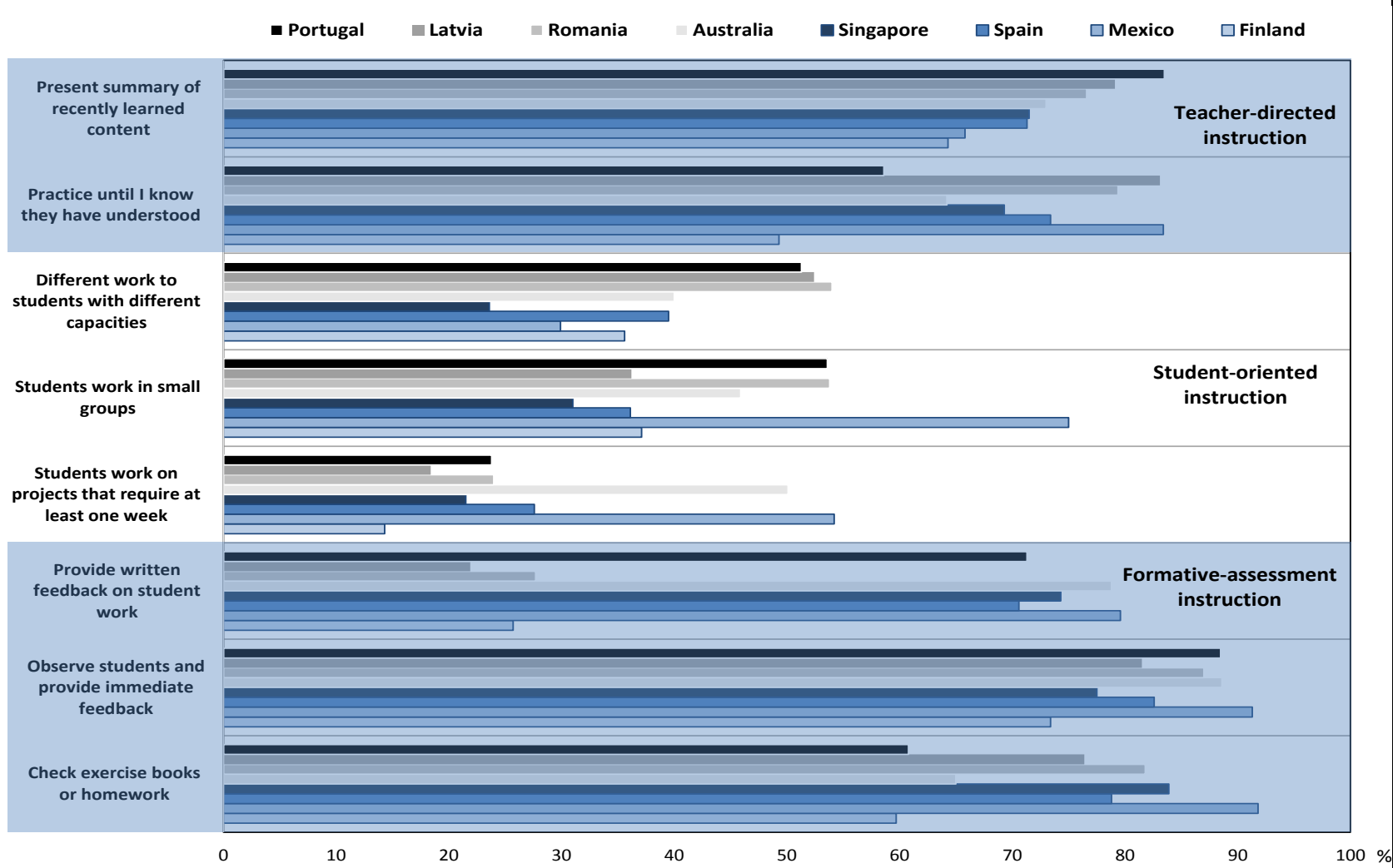

Note: Only the countries that participated in the TALIS-PISA Link study are shown.

Countries are ranked in descending order of the percentage of teachers who reported that they present a summary of what students recently learned.

Source: OECD, TALIS-PISA Link Study. 
Teachers reported that they frequently use formative-assessment instruction, particularly checking exercise books or homework. However, only $26 \%$ of teachers in Finland said they provide written feedback on student work (in addition to a mark) frequently or in all, or nearly all, their lessons, while on average across the countries participating in the TALIS-PISA Link study, more than half of teachers reported that they did.

There are some differences, both across and within countries, in how much teachers believe that challenging and stimulating students is important (Figure 3.3). A vast majority of mathematics teachers agrees or strongly agrees that thinking and reasoning is more important than the curriculum, that their role is to facilitate students' own inquiry, that students need to think of solutions before the teachers solves the problem, and that students learn best by finding solutions on their own.

Figure 3.3. Teachers' beliefs about cognitive-activation strategies (TALIS-PISA Link countries)

Percentage of teachers who agreed or strongly agreed

Thinking and reasoning is more important than the curriculum

$\square$ Students think of solutions before the teacher solves the problem

$\square$ Students learn best by finding solutions on their own

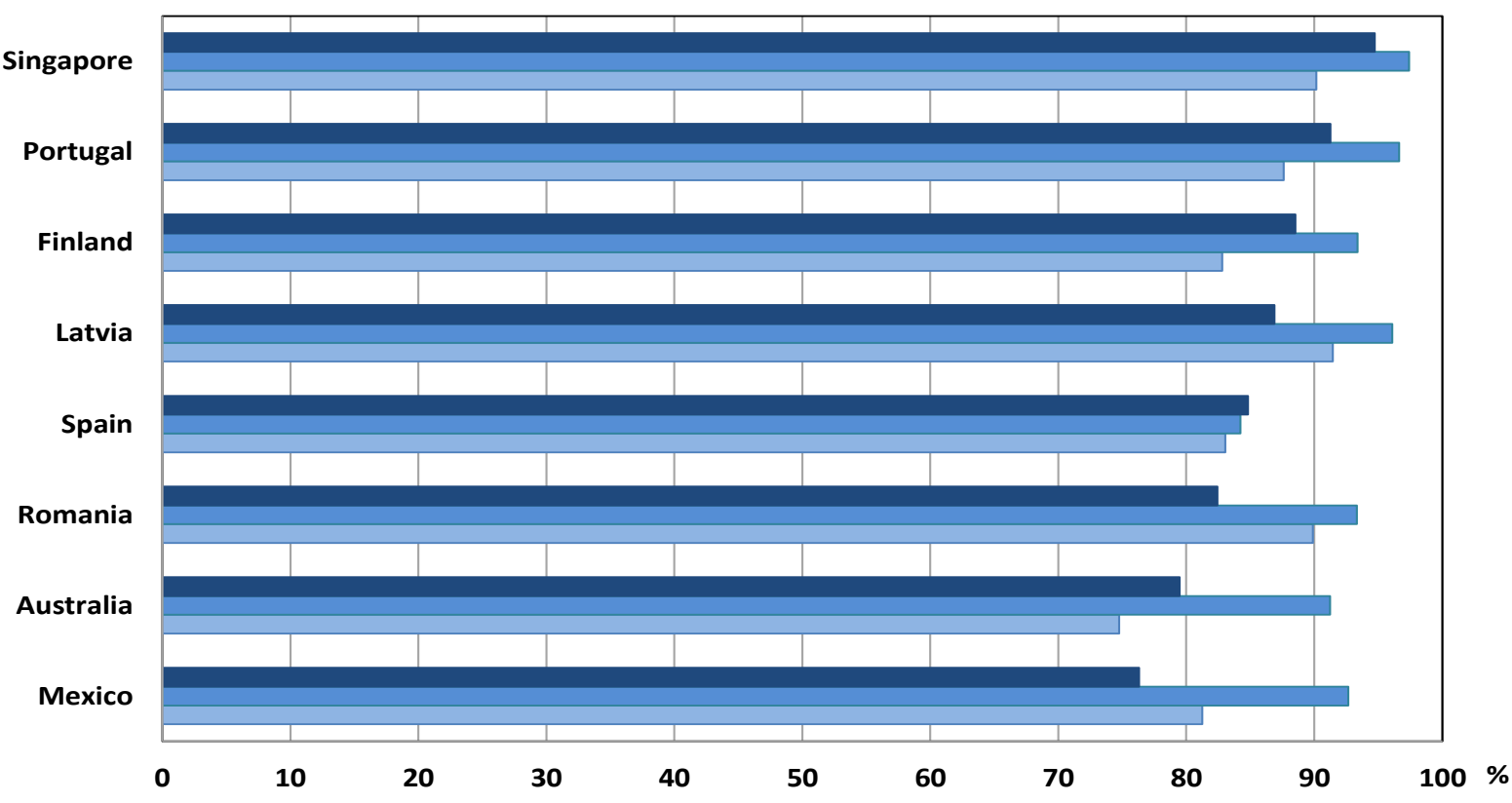

Note: Only the countries that participated in the TALIS-PISA Link study are shown.

Countries are ranked in descending order of the percentage of teachers who reported that thinking and reasoning is more important than curriculum.

Source: OECD, TALIS-PISA Link Study.

When all of these questions are used to build the four indices of teaching strategies and beliefs, Mexico and Finland stand out as the countries with the highest and lowest values, respectively, overall (Figure 3.4). Teacher-directed practices have positive values in Latvia, Mexico, Romania and Spain, which means these practices are used more frequently by the teachers in these countries than by the average teacher in the eight countries that opted to participate in the TALIS-PISA Link study.

Meanwhile, teachers in Mexico are much more likely to report using student-oriented strategies, relative to other countries that participated in the TALIS-PISA Link study, and those in Finland and Singapore much less likely. According to teachers' reports, formative-assessment practices are much more frequently used in Mexico than in other countries, and in Finland and Latvia much less so. The belief in using cognitive-activation strategies are weakest in Australia, Finland and Spain, compared to the other countries participating in the TALIS-PISA Link study. 


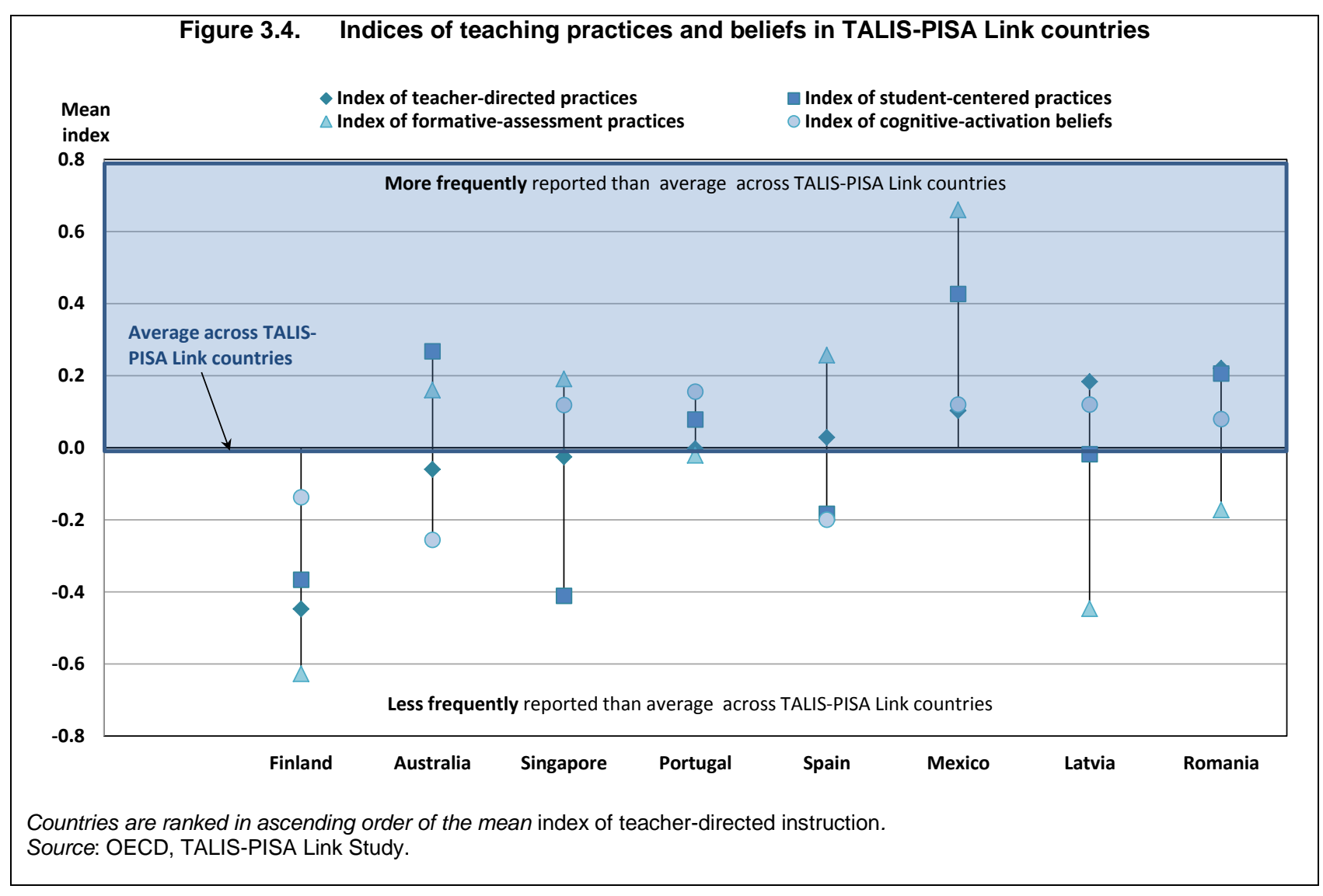

\section{Cross-national differences in the use of teaching strategies}

As explained in more detail in Box 3.2, PISA 2012 measured teaching strategies based on students' reports. One of the potential limitations of this methodology is that students in different countries might respond to questions in different ways for different reasons (e.g. social desirability, acquiescence, extreme response choice). This kind of bias is evident in students' responses to the questions included in the indices of teaching strategies, as can be seen in Figure 3.5. The figure reveals a strong negative correlation between the mean value for each country/economy in the PISA student-reported instructional indices and the average country/economy score in the mathematics assessment (coefficient of correlation is -0.67). In other words, contrary to expectations, top-performing education systems, such those of Hong Kong-China, Japan and Korea, have lower values on PISA instructional indices, while low-performing countries, such as Albania, Jordan and Kazakhstan, have the highest values. It is thus possible that the figure reflects differences in response styles rather than true cross-national differences in teacher practices.

One way to account for this potential bias in students' responses is to transform the scale of the four indices to reflect how frequent an instructional practice is used relative to both other education systems and other teaching strategies. To do this, for each student the mean of the four instructional indices was calculated, and then subtracted from each index. These transformed instructional indices can be interpreted as saying how frequently the mathematics teacher of a particular student employs an instructional strategy relative to the teachers of other students, after accounting for their response styles. The assumption behind these new indices is that the amount of teaching is constant, and that only the time allocated to each instructional practice varies. At the system level, a positive country value in these transformed indices indicates that, relative to other teaching strategies, a particular teaching approach is more frequently used than in other OECD countries. Or that, relative to other OECD countries, a particular teaching approach is more frequently used than other teaching strategies (see Figures 3.6 to 3.9). 
Figure 3.5. Response bias in students' responses to questions about teachers' instructional practices

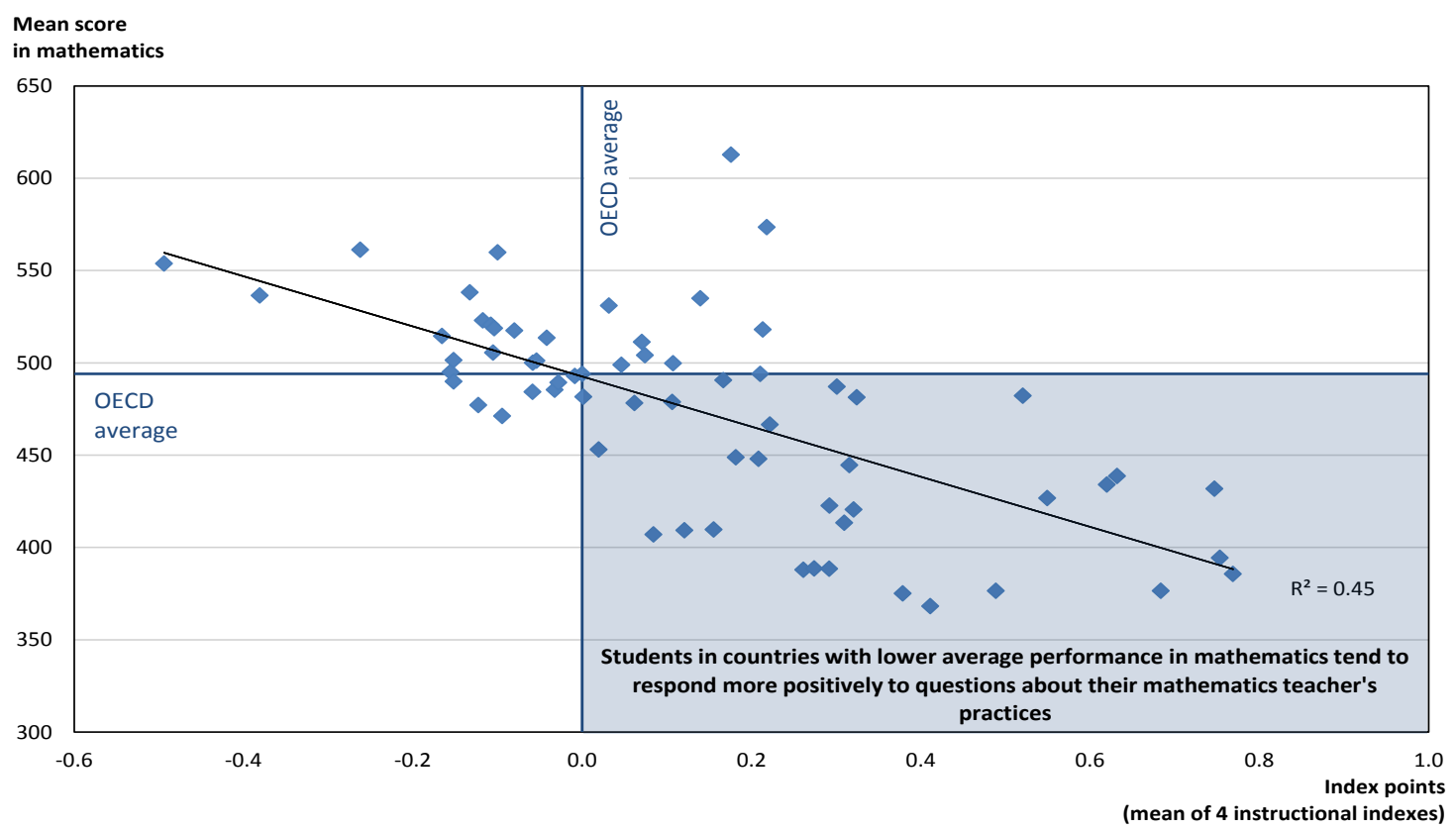

Source: OECD, PISA 2012 Database.

Figure 3.6 shows that, compared to the OECD average, teacher-directed instruction in mathematics is more commonly employed than other instructional approaches in 31 countries and economies, and by a wide margin in Shanghai-China, but also in Albania, Greece, Kazakhstan, Korea, the Russian Federation and Viet Nam. Teacher-directed instruction is also frequently used in Japan and Macao-China (but not in Singapore or Chinese-Taipei), top-performing East Asian education systems that have been widely described as emphasising traditional methods of mathematics education (Leung, 2001). By contrast, in 31 other countries and economies, teacher-directed instruction, as measured by the transformed index of teacher-directed instruction, is relatively uncommon, particularly in Denmark, New Zealand, Norway, Poland and Qatar.

Student-oriented instructional practices are used more frequently than the OECD average, relative to other instructional strategies, in 40 countries and economies, and less frequently in 23 countries and economies (Figure 3.7). These strategies are most frequently used, compared to the other three teaching strategies and the OECD average, in Iceland, Indonesia, Korea, Qatar, Sweden and Thailand. They are relatively rarely used in Croatia, France, Hungary, Ireland, Shanghai-China and Slovenia.

Figure 3.8 shows the index of formative-assessment instruction, transformed as above. In 31 countries and economies formative-assessment instruction is, relative to other teaching strategies and the OECD average, frequently used, especially in Austria, Croatia, Italy and the Slovak Republic. By contrast, in several topperforming education systems like Japan, Korea and Macao-China, and also in Argentina, Mexico and Uruguay, formative assessment is relatively uncommon.

Relative to the OECD average, in 27 countries and economies, cognitive-activation strategies are more frequently used than other practices and less commonly used in 37 countries and economies (Figure 3.9). Relative to both other teaching strategies and the OECD average, these strategies are most frequently used in Ireland, Poland, Spain and the United Kingdom, and rarely used in Albania, Kazakhstan, Thailand and Viet Nam. 
Figure 3.6. Differences accross countries in teacher-directed instruction

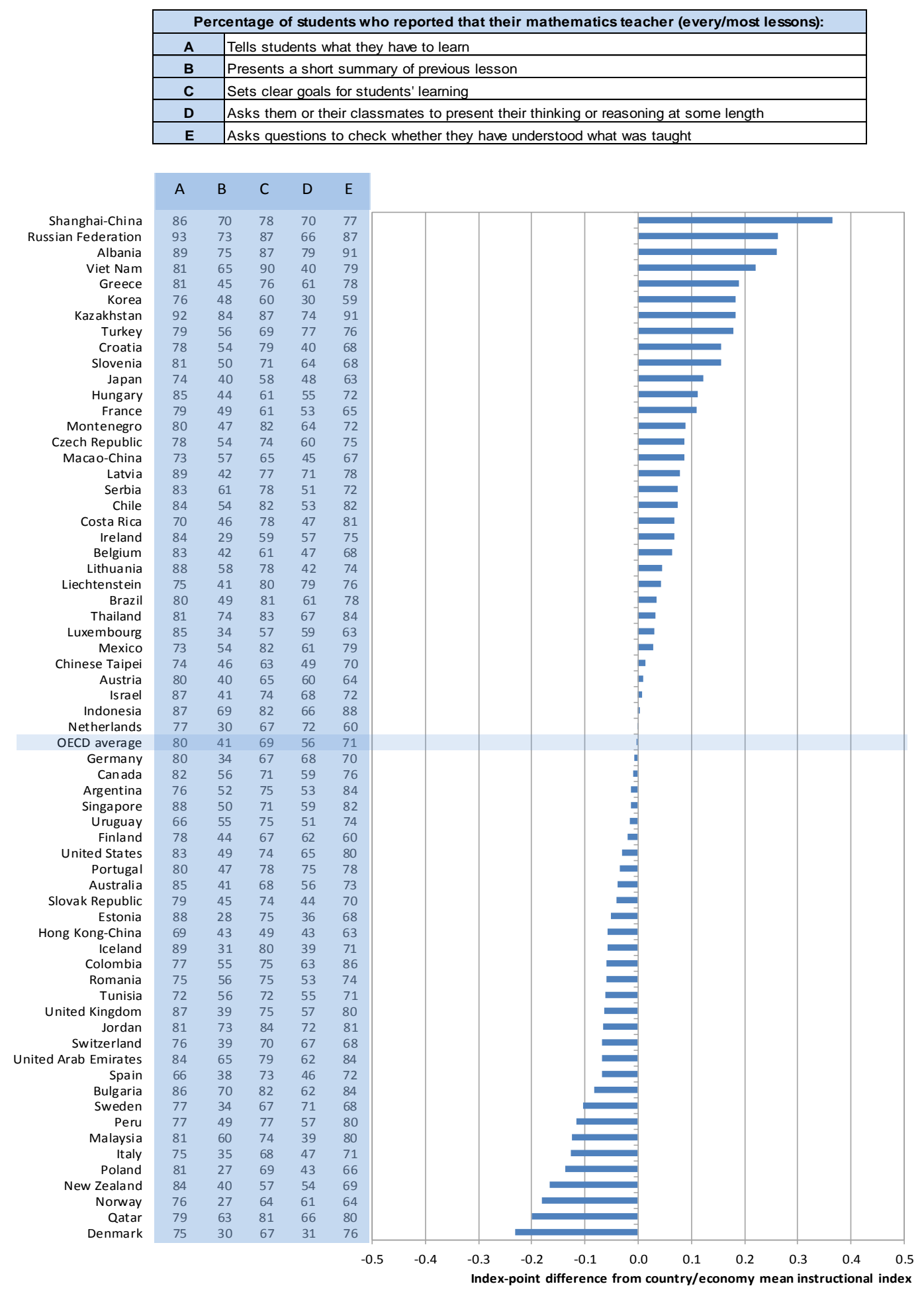

Note: The mean of the four instructional indices was subtracted from the index of teacher-directed instruction.

Countries and economies are ranked in descending order of the index-point difference (the index of teacher-directed instruction minus the average of the four PISA indices).

Source: OECD, PISA 2012 Database. 
Figure 3.7. Differences across countries in student-oriented instruction

\begin{tabular}{|c|l|}
\hline \multicolumn{2}{|c|}{ Percentage of students who reported that their mathematics teacher (every/most lessons): } \\
\hline A & Has them work in small groups \\
\hline B & Gives different work to students who have difficulties learning and/or to those who can advance faster \\
\hline C & Assigns projects that require at least one week to complete \\
\hline D & Asks them to help plan classroom activities or topics \\
\hline
\end{tabular}

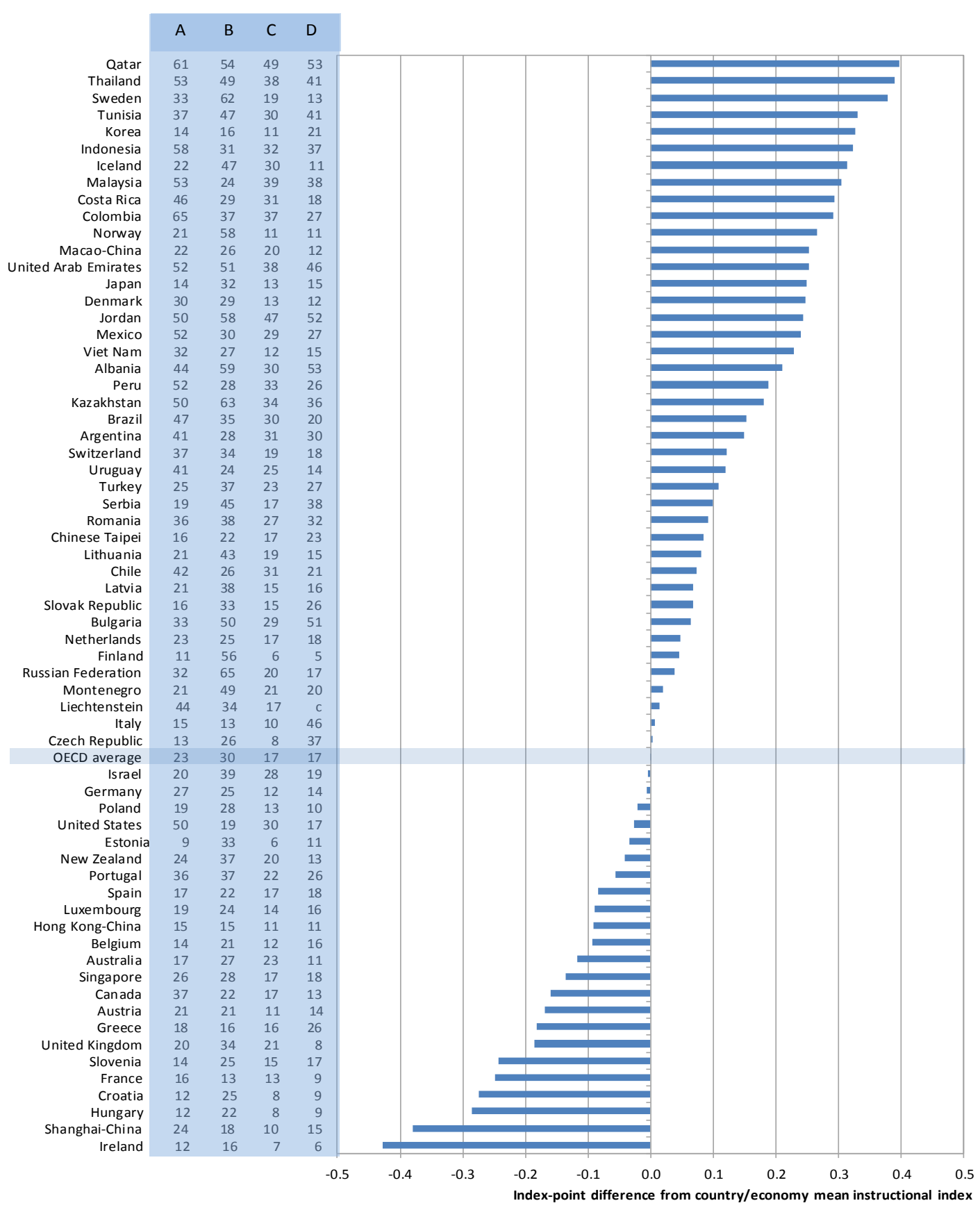

Note: The mean of the four instructional indices was subtracted from the index of student-oriented instruction.

Countries and economies are ranked in descending order of the index-point difference (the index of student-oriented instruction minus the average of the four PISA indices).

Source: OECD, PISA 2012 Database. 
Figure 3.8. Differences across countries in formative-assessment instruction

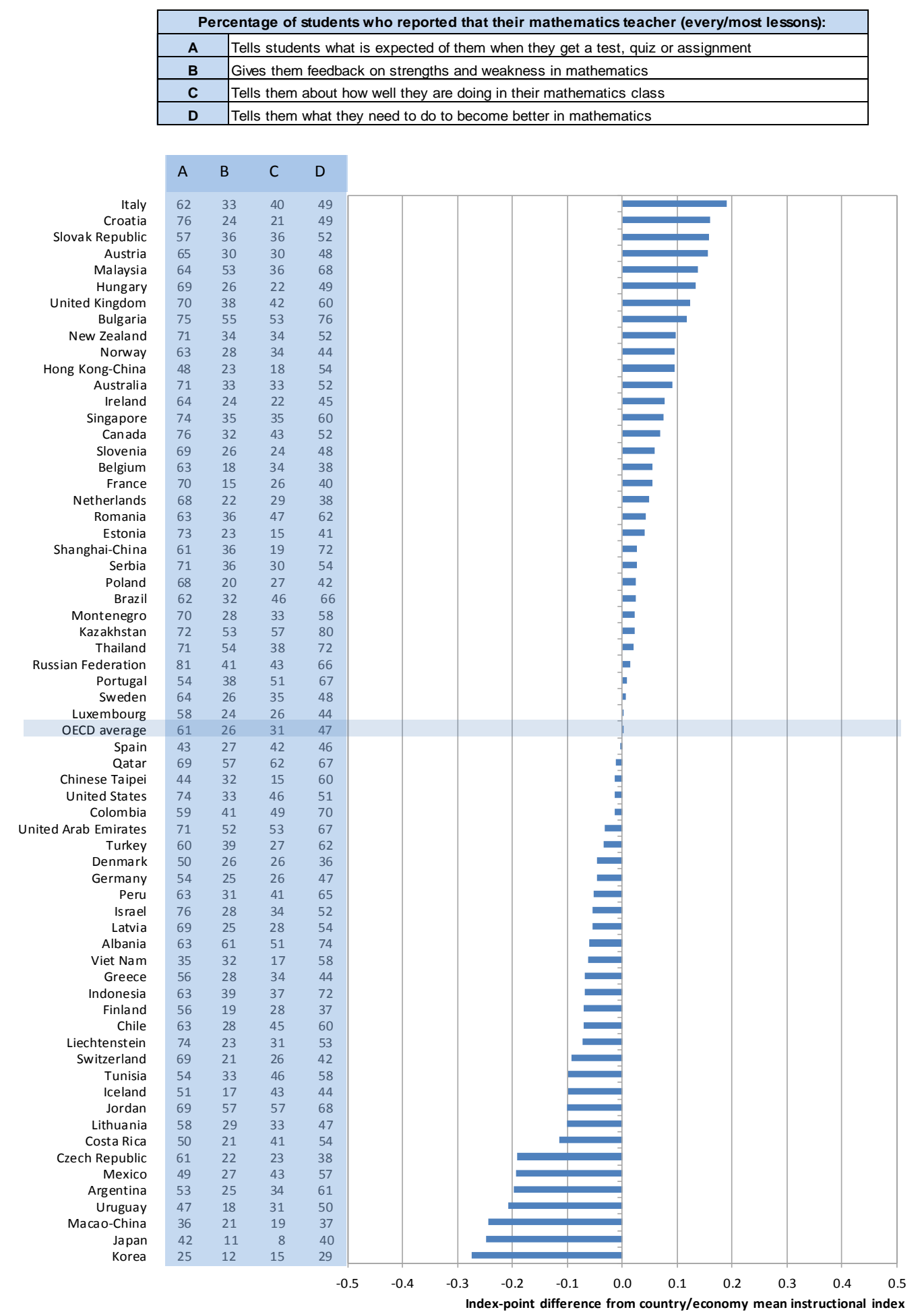

Note: The mean of the four instructional indices was subtracted from the index of formative-assessment instruction.

Countries and economies are ranked in descending order of the index-point difference (the index of formative-assessment instruction minus the average of the four PISA indices).

Source: OECD, PISA 2012 Database. 
Figure 3.9. Differences across countries in cognitive-activation instruction

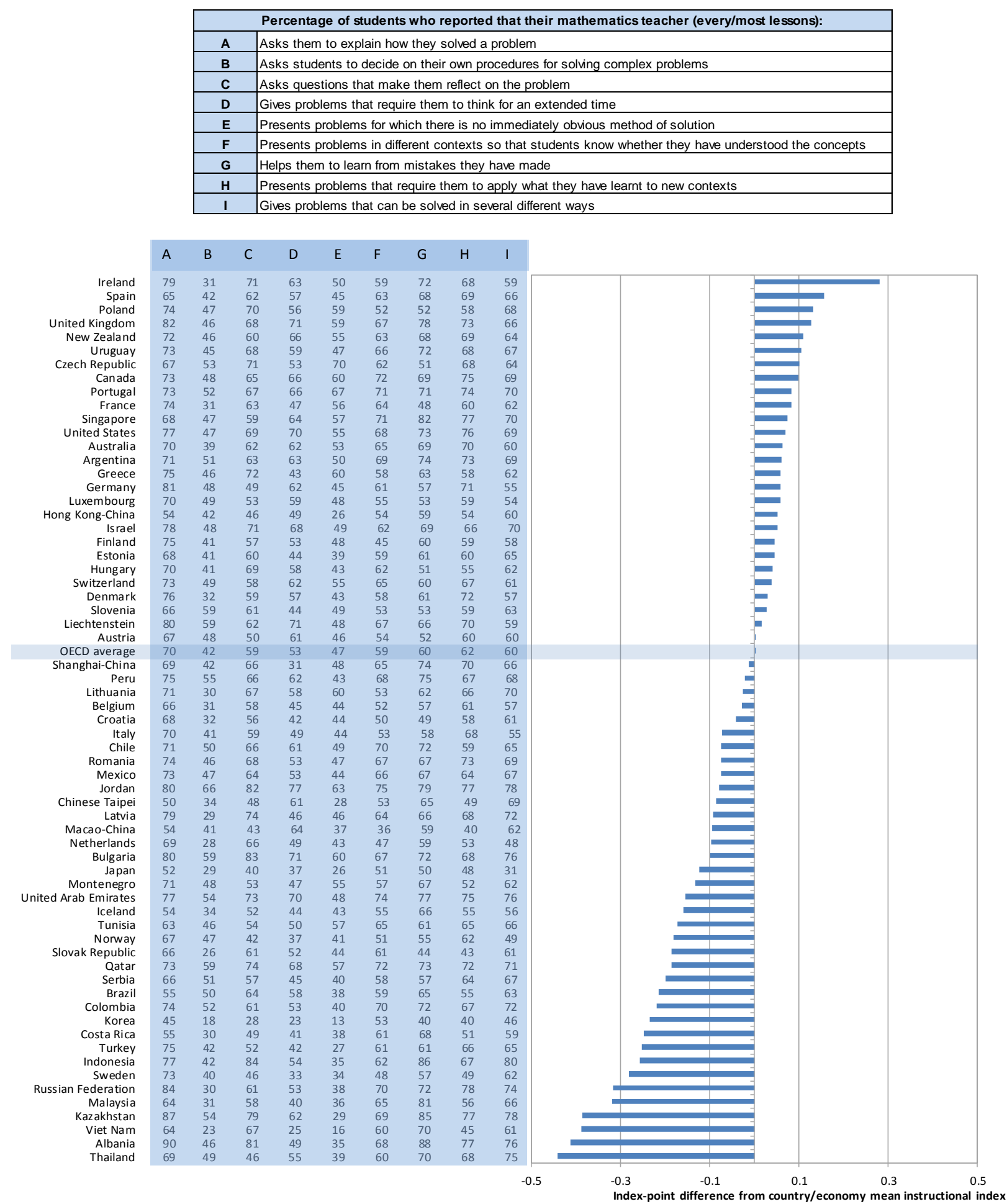

Note: The mean of the four instructional indices was subtracted from the index of cognitive-activation instruction.

Countries and economies are ranked in descending order of the index-point difference (the index of cognitive-activation instruction minus the average of the four PISA indices).

Source: OECD, PISA 2012 Database. 


\section{The relationship among teaching strategies}

Although distinct, these teaching strategies can sometimes overlap. For example, when teachers use the traditional method of lecturing and then ask questions to encourage students to think about the content of the lesson and to share their thoughts with the rest of the class, they are mixing teacher-oriented and cognitive-activation methodologies. In principle, formative-assessment practices are compatible with any of the other teaching strategies, as teachers who give well-structured lectures, have students work in small groups or in extended projects, or have them think about complex content can also provide feedback to students about their strengths and weaknesses. Indeed, students can be exposed to more than one teaching strategy over the course of a semester or even during a single lesson.

These connections are reflected in the strength of the correlations among the indices measuring teacher strategies, as shown in Figure 3.10. On average across OECD countries, the strongest correlations are found between teacher-directed instruction on one side and formative-assessment and cognitiveactivation strategies on the other (coefficient of 0.6 in both cases). This might be due, as suggested above, to the compatibility of well-structured lectures with demanding and thoughtful questions posed to students, and with the use of formative assessment after lectures, to check on and reinforce student progress.

Figure 3.10. Relationship among teaching strategies

Student-level correlations, OECD average

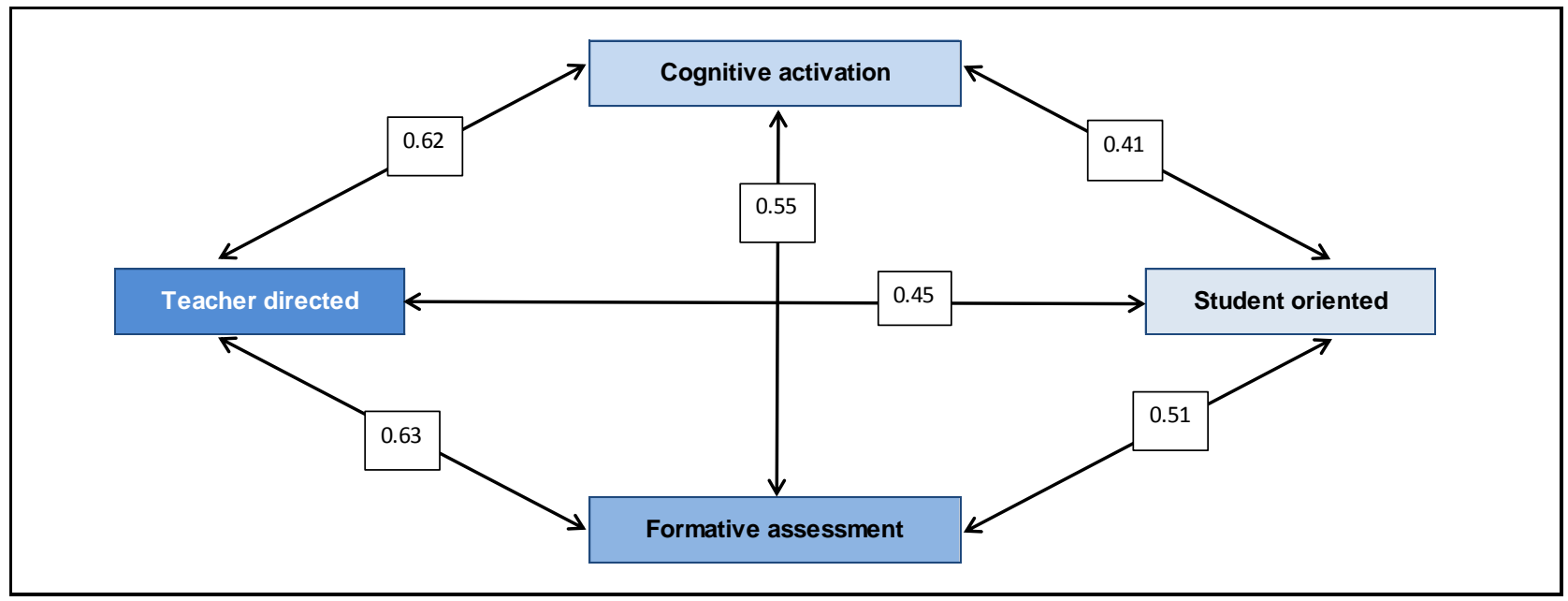

Source: OECD, PISA 2012 Database.

Student-oriented practices are more often related to formative-assessment instruction (coefficient of correlation of 0.5 ). This might be because personalised feedback is particularly useful for individual and group work and for the kinds of long-term projects typically used under student-oriented instruction.

Since teacher-directed and student-oriented strategies represent somewhat opposite ideas about instruction, it comes as no surprise that they are comparatively weakly correlated (correlation coefficient of 0.4). Yet, the fact that the correlation exits, and is statistically significant, suggests that many teachers who use traditional teaching methods, such as lecturing, are also able to combine this strategy, to some extent, with practices that address students' individual needs. 


\section{Who is being taught how?}

Teachers decide on their pedagogical strategies based on a variety of factors, including their beliefs about the nature of teaching and learning, the school and classroom climate, and such personal factors as their gender, the subjects they teach, and their training and professional development. For example, TALIS provides evidence that female teachers are more likely than male teachers, and mathematics and science teachers less likely than teachers of other subjects, to have students work in small groups or assign projects that require at least one week to complete (OECD, 2014). This section draws on data from PISA 2012 school and student questionnaires to take a deeper look into how school characteristics, such as the learning environment, resources and leadership, are related to differences in students' (perception of their) exposure to different instructional practices. Then it examines how instruction varies by students' socioeconomic status and demographic factors.

\section{Teaching strategies and the learning environment in the school and classroom}

There is a strong correlation between a positive learning environment and each of the instructional practices measured in PISA. Previous studies suggest that respectful and supportive relations between teachers and students, and orderly classrooms are a prerequisite of instruction, as they allow for more time to be used for pedagogy and learning, instead of for controlling disruptive behaviour (Creemers and Kyriakides, 2008; Harris and Chrispeels, 2006; Hopkins, 2005; OECD, 2010; Scheerens and Bosker 1997). This idea is clearly supported by PISA data, which show that students who reported that their teachers use all of the instructional strategies frequently are those who attend schools with more positive learning environments.

Figure 3.11. Teaching strategies and schools' learning environment

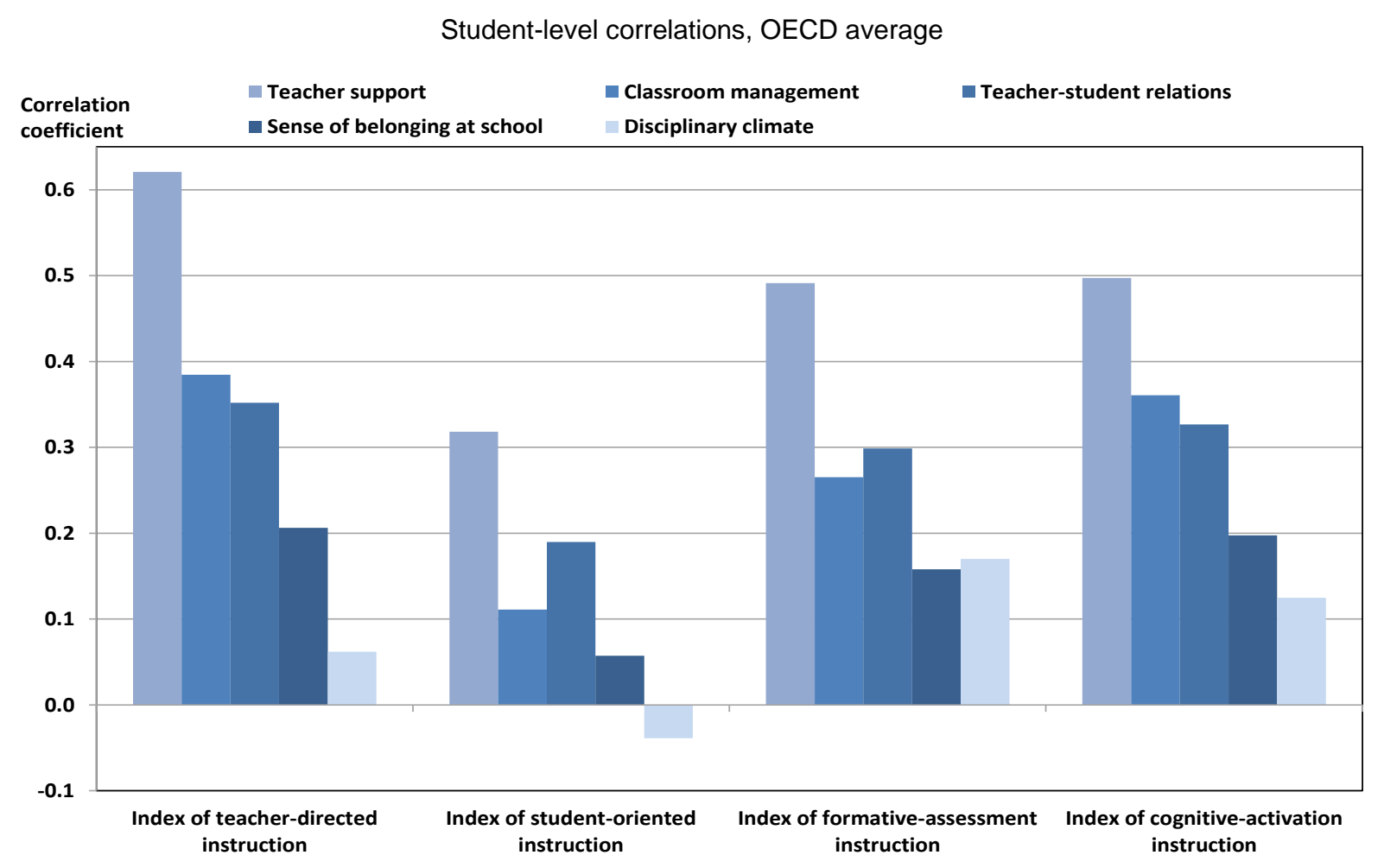

Note: All correlation coefficients are statistically significant.

Source: OECD, PISA 2012 Database. 
Figure 3.11 shows five PISA measures that capture different facets of a school's learning environment (for detailed information about these indices, see OECD, 2015). One is the PISA index of teacher support, which indicates whether students feel that mathematics teachers show an interest in students' learning, offer extra help, continue teaching until students understand the material, and let students express their opinions. Of all the facets of the school learning environment that PISA measures, teachers' support is the one that is most strongly correlated with each instructional index, on average across OECD countries. The coefficient of correlation is as large as 0.6 with teacher-directed instruction, 0.5 with cognitive-activation and formative-assessment instruction, and 0.3 with student-oriented instruction.

The PISA index of teacher-student relations indicates whether students feel that their teachers are interested in their well-being, listen to what they have to say, treat students fairly, give students extra help, and that teachers and students get along. Better relations between teachers and students are positively correlated with higher values on the index of each teaching strategy, on average across OECD countries. As in the case for teacher support, the strength of the correlation with teacher-student relations is greater for teacher-directed instruction (coefficient of 0.4), than for cognitive-activation and formative-assessment instruction (coefficient of 0.3), and it is somewhat weaker for student-oriented instruction (coefficient of 0.2).

The PISA index of classroom management, which captures whether the mathematics teacher keeps the class orderly, starts lessons on time, and gets students to listen to her or him, is most strongly correlated with teacher-directed and cognitive-activation instruction (coefficient of 0.4), then with formativeassessment (coefficient of 0.3), and most weakly with student-directed instruction (coefficient of 0.1). Interestingly, the PISA index of disciplinary climate, which indicates whether there is noise and disorder in the classroom, whether teachers have to wait a long time for students to quiet down before starting the lesson, and/or whether students don't listen to what the teacher says and cannot work well, is positively correlated with all but student-oriented instruction strategies, where a small, negative correlation is found. This may be because student-centred methodologies sometimes allow for, and perhaps even require, a less orderly classroom (e.g. small group discussions among students can create noise or commotion). Or, teachers might be more apt to use student-oriented instruction in classes with disengaged students as a way to motivate them or control their behaviour.

Finally, students in schools where their peers report a strong sense of belonging at school (the PISA index of sense of belonging at school measures whether students feel satisfied and happy at school, feel that other students like them, and declare feeling that they belong at school) reported receiving more of each kind of instruction.

\section{Teaching strategies and other school characteristics}

In contrast, other school characteristics are only weakly related to instructional practices. Figure 3.12 shows the correlation coefficients between measures of school resources, leadership, student grouping practices, programme orientation and school type. Although there are some statistically significant differences, the strength of the relationship between these school characteristics and instruction strategies is much weaker (the correlation coefficients are never larger than 0.2, on average across OECD countries) than that observed for measures of the school learning environment. 
Figure 3.12. Teaching strategies and school characteristics

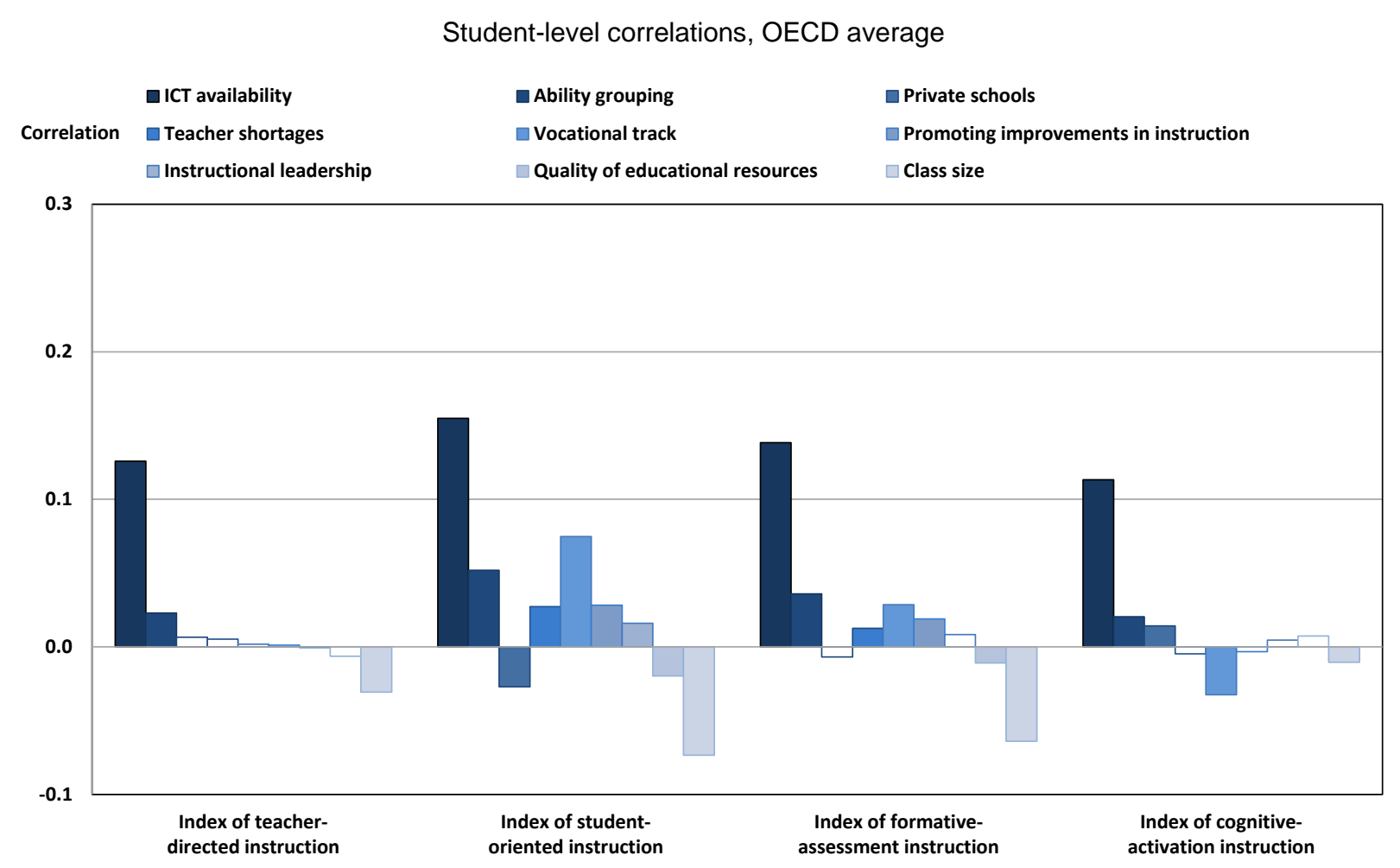

Note: Correlation coefficients that are statistically significant are marked in a darker tone.

Source: OECD, PISA 2012 Database.

Out of the range of resources available in schools, the availability of information and communication technology (ICT) is, on average across OECD countries, the most strongly correlated with each instructional strategy. Correlation coefficients between instruction strategies and the PISA index of ICT availability at school (which captures the availability of devices such as desktop computers, portable laptops, tablets, Internet connections and printers) are statistically significant in all countries and economies participating in PISA 2012. The correlation between instruction and ICT resources is strongest among teachers who use student-oriented strategies - presumably because these strategies involve more individualised and interactive teaching practices.

Higher quality educational resources and teacher shortages (as reported by school principals), including shortages of mathematics teachers, are only weakly correlated with any of the PISA instructional indices. Of course, school principals may have different expectations and benchmarks to determine whether there is a lack of qualified teachers so these findings should be interpreted with caution.

Some small differences in instruction strategies are observed as related to programme orientation. Notably, student-oriented instruction is more often reported by students in vocational programmes and schools, on average across OECD countries. This may be because the practical work students do in vocational schools is often collaborative (e.g. hands-on training).

By contrast, cognitive-activation instruction is more frequently reported by students in academically oriented schools, on average across OECD countries. The correlation coefficients are small, but in no country or economy did students in vocational schools report more than students in academically oriented 
schools that their teachers use cognitive-activation strategies. This is most likely because academically oriented schools offer more cognitively challenging curricula than do vocational schools.

The extent to which schools group students by ability for mathematics classes is also positively related to all forms of instruction, by small yet statistically significant magnitudes, on average across OECD countries (Figure 3.12). The decision to group students in this way is most often taken by the school principal or school leaders. Ability grouping within a school aims to create more homogeneous classes to allow teachers to teach the same content, at the same pace to all students in the class (Gamoran, 1992; Oaks, 2005).

Thus, finding a statistically significant correlation between teacher-directed instruction and more ability grouping in schools is to be expected. Greater use of cognitive-activation strategies in schools that practice ability grouping could reflect teachers' propensity to introduce more challenging mathematics content for high-achieving students.

The strongest correlations, however, are with student-oriented and formative-assessment teaching. These results are less intuitive because both of these strategies contain forms of personalised instruction within the classroom which, theoretically, make it unnecessary to sort students by their mathematics ability or previous performance. Yet, the data suggest that schools use some forms of ability grouping between and within classes at the same time.

PISA also shows that students in OECD countries are offered more student-oriented and formativeassessment instruction in schools with stronger instructional and institutional leadership. The PISA index of instructional leadership and the index of promoting instructional improvements, which are based on school principals' responses to various questions, capture the extent to which school principals monitor teachers' instructional strategies, promote innovative teaching practices, and provide support on pedagogical or behavioural matters when teachers need it. The correlation between both of these indices and student-oriented and formative-assessment instruction is small but statistically significant, whereas there is no correlation with teacher-oriented and cognitive-activation strategies. These differences might be due to the fact that teachers working in schools with strong, involved leaders who promote innovative teaching are more likely to feel supported when they consider using non-traditional, student-oriented teaching strategies.

Figure 3.12 also shows differences in the use of these teaching strategies by school type. It shows that private schools (a combination of "private-dependent" schools that receive government funds and "privateindependent" that do not receive such funds) tend to have slightly less student-oriented instruction, but more cognitive-activation instruction, relative to public schools, on average across OECD countries. In 22 countries and economies, the correlation between private schools and student-oriented instruction is negative, meaning that public schools use more student-centred methods; but in 6 countries and economies the correlation is positive.

The positive correlation between private schools and cognitive-activation strategies is significant in 16 countries and economies, but negative in 6 . These differences do not account for students' background, thus they might be related to school policies and practices or to schools' socio-economic profile (OECD, 2012).

Class size is the school variable that is most consistently negatively correlated with instruction methods, on average across OECD countries. This means that students in smaller classes reported receiving more instructional practices than students in larger classes. 


\section{Teaching strategies and student background}

Students' socio-economic status has some, but minimal, association with the types of teaching strategies to which students are exposed. As Figure 3.13 shows, on average across OECD countries, socioeconomically disadvantaged students (those in the bottom quarter of the PISA index of economic, social and cultural status in each country) reported being more frequently exposed to student-oriented, formativeassessment and teacher-directed teaching practices than their advantaged peers (those in the top quarter of the index). The difference between advantaged and disadvantaged students is largest on the index of student-oriented instruction ( 0.21 index point, thus more than a fifth of a standard deviation). In other words, teachers teaching disadvantaged students have their students work in small groups and assign them different work according to their learning abilities more often than teachers who work with advantaged students. Cognitive-activation strategies, by contrast, are reported more frequently among advantaged students on average across OECD countries (the difference between advantaged and disadvantaged students is 0.13 index point).

It is possible that differences in instruction strategies related to socio-economic status reflect teachers' expectations and student behaviour. Teachers tend to hold higher expectations for advantaged students, and this might lead teachers to assign advantaged students more challenging work. By contrast, lower expectations might lead teachers of disadvantaged students to give students less freedom in how they work, as it is the case in teacher-directed instruction. If disruptive behaviour is more frequent among disadvantaged students and in disadvantaged schools, as is observed in most countries (OECD, 2013b), then teachers might use more student-oriented instruction in these classes as a classroom-management strategy. Also, the differences could be the result of different response styles across socioeconomic groups.

Figure 3.13. Teaching strategies and students' socio-economic status OECD average

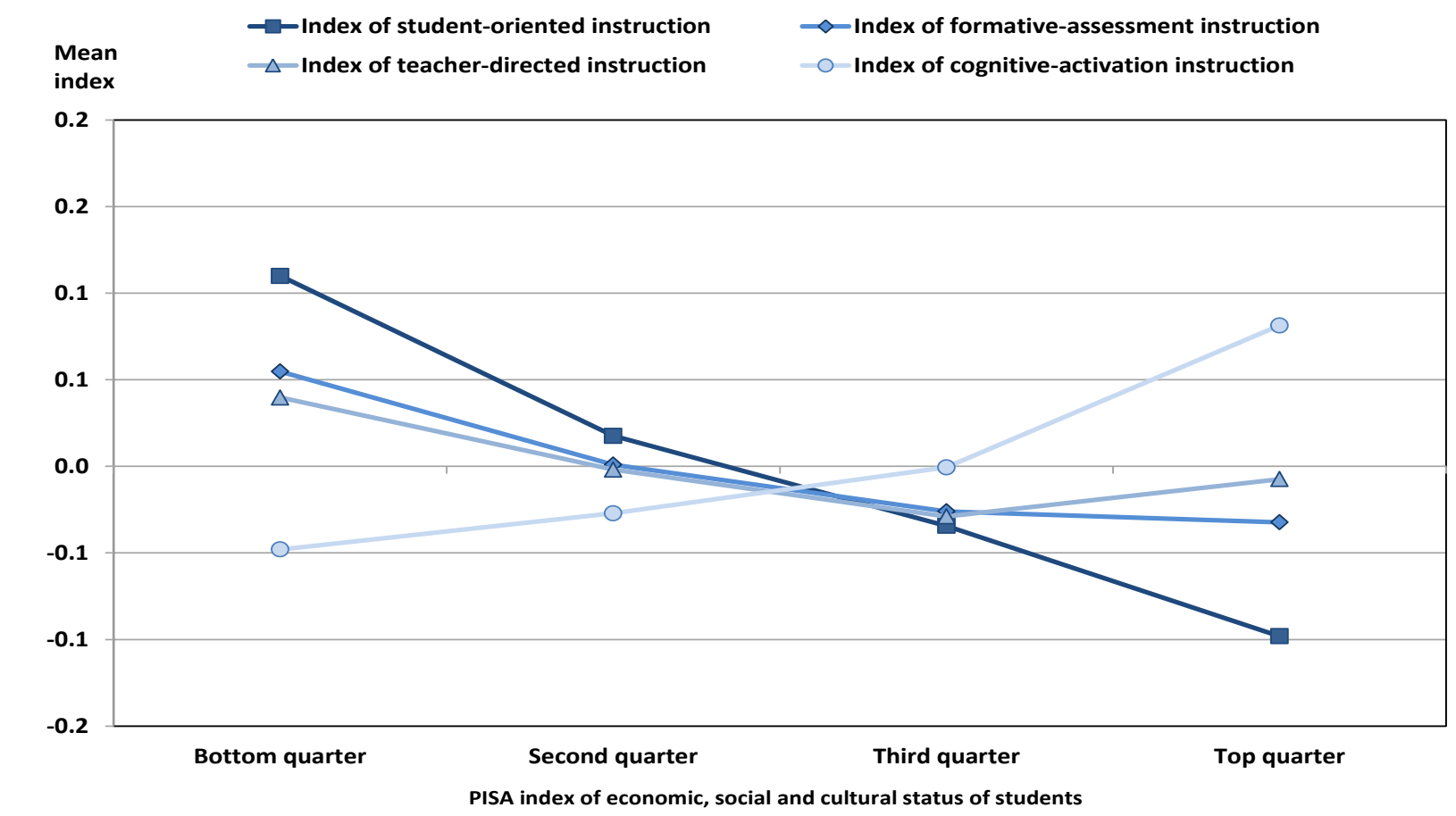

Source: OECD, PISA 2012 Database. 
Exposure to different instruction strategies also varies according to students' gender and immigrant background, according to students' reports. As shown in Figure 3.14, on each of the indices of instructional strategies, boys have statistically significantly higher values than girls, on average across OECD countries. The difference between girls and boys is larger (of 0.25 index point, or about a quarter of a standard deviation for the corresponding index) in the case of formative-assessment and student-oriented instruction, meaning that girls reported less exposure to these two teaching strategies than boys. These differences might be due to differences in response styles (e.g. social desirability) between girls and boys. They might also reflect true differences between the genders in their exposure to types of instruction because teachers use different instructional approaches based on gender stereotypes, because of genderrelated differences in student behaviour (OECD, 2015b), because boys and girls use different learning strategies (see Chapter 4), because boys attend vocational schools more frequently than girls, or other reasons.

Figure 3.14. Teaching strategies and student's gender OECD average

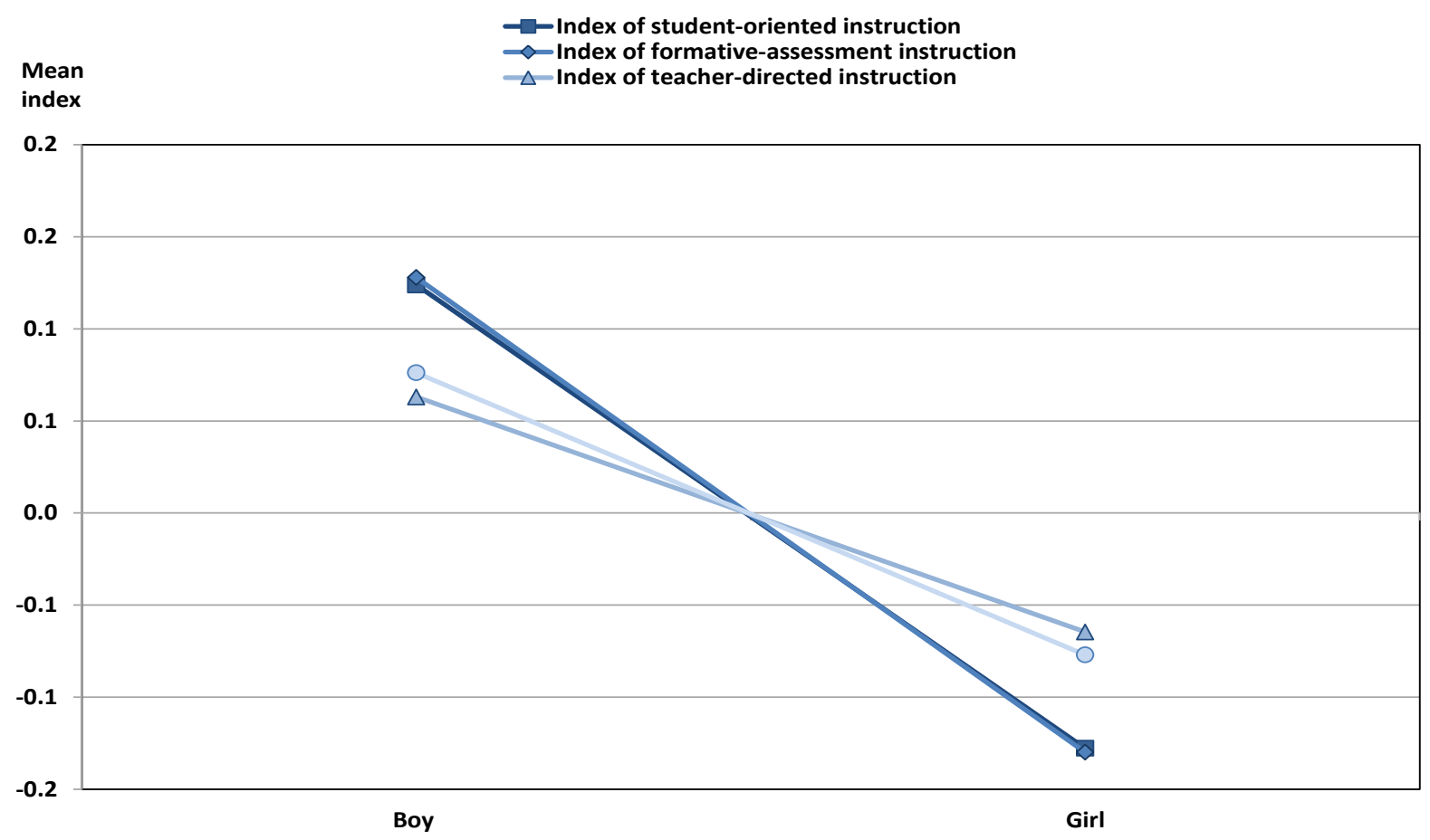

Source: OECD, PISA 2012 Database.

\section{A summary profile}

Students attending schools with better learning environments (strong teacher support, positive teacher-student relations and disciplinary climate) are more frequently exposed to the instructional practices measured by PISA. This finding supports the notion that a positive learning environment is a prerequisite for teaching and learning. Schools in which these teaching strategies are used more frequently are those with more supportive teachers, where there are good teacher-student relations, where teachers are skilled in managing their classrooms and maintaining discipline, and are those whose students reported feeling a greater sense of belonging at school. 
The strength of the relationship between learning environment and instruction strategies is greater with teacher-directed and cognitive-activation strategies, and is weaker with student-oriented strategies. Student-oriented instruction is something of an exception in that its relationship with classroom discipline is weak and often negative, most likely because small-group discussions or other methods that aim to give students a more active role in the learning process can generate or require a more dynamic - and, to some, louder - classroom environment.

Other school and student characteristics are not as strongly related to instruction strategies, but significant differences are observed. For example, on average across OECD countries, all instruction strategies are more frequently used in schools that have greater ICT resources, use more ability grouping between mathematics classes, and have smaller classes. Student-oriented instruction is also somewhat more frequently used in vocational and public schools than in academic and private schools. Also, students are offered slightly more student-oriented and formative-assessment instruction in schools with stronger instructional and institutional leadership, whereas school leadership is not related to teacher-oriented and cognitive-activation strategies.

Socio-economically disadvantaged students and girls reported being exposed to the instructional strategies more than advantaged students and boys, on average among OECD countries. However, advantaged students reported being exposed to cognitive-activation strategies more than disadvantaged students did.

\section{Teaching strategies and mathematics performance}

A large body of research has focused on the effectiveness of various teaching practices (Hattie, 2009; Wayne and Youngs, 2003; Baumert et al, 2003). This section explores the relationship between student performance and each one of the four teaching strategies measured in PISA. It begins by focusing on students' mean score in mathematics. Analysing the link between instructional strategies and mean scores indicates how the former are related to students' overall mathematics proficiency, but it does not suggest whether the relationship between instructional strategies and student performance differs depending on the level of difficulty of the mathematics tasks or problems taught. This facet is also examined through a detailed analysis by item difficulty. Since the analyses are based on correlational evidence, no causal relations should be inferred from the results.

\section{Teaching strategies and mean mathematics performance}

PISA distinguishes six proficiency levels in mathematics, from Level 1, the lowest proficiency, to Level 6, the highest proficiency. Level 2 is considered the baseline level of proficiency that students need in order to participate fully in contemporary society (OECD, 2013c).

Figure 3.15 shows that, on average across OECD countries, students who score at the lower levels of mathematics proficiency, particularly at or below Level 1, most frequently reported that they are exposed to student-oriented, formative-assessment, and teacher-directed instruction. Conversely, students who reported greater exposure to cognitive-activation instruction score, on average, at higher levels of proficiency in mathematics, particularly at Level 5 or 6. 
Figure 3.15. Teaching strategies, by proficiency level in mathematics

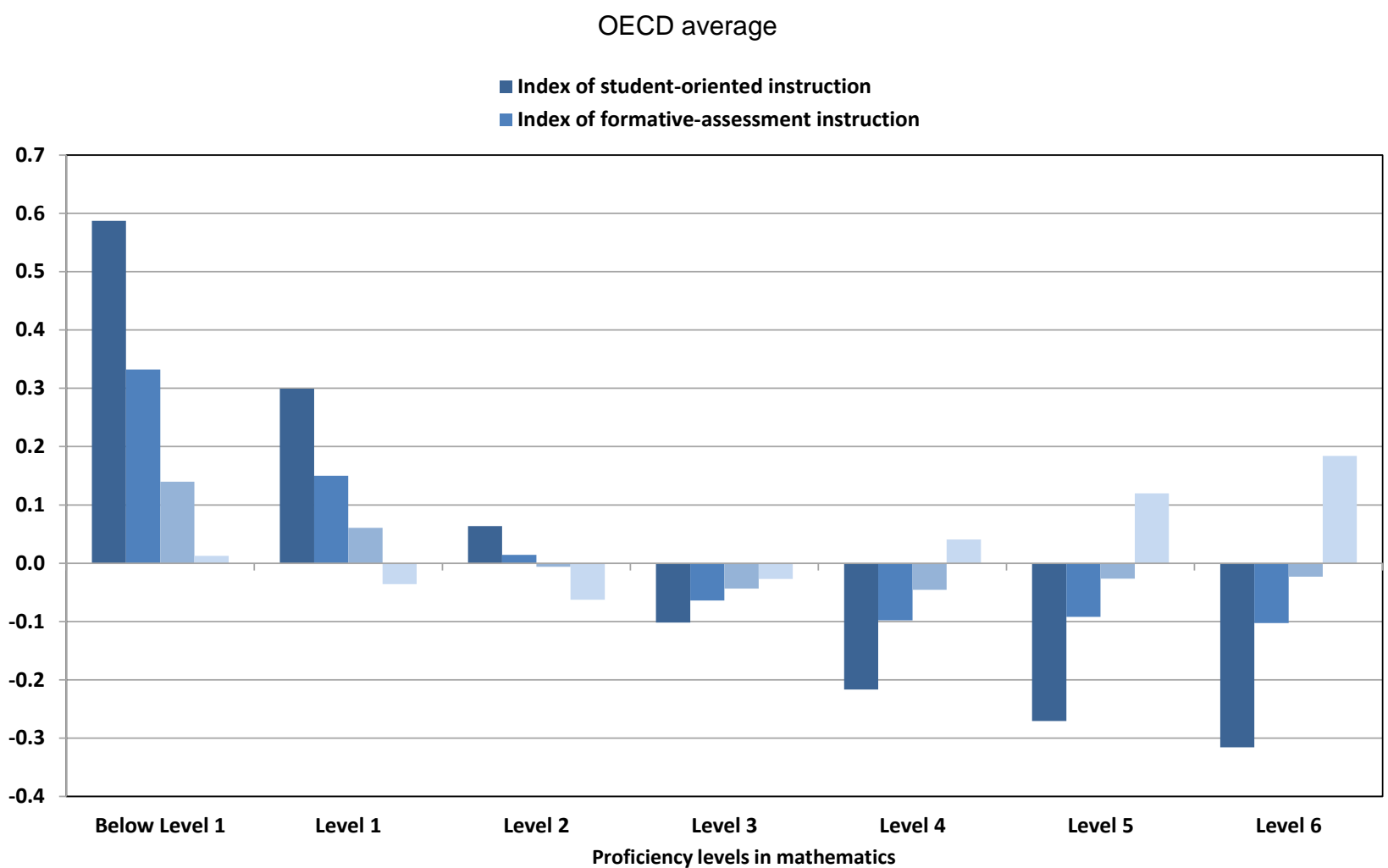

Source: OECD, PISA 2012 Database.

Figures 3.16 through 3.19 show the relationship between each instructional strategy and students' mean mathematics score in PISA 2012, before and after accounting for the other three instructional strategies considered in this analysis.

These figures reveal that cognitive-activation instruction has the greatest positive association with students' mean mathematics score, on average across OECD countries. Before accounting for other teaching strategies, cognitive-activation instruction is associated with an increase of about five score points on the PISA mathematics assessments. After accounting for the other three teaching strategies, the average improvement in mathematics performance associated with cognitive-activation instruction is as large as 19 score points. Remarkably, after accounting for the other teaching strategies, there is a positive association between cognitive-activation instruction and mean mathematics performance in every country and economy that participated in PISA 2012, except Albania (Figure 3.16).

By contrast, student-oriented instructional practices have the greatest negative relationship with students' mean mathematics score, both before and after accounting for other teaching strategies (Figure 3.17). On average across OECD countries, students who are exposed to more student-oriented instruction score about 22 points lower than students who are less exposed to this strategy, before any other variable is taken into account. After accounting for the other teaching strategies, students who reported more exposure to student-oriented instruction score about 26 points lower. This negative association is statistically significant in every country and economy that participated in PISA 2012, except Albania. 
Figure 3.16. Mathematics performance and cognitive-activation instruction Score-point difference in mathematics performance associated with one-unit increase in the index of cognitive-activation instruction

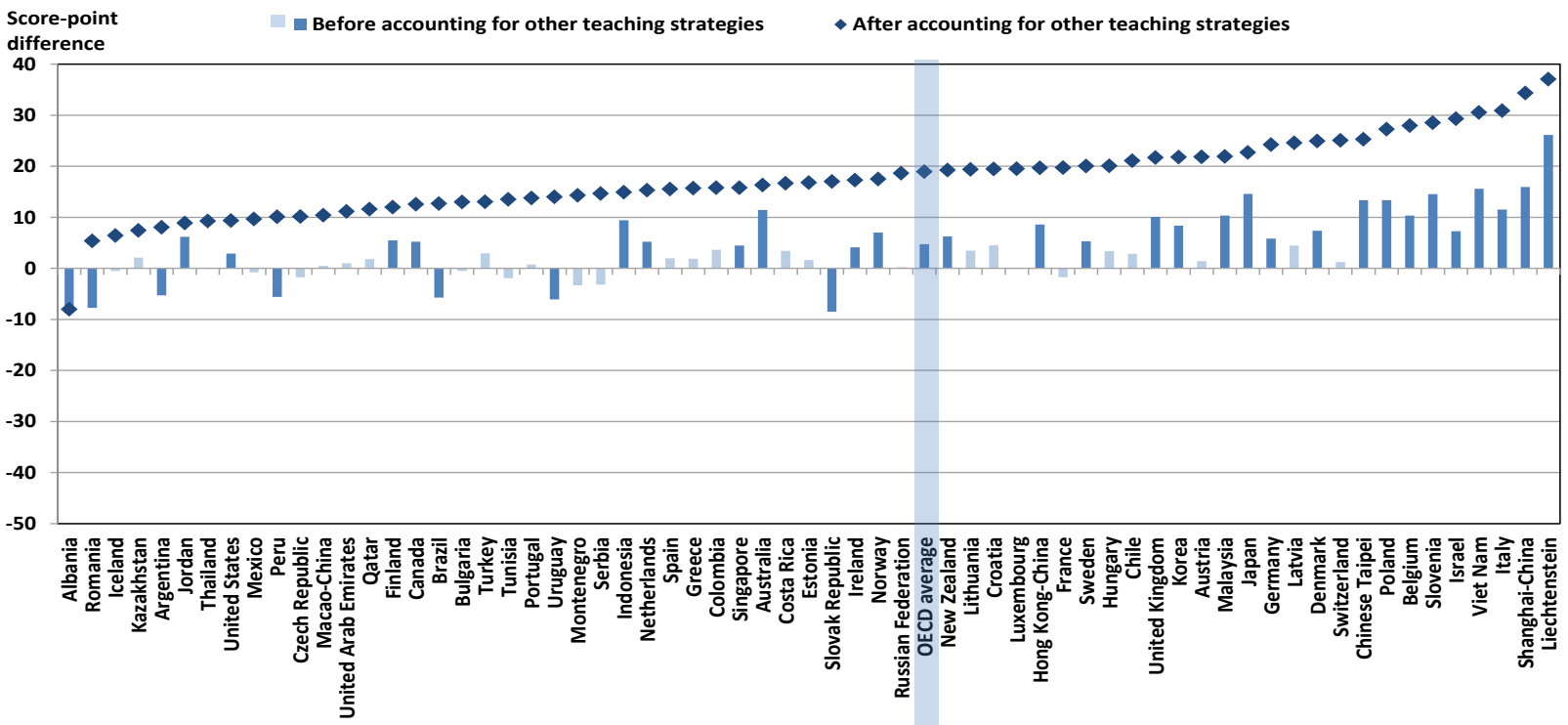

Notes: Statistically significant score-point differences are marked in a darker tone. Other teaching strategies refer to the PISA indices of teacher-directed, student-oriented and formative-assessment instruction.

Other teaching strategies refer to the PISA indices of student-oriented, formative-assessment and cognitive-activation instruction.

Countries and economies are ranked in ascending order of the score-point difference in mathematics performance, after accounting for other teaching strategies.

Source: OECD, PISA 2012 Database.

Figure 3.17. Mathematics performance and student-oriented instruction

Score-point difference in mathematics performance associated with one-unit increase in the index of student-oriented instruction

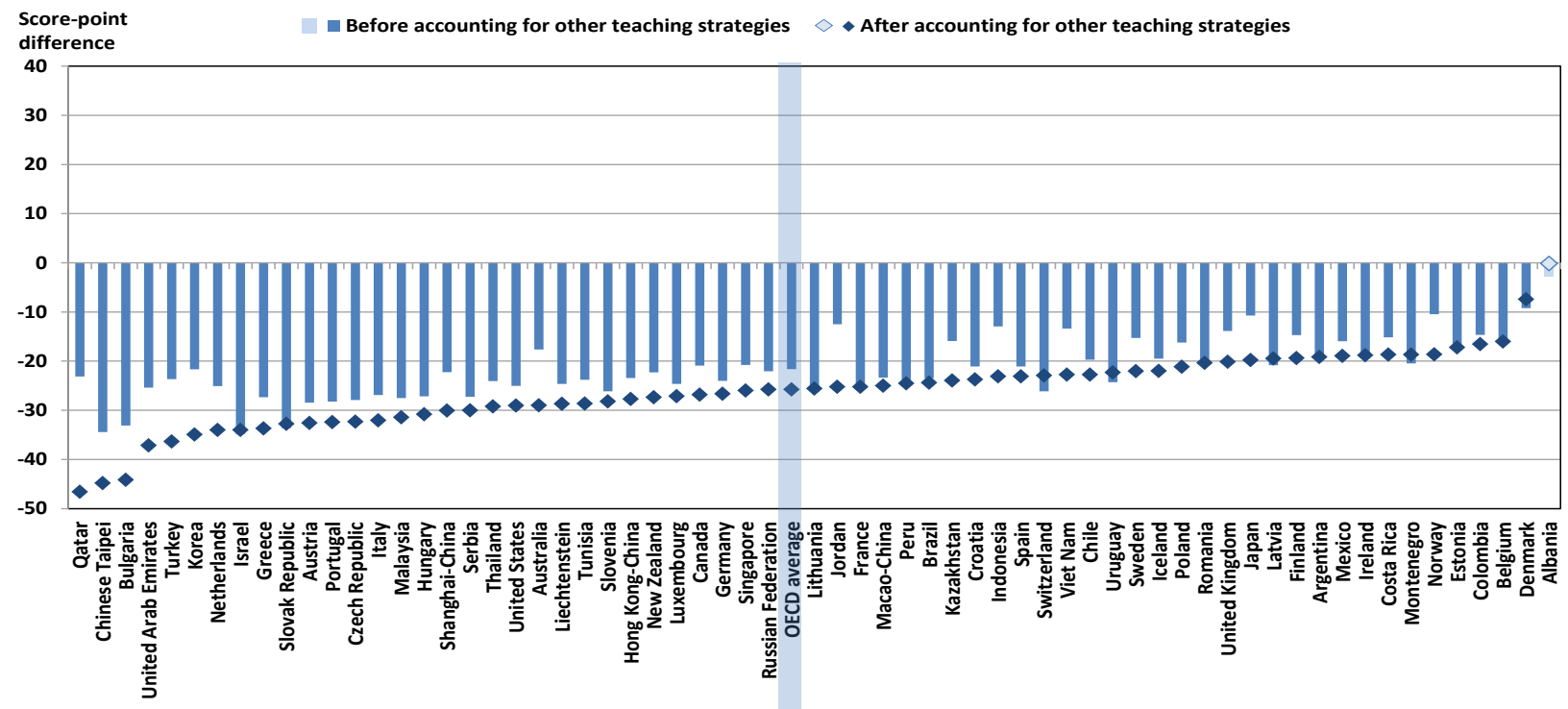

Notes: Statistically significant score-point differences are marked in a darker tone. Other teaching strategies refer to the PISA indices of teacher-directed, formative-assessment and cognitive-activation instruction.

Other teaching strategies refer to the PISA indices of student-oriented, formative-assessment and cognitive-activation instruction.

Countries and economies are ranked in ascending order of the score-point difference in mathematics performance, after accounting for other teaching strategies.

Source: OECD, PISA 2012 Database. 
Similarly, students who reported greater exposure to formative-assessment teaching perform worse in mathematics, although the magnitude of the difference is smaller than is the case when considering student-oriented practices, and the pattern is more varied across countries (Figure 3.18). Before accounting for other variables, one additional point on the index of formative-assessment instruction leads to a decrease of about 10 score points in mathematics, on average across OECD countries; after accounting for other teaching strategies, it leads to a decrease of about 8 score points. Before accounting for other teaching strategies, the negative association is observed in 54 out of 64 countries and economies. But after accounting for other teaching strategies, no association is observed in 23 countries and economies, the association is negative in 37 countries/economies, and positive in Costa Rica, the Czech Republic, Chinese Taipei and Turkey.

Figure 3.18. Mathematics performance and formative-assessment instruction Score-point difference in mathematics performance associated with one-unit increase in the index of formative-assessment instruction

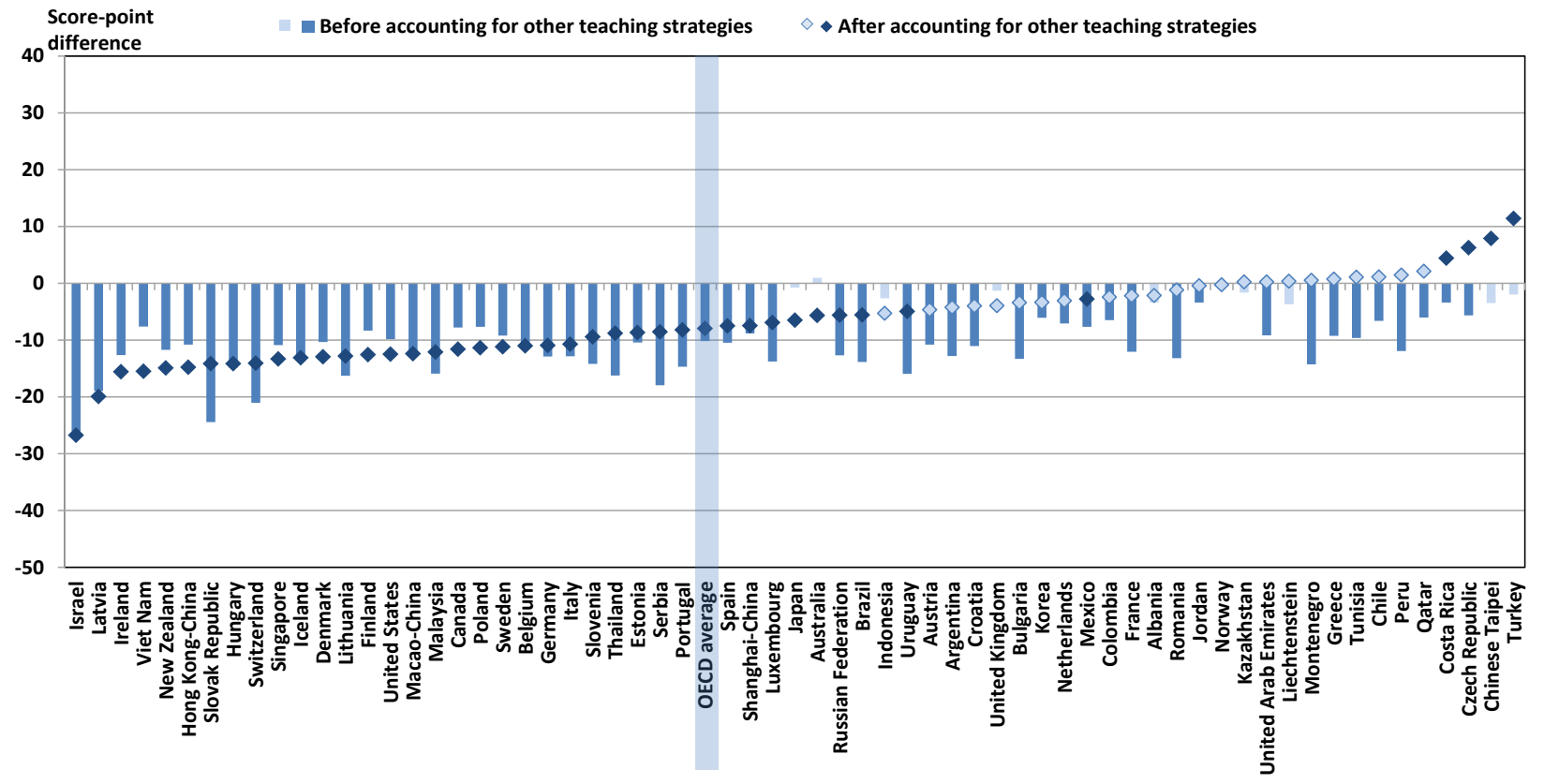

Notes: Statistically significant score-point differences are marked in a darker tone. Other teaching strategies refer to the PISA indices of teacher-directed, student-oriented and cognitive-activation instruction.

Other teaching strategies refer to the PISA indices of student-oriented, formative-assessment and cognitive-activation instruction.

Countries and economies are ranked in ascending order of the score-point difference in mathematics performance, after accounting for other teaching strategies.

Source: OECD, PISA 2012 Database.

Teacher-directed strategies show a mixed pattern (Figure 3.19). Before other teaching strategies are taken into account, their association with students' mean mathematics score is negative, by about four score points, on average across OECD countries. This negative association is observed in 35 countries and economies. Meanwhile, in Australia, Canada, Finland, Indonesia, Japan, Jordan, Kazakhstan, Korea and Viet Nam, the association is positive. However, after accounting for the other teaching strategies, teacherdirected instruction is positively related to mathematics achievement, but by only one score point. After accounting for these other strategies, the positive relationship between teacher-oriented instruction and mean mathematics score is observed in 24 countries and economies (most markedly in Australia, Qatar, Thailand and the United States), and a negative association is observed in 14 countries and economies (the largest negative effects are observed in Chile, Costa Rica, France, Mexico and Montenegro). 
Figure 3.19. Mathematics performance and teacher-directed instruction

Score-point difference in mathematics performance associated with one-unit increase in the index of teacher-directed instruction

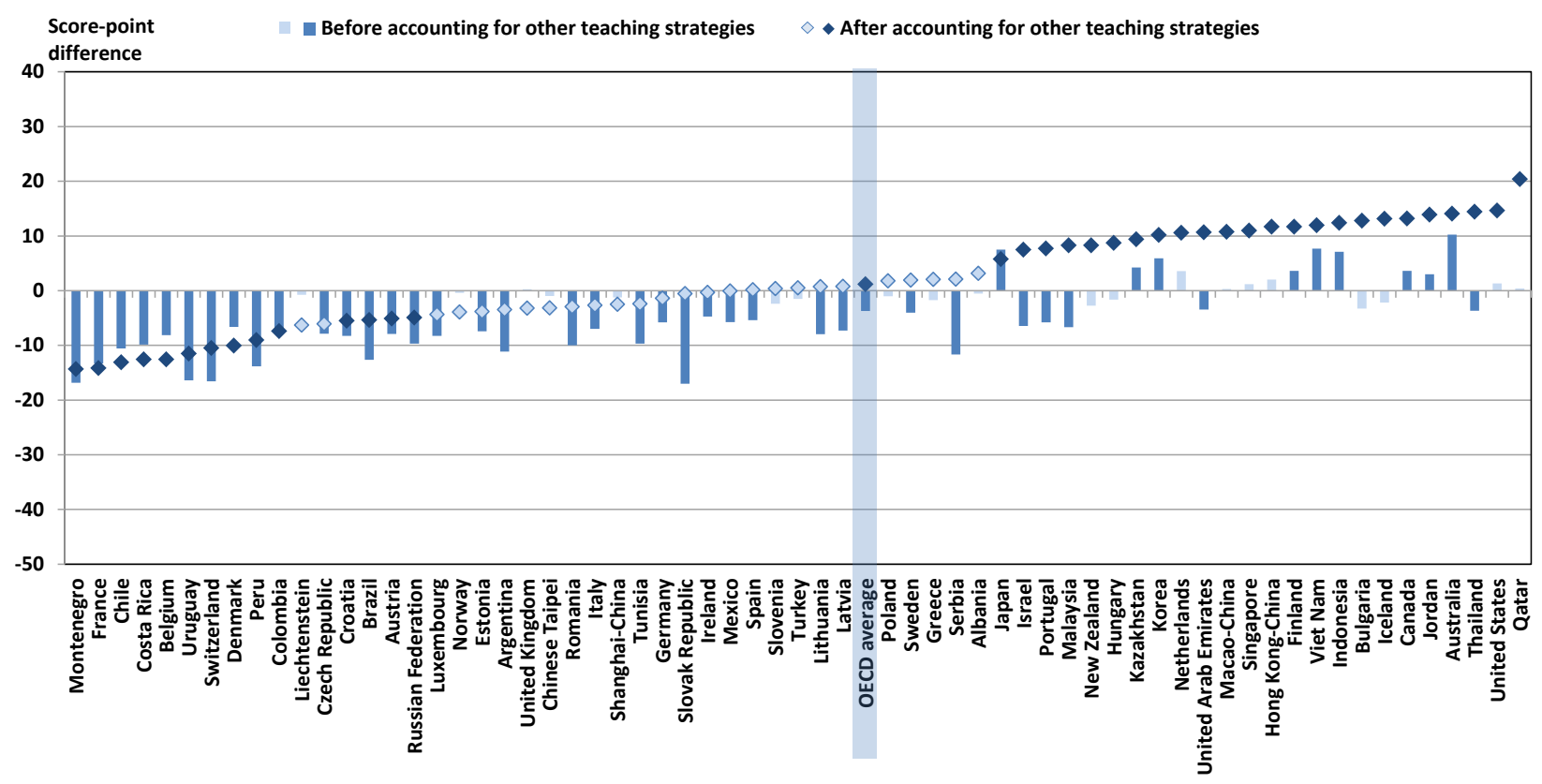

Notes: Statistically significant score-point differences are marked in a darker tone.

Other teaching strategies refer to the PISA indices of student-oriented, formative-assessment and cognitive-activation instruction.

Countries and economies are ranked in ascending order of the score-point difference in mathematics performance, after accounting for other teaching strategies.

Source: OECD, PISA 2012 Database.

The OECD average results presented in Figures 3.16 through 3.19 do not change substantially when students' socio-economic status is also taken into account, when additional school (learning environment) and student (immigrant background and gender) characteristics are taken into account, nor when different combinations of teaching strategies are included in the models. ${ }^{1}$

\section{Teaching strategies and success on PISA items, by item difficulty}

As discussed in Chapter 2, the PISA mathematics assessment measures students' mathematics literacy through items (i.e. questions/problems) whose content is related to four distinct mathematics concepts (quantity, uncertainty and data, change and relationships, and space and shape) and whose solution requires different skills. These items can also be categorised by their difficulty, which is defined empirically as a function of the proportion of students who are able to solve them (OECD, 2015; see Chapter 2 for more details).

Figure 3.20 shows that, on average across OECD countries, students exposed to more cognitiveactivation teaching strategies are more likely to give correct answers to PISA mathematics items, after taking into account the other three teaching strategies studied. The figure reveals a clear linear, positive pattern of association. Cognitive-activation strategies are associated with higher odds of success on items of all levels of difficulty; and the odds of success are greater for more difficult items. 


\section{Box 3.4. Understanding logistic regression and interpreting odds ratio}

Logistic regression analysis enables the estimation of the relationship between one or more independent variables (predictors) on categorical dependent (predicted) variables with two categories (binary logistic regression) or more than two categories (multinomial logistic regression). When a logistic regression is calculated, the statistical software output generates first the regression coefficient (B), which is the estimated increase in the log odds of the outcome per unit increase in the value of the predictor variable. These log odds $(B)$ are frequently transformed into odds ratios $(\exp (B)=\mathrm{OR})$ to make the data more interpretable in terms of probability. Three outcomes are possible for the odds ratios:

- $\quad$ OR = 1 Predictor variable does not affect odds of outcome

- $\quad$ OR $>1$ Predictor variable associated with higher odds of outcome

- $\quad$ OR $<1$ Predictor variable associated with lower odds of outcome

In the text, the language of odds ratios is often made more accessible by reformulating and rounding up in terms of likelihood and probabilities.

Odds ratios can be interpreted in such a way that for a unit increase in the predictor variable (e.g. the index of cognitive-activation instruction), the odds ratio of the outcome variable (e.g. answering a mathematics item of higher difficulty correctly) is expected to change by a factor of the respective parameter estimate, given that the variables in the model are held constant. For instance, a typical interpretation of a logistic regression would be "Everything else equal, a unit increase in the index of cognitive-activation instruction increases the likelihood of answering correctly an item of high difficulty by 50 percent" (when an odds ratio is equal to 1.5). When the answers to the questions are mutually exclusive (i.e. such as those about on learning strategies, where students need to choose between memorisation, control and elaboration strategies), one can add to the interpretation a statement such as "compared to using other learning strategies".

Note that with cross-sectional data such as the PISA and TALIS data, the direction of the effect cannot be established. Hence, it is not possible to determine if using memorisation strategies increases the probability of answering a question correctly or better academic performance increases the likelihood of using memorisation strategies. The perspective taken - i.e. the choice of independent and dependent variables - is entirely based on logic, experience and theoretical considerations.

On less difficult items, students who reported greater exposure to cognitive-activation strategies are about $10 \%$ more likely to answer correctly than students who are less frequently exposed to this strategy (odds ratio of around 1.1), after accounting for other teaching strategies. On more difficult items, the probability of answering correctly is about 50\% higher for students who are more frequently exposed to cognitive-activation strategies (odds ratio of around 1.5).

Teacher-directed instruction shows the opposite pattern of association (Figure 3.21). It moderately improves students' odds of success on less difficult items, but as the items become more difficult, this effect diminishes to the point of becoming negative among the most difficult items, on average across OECD countries. The odds ratio for successfully completing easier items (those below 500 score points) is generally statistically significant and greater than 1 (but less than 1.2), signalling that, on average, students in OECD countries perform better on easier items when receiving teacher-directed instruction. Yet on intermediate or very difficult items, the odds ratio of success are often less than 1 and are most often not statistically significant. 
Figure 3.20. Cognitive-activation instruction and success in solving mathematics problems Odds ratio, after accounting for all other teaching strategies, OECD average

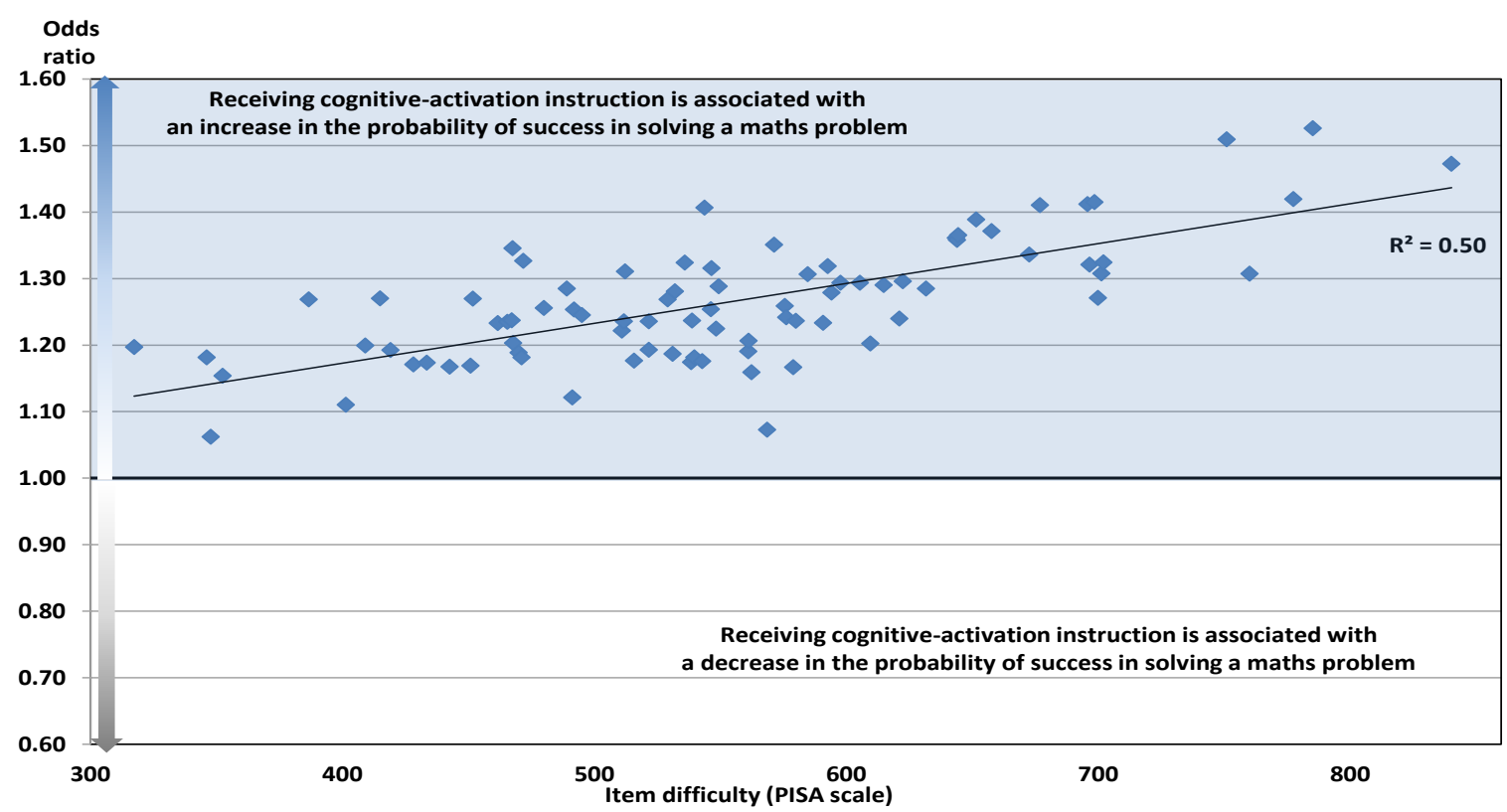

Notes: All odds ratios are statistically significant.

The figure shows the result of a series of logistic regressions that use student performance on a mathematics item of a given difficulty as outcome. Two outcome categories are possible: the student gets full credit for solving the item correctly or she/he gets no credit. Regressions were run separately for each country/economy, and then the average across OECD countries was calculated.

Source: OECD, PISA 2012 Database.

Figure 3.21. Teacher-directed instruction and success in solving mathematics problems

Odds ratio, after accounting for all other teaching strategies, OECD average

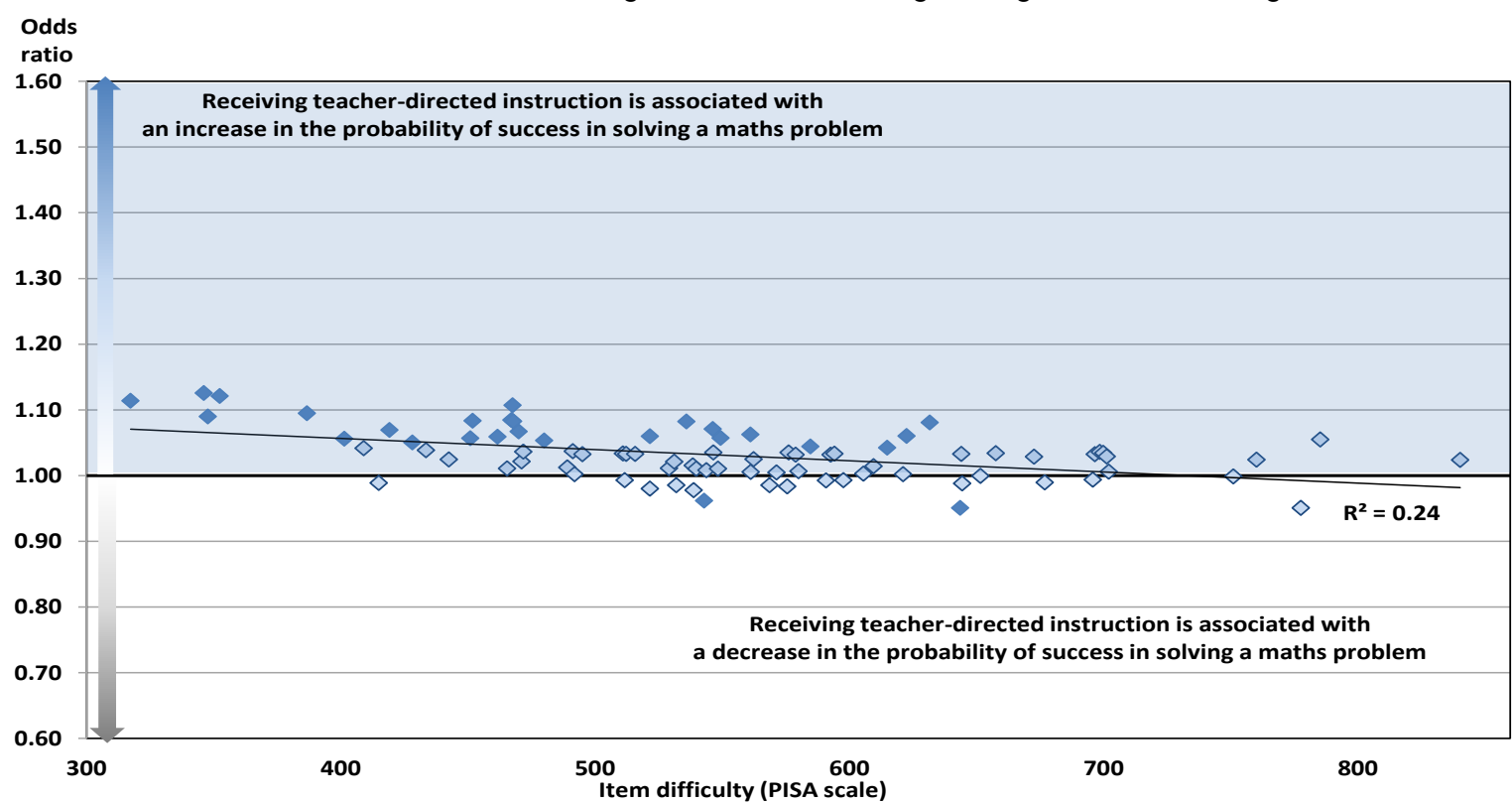

Notes: Odds ratios that are statistically significant are marked in a darker tone.

The figure shows the result of a series of logistic regressions that use student performance on a mathematics item of a given difficulty as outcome. Two outcome categories are possible: the student gets full credit for solving the item correctly or she/he gets no credit. Regressions were run separately for each country/economy, and then the average across OECD countries was calculated.

Source: OECD, PISA 2012 Database. 
Student-oriented and formative-assessment instruction offer flat and negative patterns of association with success on mathematics items across the spectrum of difficulty. On average across OECD countries, students exposed to more student-oriented instruction are around $25 \%$ less likely (statistically significant odds ratios of around 0.75) to answer mathematics items of any level of difficulty correctly, compared with students who are exposed to less student-oriented instruction, after accounting for the other three kinds of instruction (Figure 3.22). Among students exposed to more formative-assessment instruction, the probability of success on mathematics items of any level of difficulty is about $10 \%$ less than among students exposed to less of that teaching strategy (statistically significant odds ratio of around 0.9) (Figure 3.23).

The finding that student-oriented and formative-assessment strategies do not seem to be related to students' success on mathematics items of any level of difficulty might come as a surprise, given that previous studies provide some evidence in favour of these teaching methods (e.g. Bietenbeck, 2014; Blazar, 2015; Hattie, 2009). A possible explanation for these findings is that the relationship runs not from teaching strategy to student success on the items, but in the opposite direction - meaning that teachers are more likely to use student-oriented or formative-assessment strategies for those students who struggle with mathematics problems at all levels of difficulty. It is also possible that unobserved student characteristics are introducing biases in the estimation of the effects of student-oriented practices (see Box 3.6 for possible ways to overcome these problems).

Figure 3.22. Student-oriented instruction and success in solving mathematics problems

Odds ratio, after accounting for all other teaching strategies, OECD average

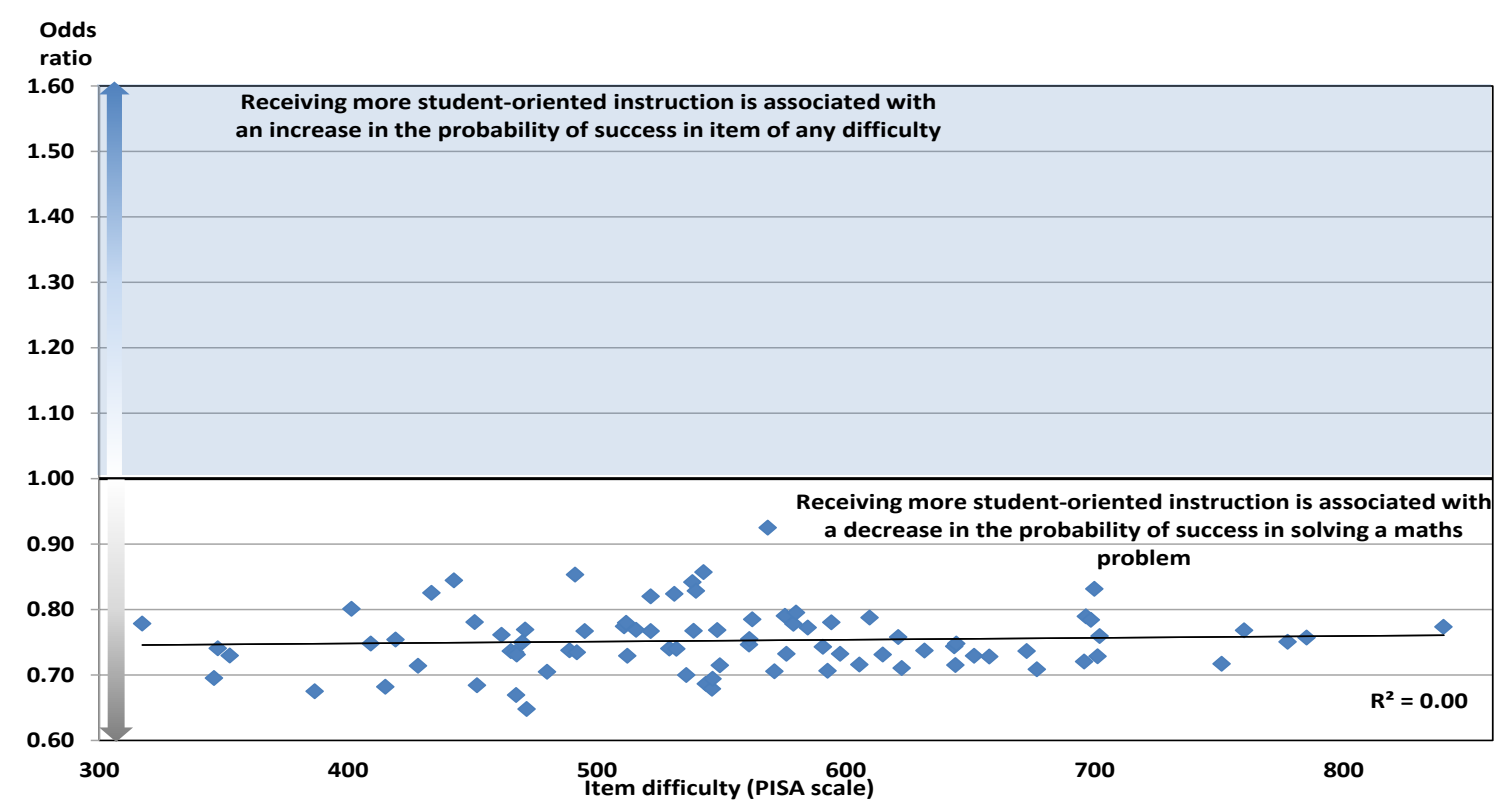

Notes: All odds ratios are statistically significant.

The figure shows the result of a series of logistic regressions that use student performance in a mathematics item of a given difficulty as outcome. Two outcome categories are possible: the student gets full credit for solving the item correctly or she/he gets no credit. Regressions were run separately for each country/economy, and then the average across OECD countries was calculated.

Source: OECD, PISA 2012 Database. 
Figure 3.23. Formative-assessment instruction and success in solving mathematics problems Odds ratio, after accounting for all other teaching strategies, OECD average

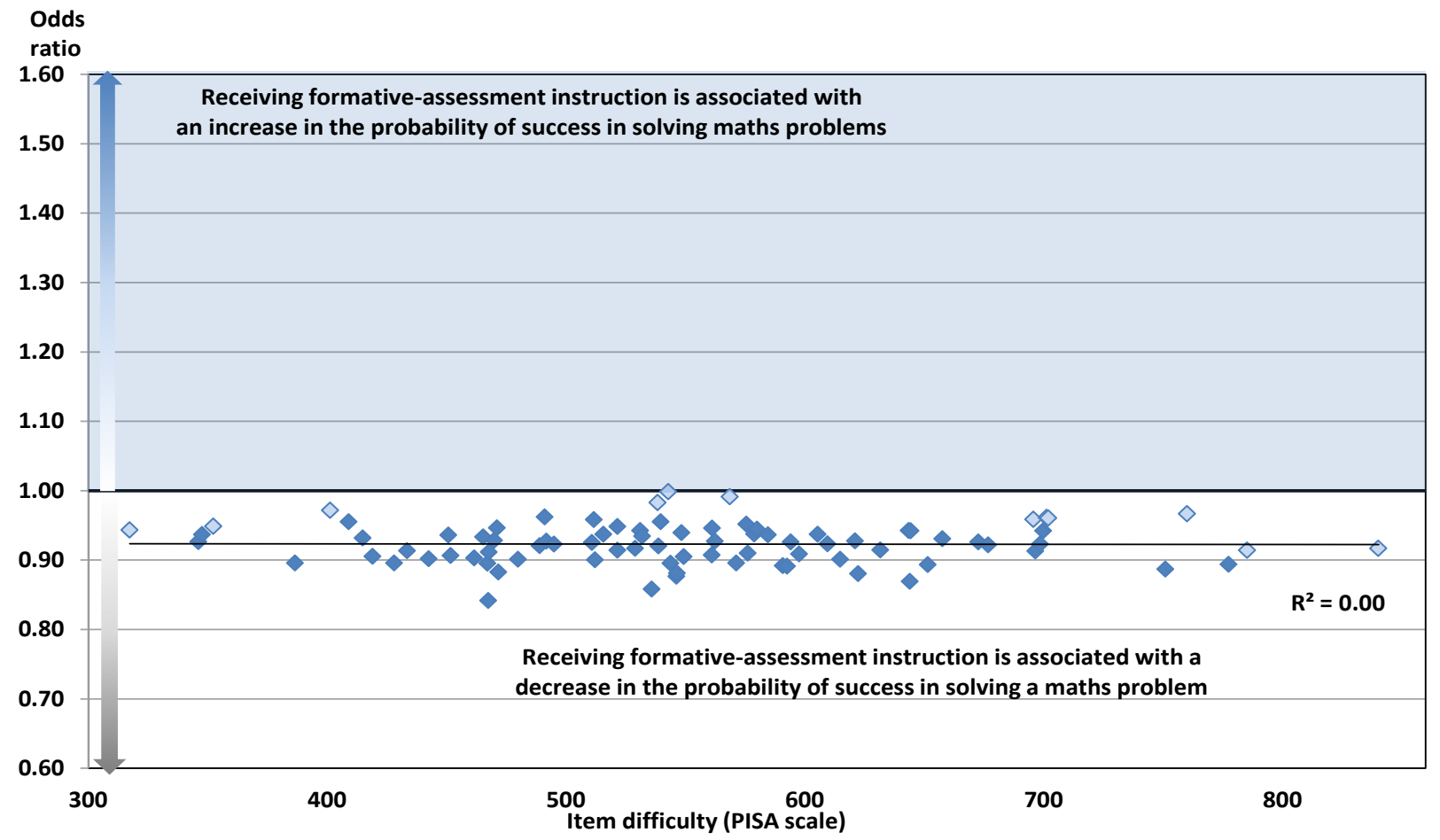

Notes: Odds ratios that are statistically significant are marked in a darker tone.

The figure shows the result of a series of logistic regressions that use student performance in a mathematics item of a given difficulty as outcome. Two outcome categories are possible: the student gets full credit for solving the item correctly or she/he gets no credit. Regressions were run separately for each country/economy, and then the average across OECD countries was calculated.

Source: OECD, PISA 2012 Database.

\section{Box 3.5. Self-reported teaching strategies and beliefs in TALIS 2013, and student performance in mathematics in PISA 2012}

Figure 3.24 illustrates the associations between teachers' practices and beliefs as reported by teachers themselves (TALIS 2013) and student performance in mathematics (PISA 2012). The analyses show the probability of students answering correctly individual PISA items, categorised by their level of difficulty, after accounting for other teaching practices and beliefs. Data for all countries that participated in the TALIS-PISA Link study, except Mexico, which opted for the "Easy Booklet Option" (see Chapter 2), were pooled together in order to attain more precise estimates.

Students were less likely to succeed in both easy and difficult mathematics items if the teachers in their school reported more frequent use of student-oriented strategies. Except for the easiest items, the same is true when the same teachers reported more frequent use of formative-assessment or teacher-directed practices. Conversely, the stronger the teachers' belief in using cognitive-activation strategies, the better their students performed overall (Figure 3.24).

These results are fairly similar to those observed when the frequency of exposure to teaching strategies is reported by students instead of teachers. Teacher-directed and formative-assessment instructional practices are both negatively associated with success on difficult mathematics items, student-oriented strategies decrease the likelihood of correctly answering easy or difficult items, and cognitive-activation practices (in PISA) or the belief in using them (in TALIS) are positively associated with success on difficult items. 


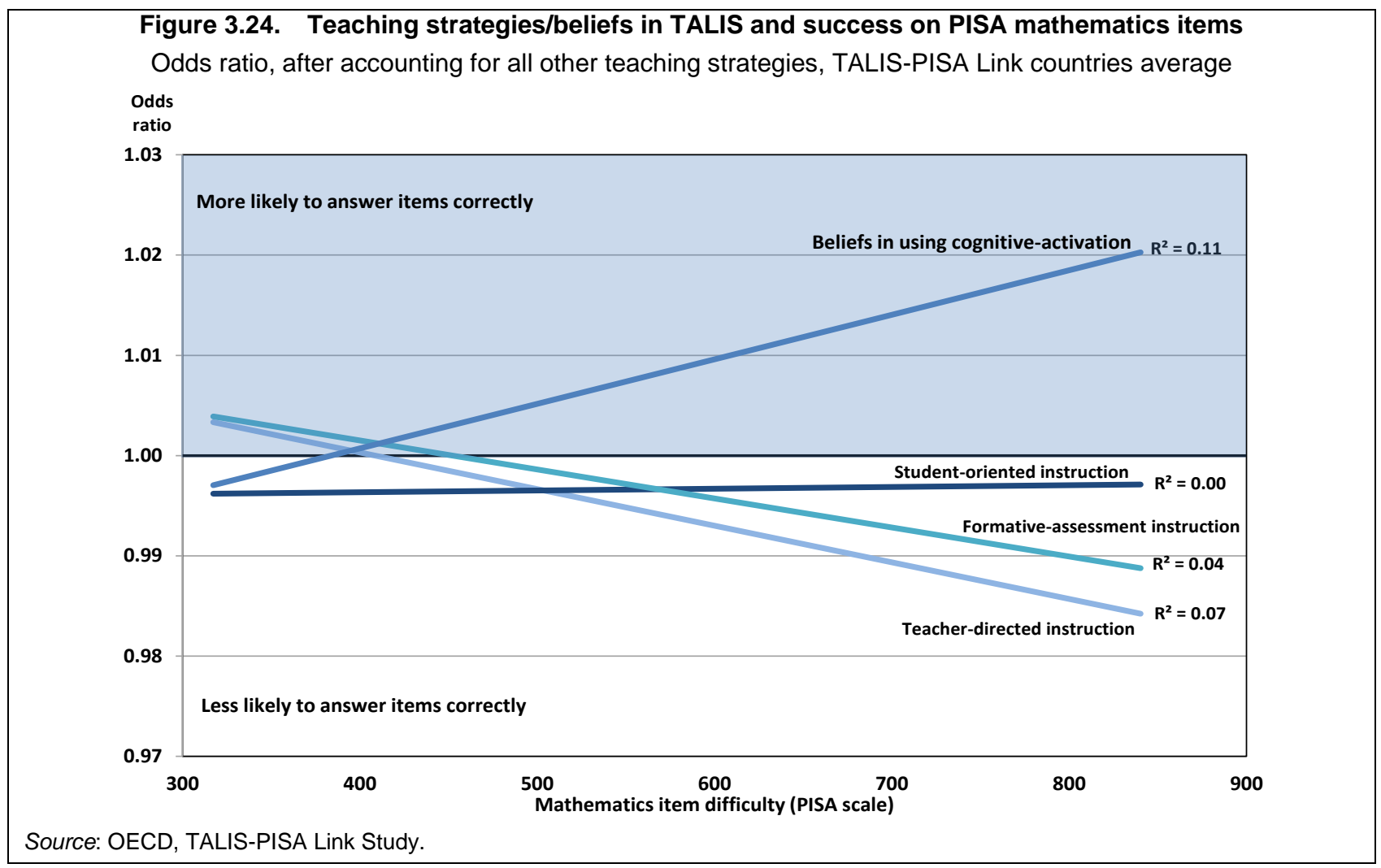

Figure 3.25. Teaching strategies and success on mathematics items

Odds ratio, after accounting for all other teaching strategies, students' socio-economic status, gender and school learning environment, OECD average

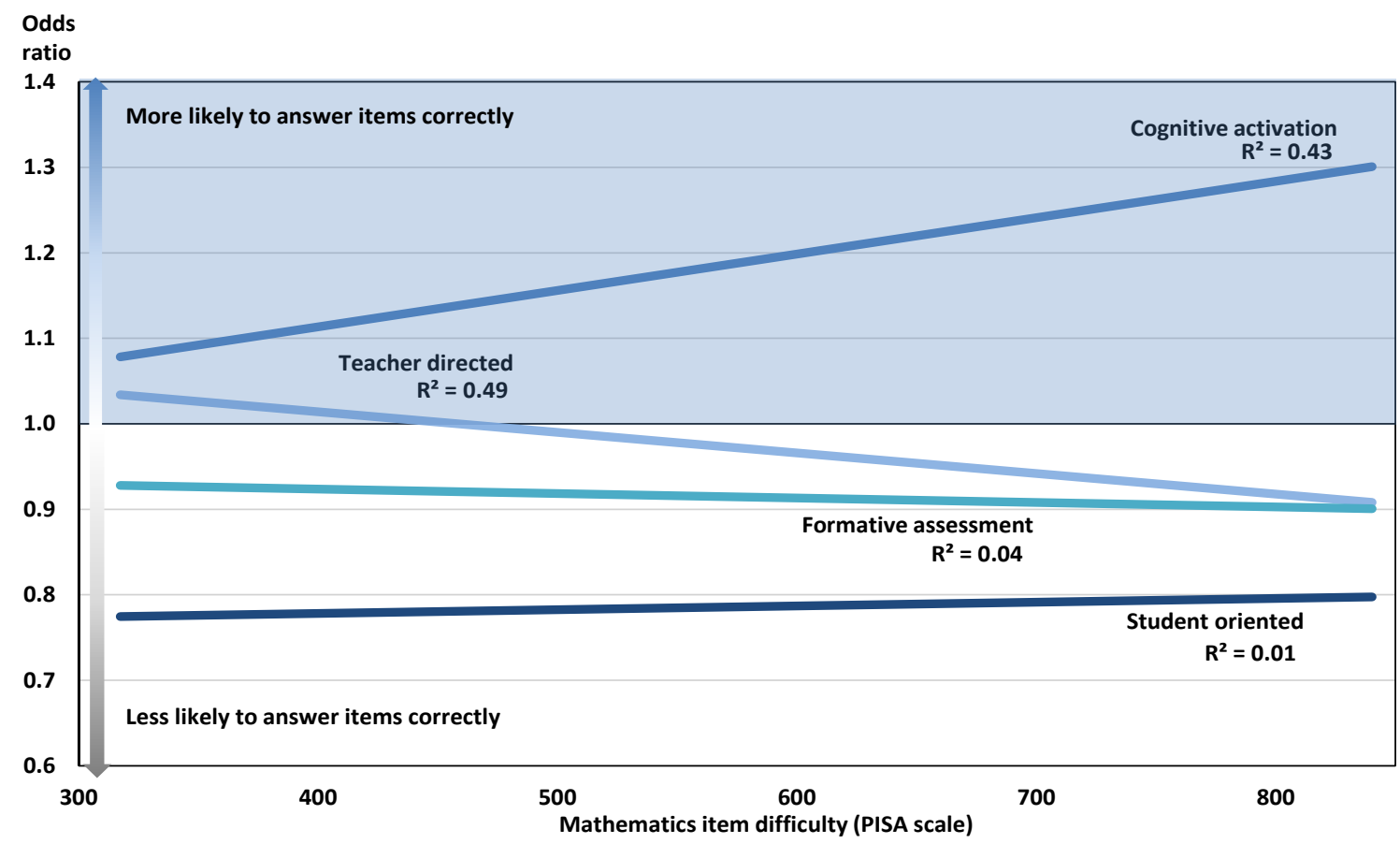

Note: The figure shows the results of a series of logistic regressions predicting the probability that a student gets full credit when answering mathematics items of a given difficulty.

Source: OECD, PISA 2012 Database. 
Also, the results above do not account for other student or school characteristics that may affect both student performance and teachers' instructional practices. Thus, Figure 3.25 reports the same models, but after accounting for students' socio-economic status and gender, and for schools' learning environment (i.e. teacher support, teacher-student relations, classroom management, disciplinary climate, students' sense of belonging at school). But the figure shows that the results do not change substantially after these student and school characteristics are taken into account.

\section{Box 3.6. A cross-subject analysis of teaching strategies and beliefs, and student performance using the TALIS-PISA Link}

Teachers often adapt their teaching practices based on their initial observation of student performance (reverse causality); and students frequently select themselves, or are streamed, into different classes with different teachers and teaching methods, according to their performance. There are also many characteristics of students, families and schools that cannot be realistically measured using survey questions. It is therefore risky to talk about the effects of certain teaching practices when analysing observational data on student performance and those practices.

Two strategies are used to mitigate this limitation. First, student performance in reading, mathematics and science in PISA 2012 is linked to the unequal emphasis teachers give to the four teaching strategies/beliefs across the three subjects assessed in PISA. This approach is appropriate whenever there are shared teaching practices among teachers of the same subject in the same school. Second, instead of analysing student performance in individual subjects separately, the explained/dependent variable is the variation in performance across the three subjects for the same individual. That is, the effect of teaching practices/beliefs is identified by comparing the differences in a student's performance in reading, mathematics and science to the relative importance that reading, mathematics and science teachers in that school give to the teaching practices cited in the TALIS questionnaire, after accounting for relevant characteristics of the teaching staff in the same school (see Annex for further details on this methodology). With this approach, it is possible to identify the relationship between the teaching practices/beliefs and student performance regardless of the students' innate intellectual ability or of other student, family or school characteristics.

TALIS 2013 provides information on teachers' gender, age, seniority in the profession and in the school, type of work contract (permanent or temporary; full-time or part-time), level of education, subject(s) taught over the previous school year, and participation in training activities over the previous year. It also includes information on the teaching practices they use and their opinions about issues related to teaching, the students and the school. Accounting for all these teacher characteristics is important for ensuring that the teaching strategies analysed really influence student outcomes. Using information from both the PISA and TALIS questionnaires, the analyses account for relevant student, teacher and school characteristics.

Figures 3.26 to 3.29 focus on the relationship between teaching strategies and beliefs, on the one hand, and overall test achievement (as measured by the proportion of PISA items, of all levels of difficulty, answered correctly), and the performance in very easy, easy, difficult and very difficult PISA items, on the other. The four levels of item difficulty are identified by estimating the 25th, 50th and 75th percentiles of the distribution of correct responses for each item in the reading, mathematics and science assessments.

In most participating countries, teacher-directed strategies are associated with poorer student performance in the PISA assessments (Figure 3.26). This negative association with overall achievement is statistically significant in Australia, Finland, Latvia, Romania and Singapore.

In Finland and Latvia, teacher-directed strategies are associated with a lower probability of correctly answering PISA reading, mathematics and science items of almost any level of difficulty; in Romania and Singapore, with a lower probability of succeeding in easy and very easy items. Conversely, in Mexico teacher-directed strategies are positively related to student performance in easy and very easy items, while in Portugal, only for very easy items.

Student-oriented teaching practices, such as having students work in small groups, assigning projects that require at least one week to complete, and working with students individually, are associated with better student performance in all participating countries except Finland (Figure 3.27). These findings are supported in previous studies, such as Lavy (2011), Algan, Cahuc and Shleifer (2013) and Bietenbeck (2014). Bietenbeck (2014), for instance, finds that the use of "modern" practices, such as group work, increases the reasoning ability of students while having no negative effect on their accumulated formal knowledge or their ability to solve routine problems. Meanwhile, Algan, Cahuc and Shleifer (2013) show that some teaching practices, like having students work in groups, do projects together, and ask their teachers questions, improve students' social capital (all of these studies use a cross-subject methodology similar to that used in this chapter). 


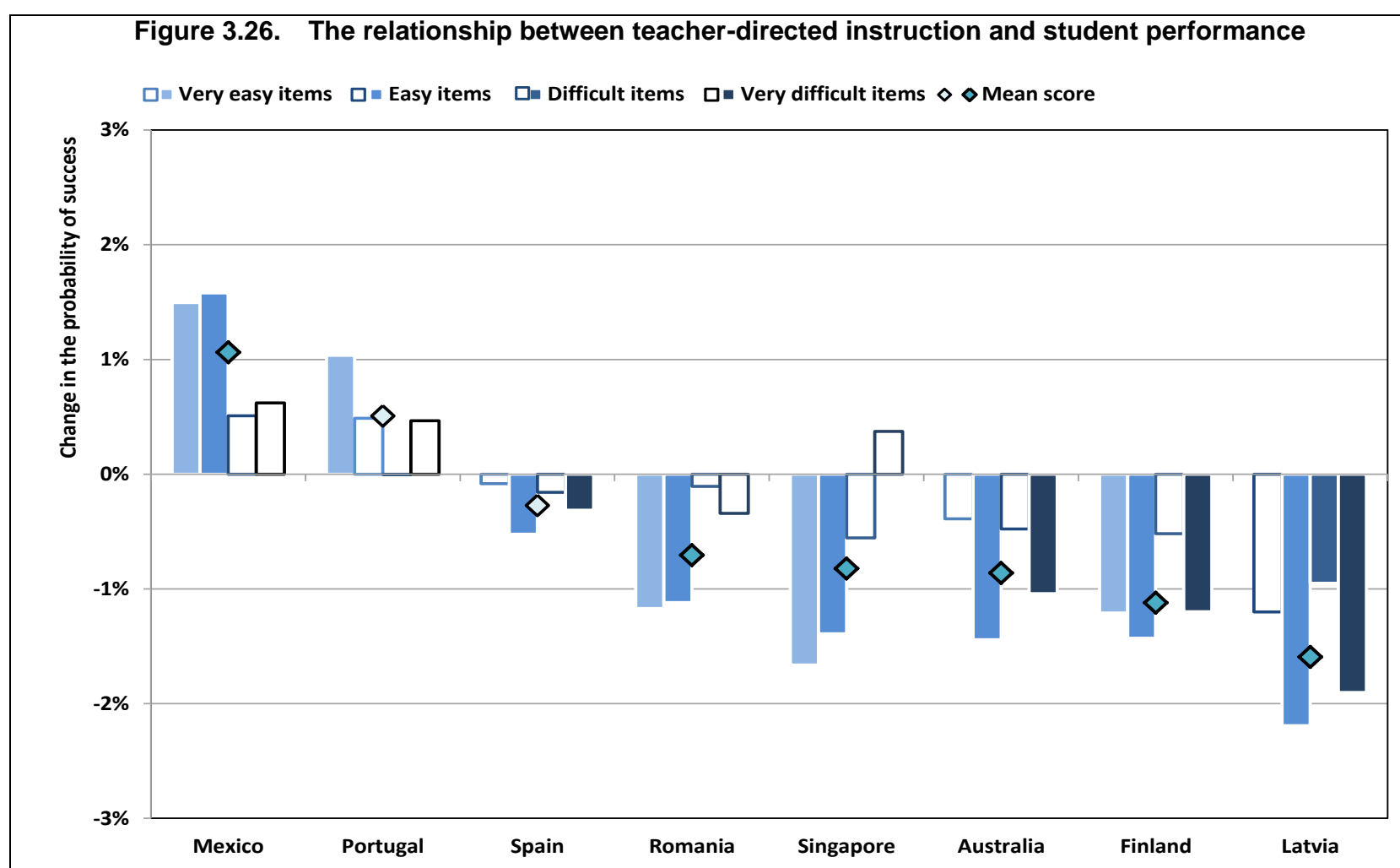

Notes: Statistically significant values are shown in a darker tone.

The analyses are based on student fixed-effect models accounting for relevant student and school characteristics.

Positive values indicate that students performed better in those subjects in which their teachers reported more frequent use of teacher-directed strategies.

Countries are ranked in descending order of the impact of teaching-practice effects on overall test achievement.

Source: OECD, PISA 2012 Database.

Student-centred teaching strategies are positively associated with the probability of students correctly answering PISA items of any level of difficulty, even though in most countries the association decreases somewhat as items become more difficult. Specifically, an increase of one standard deviation in the index of student-oriented instruction increases the probability of answering PISA items correctly by between $3 \%$ and $8 \%$ in Finland, Latvia, Portugal, Romania and Spain, depending on the difficulty of the item, and by between $6 \%$ and $12 \%$ in Australia and Singapore. These results support the theory that shifting the focus of activity from the teacher to the student results in better student outcomes.

Formative-assessment teaching practices are associated with worse overall test achievement in Mexico and Singapore (Figure 3.28). Interestingly, these teaching strategies are associated with lower success rates on very difficult items in all eight countries; also in Australia and Mexico on easy or very easy items. Only in Finland and Romania are these practices associated with greater success, and only on easy or very easy items.

Holding positive beliefs about cognitive-activation strategies seems to work for only very difficult items: they are associated with a greater probability of correctly answering very difficult items in Australia and Portugal (Figure 3.29). All other associations are trivial, which is probably explained by the fact that the index measures how strongly teachers believe that cognitive-activation strategies should be used in their reading, mathematics and science lessons, instead of their reported use of these instructional practices. Teachers' beliefs about teaching are more likely to be affected by social desirability bias - responding in a way that is favourably viewed by others - than their description of which teaching practices they used in their first class after 11 a.m. on the previous Tuesday.

These findings barely change when schools' average performance, instead of the performance of individual students, is analysed, and also when the analysis is restricted to reading and mathematics to avoid the expected correlation between mathematics and science in teachers' attributes and student performance. 


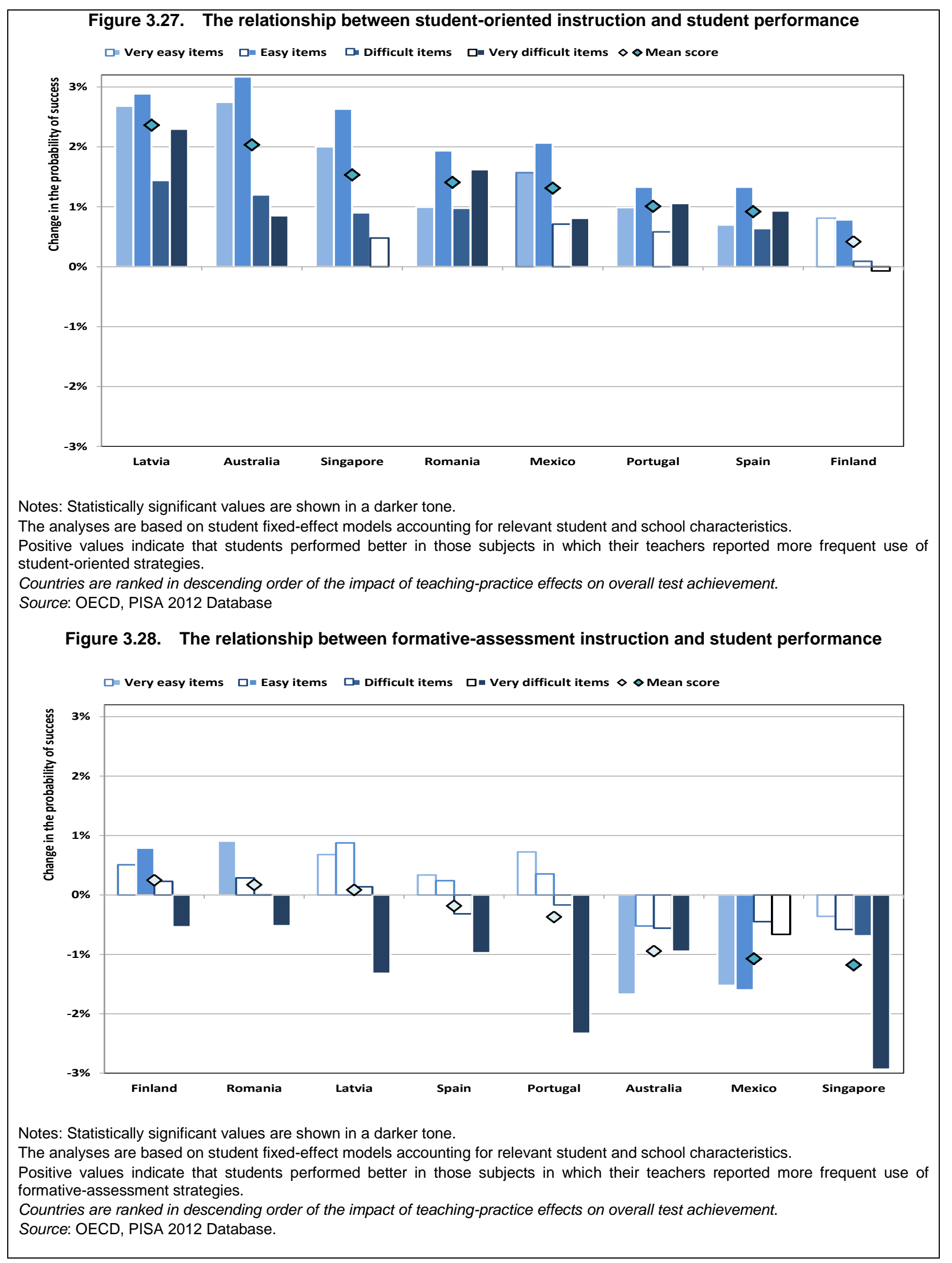




\section{Figure 3.29. The relationship between teachers' belief in cognitive-activation strategies and student} performance

$\square$ Very easy items $\square \square$ Easy items $\square=$ Difficult items $\square$ Very difficult items $\diamond \diamond$ Mean score

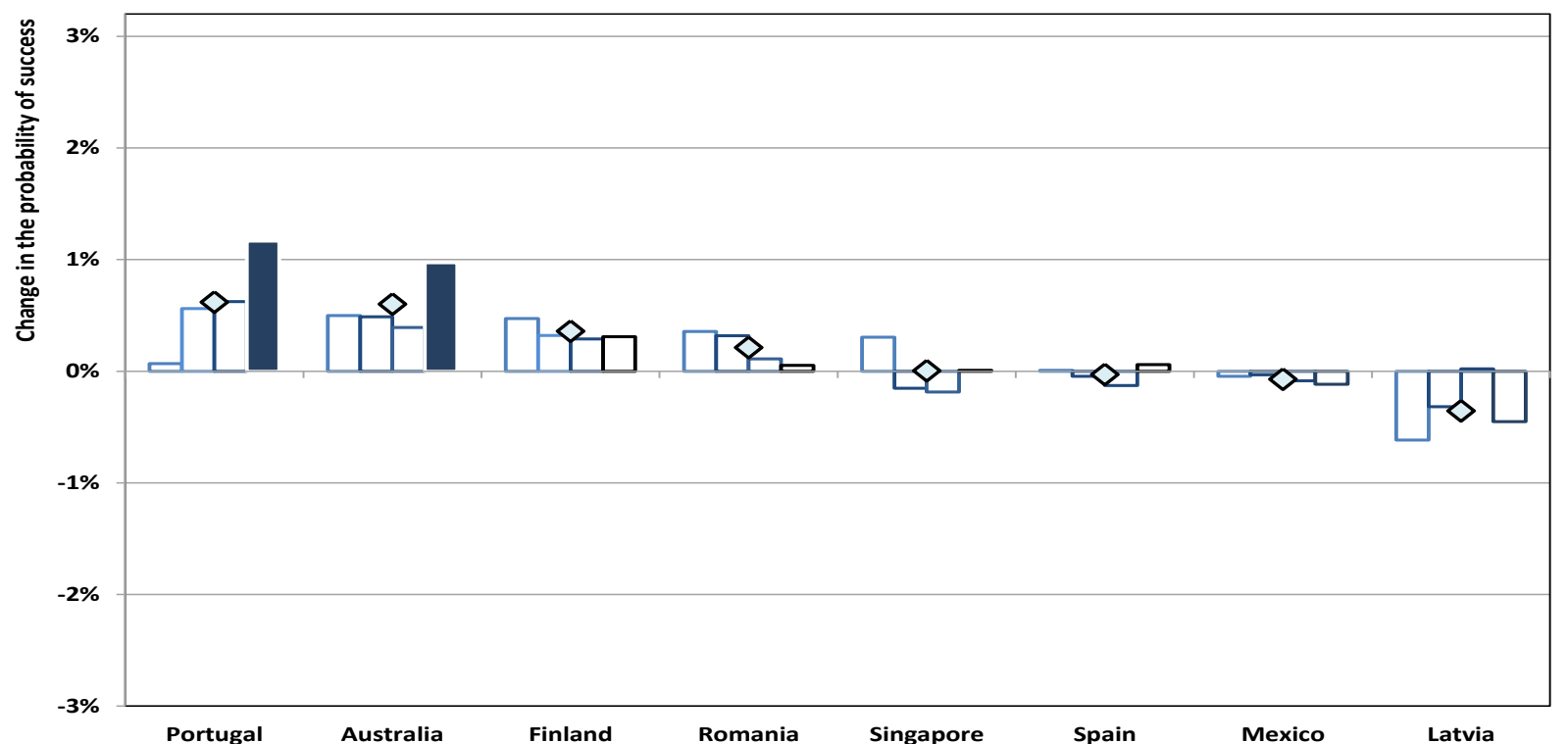

Notes: Statistically significant values are shown in a darker tone.

The analyses are based on student fixed-effect models accounting for relevant student and school characteristics.

Positive values indicate that students performed better in those subjects in which their teachers hold stronger beliefs about the importance of using cognitive-activation strategies.

Countries are ranked in descending order of the impact of teaching-practice effects on overall test achievement.

Source: OECD, PISA 2012 Database.

\section{References}

Algan, Y., P. Cahuc, P. and A. Shleifer (2013), "Teaching Practices and Social Capital", American Economic Journal: Applied Economics, Vol. 5/3, pp. 189-210.

Bietenbeck, J. (2014), "Teaching practices and cognitive skills", Labour Economics, Vol. 30, pp. 143-153.

Lavy, V. (2011), "What Makes an Effective Teacher? Quasi-Experimental Evidence" NBER Working Papers, 16885.

\section{References}

Bietenbeck, J. (2014), “Teaching practices and cognitive skills”, Labour Economics, Vol. 30, pp. 143-153.

Black, P., and Wiliam, D. (1998), "Assessment and classroom learning”, Assessment in education, Vol. 5/1, pp. 7-74.

Blazar, D. (2015), "Effective teaching in elementary mathematics: Identifying classroom practices that support student achievement", Economics of Education Review, Vol. 48, pp.16-29.

Brown, A.L. (1994), “The Advancement of Learning”, Educational Researcher, Vol. 23, No. 8, pp. 4-12.

Carroll, J.B. (1963), “A model for school learning”, Teachers College Record, Vol. 64/8, pp.723-733.

Carroll, J.B. (1989), “The Carroll Model: A 25-Year Retrospective and Prospective View”, Educational Researcher, Vol. 18/1, pp. 26-31.

Creemers, B.P.M. and L. Kyriakides (2008), The Dynamics of Educational Effectiveness: A Contribution to Policy, Practice, and Theory in Contemporary Schools, Routledge, London. 
Deboer, G. E. (2002), "Student-centered teaching in a standards-based world: Finding a sensible balance", Science \& Education, Vol. 11/4, pp. 405-417.

Felder, R. M., \& Brent, R. (1996), "Navigating the bumpy road to student-centered instruction”, College Teaching, Vol. 44/2, pp. 43-47.

Hanushek, E. and L. Woessmann (2011), "The Economics of International Differences in Educational Achievement", Handbook of the Economics of Education, Vol. 3, Elsevier.

Harris, A. and J.H. Chrispeels (eds.) (2006), Improving Schools and Educational Systems: International Perspectives, Routledge, London.

Hattie, J., and Timperley, H. (2007), “The power of feedback”, Review of Educational Research, Vol. 77/1, pp. 81-112.

Hattie, J. (2009), Visible learning: A synthesis of over 800 Meta-analyses Relating to Achievement, Routledge.

Hopkins, D. (ed.) (2005), The Practice and Theory of School Improvement: International Handbook of Educational Change, Springer, Dordrecht.

Klieme, E., C. Pauli and K. Reusser (2009), "The Pythagoras Study: Investigating Effects of Teaching and Learning in Swiss and German Classrooms", in T. Janik and T. Seidel (eds.), The Power of Video Studies in Investigating Teaching and Learning in the Classroom, Waxmann Verlag, Münster, pp. 137-160.

Kunter, M., and J. Baumert (2006), "Who is the expert? Construct and criteria validity of student and teacher ratings of instruction." Learning Environments Research, Vol. 9/3, pp. 231-251.

Kunter, M., Y.-M. Tsai, U. Klusmann, M. Brunner, S. Krauss and J. Baumert (2008), "Students' and Mathematics Teachers' Perception of Teacher Enthusiasm and Instruction", Learning and Instruction, Vol. 18, pp. 468-482.

Leung, F. K. (2001), "In search of an East Asian identity in mathematics education", Educational Studies in Mathematics, Vol. 47/1, pp. 35-51.

Lipowsky, F., K. Rakoczy, C. Pauli, B. Drollinger-Vetter, E. Klieme and K. Reusser (2009), "Quality of Geometry Instruction and its shortterm Impact on Students' Understanding of the Pythagorean Theorem", Learning and Instruction, Vol. 19, pp. 527-537.

NCTM (1991). Professional standards for teaching mathematics, National Council of Teachers of Mathematics, Reston, VA.

Neubrand and Y.-M. Tsai (2010), "Teachers' Mathematical Knowledge, Cognitive Activation in the Classroom, and Student Progress", American Educational Research Journal, Vol. 47, pp. 133-180.

Oakes, J. (2005), Keeping Track: How Schools Structure Inequality (2nd ed.), Yale University, New Haven, Connecticut.

OECD (2015), PISA Technical Report 2012, PISA, OECD Publishing, Paris.

OECD (2015b), The ABC of Gender Equality in Education: Aptitude, Behaviour, Confidence, PISA, OECD Publishing, Paris. http://dx.doi.org/10.1787/9789264229945-en 
OECD (2014), TALIS 2013 Results: An International Perspective on Teaching and Learning, TALIS, OECD Publishing, Paris. http://dx.doi.org/10.1787/9789264196261-en

OECD (2013), PISA 2012 Assessment and Analytical Framework: Mathematics, Reading, Science, Problem Solving and Financial Literacy, PISA, OECD Publishing, Paris. http://dx.doi.org/10.1787/9789264190511-en

OECD (2013b), PISA 2012 Results: Excellence through Equity (Volume II): Giving Every Student the Chance to Succeed, PISA, OECD Publishing, Paris. http://dx.doi.org/10.1787/9789264201132-en

OECD (2013c), PISA 2012 Assessment and Analytical Framework: Mathematics, Reading, Science, Problem Solving and Financial Literacy, PISA, OECD Publishing, Paris, http://dx.doi.org/10.1787/9789264190511-en

OECD (2012), Public and Private Schools: How Management and Funding Relate to their Socio-economic Profile, PISA, OECD Publishing, Paris. http://dx.doi.org/10.1787/9789264175006-en

OECD (2010), Mathematics Teaching and Learning in PISA, PISA, OECD Publishing, Paris. http://dx.doi.org/10.1787/9789264039520-en

Scheerens, J. and R.J. Bosker (1997), The Foundations of Educational Effectiveness, Pergamon, Oxford.

Schleicher, A. (2015), Schools for 21st-Century Learners: Strong Leaders, Confident Teachers, Innovative Approaches, International Summit on the Teaching Profession, OECD Publishing, Paris. http://dx.doi.org/10.1787/9789264231191-en

Schoenfeld, A.H. (ed.) (1987), Cognitive Science and Mathematics Education, Erlbaum, Hillsdale, New Jersey.

Schoenfeld, A.H. (1992), "Learning to Think Mathematically: Problem Solving, Metacognition, and Sense-Making in Mathematics", in D. Grouws, (ed.), Handbook for Research on Mathematics Teaching and Learning, MacMillan, New York, pp. 334-370.

Schwerdt, G. and A. Wuppermann (2011), "Is Traditional Teaching Really All That Bad? A WithinStudent Between-Subject Approach”, Economics of Education Review, Vol. 30/2, pp. 365-379.

Stein, M.K., R.A. Engle, M.S. Smith and E.K. Hughes (2008), "Orchestrating Productive Mathematical Discussions: Five Practices for helping Teachers move beyond show and tell”, in Mathematical Thinking and Learning, Vol. 10, pp. 313-340.

Wang, M.C., G.D. Haertel and H.D. Walberg (1993), "Toward a Knowledge Base for School Learning”, in Review of Educational Research, Vol. 63, No. 3, pp. 249 -294.

Wayne, A. and P. Youngs (2003), “Teacher Characteristics and Student Achievement Gain: A Review”, in Review of Educational Research, Vol. 73, pp. 89-122.

Note:

${ }^{1}$ Results available upon request. 
EDU/WKP(2016)4

\section{CHAPTER 4. LEARNING WITH UNDERSTANDING: APPROACHES TO MATHEMATICS LEARNING AND STUDENT PERFORMANCE}

Learning happens well before children start school and continues throughout adulthood. It happens in the family, the neighbourhood and in isolation. Above all, it happens in the classroom. It is in schools where students most strongly experience the joys and frustrations that come along with learning, and where many of them, mostly inadvertently, learn how to learn. Even if most education systems focus on "what" is learned, rather than "how" students learn, most students inevitably develop particular learning strategies to complete school assignments and prepare for exams. Which strategies they adopt can make all the difference in their learning.

As an integral part of the learning process, students' learning strategies - the thoughts and actions that students use to complete learning tasks (Chamot et al., 2004) - have a direct influence on academic performance and thus have an impact on students' daily lives (OECD, 2010). In addition to this immediate influence, learning strategies can also have long-term consequences for students. Rote learning, for instance, can be useful in certain school environments, but relying on that strategy alone may seriously penalise students later on in their educational career or in many work situations where simply storing and reproducing information may not be enough to get a job done (Dansereau, 1978). Sooner or later, a lack of deep, critical, creative and flexible thinking becomes a problem, particularly in innovative societies where the demand for non-routine skills is rising (OECD, 2013). Given how important "learning-to-learn" is for academic performance and other life outcomes, and that most education policies ultimately aspire to shape the learning process, it may be unwise to leave students' approaches to learning entirely to chance.

Learning strategies have been defined as "thoughts and actions that students use to complete learning tasks" (Chamot et al., 2004) and "behaviours and thoughts in which a learner engages and which are intended to influence the learner's encoding process" (Weinstein and Mayer, 1983). Learning strategies are here defined as cognitive and metacognitive processes employed by students as they attempt to learn something new (OECD, 2010). Examples of learning strategies include rehearsal, drilling, rote learning, summarising, paraphrasing, clarifying, making connections, seeking alternatives, inductive/deductive reasoning, critical thinking, organising/classifying material and thinking about learning itself (OECD, 2010; Pritchard, 2009; Rubin, 1981; Weinstein and Mayer, 1983). In PISA, the main strategies students use to learn mathematics are grouped into three broad approaches: memorisation, elaboration and control strategies.

Memorisation can be defined as learning something completely so that it can later be recalled or repeated. Memorisation activities include rehearsal, routine exercises, drill and practice and/or repetition. This approach is associated with concepts such as rote learning, knowledge without understanding, surface learning, routine problems, and traditional and back-to-basics education. The main purposes of memorisation strategies are to consolidate knowledge, reinforce routines and be able to retrieve information later.

Students who use elaboration strategies consciously make connections between tasks, prior knowledge and beliefs, and real-life experience (OECD, 2010; Pask, 1976, Weinstein et al., 1989). Elaboration strategies include using analogies and examples, brainstorming, using concept maps and seeking for alternative ways of finding solutions. This approach is associated with concepts such as reasoning, deep learning, holistic learning, intrinsic motivation, critical thinking, creativity, non-routine 
problems, student-centred instruction and constructivism. The main purpose of elaboration strategies is to comprehend new information; a secondary goal is to retain this information over the long term.

In the third approach, students "control" their learning by setting clear goals for themselves and monitor their progress in reaching them (OECD, 2010). Control strategies include summarising information, clarifying concepts, organising material, planning study time, checking/monitoring/evaluating progress, identifying relevant information and reflecting on their learning strategies. This approach is associated with concepts such as efficiency, strategic learning, time management, instrumental motivation, self-regulation and metacognitive awareness. The main purpose of control strategies is to direct the learning process and make it more efficient (Dansereau, 1978).

Students differ in how intensively they use these types of learning strategies. Some feel more comfortable with particular strategies; others may adopt different strategies depending on their teachers' expectations, their motivation, the type of task and, more generally, on their learning environment. Students may also give different weight to particular learning strategies when they are faced with new information, depending on in which phase of the learning process they find themselves: identification, comprehension, retention or retrieval (Dansereau, 1978). After all, "no single strategy is a panacea" (Center for Research on Learning).

This chapter will briefly review what educationalists have said about the three learning approaches, show how intensively they are used by students across PISA participating countries and economies and create a profile of the students who report employing them. The main analyses in the chapter examine how these learning approaches are related to solving PISA mathematics problems, organised according to their level of difficulty, format type, content area, context in which they are set and stage of the mathematics modelling cycle in which they mainly focus. The last sections analyse which learning approach works best for advantaged and disadvantaged students, and how the multiple combinations of learning strategies are related to the success in mathematics problems of varying levels of difficulty. ${ }^{1}$

\section{What we know about the effectiveness of learning strategies}

There has been a great deal of controversy between traditionalists and constructivists, among others, over the role that memorisation should play in learning. The dispute is apparent even in the way memorisation is defined. Some constructivists emphasise that memorising is a deliberate act that involves learning isolated facts detached from their meaning. For some traditionalists, memorisation, practice and repetition are precisely the methods through which students can better consolidate the meaning of basic concepts. In between are those who prefer to draw distinctions between "good" memorisation, such as memorisation-with-understanding and repetitive learning (recall of already-understood information), and "bad" memorisation, such as mechanical memorisation and rote learning (Biggs, 1994).

\section{Practice makes perfect...}

There are certainly some potential advantages of using memorisation as a learning strategy in mathematics, particularly when it is not just mechanical memorisation. Memorising can lay the foundation for conceptual understanding by giving students enough concrete facts on which to reflect. Repetitive learning can also ease students' anxiety towards mathematics - perceived by many as the most challenging school subject - by reducing mathematics to a set of simple facts, rules and procedures amenable to linear learning. Most important, the extensive use of repetition can lead to mathematics "automaticity", speeding up basic arithmetic computations and freeing up time for deeper mathematical reasoning (Looi et al., forthcoming). 
Neuroscientific research on learning has shown that repeating mathematics problems can reinforce neural pathways in the brain, improve the retrieval of correct information, and reduce the demands on the working memory (Delazer et al., 2005; Pauli et al., 1994). For instance, knowing the multiplication table by heart can help in solving more advanced mathematics problems by reducing the cognitive load, or mental effort, in learners. In short, by helping students to retain and retrieve basic mathematics facts, rules and procedures, repetitive learning and memorisation can help students to solve mathematics problems even the most complex - more efficiently (Cumming and Elkins, 1999). These benefits might explain why, in some education systems, particularly those in East Asia, many people believe that memorisation is compatible with creativity, understanding and a deep approach to mathematics learning, and why it has been described as the "springboard of learning" (Biggs, 1998; Hess and Azuma, 1991; Jin and Cortazzi, 1998; Kember, 1996; Orlin, 2014; Sadler-Smith and Tsang, 1998).

However, memorisation is unpopular with many educationalists. The negative view on memorisation extends to related activities and concepts, including rote learning, drills, rehearsal, practice, repetition, routine exercises and surface learning (Ausubel et al., 1976; Biggs, 1993; Marton and Saljo, 1976). The perception also extends to the students who rely on their memory when learning mathematics: that they make little effort to grasp the underlying principles of what they are learning (i.e. surface learning).

Some opponents of memorisation concede that the strategy might increase computational speed and accuracy; but they insist that no conceptual understanding is gained in the process, and that it might leave students stuck at a lower level of mathematical understanding (Rathmell, 1978). This absence of "number sense" - "an intuition that helps us make sense of number and mathematics" (Dehaene, 1997) - means that students will find it difficult to make connections between different mathematics concepts and real-life experience, which, in turn, may seriously hinder their ability to think creatively and critically (Dansereau, 1978; Hiebert and Wearne, 1996).

"Automaticity" might also lead to the loss of mathematical intuition, control over the learning process and enjoyment of mathematics (Boaler, 1998). It could also give students the erroneous impression that mathematics problems can be solved using simple operations and procedures, and in only a few minutes (Lester and Garofalo, 1982). These limitations become apparent when students are confronted with nonroutine problems, such as those containing irrelevant information, those with more than one solution/interpretation, or those that also require decision-making and communication skills (Mevarech and Kramarski, 2014; Wong et al., 2002).

\section{...but understanding should be the goal}

Given the pace of change in society, the construction of sound knowledge should be given priority over mere reproduction of facts. Many educationalists therefore advocate moving away from memorisation and recommend instead using elaboration strategies. By making links between new concepts and preexisting knowledge and experience, students gain understanding and develop their number sense. Seeking alternative ways of finding solutions to mathematics problems, even if discovered through a collaborative effort, can foster critical-thinking skills.

Elaboration strategies not only enhance comprehension, they can also improve long-term retention of information. Adding meaning and structure to separate pieces of information can lead to more effective and efficient memorisation, if only because the brain appears to resist the "imposition of meaningless patterns" (Caine and Caine, 1997). This is precisely the idea behind some mnemonic techniques, which connect unrelated pieces of information so that they become easier to remember. Elaboration strategies can also create a suitable "psychological climate" for learning (Dansereau, 1978) by turning mathematics from a set of simple facts, rules and procedures into a more meaningful and engaging subject. After all, students need a dose of excitement to become effective learners (Pritchard, 2009). 
Even if the debate has been framed as a dichotomy between memorisation and understanding, the real questions are when, how and to what extent each strategy should be used when learning mathematics. While there seems to be some agreement that drilling should be preceded or followed by understanding some argue that rehearsal works best after a concept is understood and placed into context, but before a new one is introduced, to allow for automaticity and scaffolding (Biggs, 1998) - there is much less consensus on how much drill and practice is needed. Ischebeck et al. (2007), for instance, showed that training effects become significant after repeating a problem only eight times, meaning that the activity of the brain shifts relatively quickly from calculation (placed in the parietal lobe from the intraparietal sulci) to the more efficient result-retrieval function (placed in the angular gyrus). Memorisation might not be deep learning, but it can be suitable at early stages of child development, when not knowing certain information can hinder the learning process or when it complements other learning strategies in developing conceptual clarity, creativity and critical thinking (Pritchard, 2009; Wray and Lewis, 1997).

Control strategies, including setting clear goals, monitoring progress and identifying important material when studying mathematics, have their own drawbacks. Certainly, students who control their learning (i.e. strategic learners) are well-placed to allocate their time and energy wisely and become efficient learners (Dansereau, 1978). However, over-controlling the learning process, and placing too much emphasis on efficiency, can stifle the full development of students' understanding, creativity and critical thinking, and also their ability to retain information over time. These shortcomings may only be revealed when students attempt to solve very complex and completely unfamiliar problems, but they can still have adverse effects on students' self-confidence and interest in mathematics.

\section{Measuring cross-country variations in learning strategies}

\section{Box 4.1. Learning strategies in the PISA student questionnaire}

For each group of three items, please choose the item that best describes your approach to mathematics.

Labels (not shown in the questionnaire): (m) memorisation (e) elaboration (c) control

a) Please tick only one of the following three boxes.

$\square 1$ When I study for a mathematics test, I try to work out what the most important parts to learn are. (c)

$\square 2$ When I study for a mathematics test, I try to understand new concepts by relating them to things I already know. (e)

$\square 3$ When I study for a mathematics test, I learn as much as I can off by heart. (m)

b) Please tick only one of the following three boxes.

$\square 1$ When I study mathematics, I try to figure out which concepts I still have not understood properly. (c)

$\square 2$ When I study mathematics, I think of new ways to get the answer. (e)

$\square 3$ When I study mathematics, I make myself check to see if I remember the work I have already done. (m)

c) Please tick only one of the following three boxes.

$\square 1$ When I study mathematics, I try to relate the work to things I have learnt in other subjects. (e)

$\square 2$ When I study mathematics, I start by working out exactly what I need to learn. (c)

$\square 3$ When I study mathematics, I go over some problems so often that I feel as if I could solve them in my sleep. $(\mathrm{m})$

d) Please tick only one of the following three boxes.

$\square 1$ In order to remember the method for solving a mathematics problem, I go through examples again and again. (m)

$\square 2$ I think about how the mathematics I have learnt can be used in everyday life. (e)

$\square 3$ When I cannot understand something in mathematics, I always search for more information to clarify the problem. (c) 
PISA asked students which learning strategy best described their approach to mathematics using four questions with three mutually exclusive responses to each (Box 4.1). Even if not explicitly stated to students, the three options correspond to the three learning approaches analysed in this chapter: memorisation, elaboration and control. Indices of the learning strategies were constructed by adding the number of times a student chose a particular learning strategy, ranging from zero, indicating that the student never selected the learning strategy, to four, when the student did so in all four questions. Since the responses to the four questions on learning strategies are mutually exclusive, the values on the indices of memorisation, elaboration and control always add up to four.

\section{Memorisation}

The index of memorisation has a value of four when students agreed with all of the following statements: (a) "When I study for a mathematics test, I learn as much as I can by heart"; (b) "When I study mathematics, I make myself check to see if I remember the work I have already done"; (c) "When I study mathematics, I go over some problems so often that I feel as if I could solve them in my sleep"; and (d) "In order to remember the method for solving a mathematics problem, I go through examples again and again". Question (a) assesses the extent to which students learn without attention to meaning (i.e. rote learning), whereas the other three questions come closer to the ideas of drill, practice and repetitive learning.

Memorisation is fairly commonly used by 15 -year-olds. In almost every country, students agreed with the memorisation-related statement in at least one of the four questions on learning strategies (OECD average: 1.25 questions) (Figure 4.1). The use of memorisation varies greatly across countries, and challenges some deep-rooted beliefs about the over-reliance on rote learning and memorisation in East Asian countries, particularly those sharing a Confucian heritage (Biggs, 1994; Leung, 2001).

Figure 4.1. Self-reported use of memorisation strategies

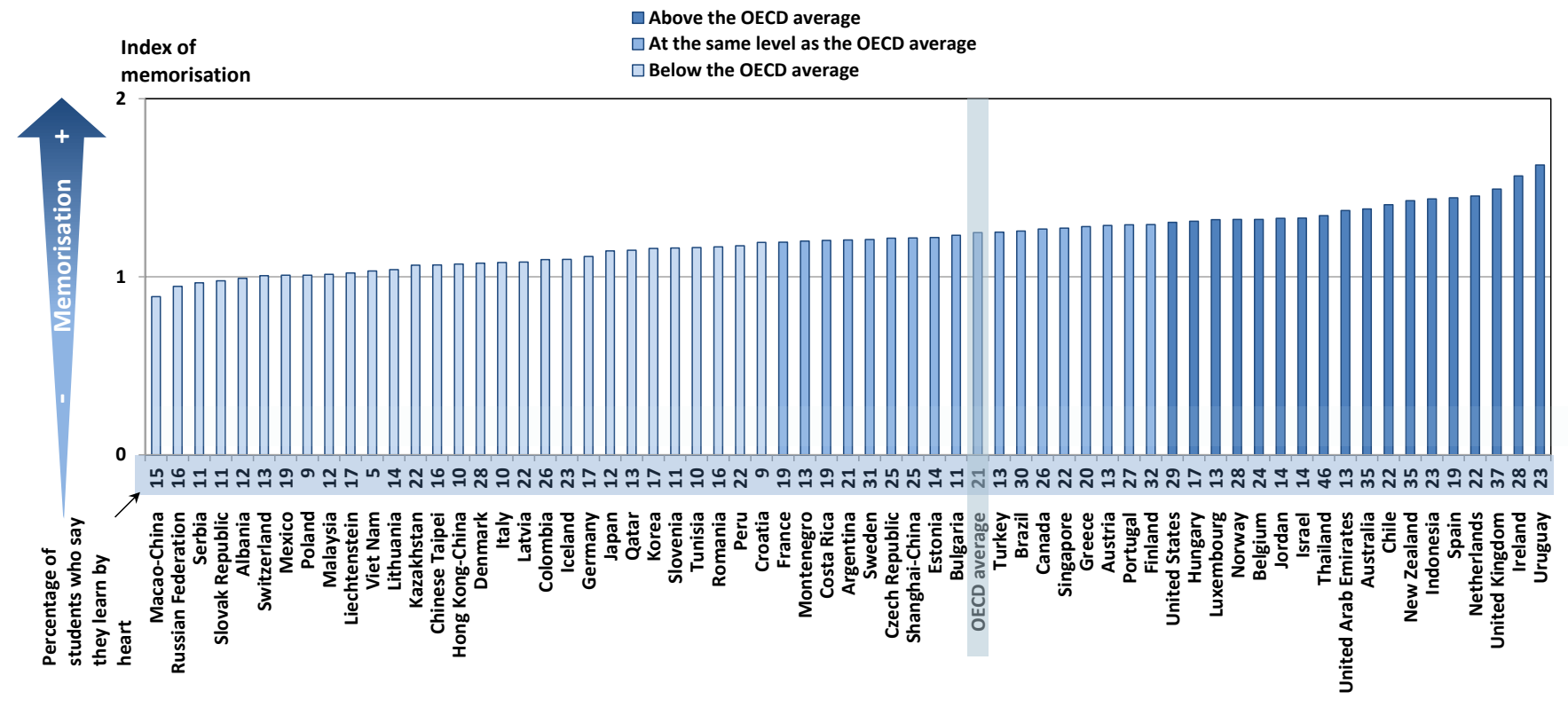

Countries and economies are ranked in ascending order of the number of questions selected by students.

Source: OECD, PISA 2012 Database. 
Fewer 15-year-olds in Hong Kong-China, Japan, Korea, Macao-China, Chinese Taipei and Viet Nam reported that they use memorisation as a learning strategy than did 15-year-olds in some of the Englishspeaking countries to which they are often compared (Purdie and Hattie, 1996). For instance, 12\% of students in Japan and 17\% in Korea said they learn as much as they can by heart when they study for a mathematics test. By contrast, 26\% of students in Canada, 28\% in Ireland, 29\% in the United States, 35\% in Australia and New Zealand, and 37\% in the United Kingdom reported so (Figure 4.1). This may sound surprising to many but mathematics instruction has changed considerably in many of these countries (OECD, 2011). Students in Ireland, the Netherlands, Spain, the United Kingdom and Uruguay reported the most frequent use of memorisation strategies, while those in Albania, Macao-China, the Russian Federation, Serbia and the Slovak Republic reported the least frequent use.

\section{Elaboration}

The index of elaboration has a value of four when students agreed with all of the following statements: (a) "When I study for a mathematics test, I try to understand new concepts by relating them to things I already know"; (b) "When I study mathematics, I think of new ways to get the answer"; (c) "When I study mathematics, I try to relate the work to things I have learned in other subjects"; and (d) "I think about how the mathematics I have learned can be used in everyday life". Statements (a), (c) and (d) are directly connected to the definition of elaboration: they measure the extent to which students make connections between the task at hand, prior knowledge, other topics and real-life experience (Pask, 1976). Statement (b) reflects the idea of seeking alternatives, a creative process that is inherent in the process of elaboration and that, like making connections, is considered by many as a positive learning habit (DarlingHammond, Ancess and Falk, 1995).

Compared to the other two learning strategies under consideration, fewer students reported using elaboration strategies. In just one out of three PISA participating countries, students selected the elaboration-related statements in at least one of the four questions on learning strategies (Figure 4.2). This results in a value on the index of elaboration of barely 0.8 across OECD countries, which is surprisingly low, given the positive reputation that making connections and exploring different ways of solving problems has among educationalists (Caine and Caine, 1991; Darling-Hammond, Ancess and Falk,1995).

\section{Figure 4.2. Students' self-reported use of elaboration strategies}

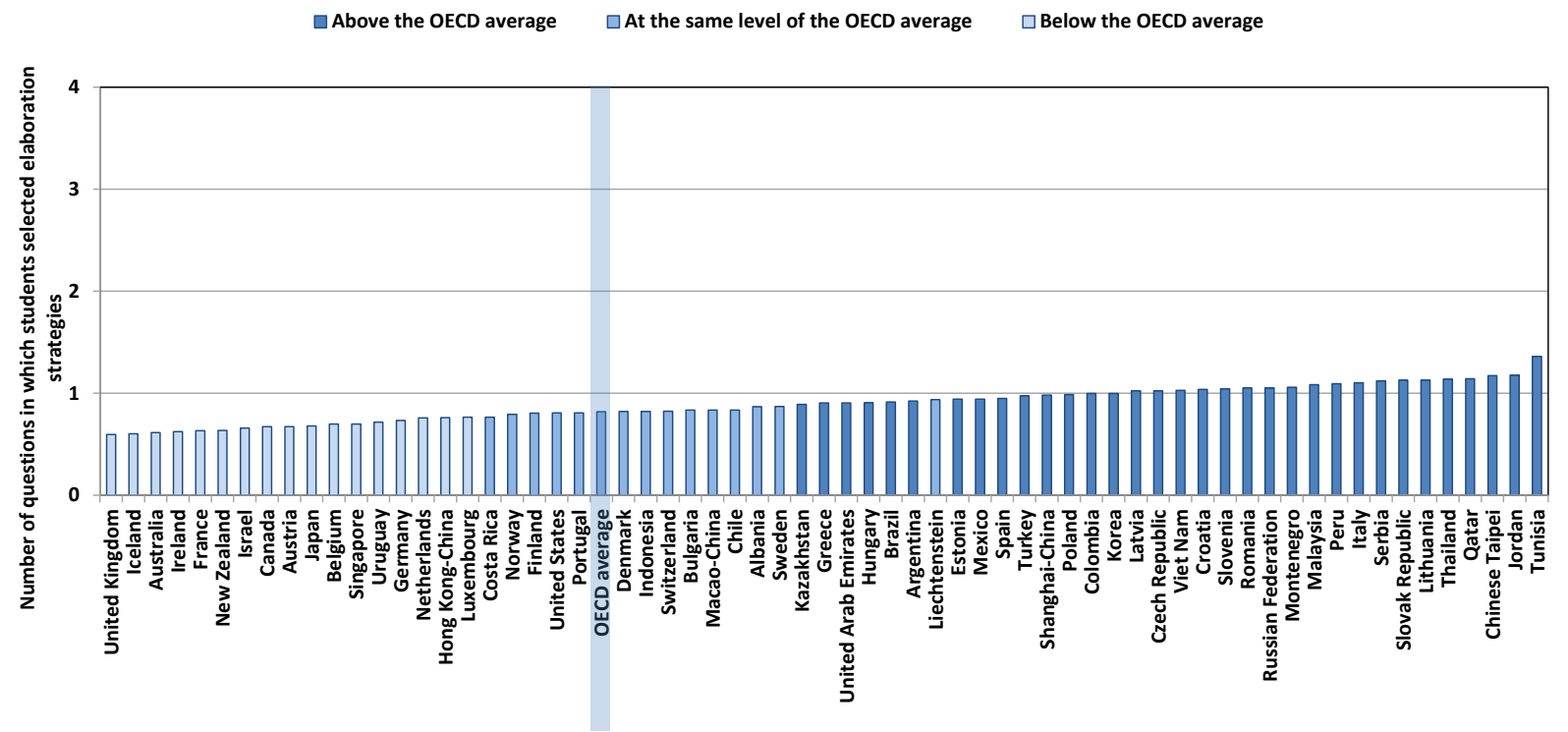

Countries and economies are ranked in ascending order of the number of questions selected by students.

Source: OECD, PISA 2012 Database. 
The index is particularly low in English-speaking countries, including Australia, Canada, Ireland, New Zealand and the United Kingdom, and also in France, Ireland and Israel. The education systems with the highest values - Jordan, Lithuania, Qatar, Serbia, the Slovak Republic, Chinese Taipei, Thailand and Tunisia, are extremely diverse, but some patterns emerge when values above the OECD average are analysed. Students in the 15 former communist countries in Europe that participated in PISA 2012, except Bulgaria, reported using elaboration strategies more intensively than the average OECD student. The use of elaboration strategies varies widely among East Asian countries and economies.

\section{Control strategies}

The index of control has a value of four when students agreed with all of the following statements: (a) "When I study for a mathematics test, I try to work out what the most important parts to learn are"; (b) "When I study mathematics, I try to figure out which concepts I still have not understood properly"; (c) "When I study mathematics, I start by working out exactly what I need to learn"; and (d) "When I cannot understand something in mathematics, I always search for more information to clarify the problem". All four statements try to measure how systematic students are in identifying important, difficult and unfamiliar material and, to some extent, how much they control their learning process. Whereas statements (a) and (c) assess the extent to which students are efficient learners, statements (b) and (d) try to capture how effective they are.

Figure 4.3. Students' self-reported use of control strategies

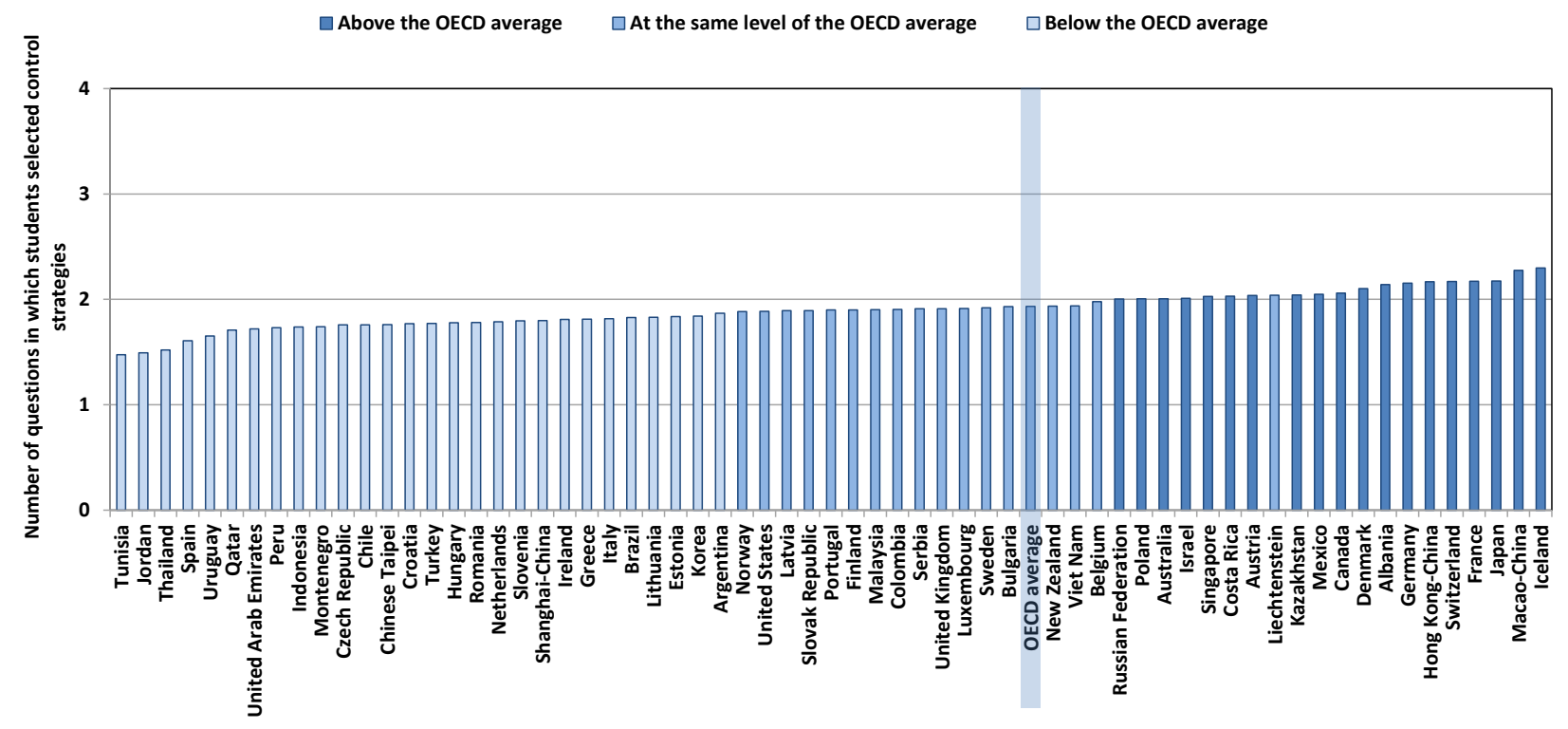

Countries and economies are ranked in ascending order of the number of questions selected by students.

Source: OECD, PISA 2012 Database.

Control strategies are by far the most common strategy according to students' self-reports. On average across OECD countries, students agreed with the control-related statements, such as "I start by working out exactly what I need to learn", in roughly half of the questions on learning strategies (Figure 4.3). These findings are consistent with the idea that students approach learning strategically, mainly to maximise achievement in assessments (Brown, 2004). As Hattie (2009) explains, most students "acquire sufficient surface and whatever deeper understanding is needed to complete assignments and examinations". Students in the countries and economies with higher academic performance are more likely to report using 
control strategies. The ten countries with the lowest values on the index of control all score below the OECD average in mathematics. Albania is the only country that has one of the ten highest values on the index but scores below the OECD average in mathematics.

\section{Creating profiles of students who use memorisation, elaboration and control strategies}

There are many reasons why students use particular learning strategies, or a combination of them, when learning mathematics. Among students who mainly use memorisation, drilling and repetitive learning, some may shun intense mental effort, particularly if they are not naturally drawn to mathematics; others may find it pointless to go beyond memorisation if they have been exposed only to rudimentary and routine problems; yet others might simply believe they are not gifted enough to venture into the realm of conceptual mathematics. Students who use elaboration strategies may do so because they like mathematics and solving problems, or because their teachers use real-life problems in their mathematics lessons. Students who use control strategies may do so because their teachers recommend these approaches to foster strategic learning.

\section{Memorisation strategies}

PISA data shows that, across OECD countries, perseverant students, students with positive attitudes towards problem solving and mathematics, including high instrumental motivation, interest in mathematics, high self-efficacy and self-concept, and low mathematics anxiety, and boys are less likely to use memorisation strategies (Figure 4.4). In fact, in no education system did boys report more intensive use of memorisation when learning mathematics than girls. In 45 of the 64 PISA-participating countries and economies, girls reported relying more heavily on their memory for mathematics.

Figure 4.4. Student characteristics and teacher practices associated with students' use of memorisation strategies

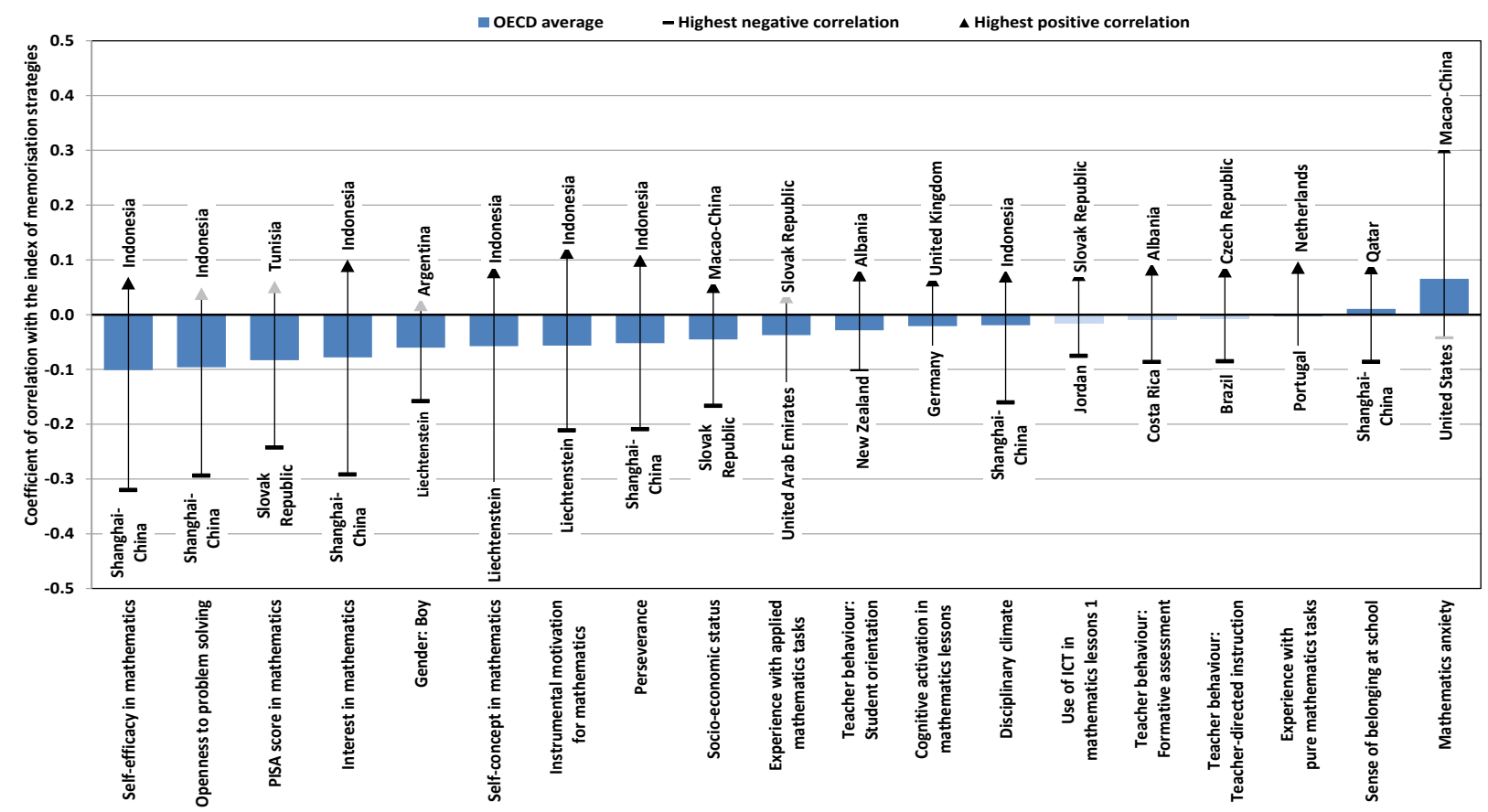

1. Only 42 countries and economies with available data. OECD average is based on 29 countries.

Notes: Statistically significant coefficient correlations are marked in a darker tone. Only countries and economies with statistically significant coefficients are shown.

Source: OECD, PISA 2012 Database. 
In 47 of these education systems, students who performed better in mathematics agreed with the statements related to memorisation fewer times. These countries include Australia and Japan, where results of a study published by Purdie and Hattie (1996) showed the opposite: that high-achieving students use memorisation strategies more frequently than low-achieving students. This discrepancy could be related to different study populations, sampling methodology or questionnaire wording; and much could have changed in the way mathematics is taught in these countries over the intervening years.

What happens in mathematics classes appears to be weakly linked, if at all, with students' use of memorisation. Students can be in classes with good or bad disciplinary climates, use ICT a little or a lot in class, be frequently or infrequently exposed to pure or applied mathematics problems, have teachers who use different teaching strategies, and still report similar use of memorisation strategies. Students with less exposure to applied mathematics tasks do report more intensive use of memorisation strategies, but the association, while statistically significant, is weak.

In some countries, students who rely heavily on their memory when learning mathematics have a clearly differentiated profile from those who do not. For instance, in Austria, Finland, Germany, Liechtenstein, Lithuania and Macao-China, girls draw on their memory much more than boys (Table 4.1). In Shanghai-China, students who are more interested in mathematics, show more openness to problem solving and/or report higher self-efficacy in mathematics do not use memorisation strategies as much as students with the opposite profile do.

Table 4.1. Gender difference in learning strategies

Results based on students' self-reports

\begin{tabular}{|c|c|c|c|c|c|c|}
\hline & \multicolumn{6}{|c|}{ Difference between boys and girls (boys minus girls) } \\
\hline & \multicolumn{2}{|c|}{ Index of memorisation } & \multicolumn{2}{|c|}{ Index of elaboration } & \multicolumn{2}{|c|}{ Index of control } \\
\hline & Dif. & S.E. & Dif. & S.E. & Dif. & S.E. \\
\hline OECD & & & & & & \\
\hline Australia & -0.14 & $(0.02)$ & 0.21 & $(0.02)$ & -0.07 & $(0.03)$ \\
\hline Austria & -0.23 & $(0.04)$ & 0.15 & $(0.03)$ & 0.07 & $(0.04)$ \\
\hline Belgium & -0.09 & $(0.03)$ & 0.19 & $(0.03)$ & -0.10 & $(0.03)$ \\
\hline Canada & -0.09 & $(0.02)$ & 0.22 & $(0.02)$ & -0.13 & $(0.03)$ \\
\hline Chile & -0.08 & $(0.03)$ & 0.13 & $(0.03)$ & -0.05 & $(0.03)$ \\
\hline Czech Republic & -0.19 & $(0.04)$ & 0.16 & $(0.04)$ & 0.03 & $(0.05)$ \\
\hline Denmark & -0.02 & (0.03) & 0.20 & $(0.03)$ & -0.18 & $(0.04)$ \\
\hline Estonia & -0.06 & $(0.03)$ & 0.16 & $(0.04)$ & -0.11 & $(0.04)$ \\
\hline Finland & -0.23 & $(0.04)$ & 0.29 & $(0.03)$ & -0.06 & $(0.03)$ \\
\hline France & -0.14 & $(0.04)$ & 0.26 & $(0.03)$ & -0.12 & $(0.03)$ \\
\hline Germany & -0.28 & $(0.04)$ & 0.25 & $(0.04)$ & 0.03 & $(0.04)$ \\
\hline Greece & -0.06 & $(0.03)$ & 0.20 & $(0.04)$ & -0.13 & $(0.04)$ \\
\hline Hungary & -0.19 & $(0.04)$ & 0.17 & $(0.04)$ & 0.02 & $(0.04)$ \\
\hline Iceland & -0.05 & $(0.04)$ & 0.21 & $(0.04)$ & -0.16 & $(0.05)$ \\
\hline Ireland & -0.06 & $(0.04)$ & 0.14 & $(0.03)$ & -0.08 & $(0.04)$ \\
\hline Israel & -0.08 & $(0.03)$ & 0.13 & $(0.04)$ & -0.05 & $(0.03)$ \\
\hline Italy & -0.06 & $(0.02)$ & 0.23 & $(0.02)$ & -0.16 & $(0.02)$ \\
\hline Japan & -0.04 & $(0.03)$ & 0.16 & $(0.03)$ & -0.12 & $(0.03)$ \\
\hline Korea & -0.17 & $(0.03)$ & 0.26 & $(0.03)$ & -0.08 & $(0.04)$ \\
\hline Luxembourg & -0.19 & (0.03) & 0.21 & $(0.03)$ & -0.02 & $(0.04)$ \\
\hline
\end{tabular}

Note: Values that are statistically significant are indicated in bold.

Source: OECD, PISA 2012 Database. 


\begin{tabular}{|c|c|c|c|c|c|c|}
\hline & \multicolumn{6}{|c|}{ Difference between boys and girls (boys minus girls) } \\
\hline & \multicolumn{2}{|c|}{ Index of memorisation } & \multicolumn{2}{|c|}{ Index of elaboration } & \multicolumn{2}{|c|}{ Index of control } \\
\hline & Dif. & S.E. & Dif. & S.E. & Dif. & S.E. \\
\hline Mexico & 0.02 & $(0.01)$ & 0.17 & $(0.02)$ & -0.19 & $(0.02)$ \\
\hline Netherlands & -0.19 & $(0.04)$ & 0.16 & $(0.03)$ & 0.03 & $(0.04)$ \\
\hline New Zealand & -0.17 & $(0.04)$ & 0.24 & $(0.03)$ & -0.07 & $(0.04)$ \\
\hline Norway & -0.10 & $(0.04)$ & 0.20 & $(0.03)$ & -0.09 & $(0.04)$ \\
\hline Poland & -0.09 & $(0.03)$ & 0.24 & $(0.04)$ & -0.15 & $(0.04)$ \\
\hline Portugal & 0.00 & $(0.03)$ & 0.18 & $(0.03)$ & -0.18 & $(0.04)$ \\
\hline Slovak Republic & -0.08 & $(0.04)$ & 0.22 & $(0.04)$ & -0.14 & $(0.05)$ \\
\hline Slovenia & -0.08 & $(0.04)$ & 0.09 & $(0.04)$ & -0.01 & $(0.04)$ \\
\hline Spain & -0.15 & $(0.03)$ & 0.19 & $(0.03)$ & -0.04 & $(0.03)$ \\
\hline Sweden & -0.07 & $(0.04)$ & 0.20 & $(0.04)$ & -0.13 & $(0.04)$ \\
\hline Switzerland & -0.16 & $(0.03)$ & 0.26 & $(0.03)$ & -0.10 & $(0.04)$ \\
\hline Turkey & -0.20 & $(0.04)$ & 0.28 & $(0.04)$ & -0.09 & $(0.04)$ \\
\hline United Kingdom & -0.08 & $(0.03)$ & 0.17 & $(0.03)$ & -0.08 & $(0.03)$ \\
\hline United States & -0.13 & $(0.03)$ & 0.25 & $(0.03)$ & -0.13 & $(0.04)$ \\
\hline OECD average & -0.12 & $(0.01)$ & 0.20 & $(0.01)$ & -0.08 & $(0.01)$ \\
\hline \multicolumn{7}{|l|}{ Partners } \\
\hline Albania & -0.02 & $(0.03)$ & -0.03 & $(0.04)$ & 0.05 & $(0.05)$ \\
\hline Argentina & 0.03 & $(0.04)$ & 0.16 & $(0.03)$ & -0.19 & $(0.04)$ \\
\hline Brazil & -0.04 & $(0.02)$ & 0.17 & $(0.02)$ & -0.13 & $(0.02)$ \\
\hline Bulgaria & -0.09 & $(0.03)$ & 0.31 & $(0.03)$ & -0.21 & $(0.04)$ \\
\hline Colombia & -0.04 & $(0.03)$ & 0.18 & $(0.04)$ & -0.15 & $(0.04)$ \\
\hline Costa Rica & -0.07 & $(0.03)$ & 0.06 & $(0.04)$ & 0.01 & $(0.05)$ \\
\hline Croatia & -0.02 & $(0.03)$ & 0.08 & $(0.03)$ & -0.06 & $(0.03)$ \\
\hline Hong Kong-China & -0.21 & $(0.03)$ & 0.38 & $(0.04)$ & -0.17 & $(0.04)$ \\
\hline Indonesia & -0.18 & $(0.04)$ & 0.20 & $(0.03)$ & -0.02 & $(0.03)$ \\
\hline Jordan & -0.11 & $(0.03)$ & 0.07 & $(0.04)$ & 0.05 & $(0.04)$ \\
\hline Kazakhstan & 0.01 & $(0.04)$ & 0.19 & $(0.03)$ & -0.20 & $(0.04)$ \\
\hline Latvia & -0.10 & $(0.03)$ & 0.20 & $(0.04)$ & -0.10 & $(0.03)$ \\
\hline Liechtenstein & -0.28 & $(0.13)$ & 0.40 & $(0.13)$ & -0.11 & $(0.14)$ \\
\hline Lithuania & -0.24 & $(0.03)$ & 0.32 & $(0.04)$ & -0.08 & $(0.04)$ \\
\hline Macao-China & -0.27 & $(0.03)$ & 0.38 & $(0.03)$ & -0.12 & $(0.04)$ \\
\hline Malaysia & -0.11 & $(0.03)$ & 0.16 & $(0.03)$ & -0.04 & $(0.03)$ \\
\hline Montenegro & -0.11 & $(0.03)$ & 0.20 & $(0.04)$ & -0.09 & $(0.03)$ \\
\hline Peru & 0.01 & $(0.03)$ & 0.13 & $(0.03)$ & -0.14 & $(0.03)$ \\
\hline Qatar & -0.21 & $(0.02)$ & 0.21 & $(0.02)$ & 0.01 & $(0.02)$ \\
\hline Romania & -0.07 & $(0.03)$ & 0.12 & $(0.04)$ & -0.05 & $(0.04)$ \\
\hline Russian Federation & -0.06 & $(0.03)$ & 0.23 & $(0.04)$ & -0.17 & $(0.04)$ \\
\hline Serbia & -0.13 & $(0.03)$ & 0.32 & $(0.04)$ & -0.20 & $(0.03)$ \\
\hline Shanghai-China & -0.22 & $(0.04)$ & 0.41 & $(0.04)$ & -0.19 & $(0.05)$ \\
\hline Singapore & -0.07 & $(0.03)$ & 0.19 & $(0.03)$ & -0.11 & $(0.04)$ \\
\hline Chinese Taipei & -0.20 & $(0.03)$ & 0.32 & $(0.03)$ & -0.12 & $(0.04)$ \\
\hline Thailand & -0.22 & $(0.03)$ & 0.35 & $(0.03)$ & -0.13 & $(0.03)$ \\
\hline Tunisia & -0.16 & $(0.04)$ & 0.18 & $(0.05)$ & -0.02 & $(0.05)$ \\
\hline United Arab Emirates & -0.19 & $(0.03)$ & 0.25 & $(0.03)$ & -0.07 & $(0.03)$ \\
\hline Uruguay & -0.11 & $(0.04)$ & 0.18 & $(0.03)$ & -0.06 & $(0.04)$ \\
\hline Viet Nam & -0.04 & $(0.03)$ & 0.16 & $(0.03)$ & -0.12 & $(0.04)$ \\
\hline
\end{tabular}

Note: Values that are statistically significant are indicated in bold.

Source: OECD, PISA 2012 Database. 


\section{Elaboration strategies}

Students who are self-confident about their abilities in mathematics - they have high self-concept, high self-efficacy and low anxiety towards mathematics - who are also open to problem solving and are interested in mathematics are more likely to use elaboration strategies (Figure 4.5). Boys are also considerably more likely than girls to use these strategies. Only in Albania, Costa Rica and Jordan were boys less likely than girls to have reported that they use these strategies (Table 4.1).

However, students' performance in mathematics, socio-economic status, sense of belonging at school and instrumental motivation for learning mathematics are only weakly associated with using elaboration strategies. Interestingly, students who reported that they study mathematics by seeking alternative solutions and making connections with prior knowledge and real-life experience also reported more positive attitudes towards mathematics without necessarily scoring higher in the PISA mathematics assessment.

In contrast to the results for memorisation strategies, some teaching strategies and classroom practices are somewhat associated with the use of elaboration strategies. Using ICT in mathematics lessons and exposing students to applied mathematics problems, for example, were positively associated with students' self-reported use of elaboration strategies. The relationships with three teaching practices - formative assessments, cognitive-activation strategies and student orientation - were a little stronger than for memorisation. When students reported that their mathematics teachers assign complex tasks, encourage students to work in small groups, give regular feedback and/or ask students to explain how they solve problems, students use elaboration strategies more frequently. This is expected, given that encouraging students to make connections and be creative are some of the reasons why these strategies are adopted by teachers in the first place.

Figure 4.5. Student characteristics and teacher practices associated with students' use of elaboration strategies

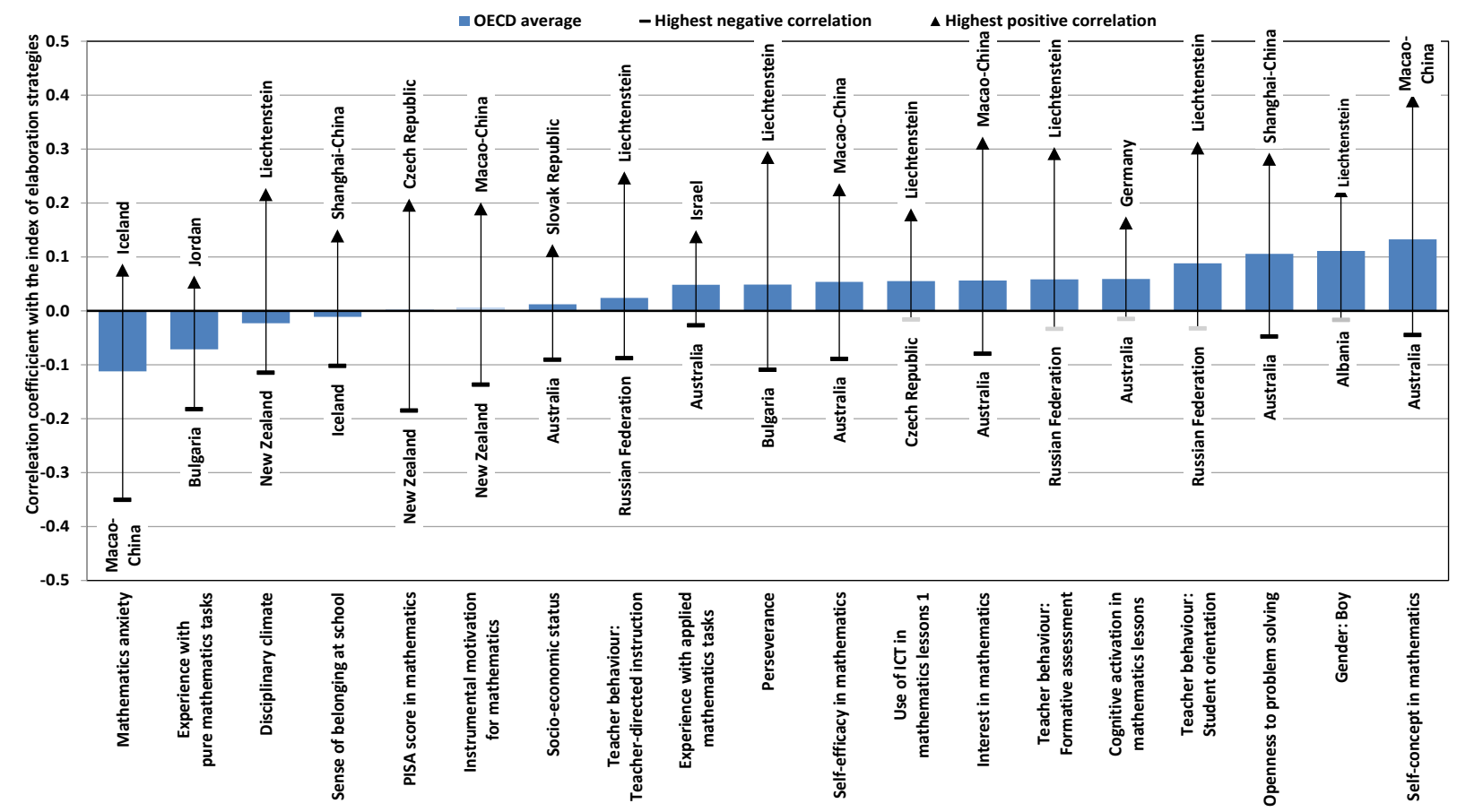

1. Only 42 countries and economies with available data. OECD average is based on 29 countries.

Notes: Statistically significant coefficient correlations are marked in a darker tone. Only countries and economies with statistically significant coefficients are shown.

Source: OECD, PISA 2012 Database. 
The link between students' attitudes towards mathematics and their use of elaboration strategies is strongest in Macao-China. Boys in Macao-China are also much more likely than girls to use these strategies - as are boys in Hong Kong-China, Liechtenstein, Shanghai-China and Thailand (Table 4.1).

\section{Control strategies}

Students who use control strategies more often score higher in mathematics than students who use memorisation or elaboration strategies, even if they do not have more positive attitudes towards mathematics (Figure 4.6). The self-reported use of control strategies is negatively associated with students' self-concept in mathematics, positively associated with greater mathematics anxiety, and is almost uncorrelated with being interested in mathematics and open to problem solving.

While this could be interpreted as a sign that students' attitudes do not affect their performance in the PISA mathematics test, there is ample evidence showing that this is not the case (OECD, 2013b). More likely, these results show that some students can perform reasonably well in the mathematics assessment, even above the OECD average, without necessarily enjoying mathematics and or being self-confident in their mathematics abilities. As will be discussed later, students who emphasise the control and efficiency aspects of the learning process may improve their chances to solve easy, intermediate and moderately difficult mathematics problems; but solving the most challenging problems might require out-of-the-box thinking and self-confidence - two attributes that appear to be associated with elaboration rather than control strategies.

Figure 4.6. Student characteristics and teacher practices associated with students' use of control strategies

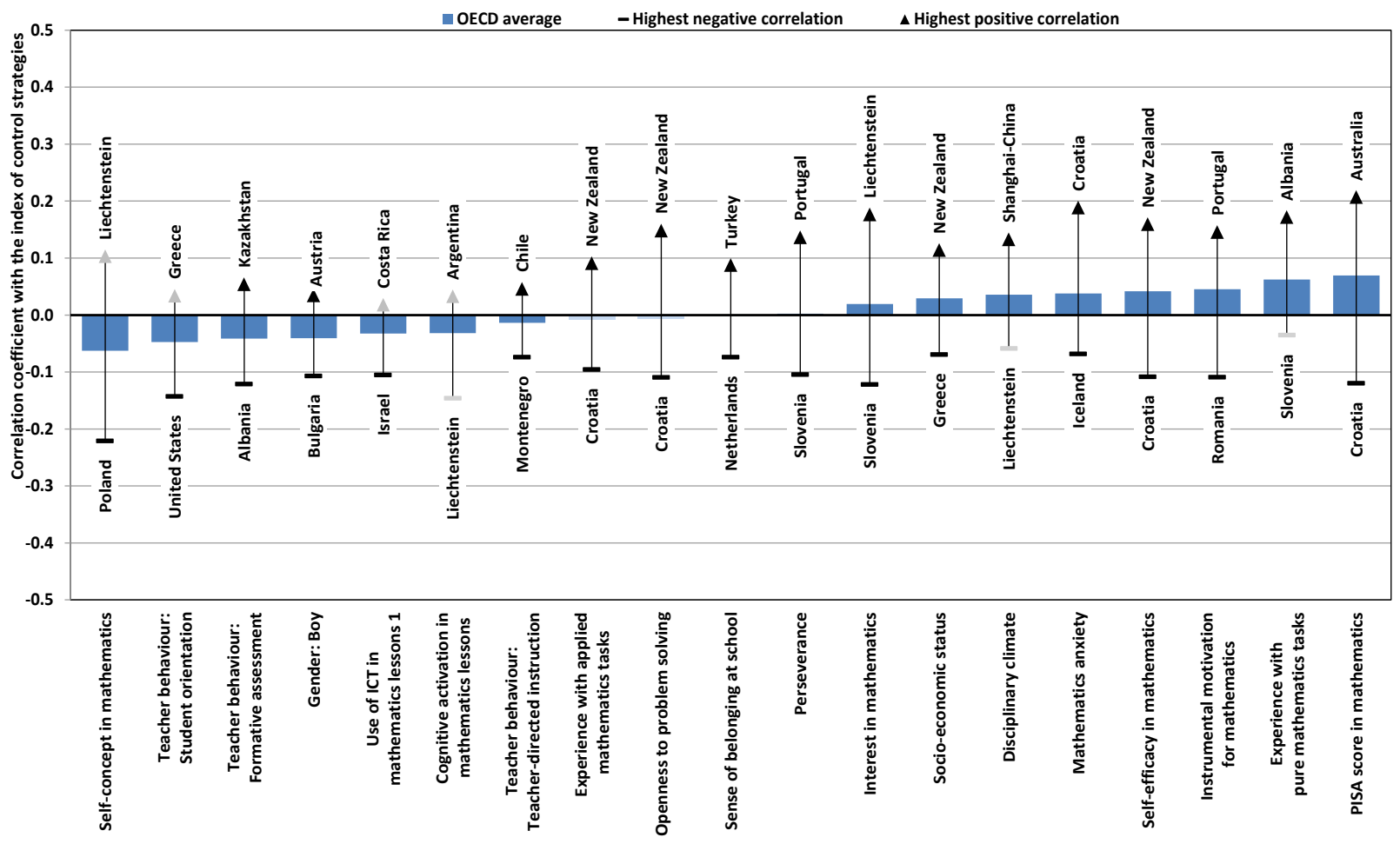

1. Only 42 countries and economies with available data. OECD average is based on 29 countries.

Notes: Statistically significant coefficient correlations are marked in a darker tone. Only countries and economies with statistically significant coefficients are shown.

Source: OECD, PISA 2012 Database. 
There are few differences in the self-reported use of control strategies related to students' responses to questions about teaching strategies, disciplinary climate and use of ICT in their mathematics lessons (Figure 4.6). A better disciplinary climate and more exposure to pure mathematics tasks are associated with a slight preference for control strategies. But more formative assessments, student orientation and use of cognitive-activation strategies by mathematics teachers, and a more frequent use of ICT, are associated with slightly less use of control strategies.

While these learning strategies are the most frequently used in every PISA-participating country and economy, only in some countries, such as Croatia, Liechtenstein or Poland, there are marked differences between students who employ and do not employ these strategies. For instance, students in Poland who reported having a low self-concept in mathematics also reported considerably less use of control strategies than more self-confident students did. Students in Liechtenstein also reported less use of control strategies when their teachers use formative assessments, as did students in Croatia who reported less mathematics anxiety.

\section{The use of learning strategies and success in solving PISA mathematics problems}

The main thesis of this report is that some learning approaches are better suited for solving certain types of mathematics problems. For example, memorisation is often considered an elementary strategy that is better suited to solving routine mathematics problems that require only a shallow understanding of mathematical concepts. Thus, memorisation should work better for easy and single-step problems. By contrast, elaboration strategies that make connections, seek alternative ways of finding solutions and discover underlying concepts and principles should help students to solve challenging problems that require creativity and a deep understanding of mathematics. Meanwhile, the strategic and efficient learners who use control strategies should, in theory, perform better overall.

To analyse the relationship between students' learning strategies and academic performance, this section focuses on three (disclosed) mathematics problems from the PISA 2012 assessment that were answered by students in 48 countries and economies (the remaining 16 countries opted for the easy booklet; see Chapter 2 for further information). "Charts Q1" asks for a multiple-choice response to a question referring to a simple bar chart. With an $87 \%$ success rate among students across the 48 school systems, and an empirical difficulty of 347 points (see Chapter 2 for further information), it was the easiest of the disclosed items from the PISA 2012 mathematics test. "Sailing ships Q1" requires a multiple-choice response to a problem that tests students' ability to calculate percentages in a real-world situation. Some $60 \%$ of students answered the item correctly, which corresponds to an intermediate level of difficulty (512 points). "Revolving door Q2" was the most challenging question from the PISA 2012 mathematics test. It asks for a constructed, or open-ended, response to a problem that requires substantial geometric reasoning and creativity, involves multiple steps, and draws heavily on students' ability to translate a real situation into a mathematical problem. Only 3\% of participants answered correctly, corresponding to a difficulty level of 840 points.

Figure 4.7 shows that students who use their memory to learn and study mathematics have about the same success rate on the easy item "Charts Q1" as students using other learning strategies. The average odds ratio across OECD countries is exactly one. In some school systems, including those in Albania, Lithuania and Slovenia, students who reported that they use memorisation strategies frequently have an even higher success rate than students using other learning strategies.

These results contrast with the results for "Sailing ships Q1" and "Revolving door Q2", where using memorisation strategies is associated with a lower probability of answering correctly. In Israel, for instance, each one-unit increase in the index of memorisation strategies is associated with a $3 \%$ increase in the success rate on "Charts Q1" but a 14\% decrease in the success rate on "Sailing ships Q1" and a 
staggering $62 \%$ decrease in the success rate on "Revolving door Q2". Similarly large differences among the odds ratios of solving the three problems are observed in Albania, Greece, Poland and Thailand.

Figure 4.7. Memorisation strategies and success rates on specific PISA mathematics problems

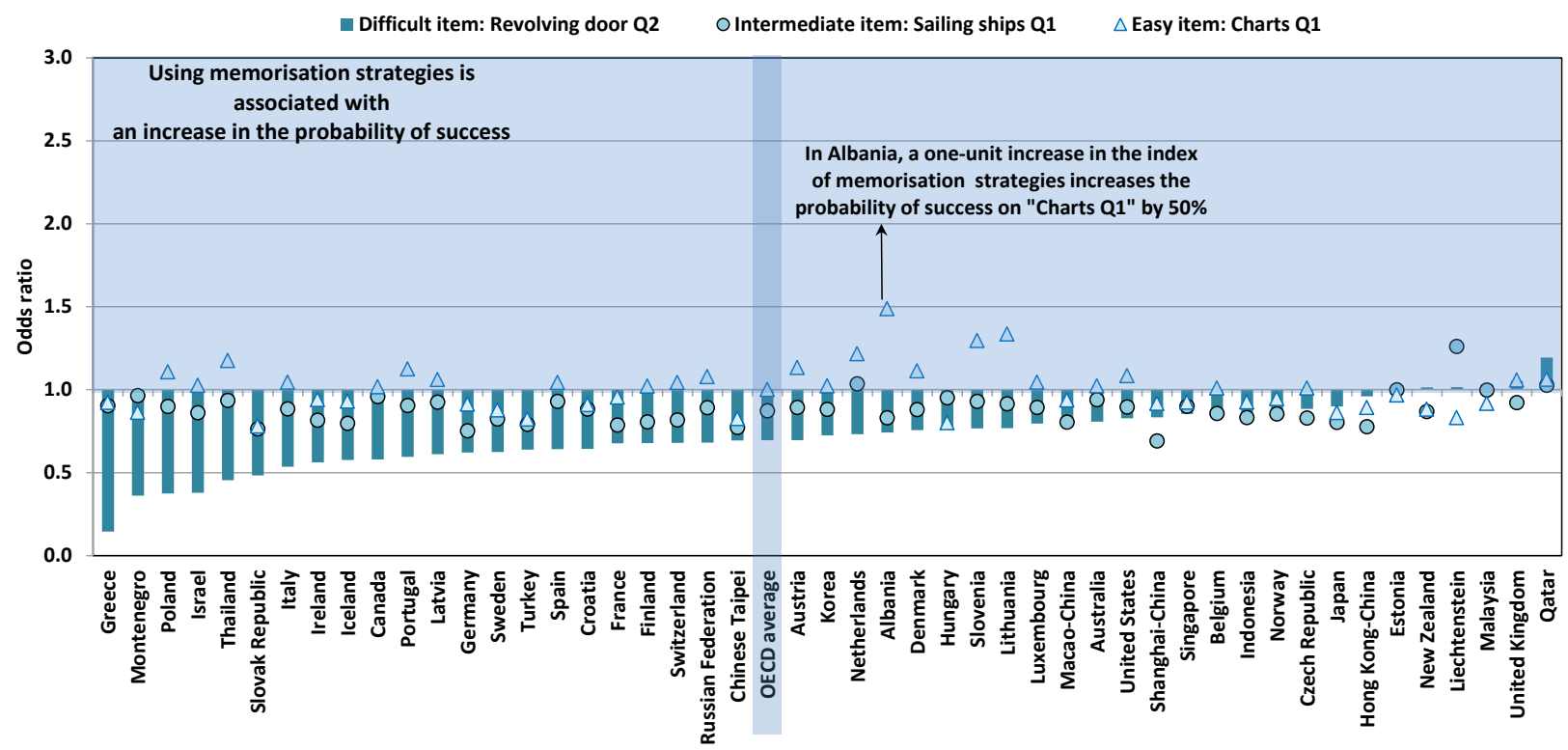

Note: Countries that opted for the easy booklet are not included in the analyses.

Countries and economies are ranked in ascending order of the odds ratio of success on the item "Revolving door Q2".

Source: OECD, PISA 2012 Database.

Memorisation strategies seem to work best for the easy item, while elaboration strategies work best for the difficult item. On average across OECD countries, a one-unit increase in the index of elaboration is associated with a $13 \%$ decrease in the probability of solving the problem "Charts Q1". This contrasts with results for the item of intermediate difficult, "Sailing ships Q1". Students who use elaboration strategies when studying mathematics, fared better than those using memorisation strategies (Figure 4.8), as did students who approached the most difficult problem, "Revolving door Q2" - and by a wide margin. For every one-unit increase in the index of elaboration strategies, the chance of success increased by $35 \%$. This means that students who agreed with the statements related to elaboration strategies in all four of the questions about their learning strategies were about three times as likely to succeed as students who always cited other learning strategies.

Using elaboration strategies is most strongly related to success in solving the "Revolving door Q2" problem in Croatia, Germany, Greece, Spain and Thailand. In Austria, Canada and Iceland, using elaboration strategies both reduces the probability of success on "Charts Q1" and increases the probability of success on "Revolving door Q2".

Control strategies generally improve the success rate in all three mathematics items, though the positive association weakens slightly as the items become harder (Figure 4.9). On average across OECD countries, a one-unit increase in the index of control strategies increases the success rate by $12 \%$ on the easy item "Charts Q1", by 6\% on the intermediate "Sailing ships Q1" item, and by only 3\% on the difficult item "Revolving door Q2". Even if the positive association almost disappears for the most challenging item, using control strategies do not seem to harm student performance in any of the three PISA mathematics items. 
Figure 4.8. Elaboration strategies and success rates on specific PISA mathematics problems

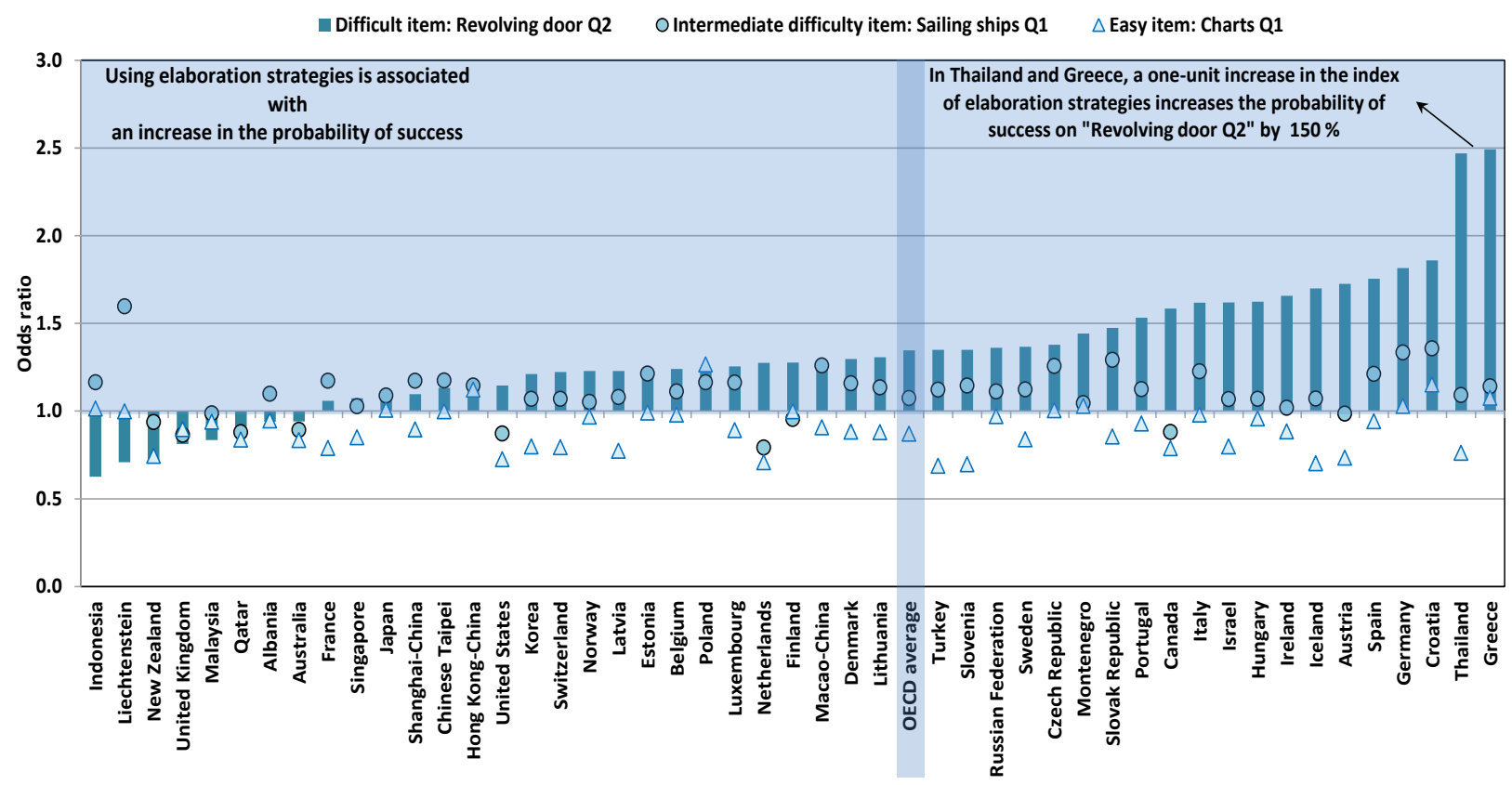

Note: Countries that opted for the easy booklet are not included in the analyses.

Countries and economies are ranked in ascending order of the odds ratio of success on the item "Revolving door Q2".

Source: OECD, PISA 2012 Database.

Figure 4.9. Control strategies and success rates on specific PISA mathematics problems

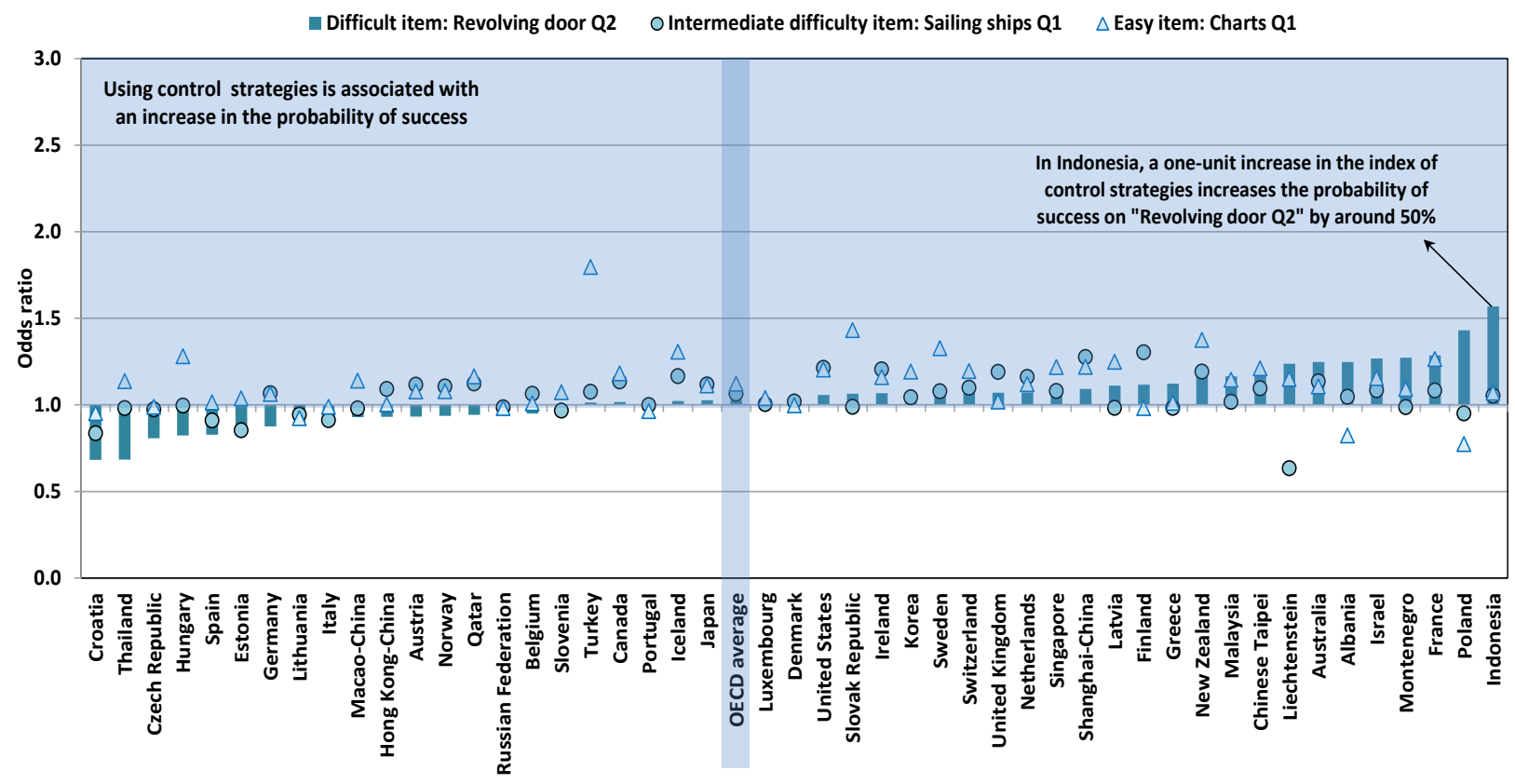

Note: Countries that opted for the easy booklet are not included.

Countries and economies are ranked in ascending order of the odds ratio of success on the item "Revolving door Q2".

Source: OECD, PISA 2012 Database. 


\section{Learning strategies and success rates across all PISA mathematics items}

Can the results of the comparisons detailed above (Figures 4.7, 4.8 and 4.9) be generalised to the remaining items in the PISA 2012 mathematics test? To answer this question, the same analyses conducted for "Charts Q1", "Sailing ships Q1" and "Revolving door Q2" in the previous section are repeated for the 84 mathematics items that were used in 48 education systems (the remaining 25 mathematics items were used only in the 16 PISA-participating countries that opted for the easy booklet). ${ }^{2}$ The average odds ratios of the learning strategies indices - how much the probability of answering an item correctly changes, on average, every time a student agreed with a statement related to one of the three learning approaches on the student questionnaire - are reported in Figures $4.10 \mathrm{a}, \mathrm{b}$ and $\mathrm{c}$. The results would be fairly similar across countries if only OECD countries were included.

Using memorisation instead of control and elaboration strategies results in a lower likelihood of answering correctly 78 of the 84 mathematics items analysed (Figure 4.10a). More important, the rate of success decreases as the difficulty of the item increases. Whereas the use of memorisation appears to make little difference when answering the easiest items, a one-unit increase in the index of memorisation strategies is associated with a $10 \%$ decrease in the probability of answering problems of intermediate difficulty correctly (compared to using one of the other learning strategies), and with a more than $20 \%$ decrease in the probability of answering the most challenging items correctly. This implies that students who agreed with the statements related to elaboration or control strategies in all four questions on learning strategies are three times more likely to succeed in the five most challenging items in the PISA mathematics test than students who only agreed with the statements related to memorisation strategies.

\section{Figure 4.10a. Memorisation strategies and item difficulty}

Average across 48 education systems

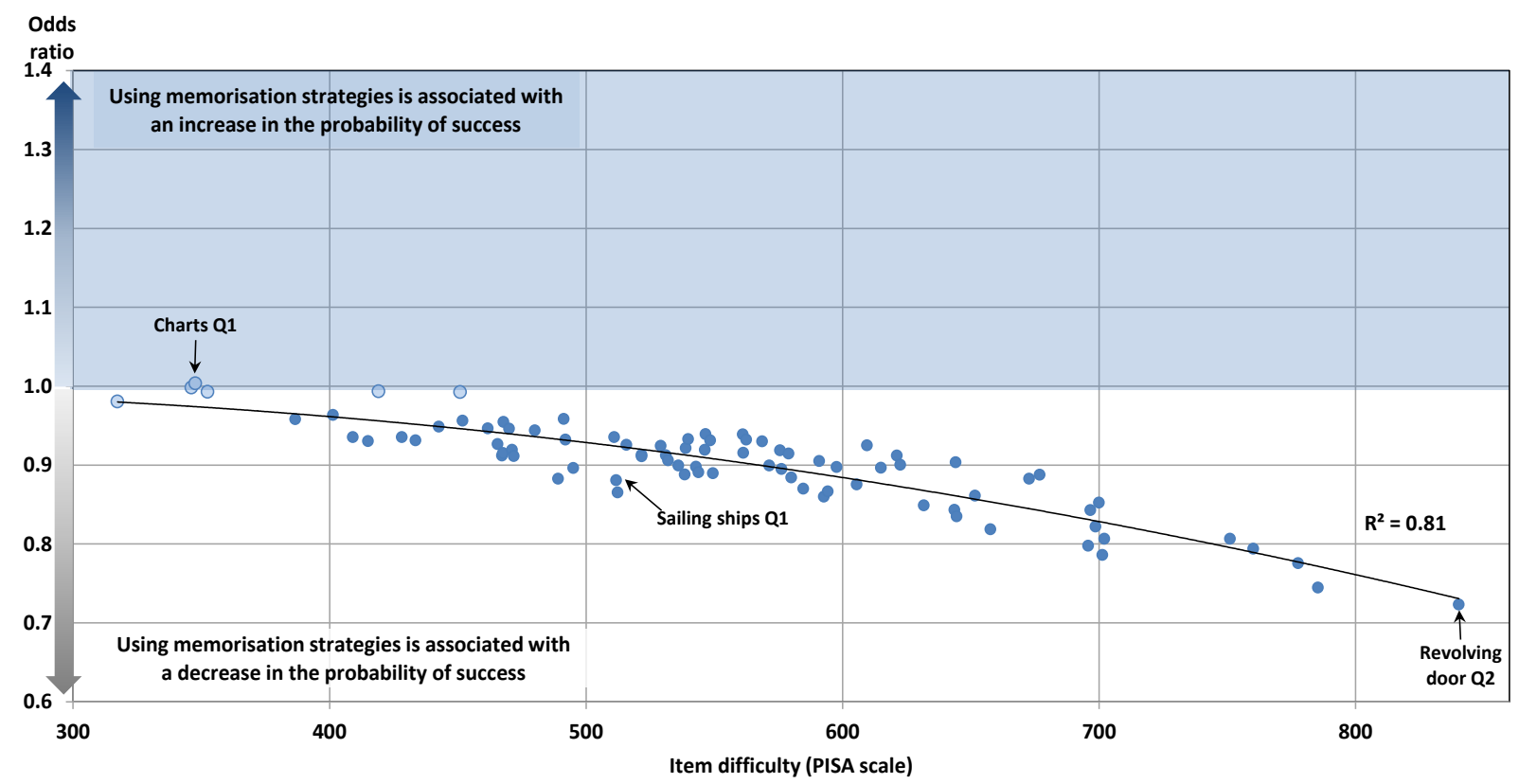

Note: Dots in a darker tone indicate a statistically significant odds ratio.

Source: OECD, PISA 2012 Database. 
Figure 4.10b. Elaboration strategies and item difficulty

Average across 48 education systems

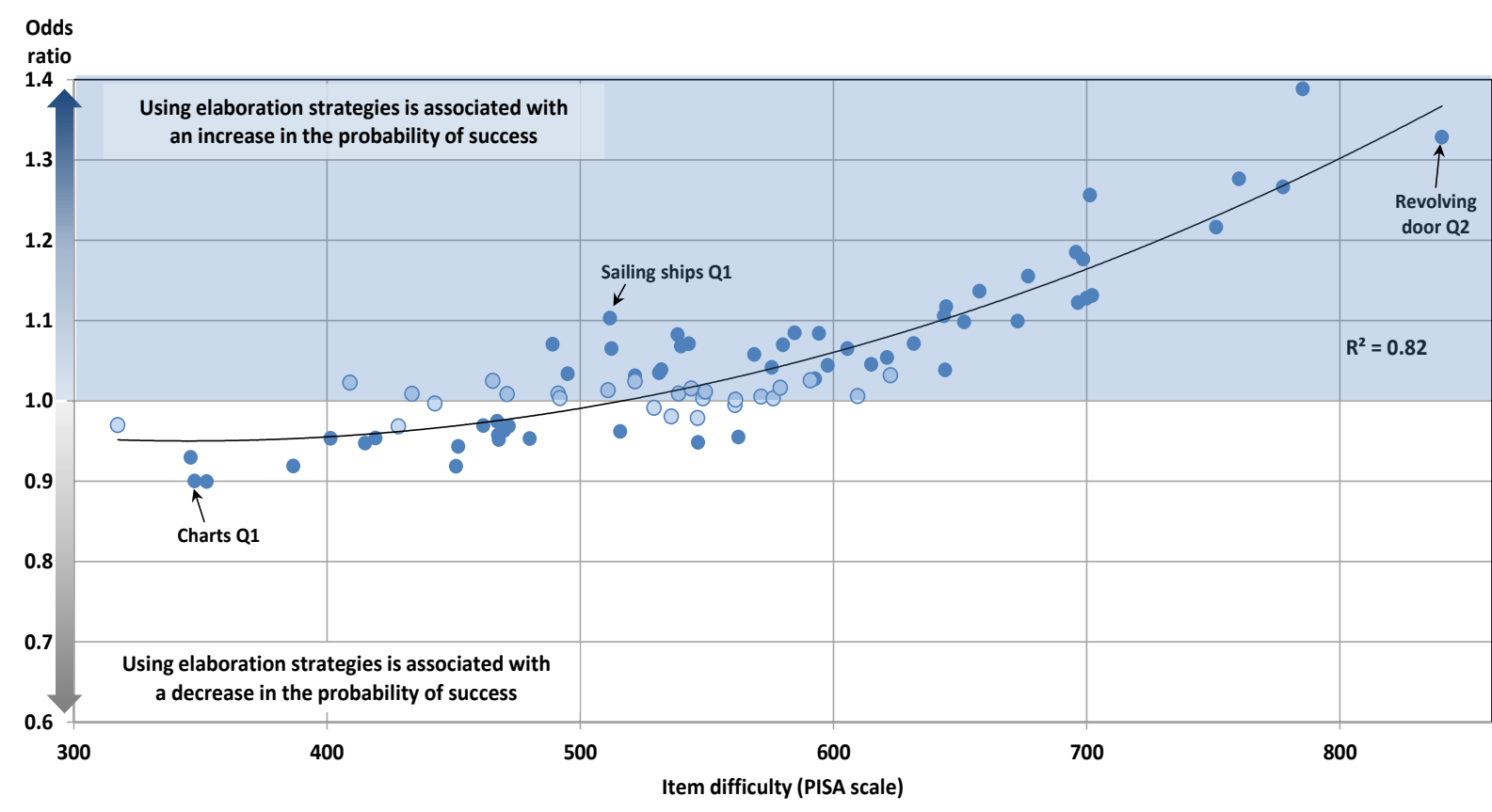

Note: Dots in a darker tone indicate a statistically significant odds ratio.

Source: OECD, PISA 2012 Database.

Figure 4.10c. Control strategies and item difficulty

Average across 48 education systems

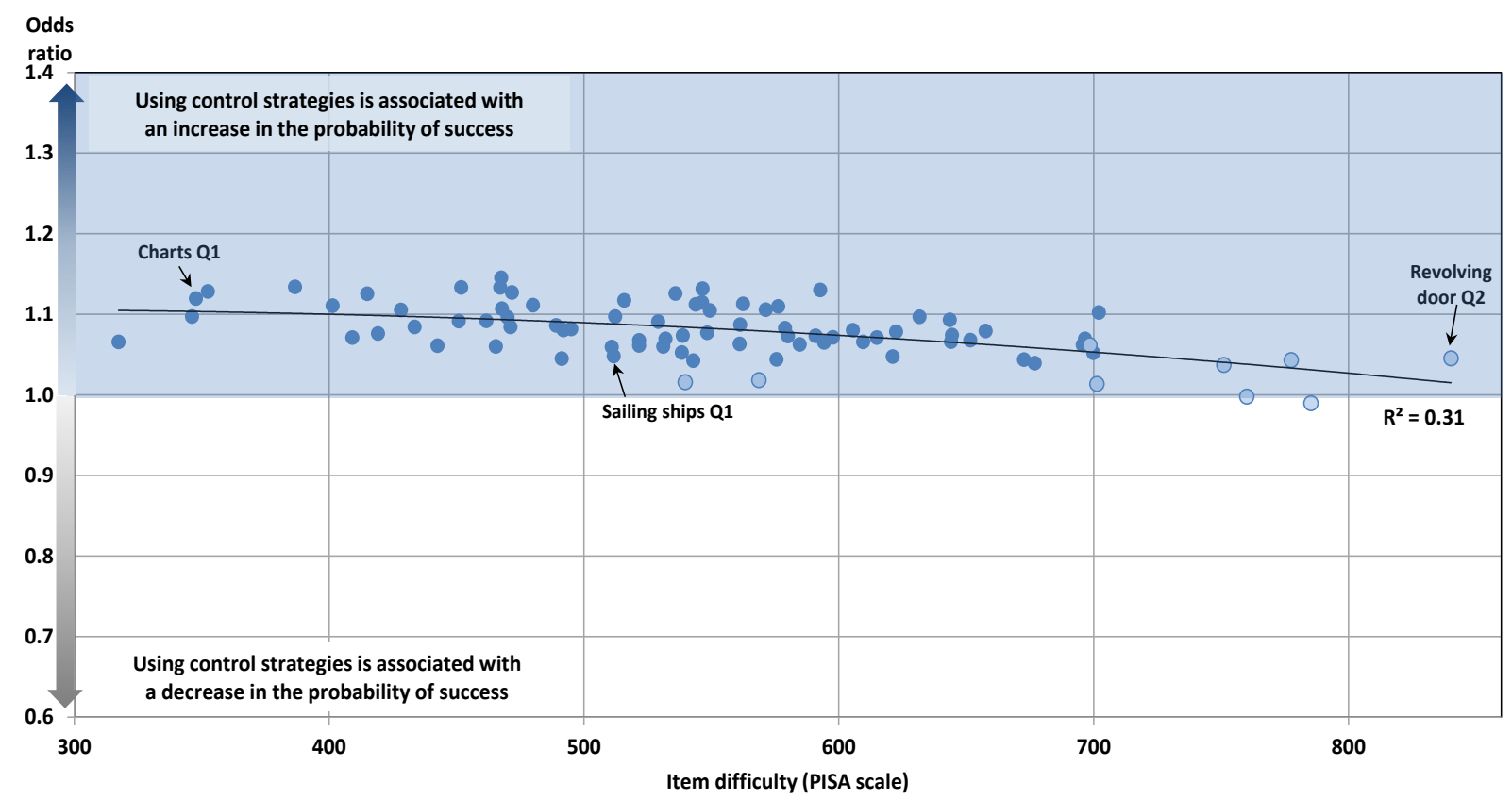

Note: Dots in a darker tone indicate a statistically significant odds ratio.

Source: OECD, PISA 2012 Database. 
Using elaboration strategies more frequently is associated with less success in correctly solving the easiest mathematics problems (those below 480 points in difficulty; Figure 4.10b). More important, for many of these simple items, memorisation is associated with better results than elaboration strategies.

However, as the items become more difficult, students who reported using elaboration strategies more frequently improve their chances of succeeding, especially when the items surpass 600 points in difficulty on the PISA scale. Elaboration strategies are associated with better results than memorisation strategies for items of intermediate difficulty; but they seem to be even better than control strategies for solving the most difficult items, especially those above 700 points on the PISA scale (Figures 4.10a to 4.10c).

Take, for example, the four most challenging items, which less than $10 \%$ of students answered correctly. Students who agreed with all the statements related to elaboration strategies, in response to the four questions on learning strategies in the student questionnaire, were almost 3 times more likely to succeed in solving those most difficult problems than students who agreed with all the statements related to control strategies and 9 times more likely to succeed compared with students who agreed with statements related to memorisation strategies. In addition to knowing the subject well, solving these challenging items requires a great deal of creativity, which students who reported that they "seek alternatives" and "make connections" may have developed to a greater extent.

Using control strategies is associated with a greater probability of success across all but the most difficult PISA mathematics items (Figure 4.10c). A more frequent use of control strategies means a higher success rate in 75 of the 84 items in the mathematics assessment (compared to using other learning strategies), and no significant change in the likelihood of solving 6 of the 7 most difficult items (those with a difficulty above 700 points on the PISA scale). If the effectiveness of learning strategies could be inferred from these analyses, control strategies should certainly be recommended to students as part of their learning toolkit. This approach, which emphasises strategy and efficiency when learning mathematics, is associated with good overall performance in the test.

It might be discomfiting to acknowledge the relative advantages of control strategies, and even memorisation strategies, over an approach that fosters a deeper understanding of mathematics, as elaboration strategies do, even if this advantage is related to the easiest items. However, these results suggest that memorisation and control strategies, while they can help students on the easiest and somewhat more difficult items, are not sufficient when it comes to solving the most challenging problems. To perform at the very top of the PISA scale, students need to learn mathematics in a more reflective, ambitious and creative way - one that involves alternative ways of finding solutions, making connections, adopting different perspectives and looking for meaning (Darling-Hammond, Ancess and Falk, 1995).

But why are students who use elaboration strategies so successful in solving the most difficult mathematics problems? Adding a third variable to the analysis (mediation analysis) can help to explain why. ${ }^{3}$ Figures $4.11 \mathrm{a}, \mathrm{b}$ and $\mathrm{c}$ suggest that students using elaboration strategies may be successful in difficult mathematics items because, compared to students using other learning approaches, they (in decreasing order of importance):

- Show a higher self-concept in mathematics;

- report less mathematics anxiety;

- $\quad$ are more open to problem solving;

- $\quad$ are more interested in mathematics;

- $\quad$ are more perseverant;

- $\quad$ are more likely to be boys;

- are more exposed to cognitive-activation teaching practices. 
Figure 4.11a. Elaboration strategies and item difficulty, before and after accounting for perseverance, interest in mathematics and openness to problem solving

Average across 45 education systems

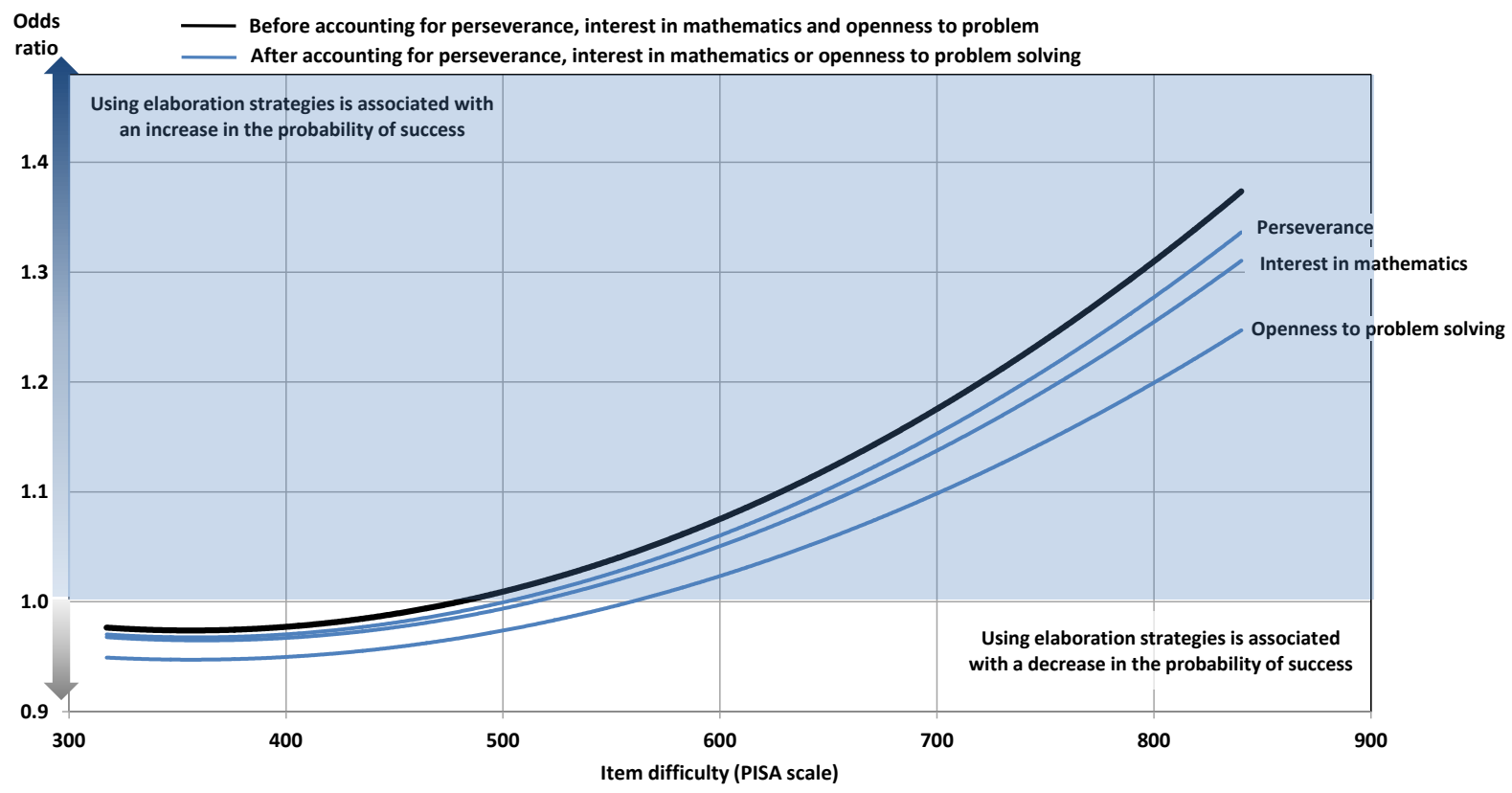

Note: Based on responses from students who answered "Student Questionnaire - Form A" and "Student Questionnaire - Form B". Source: OECD, PISA 2012 Database.

Figure 4.11b. Elaboration strategies and item difficulty, before and after accounting for mathematics anxiety, self-concept in mathematics, student-oriented instruction and cognitive-activation instruction

\section{Average across 45 education systems}

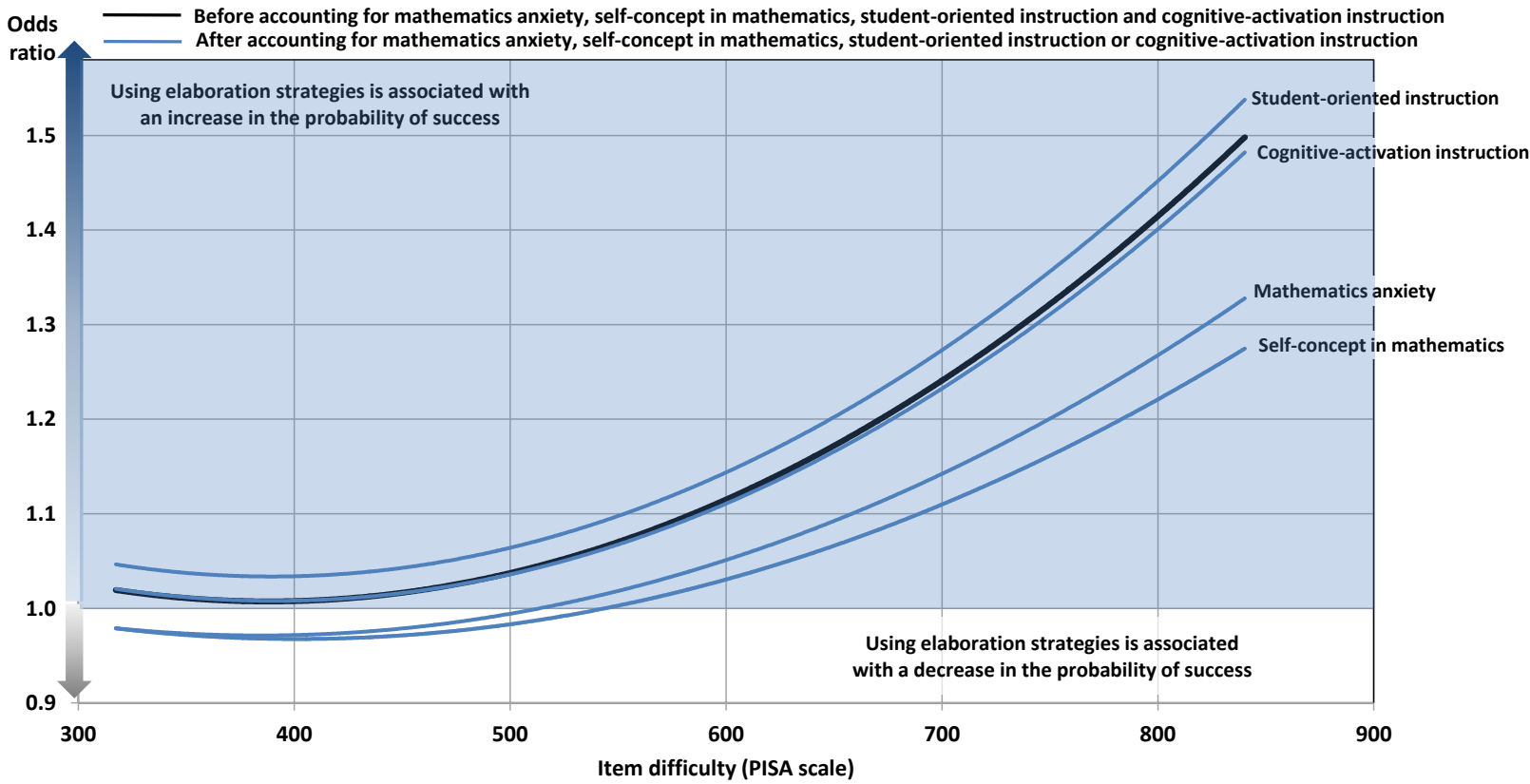

Notes: Based on responses from students who answered "Student Questionnaire - Form B" and "Student Questionnaire - Form C". Analyses of teacher-directed and formative-assessment instruction are not shown because they have no mediating effect on the relationship.

Source: OECD, PISA 2012 Database. 
Figure 4.11c. Elaboration strategies and item difficulty, before and after accounting for gender and experience with pure mathematics

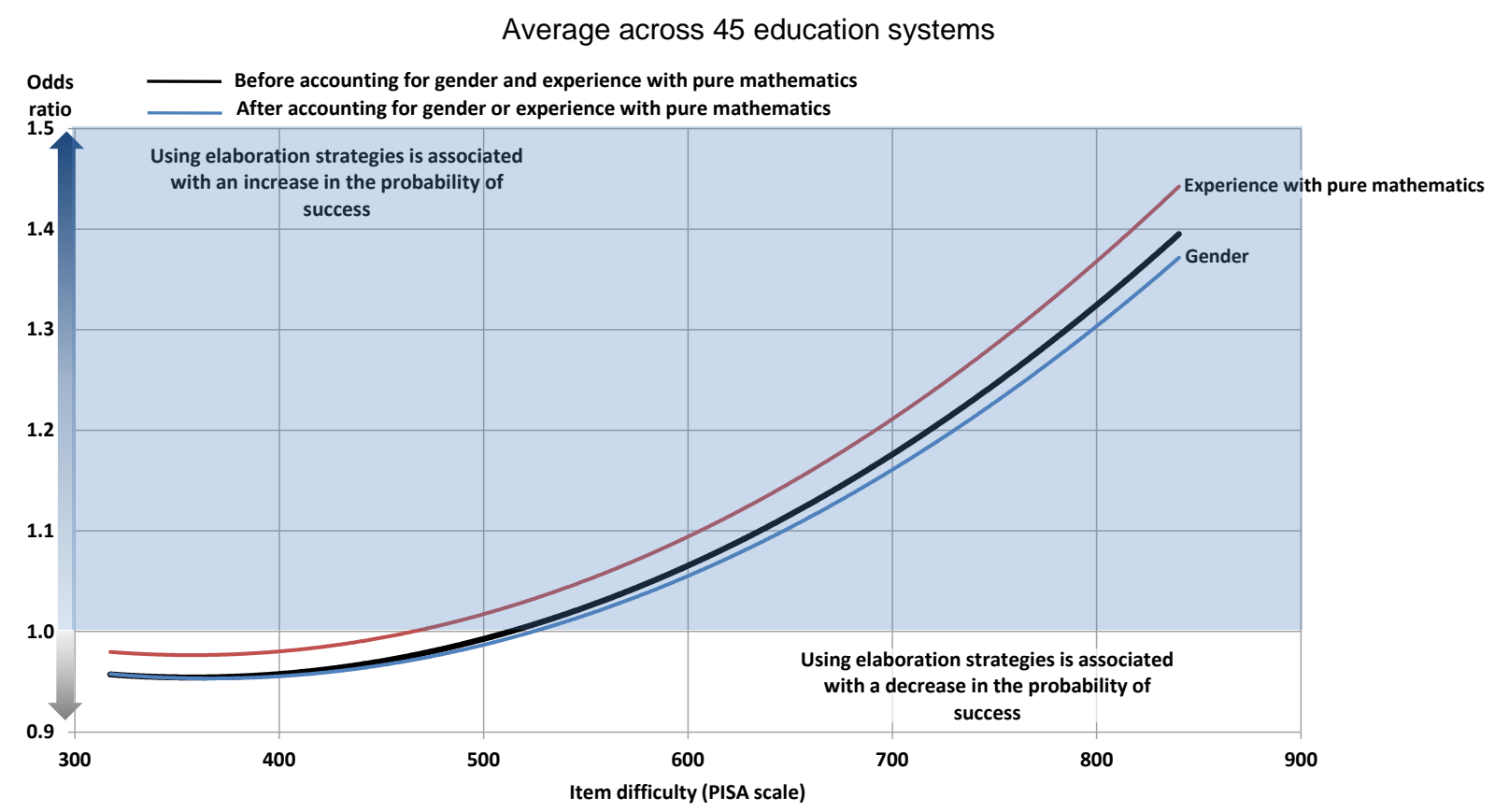

Notes: Based on responses from students who answered "Student Questionnaire - Form A" and "Student Questionnaire - Form C". Analyses of the PISA index of economic, social and cultural status and experience with pure mathematics are not shown because they have no mediating effect on the relationship.

Source: OECD, PISA 2012 Database.

By contrast, students' reports on the frequency with which they are exposed to teacher-directed, student-oriented and formative assessment teaching practices, the extent to which they are exposed to pure and applied mathematics, and their Economic, Social and Cultural Status (ESCS) do not help to explain why students who use elaboration strategies are particularly successful in solving the hardest mathematics problems.

\section{Learning strategies and other item characteristics}

The learning strategies assessed in PISA are associated with the individual test items in different ways, depending on the items' relative level of difficulty. PISA items also differ in four other characteristics: response format, the processes they represent, their content and their context.

Mathematics items in PISA 2012 were presented using five different response formats: simple multiple choice, complex multiple choice, constructed response (manual), constructed response (autocoded) and constructed response (expert). ${ }^{4}$ In theory, memorisation strategies should work better with multiple-choice questions, which allow for random guessing, while elaboration strategies should work better with open-ended or constructed responses, which usually call for more creativity (answers need to be "created"). For example, random guessing to solve the challenging "Revolving door Q2" problem would rarely result in a correct answer.

Memorisation strategies are associated with higher success rates for simple multiple-choice and constructed (manual) responses compared to other response types, though the differences across response categories are not large (Figure 4.12a). By contrast, elaboration strategies are associated with a higher 
success rate for both expert and auto-coded constructed responses. Students who use control strategies more frequently perform better overall, with little or no difference in the probability of answering correctly related to the response format.

Figure 4.12a. Learning strategies and response format

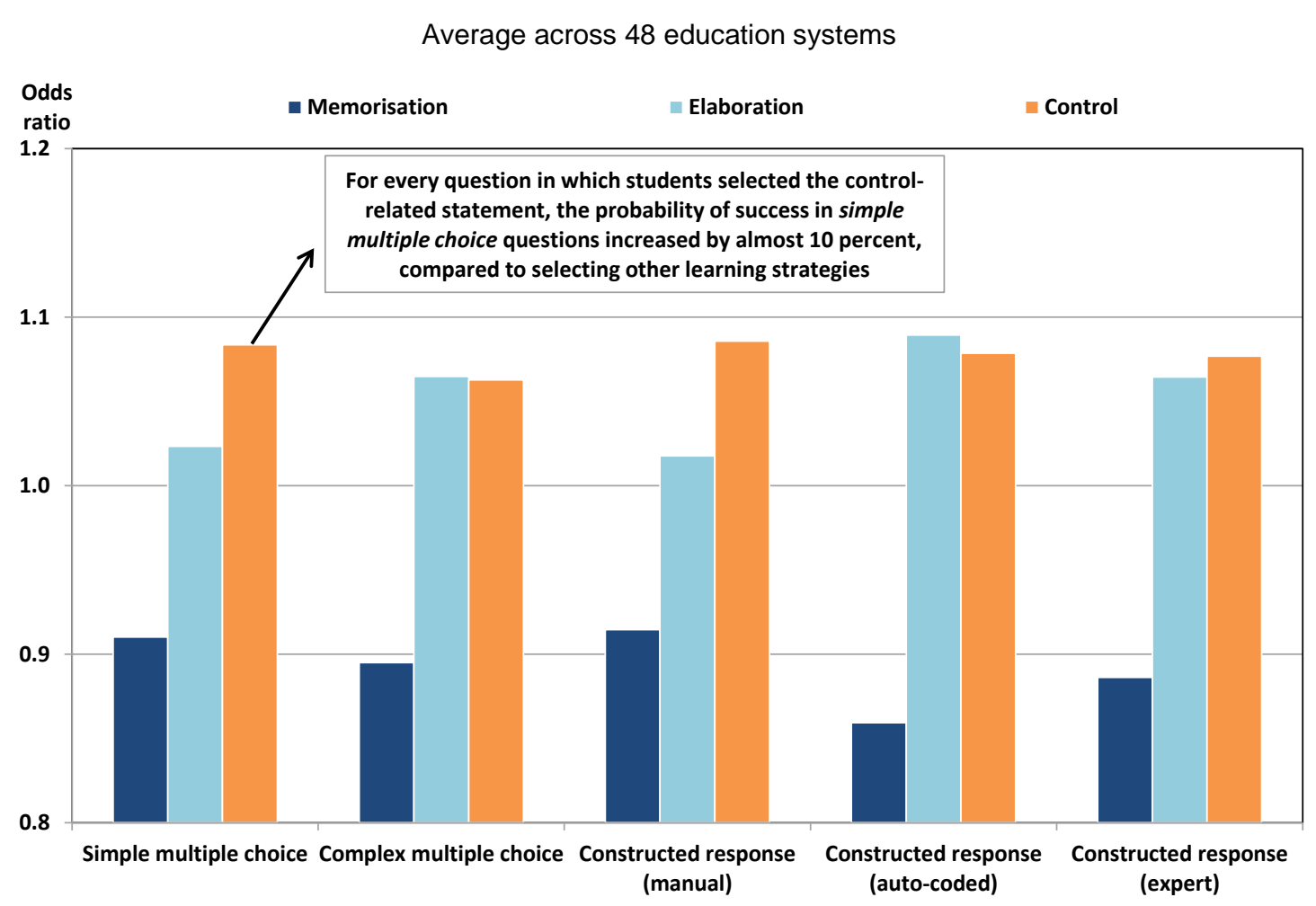

Note: All odds ratios are statistically significant.

Source: OECD, PISA 2012 Database.

Students must actively engage in solving the problems presented in the PISA test. This means they have to formulate situations mathematically; employ mathematics concepts, facts, procedures and reasoning; and/or interpret, apply and evaluate mathematical outcomes. The level of uncertainty and creativity involved in the formulating process means that students who use memorisation strategies should be at a disadvantage over those who rely on other learning strategies more closely connected to divergent/lateral ways of thinking (De Bono, 1968), particularly elaboration strategies (Guilford, 1967). For items in which the interpret and employ processes are more important, students using elaboration strategies should be at a relative disadvantage. Success in solving these items may depend little on creativity, at least compared with items where the formulate process dominates, and more on students' ability to remain focused and avoid mistakes.

PISA results show that memorisation strategies appear to be less detrimental (the negative association decreases) as the processes progress from formulating to employing to interpreting, while the opposite is true for elaboration strategies (Figure 4.12b). As observed with response format type, more intensive use of control strategies barely changes the success rate across the processes represented in the different items. For example, a one-unit increase in the index of control strategies raises the probability of answering correctly by $7 \%$ in items classified as formulate, by $8 \%$ in items classified as employ, and by $10 \%$ in items categorised as interpret. 
Figure 4.12b. Learning strategies and item process

Average across 48 education systems

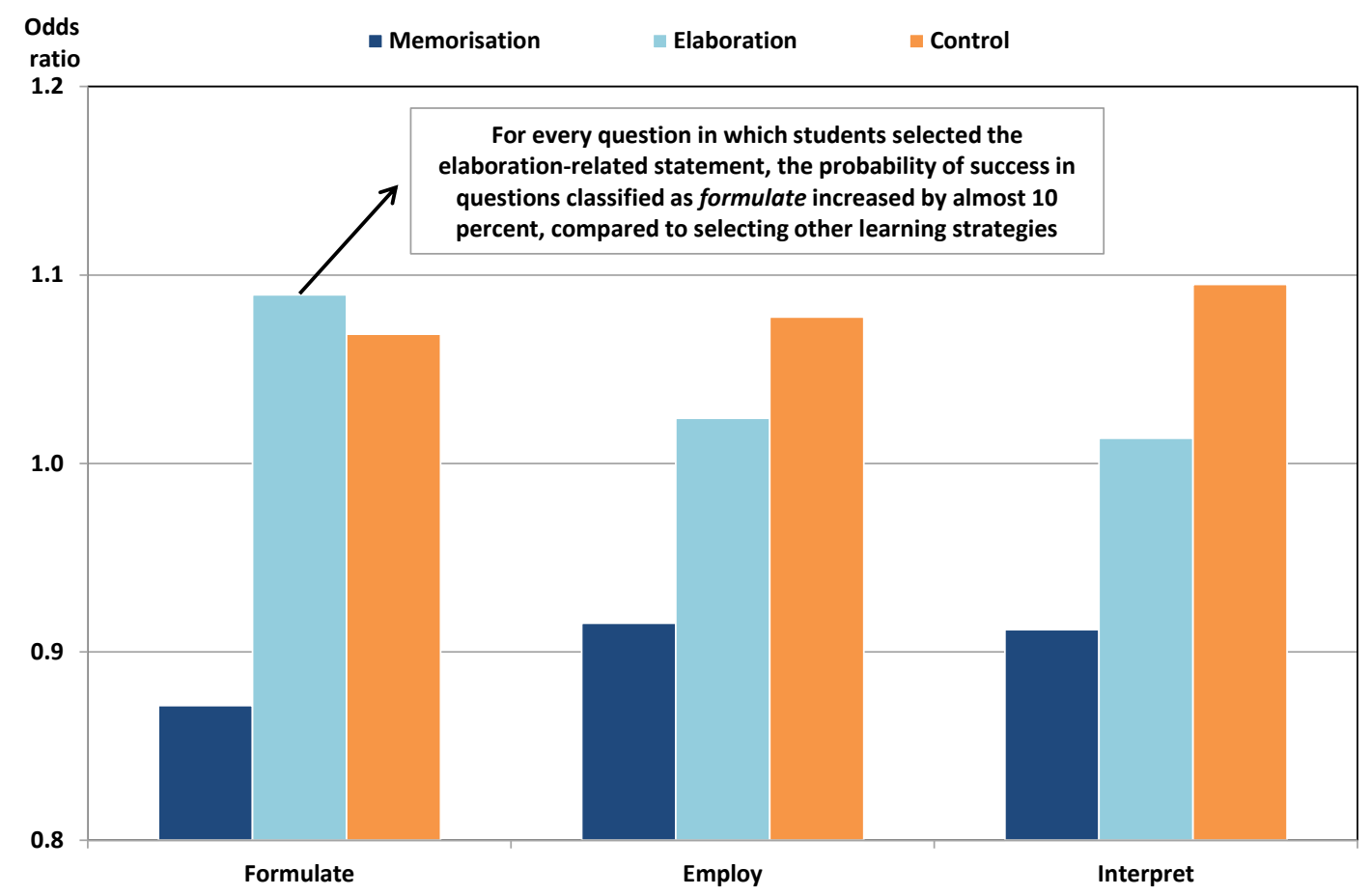

Note: All odds ratios are statistically significant.

Source: OECD, PISA 2012 Database.

PISA 2012 mathematics items were also classified into four content areas - change and relationships, space and shape, quantity, and uncertainty and data - and four contexts - personal, societal, occupational and scientific. It is difficult to predict which learning strategies are best suited for the different content areas and contexts. If anything, it could be argued that learning strategies that help students to "make connections" with real-life experiences should work better with mathematics items set in a real-life context (personal, societal and occupational) than with problems set in a scientific context.

Results clearly indicate that students using memorisation strategies perform particularly poorly on problems classified as space and shape or set in an occupational context, particularly when compared with students who reported using elaboration strategies (Figures 4.12c and 4.12d). Whereas a one-unit increase in the index of memorisation strategies is associated with a $13 \%$ decrease in the probability of answering space and shape problems correctly, for every one-unit increase in the index of elaboration strategies the same probability rises by $8 \%$. This means that students who agreed with statements related to elaboration strategies in all four questions concerning learning strategies were $135 \%$ more likely to solve space and shape problems correctly than students who agreed with statements related to memorisation strategies. This compares with a 50\% increase in probability of success in solving problems related to quantity, a $60 \%$ increase in probability of success in solving problems related to uncertainty and data, and an $80 \%$ increase in the probability of success in solving problems related to change and relationship. 
Figure 4.12c. Learning process and item content Average across 48 economies

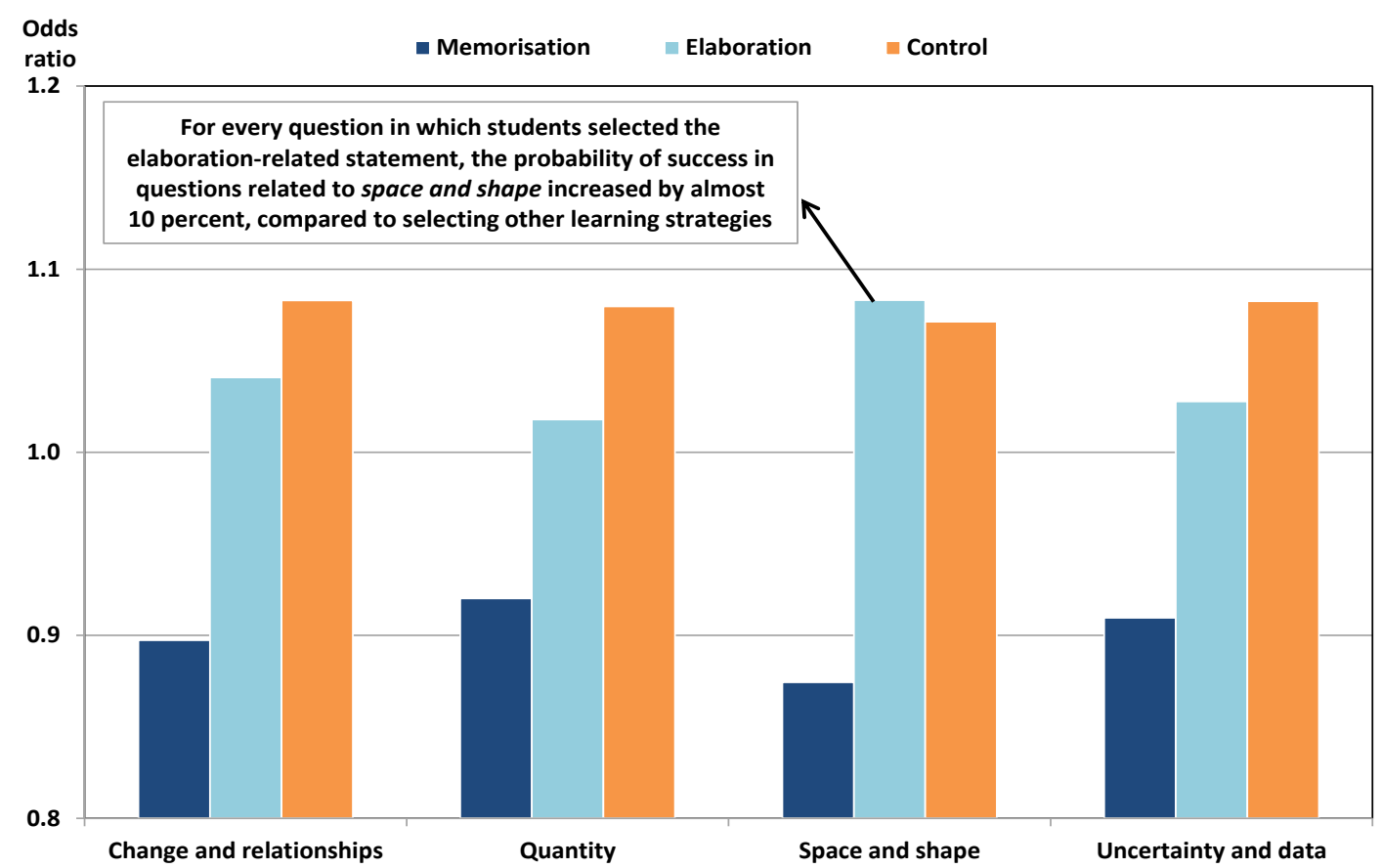

Note: All odds ratios are statistically significant.

Source: OECD, PISA 2012 Database.

Figure 4.12d. Learning process and item context

Average across 48 economies

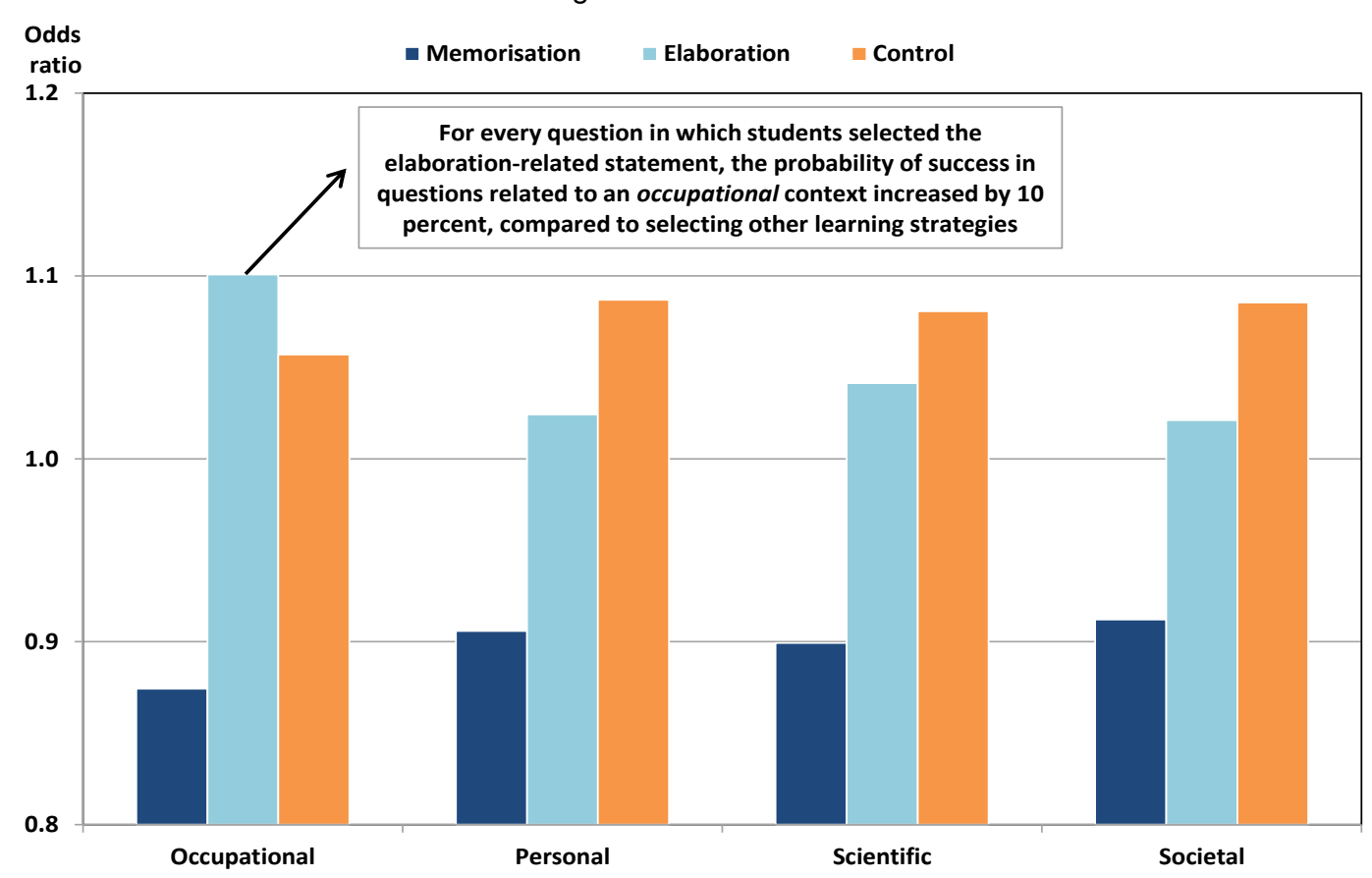

Note: All odds ratios are statistically significant.

Source: OECD, PISA 2012 Database. 
The characteristics of mathematics items in PISA frequently overlap. For example, the most difficult items tend to use open-ended response formats, are related to space and shape content, and require solid formulating skills (see Chapter 2). This means that, based on the results presented so far, it is difficult to tell why students who use a particular learning strategy perform better on specific items.

Figure 4.13. Summary of learning strategies and item characteristics

Explaining the odds ratio of learning strategies on success in 84 mathematics items

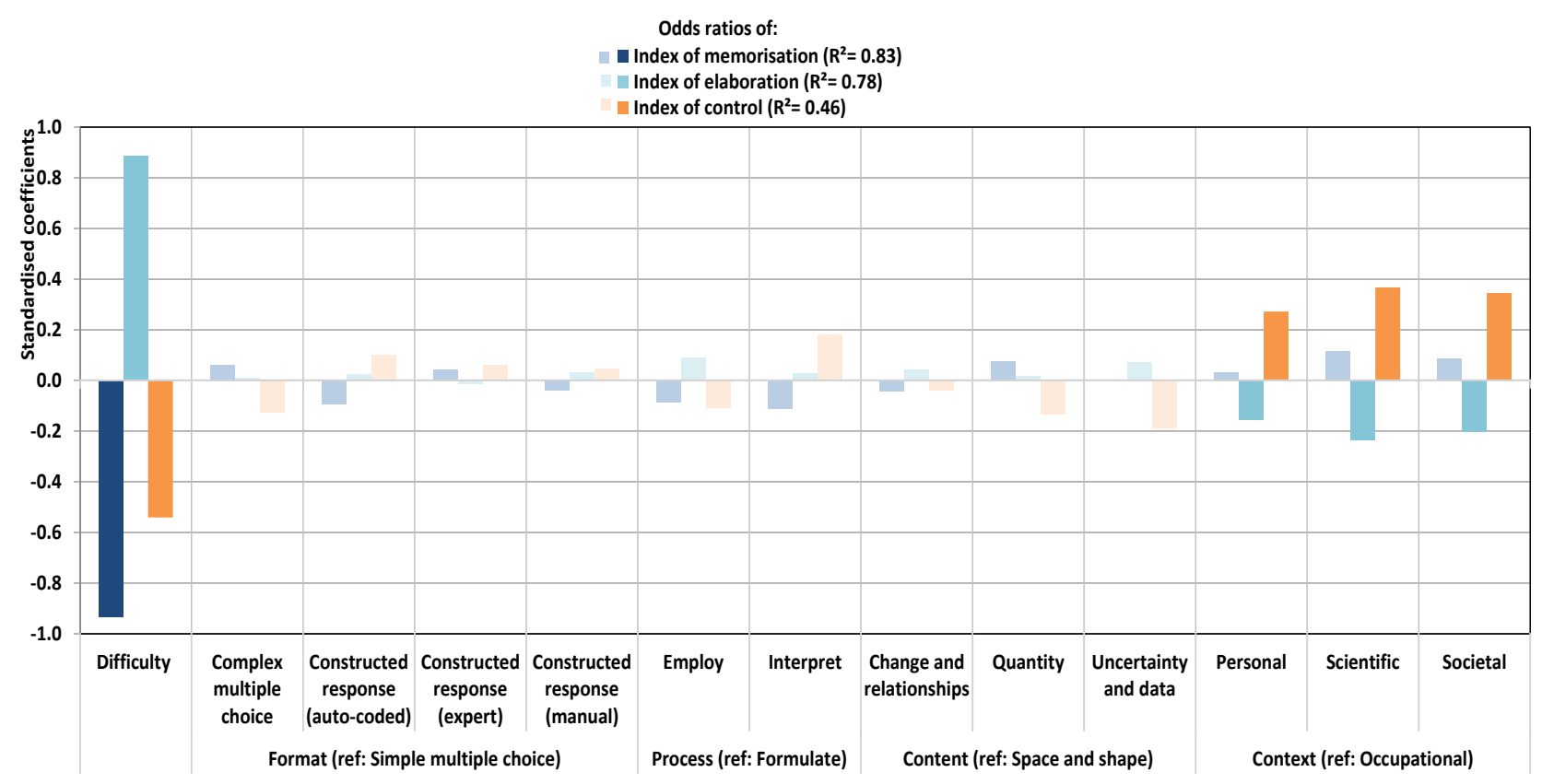

Note: Statistically significant coefficients are marked in a darker tone.

Source: OECD, PISA 2012 Database.

Students who agreed with the statements related to the use of elaboration strategies perform particularly well on the "Revolving door Q2" problem. Is that because "Revolving door Q2" was the toughest item in the PISA mathematics test? Or because it required an open-ended response, or involves space and shape content? Or is it because the item calls on students' ability to formulate situations mathematically? To find out which item characteristics are more important, three regression models (one for each learning strategy) were computed. In the models, the explanatory variables are the item characteristics (difficulty, response format, process, context and content) and the explained variables are the associations between the self-reported use of learning strategies and the success on the 84 mathematics items, measured in odds ratio.

Figure 4.13 shows clearly that the main characteristic associated with the relative effectiveness of the different learning strategies is the items' level of difficulty. After accounting for all item characteristics, the performance of students who use elaboration strategies improves as the difficulty of the mathematics problems increases, while the performance of the students using control and memorisation strategies deteriorates.

An item's context is another telling characteristic. Students using elaboration strategies perform relatively better on the items set in an occupational context, while students using control strategies fare relatively worse on the same items (Figure 4.13). When analysed separately, the response format, the process and the content areas of the mathematics problems appear to have some effect on the effectiveness 
of the learning strategies, but this association disappears entirely after accounting for the items' level of difficulty. Thus, in response to the above questions about "Revolving door Q2", these results mean that students using elaboration strategies perform particularly well on this item because it is the most challenging problem, and not necessarily because it requires an open-ended response, demands that students formulate the problem mathematically, or is related to questions of space and shape.

\section{Combining learning strategies}

Some educators suggest that the best learning approach is the one that combines various learning strategies, including those related to memorisation (Marton, Dall'Alba and Tse, 1996; Wong, 2002). In reaction to the paradox of the Asian learner - why do East Asian students perform so well in international standardised tests if they rely so much on their memory? (Watkins and Biggs, 1996) - many educators argued that combining memorisation and understanding may not only be possible, it may even be desirable (Kember, 1996). Others believe that the distinction between memorisation and understanding is difficult to draw in practice (Entwistle and Entwistle, 2003). While there may be doubts about the benefits of combining memorisation and elaboration strategies, there should be fewer of them about the benefits of adding some strategic thinking, focus and efficient learning (i.e. control strategies) to an approach that focuses on making connections and seeking alternative ways of finding solutions (i.e. elaboration strategies). Equally, adding a touch of creativity and "lateral thinking" (de Bono, 1967) can do no harm to students who are primarily strategic and efficient learners.

To analyse the effectiveness of the combinations of learning strategies, a new variable was created whereby students were categorised as using a single learning strategy when they agreed with statements linked to one of the three learning strategies more times than they agreed with statements linked to either of the other two strategies in the four questions about learning strategies. Students were classified as using a combination of learning strategies if they agreed with statements related to one strategy in two of the questions, and agreed with statements related to a different strategy in the other two questions. The association of the six possible strategies (memorisation, elaboration, control, memorisation + elaboration, memorisation + control, and elaboration + control) with the probability of success in solving "Charts Q1", "Sailing ships Q1" and "Revolving door Q2" is calculated for 48 education systems. ${ }^{5}$

Students using mostly control strategies perform better overall than those using mostly memorisation (the reference group) or elaboration strategies (Figure 4.14). Meanwhile, students who combine memorisation and control strategies perform best on the easy item "Charts Q1", as do students who mostly use control strategies. But the best strategy overall is the combination of control and elaboration strategies. Students combining these two approaches perform the best on both "Sailing ships Q1" and "Revolving door Q2".

Based on this correlational evidence, combining elaboration and control strategies should be recommended as the optimal learning approach. How this is done, in practice, is another matter, for striking a balance between strategic and efficient learning, on the one hand, and creative thinking, on the other, is a challenge. Moreover, memorising, drilling and repetitive learning should not be entirely discarded but rather conceived as supporting practices that can help make the learning process more efficient, for instance in the early years of education and once a mathematical concept is understood (Biggs, 1998; Dahlin and Watkins, 2000; English and Halford, 1995). 
Figure 4.14. Pure and mixed learning strategies

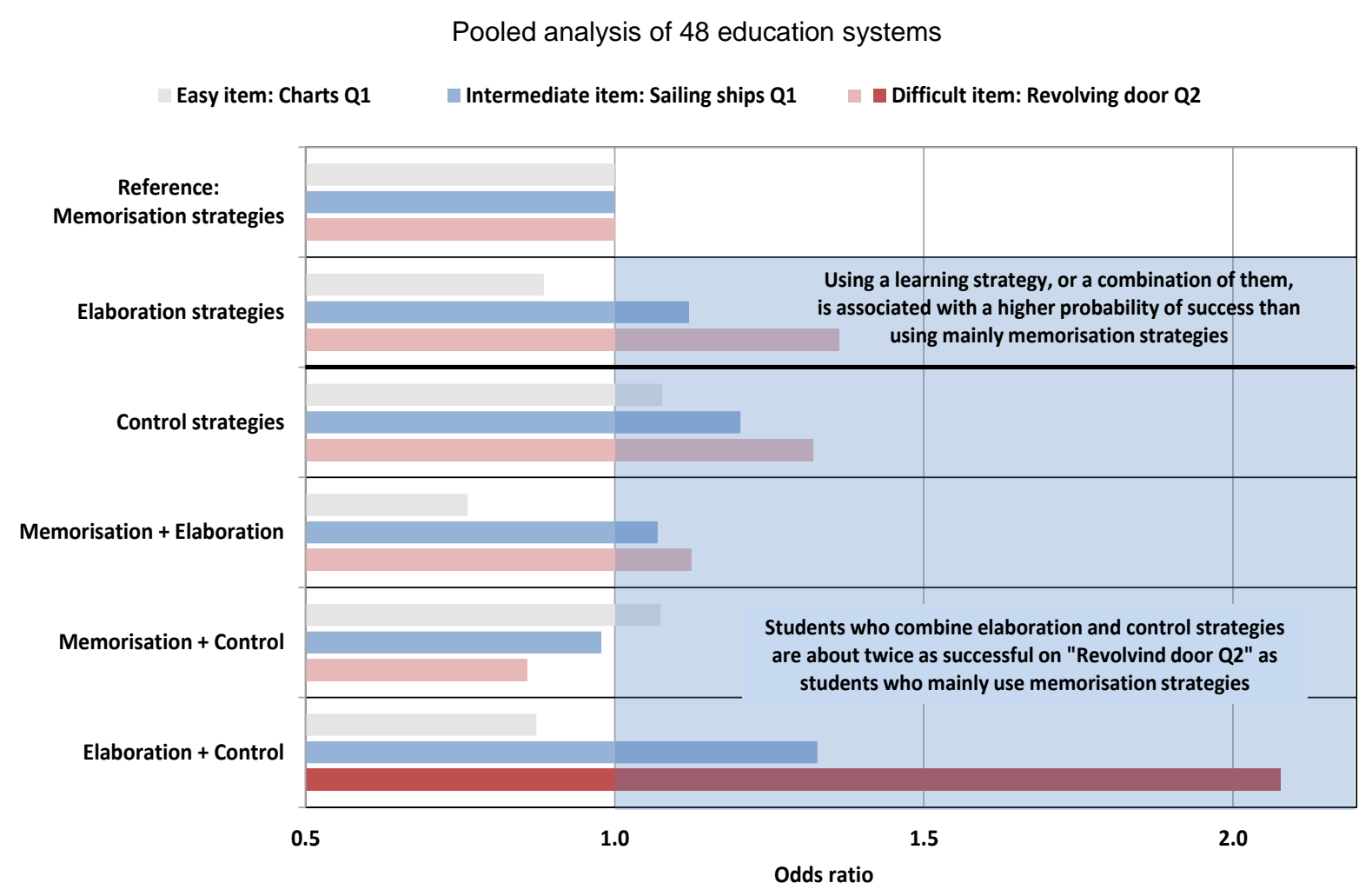

Notes: Odds ratios for the easy and intermediate items are not statistically significant. Statistically significant odds ratios for difficult items are marked in a darker tone.

Source: OECD, PISA 2012 Database.

\section{Learning strategies and socio-economic status}

Not all students are equally capable of making the most of a learning strategy. Some are faster at acquiring new information and could soon become bored if they have to repeat too often what they've learned by memory. Others might feel that being creative is "not for them"; only memorisation allows them to discover complex material. Other students might simply feel more comfortable with a learning strategy because they have been more exposed to it in school or at home. For example, in their study of German and Chinese secondary school students in Hong Kong-China, Dahlin and Watkins (2000) observed that almost all Chinese students but only half of German students remembered being asked to recite texts at school. These early experiences with memorisation strategies probably explain why these strategies appear to be less detrimental to students in Hong Kong-China than to students in Germany (Figure 4.7).

Following this idea that the effectiveness of learning strategies might differ across students, this section discusses how the relationship between memorisation, elaboration and control strategies and performance on the mathematics items varies across students of different socio-economic status.

Dividing students in two groups, based on their country's/economy's median socio-economic profile, ${ }^{6}$ there are no apparent differences in the relationship (Figure 4.15). For both advantaged and disadvantaged students, using memorisation strategies is associated with better performance on the easy item, elaboration strategies are associated with better performance on the challenging item, and using control strategies 
works similarly across the three items. If anything, it could be argued that memorisation and control strategies work better for disadvantaged students and elaboration strategies work better for advantaged students. But this correlational evidence does not support the notion that the effectiveness of different learning strategies is strongly linked to students' socio-economic status.

Figure 4.15. Learning strategies and students' socio-economic status

Average across 45 education systems

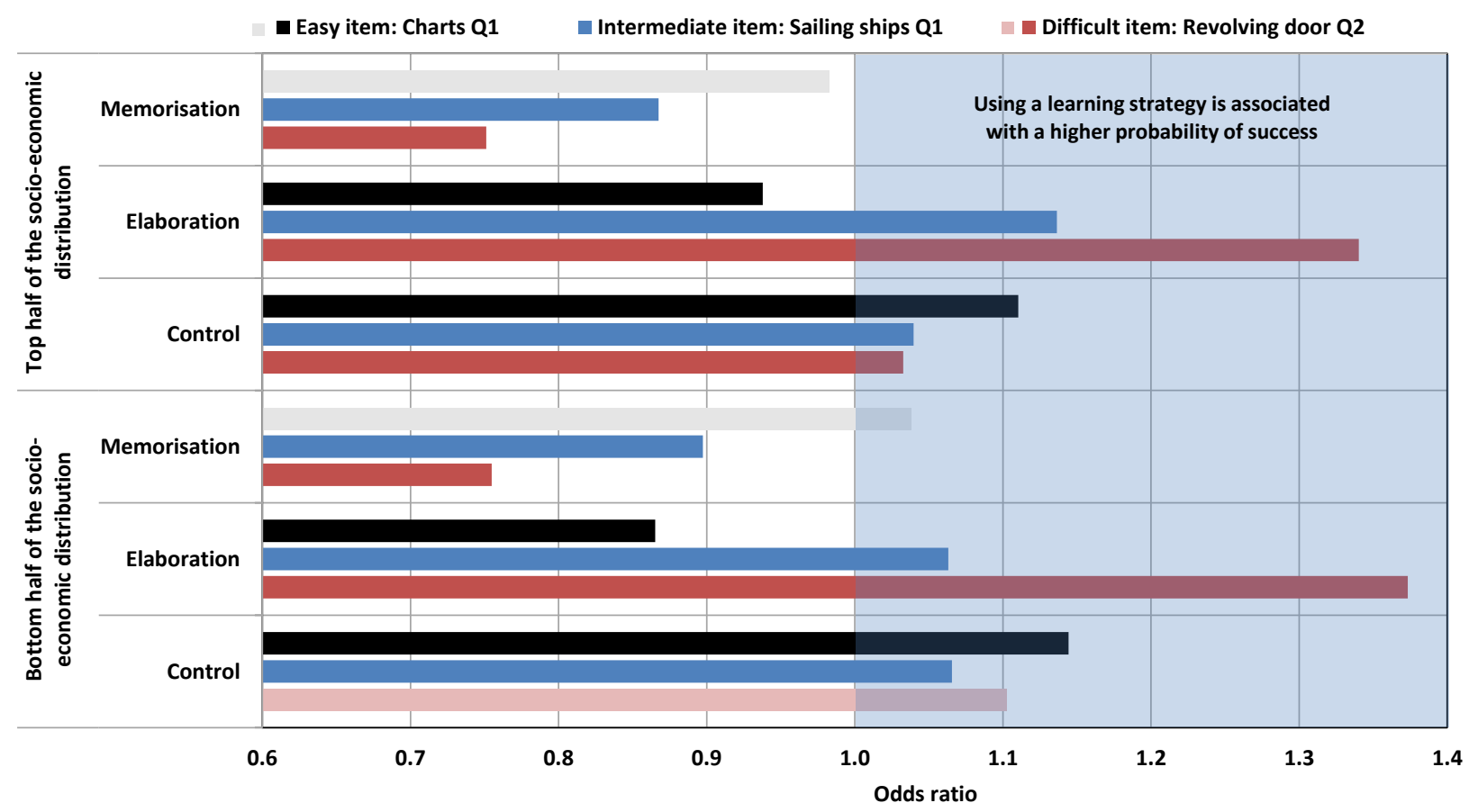

Notes: Subsamples based on the PISA index of economic, social and cultural status (ESCS).

All odds ratios for intermediate items are statistically significant. Statistically significant odds ratios for easy and difficult items are marked in a darker tone.

Source: OECD, PISA 2012 Database.

\section{References}

Ausubel, D., J. Novak, and H. Hanesian (1976), Psicología Educativa: un Punto de Vista Cognoscitivo. México: Trillas.

Biggs, J. (1998), “Learning from the Confucian Heritage: so Size Doesn't Matter?”, International Journal of Educational Research, Vol. 29/8, pp. 723-738.

Biggs, J. (1994), "Student Learning Research and Theory: Where Do we Currently Stand", in G. Gibbs (ed.), Improving student learning: Theory and practice, Oxford: Oxford Centre for Staff Development.

Biggs, J. (1993), “What Do Inventories of Students' Learning Processes Really Measure? A Theoretical Review and Clarification", British Journal of Educational Psychology, Vol. 63/1, pp. 3-19.

Boaler, J. (1998), “Open and Closed Mathematics: Student Experiences and Understandings”, Journal for Research in Mathematics Education, Vol. 29/1, pp. 41-62. 
Brown G. (2004), “Teachers' Conceptions of Assessments: Implications for Policy and Professional Development", Assessment in Education: Principles, Policy and Practice, Vol. 11/3, pp. 301-318.

Caine, R., and G. Caine (1997), Education on the Edge of Possibility, Alexandria, Virginia: Association for Supervision and Curriculum Development.

Caine, R., and G. Caine (1991), Making Connections: Teaching and the Human Brain, Alexandria, Virginia: Association for Supervision and Curriculum Development.

Center for Research on Learning (2016), Learning Strategies, www.kucrl.org/sim/strategies.shtml (accessed 21 January 2016).

Chamot, A. (2004), "Issues in Language Learning Strategy Research and Teaching”, Electronic Journal of Foreign Language Teaching, Vol. 1/1, pp. 14-26.

Cumming, J., and J. Elkins (1999), "Lack of Automaticity in the Basic Addition Facts as a Characteristic of Arithmetic Learning Problems and Instructional Needs", Mathematical Cognition, Vol. 5/2, pp. 149-180.

Dahlin, B., and D. Watkins (2000), "The Role of Repetition in the Processes of Memorising and Understanding: A Comparison of the Views of German and Chinese Secondary School Students in Hong Kong”, British Journal of Educational Psychology, Vol. 70/1, pp. 65-84.

Dansereau, D. (1978), “The Development of a Learning Strategies Curriculum”, in H. O’Neil (ed.), Learning strategies, London: Academic Press.

Darling-Hammond, L., J. Ancess, and B. Falk (1995), Authentic Assessment in Action: Studies of Schools and Students at Work, Teachers College Press.

De Bono, E. (1967), The Use of Lateral Thinking, London: Jonathan Cape.

Dehaene, S. (1997), The Number Sense: How the Mind Creates Mathematics. Oxford, UK: Oxford University Press.

Delazer, M. et al. (2004), "Number Processing and Basal Ganglia Dysfunction: a Single Case Study", Neuropsychologia, Vol. 42/8, pp. 1050-1062.

English, L., and G. Halford (1995), Mathematics Education: Models and Processes, Mahwah, New Jersey: Lawrence Erlbaum Associates.

Entwistle N., and D. Entwistle (2003), Preparing for Examinations: The Interplay of Memorising and Understanding, and the Development of Knowledge Objects, Higher Education Research \& Development, Vol. 22/1, pp. 19-41.

Frey, C., and M. Osborne (2013), "The Future of Employment: How Susceptible Are Jobs to Computerisation", Oxford, UK: Oxford Martin School Study.

Hattie, J. (2009), Visible Learning: A Synthesis of over 800 Meta-analysis Relating to Achievement, Abingdon: Routledge.

Hess, R., and H. Azuma (1991), "Cultural Support for Schooling: Contrasts Between Japan and the United States", Educational Researcher, Vol. 20/9, pp. 2-9. 
Hiebert, J., and Wearne, D. (1996), "Instruction, Understanding, and Skill in Multidigit Addition and Subtraction", Cognition and Instruction, Vol. 14/3, pp. 251-283.

Ischebeck, A. et al. (2006), "How Specifically Do We Learn? Imaging the Learning of Multiplication and Subtraction", Neuroimage, Vol. 30/4, pp. 1365-1375.

Jin, L., and M. Cortazzi (1998), "Dimensions of Dialogue: Large Classes in China", International Journal of Educational Research, Vol. 29/8, pp. 739-761.

Kember, D. (1996). The Intention to Both Memorise and Understand: Another Approach to Learning?, Higher Education, Vol. 31(3), 341-354.

Lester F., and J. Garofalo (1982), Mathematical Problem Solving. Issues in Research. Philadelphia: Franklin Institute Press.

Leung, F. (2001), "In Search of an East Asian Identity in Mathematics Education", Educational Studies in Mathematics, Vol. 47/1, pp. 35-51.

Looi, C., J. Thompson, B. Krause, and R. Kadosh (forthcoming), The Neuroscience of Mathematical Cognition and Learning, OECD Working Paper.

Marton, F., and R. Säljö (1976), “On Qualitative Differences in Learning: I—Outcome and process”, British Journal of Educational Psychology, Vol. 46/1, pp. 4-11.

Marton, F., G. Dall'Alba, and L. Tse (1996), "Memorizing and Understanding: The Keys to the Paradox", In D. Watkins and J. Biggs (eds.), The Chinese Learner: Cultural, Psychological and Contextual Influences, Hong Kong/Melbourne: Comparative Education Research Centre/Australian Council for Educational Research.

Mevarech, Z., and B. Kramarski (2014), Critical Maths for Innovative Societies: The Role of Metacognitive Pedagogies, Paris, OECD Publishing. http://dx.doi.org/10.1787/9789264223561-en

OECD (2013a), OECD Skills Outlook 2013: First Results from the Survey of Adult Skills, OECD Publishing, Paris, http://dx.doi.org/10.1787/9789264204256-en.

OECD (2013b), PISA 2012 Results: Ready to Learn: Students' Engagement, Drive and Self-Beliefs (Volume III), OECD Publishing, Paris, http://dx.doi.org/10.1787/9789264201170-en

OECD (2011), Lessons from PISA for the United States, Strong Performers and Successful Reformers in Education, OECD Publishing, Paris, http://dx.doi.org/10.1787/9789264096660-en

OECD (2010), Mathematics Teaching and Learning Strategies in PISA, OECD Publishing. Paris, http://dx.doi.org/10.1787/9789264039520-en.

Orlin, B. (18 June 2014), "When Not Memorizing Gets in the Way of Learning”, Blog Math with Bad Drawings, http://mathwithbaddrawings.com/2014/06/18/

Pask, G. (1976), "Styles and Strategies of Learning", British Journal of Educational Psychology, Vol. 46/2, pp. 128-148.

Pauli, P. et al. (1994), "Brain Potentials during Mental Arithmetic: Effects of Extensive Practice and Problem Difficulty", Cognitive Brain Research, Vol. 2/1, pp. 21-29. 
Pritchard, A. (2009), Ways of Learning: Learning Theories and Learning Styles in the Classroom (Second Edition), New York: Routledge.

Purdie, N., and J. Hattie (1996), "Cultural Differences in the Use of Strategies for Self-Regulated Learning”, American Educational Research Journal, Vol. 33/4, pp. 845-871.

Rathmell, E. (1978), “Using Thinking Strategies to Teach the Basic Facts”, NCTM Yearbook, Vol. 13/38.

Rubin, J. (1981), "Study of Cognitive Processes in Second Language Learning”, Applied linguistics, Vol. 2/2, pp. 117-131.

Sadler-Smith, E., and F. Tsang (1998), "A Comparative Study of Approaches to Studying in Hong Kong and the United Kingdom”, British Journal of Educational Psychology, Vol. 68/1, pp. 81-93.

Watkins, D. and J. Biggs (eds.) (1996), The Chinese Learner: Cultural, Psychological, and Contextual Influences, Hong Kong/Melbourne: Comparative Education Research Centre/Australian Council for Educational Research.

Weinstein, C., and R. Mayer (1983), "The Teaching of Learning Strategies", Innovation Abstracts, Vol. 5/32.

Weinstein, C. et al. (1989), "Helping Students Develop Strategies for Effective Learning", Educational Leadership, Vol. 46/4, pp. 17-19.

Wong N. (2002), "Conceptions of Doing and Learning Mathematics among Chinese”, Journal of Intercultural Studies, Vol. 23/2, pp. 211-229.

Wong, N. et al. (2002), "The Lived Space of Mathematics Learning", The Journal of Mathematical Behavior, Vol. 21/1, pp. 25-47.

Wray, D., and M. Lewis (1997), Extending Literacy: Children Reading and Writing Non-Fiction, Abingdon: Routledge.

Notes:

${ }^{1}$ The real effectiveness of the learning strategies cannot be unambiguously established, since the analyses are based on correlational evidence and it is always possible that students' skills determine the learning strategies they use, rather than the reverse.

${ }^{2}$ More information is provided in Chapter 2.

${ }^{3}$ Mediation analysis identifies the reasons behind a relationship between an explanatory variable and a dependent variable by including a third explanatory variable, known as a mediating or intervening variable.

${ }^{4}$ See Chapter 2 for a more detailed description of classifications of the mathematics items.

${ }^{5}$ Because of insufficient data in some education systems, the analysis is a pooled regression of the 48 countries and economies where students answered the three items, including fixed effects by country.

${ }^{6}$ Dividing student populations into trisections or quartiles, while more informative, means that in one-third of the 48 countries and economies analysed, reliable estimates could not be computed. In these education systems, there were either not enough students who answered the easy item "Charts Q1" incorrectly or, more frequently, not enough students who answered the difficult item "Revolving door Q2" correctly. 
EDU/WKP(2016)4

\section{CHAPTER 5. WHAT WE HAVE LEARNED: SUMMARY OF FINDINGS}

\section{What we have learned about learning strategies}

\section{To perform at the top, students cannot rely on memory alone}

Memorisation has a role to play in the learning process. It might help students build the foundations in their early years of education, acquire knowledge to reflect on, gain proficiency and become efficient learners. It may even be the best strategy for less-able students, or for those who have simply encountered unexpected hurdles along the way, to reduce anxiety by translating complex problems into a set of rules and procedures that can be rehearsed. As Pritchard (2009) puts it, memorisation "can be accepted as a valuable halfway house in some cases".

To perform at the top, however, students need to go beyond memorising facts; they need to venture into a more conceptual and deep understanding of mathematics. On the easiest PISA mathematics items, students who rely more heavily on their memory perform similarly to students using other learning strategies; but on the hardest items they are much less likely to succeed. In some countries, like Greece, Israel, Montenegro and Poland, students who mainly use memorisation strategies almost always fail on the most challenging mathematics problems. Education systems that seek to reduce the share of low performers could encourage students to learn material by heart and drill; but those that aspire to increase the share of top performers should foster "elaboration" learning strategies to complement memorisation.

\section{Making connections and seeking alternative ways of finding solutions can help students succeed in solving the most difficult mathematics problems}

Using elaboration strategies more intensively, such as thinking of new ways to find solutions or understanding new concepts by relating them to already acquired knowledge, is associated with better performance on the hardest mathematics problems. Despite the apparent advantage of these learning strategies, at least for complex problems, fewer students report using them compared to other learning strategies. Problem solving in mathematics can be improved by encouraging students to use elaboration strategies more intensively, particularly in countries where these strategies are rarely used and are strongly associated with success on difficult problems, such as in Austria, Canada, Iceland, Ireland and Israel.

Students using these strategies appear to be in a state of "relaxed alertness" (Caine and Caine, 1991); they are more interested in mathematics, more open to problem solving, and less likely to get nervous, tense and anxious doing mathematics problems. Using elaboration strategies also seems to benefit socioeconomically advantaged and disadvantaged students equally: both groups perform better on the most challenging problems when they make connections and seek for alternative ways of finding solutions.

\section{When students are strategic learners their overall performance is higher}

Control learning strategies, such as identifying relevant content and monitoring progress, are the most frequently used (for mathematics) across all PISA-participating countries and economies - and probably for a reason. Students who claim to approach learning strategically and efficiently perform better in mathematics, particularly in Australia, France, Israel, New Zealand, Shanghai-China and Chinese Taipei. However, too much control and efficiency may hinder students' ability to solve complex problems - those that require more motivation and creativity. For instance, the K-W-L grid, a tool that asks students to answer three questions: "What do I know?", "What do I want to find out?" and "What have I learnt"? (Ogle, 1986), is certainly useful for controlling the learning process, but may feel too mechanistic and 
uninspiring to many students. Among other things, it assumes that students necessarily know what their learning goals are; and much learning follows non-linear, and even erratic, pathways.

\section{Learners need to be versatile}

A good learner is a flexible learner who can use and combine strategies, depending on the task at hand (acquiring new knowledge or improving proficiency) and the context in which the learning occurs (a novel situation or a frequently encountered one). In this way, the student makes his or her "whole brain" function (Torrance and Rockenstein, 1988). The report shows that some learning strategies appear to work better for some mathematics problems than for others. It also shows that combining strategies, particularly control and elaboration strategies, appears as the best strategy overall: one that gives students enough direction and strategic thinking for the easier mathematics problems, and enough motivation and creativity for the most complex problems.

\section{What we have learned about teaching strategies}

\section{More teaching occurs in positive environments}

More teaching, and presumably learning, occurs when there is a positive school environment, including support from teachers, good classroom management and teacher-student relations, and when students feel they belong at school. A positive disciplinary climate does not seem as important, particularly for student-oriented teaching practices. Students also reported more teaching in schools with ability grouping and smaller classes, and where information and communication technologies are available. Student-oriented and formative-assessment practices, in turn, are more frequently used in schools with vocational tracks and where principals promote improvements in instruction.

\section{Some knowledge transmission is necessary...}

Some degree of knowledge transmission, from a "more knowledgeable other" to students, is essential for learning to happen. Not surprisingly, when students or teachers are asked about teaching practices in mathematics lessons, teacher-directed instructional practices are the most frequently reported across most PISA-participating countries and economies. This report's findings about teaching-directed instruction are not conclusive, partly because teachers differ relatively little in the frequency with which they use these strategies. One thing is clear, however: they appear to work better for easier mathematics problems.

\section{...but students need to work independently and collaboratively sometimes...}

However, students also need a break from "chalk and talk" teaching, for instance by working independently, co-operatively and in projects with little teacher intervention. Among other skills, these strategies can foster creativity, co-operation and leadership, deep learning and engagement. Since studentoriented practices are relatively uncommon, for instance, only $23 \%$ of students in OECD countries reported that their teachers had students work in small groups regularly, there is considerable room for innovation. These time-consuming strategies might not be frequently used because teachers need to cover lengthy curricula or prepare students for high-stakes qualification examinations, which are often cited by teachers as determining the repertoire of strategies they can use in their lessons (Boardman and Woodruff, 2004).

Some teachers might be discouraged from using student-oriented strategies (at least as reported by students), given their negative correlation with student performance (Figure 3.25). However, when teachers are doing the reporting, and the effect of using those strategies frequently is analysed after accounting for numerous relevant factors, even those that have not been directly measured through the TALIS or PISA questionnaires, students show a higher probability of correctly answering PISA items in those subjects where their school teachers emphasise student-oriented practices. Remarkably, these results are observed 
in seven of the eight countries in the TALIS-PISA Link study (Australia, Latvia, Mexico, Portugal, Romania, Singapore and Spain).

\section{...and be informed about their progress}

Formative-assessment instructional practices, such as checking exercise books or homework, providing written feedback on student work, or giving feedback on the strengths and weaknesses of students, are relatively uncommon, according to both teachers and students. For instance, only $26 \%$ of students in OECD countries reported that their teachers give them feedback on their strengths and weaknesses in mathematics, and across the eight countries that participated in the TALIS-PISA Link study, only about half of the teachers reported providing written feedback on student work (in addition to a mark), on average.

The results in the report are not necessarily encouraging for teachers who use these teaching strategies since they are negatively related to student performance (when analysed using the PISA student questionnaire), and to performance on very difficult items (when analysed using the TALIS-PISA Link study). These findings contradict those found in Hattie (2009) and the Teaching and Learning Toolkit (Education Endowment Foundation), where education interventions that emphasise feedback have a large impact on student performance. However, the questions in PISA and TALIS mainly refer to the feedback that teachers provide to students, and not to the more powerful feedback that students provide to teachers (Hattie, 2009). If feedback goes only in one direction, it might simply be another type of teacher-directed instructional practice. Also, the effectiveness of formative-assessment strategies is dependent on the way in which students receive and interpret the feedback (Hattie, 2009), and neither PISA nor TALIS provides sufficient information on this aspect of learning.

\section{Above all, students need to be constantly challenged.}

Most teachers believe that their students need to be constantly challenged in the classroom. On average across TALIS-participating countries, $83 \%$ of teachers agreed or strongly agreed that students learn best by finding solutions to problems on their own (OECD, 2014). However, only $42 \%$ of students, on average across OECD countries, reported that their teachers regularly ask them to decide, on their own, the procedures for solving complex problems. Other cognitive-activation strategies include asking students to explain how they have solved a problem, or giving problems that can be solved in different ways, that are presented in different contexts, that require students to think for an extended time or for which there is no immediately obvious method of solution. According to students' reports of how frequently these strategies are used in their mathematics classes, these strategies are positively related to student performance on mathematics items of all levels of difficulty. The more teachers of one subject use these strategies, the better the student performance in that subject - but only on the most difficult items and only in some countries.

All learning strategies have benefits and drawbacks for student outcomes. Teachers need to decide not which strategies to use - all have a role to play in the classroom - but rather when and how to use them. However, if the goal is to instil a feeling of "relaxed alertness" in students that combines high expectations with low threat (Caine and Caine, 1991), one thing is clear: teachers should constantly challenge students by asking them how they arrive at solutions, assigning problems at the right level of difficulty (challenging enough, but not intimidating) and placing problems in different contexts. These cognitive-activation strategies are positively related to student performance, and can be combined with other instructional practices. 


\section{Teaching and learning strategies are not one-to-one relationships.}

Contrary to what common sense would suggest, more "traditional" ways of teaching, reflected in statements such as "the teacher tells us what we have to learn" or "the teacher sets clear goals for our learning", do not always lead to a more intensive use of memorisation, rehearsal and drilling. Countries where students are most likely to say their mathematics teachers use teacher-directed instruction are not necessarily those where students reported using memorisation strategies most frequently. Some education systems, like that in Ireland, appear as traditional in both their teaching and learning, but many education systems appear as traditional only in their teaching methods (Croatia, Hong Kong-China, Hungary and Shanghai-China) or in their learning strategies (Australia, New Zealand, the United Kingdom and Uruguay).

In addition, there is no correlation between a student's exposure to teacher-directed instructional practices (based on students' reports) and using memorisation strategies in mathematics; and there is only a weak association between being exposed to student-oriented practices and using elaboration strategies. Even students' exposure to applied or pure mathematics, which appears to have a strong impact on student outcomes (Schmidt et al., 2015), is only weakly associated with the use of particular learning approaches. If anything, the more students are exposed to pure mathematics, the more they reported using control strategies, and the less they reported using elaboration strategies.

\section{What we have learned about international assessments}

High-stakes assignments and assessments often determine how students learn. The findings in this report show that even international standardised tests can and should test for deep understanding and creativity, as well as surface learning and procedural knowledge. Both easy and difficult problems provide valuable information to policy makers, schools and teachers; they require different skills, and different teaching and learning strategies. The most difficult problems in the PISA mathematics assessment are open-ended questions related to space and shape that require students to formulate situations mathematically; the easiest ones are simple multiple-choice questions related to quantity that require students to interpret mathematical problems. Without the wide array of content areas, contexts, question formats and levels of difficulty assessed, PISA would simply not do justice to the complex world in which students currently live, let alone the world they will live in even a few short years from now.

\section{References}

Boardman, A., and Woodruff, A. (2004), "Teacher Change and "High-Stakes" Assessment: What Happens to Professional Development?", Teaching and Teacher Education, Vol. 20/6, pp. 545-557.

Caine, R., and G. Caine (1991), Making Connections: Teaching and the Human Brain, Alexandria, Virginia: Association for Supervision and Curriculum Development.

Education Endowment Foundation, Teaching and Learning Toolkit, https://educationendowmentfoundation.org.uk/toolkit (last accessed on 4 March 2016)

Hattie, J. (2009), Visible Learning: A Synthesis of over 800 Meta-analysis Relating to Achievement, Abingdon: Routledge.

OECD (2014), TALIS 2013 Results: An International Perspective on Teaching and Learning, OECD Publishing, Paris, http://dx.doi.org/10.1787/9789264196261-en.

Ogle, D (1986), "KWL: A Teaching Model that Develops Active Reading of Expository Text", The Reading Teacher, Vol. 39/6, pp. 564-570. 
Pritchard, A. (2009), Ways of Learning: Learning Theories and Learning Styles in the Classroom (Second Edition), Routledge: New York.

Schmidt, W., N. Burroughs, P. Zoido and R. Houang (2015), "The Role of Schooling in Perpetuating Educational Inequality: An International Perspective”, Educational Researcher, Vol. 44/7, pp. 371-386.

Torrance, E., and Z. Rockenstein (1988), "Styles of Thinking and Creativity", in R. Schmeck (Ed.), Learning Strategies and Learning Styles, Plenum Press: New York. 


\section{ANNEX A. MATHEMATICS ITEMS IN PISA 2012}

Table A.1. List of mathematics items PISA 2012 [Part 1/4]

\begin{tabular}{|c|c|c|c|c|c|c|c|}
\hline Unit Name & $\begin{array}{l}\text { No. } \\
\text { countries }\end{array}$ & Item Format & Content & Context & Process & $\begin{array}{c}\% \\
\text { correct }\end{array}$ & $\begin{array}{l}\text { PISA } \\
\text { scale }^{2}\end{array}$ \\
\hline $\begin{array}{l}\text { "MATH - P2003 Computer } \\
\text { Game Q1" }\end{array}$ & 64 & $\begin{array}{l}\text { Simple Multiple } \\
\text { Choice }\end{array}$ & Quantity & Personal & Employ & 88.39 & 317.3 \\
\hline $\begin{array}{l}\text { "MATH - P2012 Part-Time } \\
\text { Work Q1" }\end{array}$ & 16 & $\begin{array}{l}\text { Simple Multiple } \\
\text { Choice }\end{array}$ & Quantity & Occupational & Interpret & 85.91 & 327.7 \\
\hline $\begin{array}{l}\text { "MATH - P2012 Which Car } \\
\text { Q1" }\end{array}$ & 16 & $\begin{array}{l}\text { Simple Multiple } \\
\text { Choice }\end{array}$ & $\begin{array}{l}\text { Uncertainty } \\
\text { and data }\end{array}$ & Personal & Interpret & 81.14 & 327.8 \\
\hline $\begin{array}{l}\text { "MATH - P2012 Speeding } \\
\text { Fines Q1" }\end{array}$ & 64 & $\begin{array}{l}\text { Constructed } \\
\text { Response Manual }\end{array}$ & Quantity & Societal & Interpret & 89.34 & 346.1 \\
\hline $\begin{array}{l}\text { "MATH - P2012 Charts } \\
\text { Q1" }\end{array}$ & 48 & $\begin{array}{l}\text { Simple Multiple } \\
\text { Choice }\end{array}$ & $\begin{array}{l}\text { Uncertainty } \\
\text { and data }\end{array}$ & Societal & Interpret & 87.27 & 347.7 \\
\hline $\begin{array}{l}\text { "MATH - P2012 } \\
\text { Employment Data Q1" }\end{array}$ & 64 & $\begin{array}{l}\text { Constructed } \\
\text { Response Manual }\end{array}$ & $\begin{array}{l}\text { Uncertainty } \\
\text { and data }\end{array}$ & Societal & Employ & 87.30 & 352.4 \\
\hline $\begin{array}{l}\text { "MATH - P2012 Zs Fan } \\
\text { Merchandise Q1" }\end{array}$ & 48 & $\begin{array}{l}\text { Constructed } \\
\text { Response Manual }\end{array}$ & Quantity & Personal & Employ & 84.51 & 386.6 \\
\hline $\begin{array}{l}\text { "MATH - P2003 Tossing } \\
\text { Coins Q1" }\end{array}$ & 64 & $\begin{array}{l}\text { Simple Multiple } \\
\text { Choice }\end{array}$ & $\begin{array}{l}\text { Uncertainty } \\
\text { and data }\end{array}$ & Personal & Interpret & 79.05 & 401.4 \\
\hline $\begin{array}{l}\text { "MATH - P2012 Spacers } \\
\text { Q1" }\end{array}$ & 64 & $\begin{array}{l}\text { Constructed } \\
\text { Response Manual }\end{array}$ & $\begin{array}{l}\text { Space and } \\
\text { shape }\end{array}$ & Occupational & Formulate & 77.60 & 409.1 \\
\hline $\begin{array}{l}\text { "MATH - P2012 Part-Time } \\
\text { Work Q2" }\end{array}$ & 16 & $\begin{array}{l}\text { Constructed } \\
\text { Response Manual }\end{array}$ & Quantity & Occupational & Employ & 64.13 & 410.5 \\
\hline $\begin{array}{l}\text { "MATH - P2012 Charts } \\
\text { Q2" }\end{array}$ & 48 & $\begin{array}{l}\text { Simple Multiple } \\
\text { Choice }\end{array}$ & $\begin{array}{l}\text { Uncertainty } \\
\text { and data }\end{array}$ & Societal & Interpret & 79.54 & 415.0 \\
\hline $\begin{array}{l}\text { "MATH - P2012 Tennis } \\
\text { Balls Q1" }\end{array}$ & 48 & $\begin{array}{l}\text { Complex Multiple } \\
\text { Choice }\end{array}$ & Quantity & Occupational & Interpret & 77.71 & 419.1 \\
\hline $\begin{array}{l}\text { "MATH - P2012 Garage } \\
\text { Q1" }\end{array}$ & 16 & $\begin{array}{l}\text { Simple Multiple } \\
\text { Choice }\end{array}$ & $\begin{array}{l}\text { Space and } \\
\text { shape }\end{array}$ & Occupational & Interpret & 65.14 & 419.6 \\
\hline $\begin{array}{l}\text { "MATH - P2012 Charts } \\
\text { Q5" }\end{array}$ & 48 & $\begin{array}{l}\text { Simple Multiple } \\
\text { Choice }\end{array}$ & $\begin{array}{l}\text { Uncertainty } \\
\text { and data }\end{array}$ & Societal & Employ & 76.67 & 428.2 \\
\hline $\begin{array}{l}\text { "MATH - P2000 A View } \\
\text { with a Room Q1" }\end{array}$ & 64 & $\begin{array}{l}\text { Simple Multiple } \\
\text { Choice }\end{array}$ & $\begin{array}{l}\text { Space and } \\
\text { Shape }\end{array}$ & Personal & Interpret & 75.78 & 433.5 \\
\hline $\begin{array}{l}\text { "MATH - P2012 Helen The } \\
\text { Cyclist Q1" }\end{array}$ & 16 & $\begin{array}{l}\text { Simple Multiple } \\
\text { Choice }\end{array}$ & $\begin{array}{l}\text { Change and } \\
\text { relationships }\end{array}$ & Personal & Employ & 52.91 & 440.5 \\
\hline $\begin{array}{l}\text { "MATH - P2003 Running } \\
\text { Time Q1" }\end{array}$ & 64 & $\begin{array}{l}\text { Constructed } \\
\text { Response Manual }\end{array}$ & Quantity & Personal & Employ & 74.31 & 442.6 \\
\hline $\begin{array}{l}\text { "MATH - P2012 Migration } \\
\text { Q1" }\end{array}$ & 64 & $\begin{array}{l}\text { Constructed } \\
\text { Response Manual }\end{array}$ & $\begin{array}{l}\text { Uncertainty } \\
\text { and data }\end{array}$ & Societal & Interpret & 72.12 & 450.9 \\
\hline $\begin{array}{l}\text { "MATH - P2012 Carbon } \\
\text { Tax Q2" }\end{array}$ & 64 & $\begin{array}{l}\text { Constructed } \\
\text { Response Manual }\end{array}$ & $\begin{array}{l}\text { Change and } \\
\text { relationships }\end{array}$ & Societal & Employ & 68.24 & 451.8 \\
\hline $\begin{array}{l}\text { "MATH - P2012 Bike } \\
\text { Rental Q2" }\end{array}$ & 64 & $\begin{array}{l}\text { Constructed } \\
\text { Response Manual }\end{array}$ & $\begin{array}{l}\text { Change and } \\
\text { relationships }\end{array}$ & Personal & Interpret & 71.57 & 461.6 \\
\hline $\begin{array}{l}\text { "MATH - P2012 Climbing } \\
\text { Mount Fuji Q1" }\end{array}$ & 16 & $\begin{array}{l}\text { Simple Multiple } \\
\text { Choice }\end{array}$ & Quantity & Societal & Formulate & 46.93 & 464.0 \\
\hline $\begin{array}{l}\text { "MATH - P2003 Tile } \\
\quad \text { Arrangement Q1" }\end{array}$ & 64 & $\begin{array}{l}\text { Simple Multiple } \\
\text { Choice }\end{array}$ & $\begin{array}{l}\text { Space and } \\
\text { Shape }\end{array}$ & Societal & Employ & 68.33 & 465.5 \\
\hline $\begin{array}{l}\text { "MATH - P2012 Roof Truss } \\
\text { Design Q1" }\end{array}$ & 64 & $\begin{array}{l}\text { Complex Multiple } \\
\text { Choice }\end{array}$ & $\begin{array}{l}\text { Space and } \\
\text { shape }\end{array}$ & Occupational & Employ & 67.51 & 467.2 \\
\hline $\begin{array}{l}\text { "MATH - P2012 Medicine } \\
\text { Doses Q1" }\end{array}$ & 48 & $\begin{array}{l}\text { Constructed } \\
\text { Response Manual }\end{array}$ & $\begin{array}{l}\text { Change and } \\
\text { relationships }\end{array}$ & Scientific & Employ & 65.40 & 467.6 \\
\hline $\begin{array}{l}\text { "MATH - P2012 } \\
\text { Employment Data Q3" }\end{array}$ & 64 & $\begin{array}{l}\text { Complex Multiple } \\
\text { Choice }\end{array}$ & $\begin{array}{l}\text { Uncertainty } \\
\text { and data }\end{array}$ & Societal & Interpret & 64.95 & 467.8 \\
\hline $\begin{array}{l}\text { "MATH - P2003 Cash } \\
\text { Withdrawal Q2" }\end{array}$ & 64 & $\begin{array}{l}\text { Constructed } \\
\text { Response Manual }\end{array}$ & & Societal & Employ & 66.74 & 470.0 \\
\hline
\end{tabular}

1. Items administered in the 16 countries that opted for the easy booklet (Argentina, Brazil, Bulgaria, Chile, Colombia, Costa Rica, Jordan, Kazakhstan, Mexico, Peru, Romania, Serbia, Tunisia, United Arab Emirates, Uruguay and Viet Nam) are not analysed in this paper.

2. Only full credit

Source: OECD, PISA 2012 Database. 
Table A.1. List of mathematics items PISA 2012 [Part 2/4]

\begin{tabular}{|c|c|c|c|c|c|c|c|}
\hline Unit Name & $\begin{array}{c}\text { No. } \\
\text { countries }\end{array}$ & Item Format & Content & Context & Process & $\begin{array}{c}\% \\
\text { correct }\end{array}$ & $\begin{array}{l}\text { PISA } \\
\text { scale }^{2}\end{array}$ \\
\hline $\begin{array}{l}\text { "MATH - P2003 Telephone } \\
\text { Rates Q1" }\end{array}$ & 64 & $\begin{array}{l}\text { Simple Multiple } \\
\text { Choice }\end{array}$ & Quantity & Societal & Interpret & 63.14 & 471.2 \\
\hline $\begin{array}{l}\text { "MATH - P2003 The } \\
\text { Thermometer Cricket } \\
\text { Q1" }\end{array}$ & 64 & $\begin{array}{l}\text { Constructed } \\
\text { Response Manual }\end{array}$ & $\begin{array}{l}\text { Change and } \\
\text { Relationships }\end{array}$ & Scientific & Formulate & 68.57 & 471.8 \\
\hline "MATH - P2012 Racing Q1" & 16 & $\begin{array}{l}\text { Simple Multiple } \\
\text { Choice }\end{array}$ & $\begin{array}{l}\text { Uncertainty } \\
\text { and data }\end{array}$ & Societal & Interpret & 45.71 & 472.0 \\
\hline $\begin{array}{l}\text { "MATH - P2000 Pop } \\
\text { Pyramids Q1" }\end{array}$ & 64 & $\begin{array}{l}\text { Constructed } \\
\text { Response Expert }\end{array}$ & $\begin{array}{l}\text { Change and } \\
\text { Relationships }\end{array}$ & Scientific & Interpret & 67.67 & 480.0 \\
\hline $\begin{array}{l}\text { "MATH - P2012 London } \\
\text { Eye Q2" }\end{array}$ & 16 & $\begin{array}{l}\text { Simple Multiple } \\
\text { Choice }\end{array}$ & $\begin{array}{l}\text { Space and } \\
\text { shape }\end{array}$ & Societal & Formulate & 43.60 & 481.0 \\
\hline $\begin{array}{l}\text { "MATH - P2012 Chocolate } \\
\text { Q3" }\end{array}$ & 16 & $\begin{array}{l}\text { Simple Multiple } \\
\text { Choice }\end{array}$ & $\begin{array}{l}\text { Change and } \\
\text { relationships }\end{array}$ & Scientific & Employ & 44.68 & 482.4 \\
\hline "MATH - P2012 Sauce Q2" & 48 & $\begin{array}{l}\text { Constructed } \\
\text { Response Manual }\end{array}$ & Quantity & Personal & Formulate & 63.45 & 489.1 \\
\hline $\begin{array}{l}\text { "MATH - P2012 Which Car } \\
\text { Q2" }\end{array}$ & 16 & $\begin{array}{l}\text { Simple Multiple } \\
\text { Choice }\end{array}$ & Quantity & Personal & Employ & 37.48 & 490.9 \\
\hline "MATH - P2000 Map Q1" & 64 & $\begin{array}{l}\text { Simple Multiple } \\
\text { Choice }\end{array}$ & $\begin{array}{l}\text { Space and } \\
\text { Shape }\end{array}$ & Societal & Employ & 60.36 & 491.2 \\
\hline $\begin{array}{l}\text { "MATH - P2012 Speeding } \\
\text { Fines Q2" }\end{array}$ & 64 & $\begin{array}{l}\text { Simple Multiple } \\
\text { Choice }\end{array}$ & Quantity & Societal & Employ & 63.12 & 491.9 \\
\hline $\begin{array}{l}\text { "MATH - P2012 Crazy Ants } \\
\text { Q1" }\end{array}$ & 64 & $\begin{array}{l}\text { Simple Multiple } \\
\text { Choice }\end{array}$ & Quantity & Scientific & Employ & 60.65 & 495.1 \\
\hline $\begin{array}{l}\text { "MATH - P2012 Seats In A } \\
\text { Theatre Q1" }\end{array}$ & 16 & $\begin{array}{l}\text { Constructed } \\
\text { Response Manual }\end{array}$ & $\begin{array}{l}\text { Change and } \\
\text { relationships }\end{array}$ & Occupational & Employ & 28.95 & 495.5 \\
\hline $\begin{array}{l}\text { "MATH - P2012 Seats In A } \\
\text { Theatre Q2" }\end{array}$ & 16 & $\begin{array}{l}\text { Constructed } \\
\text { Response Expert }\end{array}$ & $\begin{array}{l}\text { Change and } \\
\text { relationships }\end{array}$ & Occupational & Formulate & 30.36 & 508.8 \\
\hline $\begin{array}{l}\text { "MATH - P2012 Helen The } \\
\text { Cyclist Q2" }\end{array}$ & 16 & $\begin{array}{l}\text { Simple Multiple } \\
\text { Choice }\end{array}$ & $\begin{array}{l}\text { Change and } \\
\text { relationships }\end{array}$ & Personal & Employ & 36.86 & 510.6 \\
\hline $\begin{array}{l}\text { "MATH - P2003 Carbon } \\
\text { Dioxide Q2" }\end{array}$ & 64 & $\begin{array}{l}\text { Constructed } \\
\text { Response Manual }\end{array}$ & $\begin{array}{l}\text { Uncertainty } \\
\text { and data }\end{array}$ & Scientific & Employ & 55.95 & 511.0 \\
\hline $\begin{array}{l}\text { "MATH - P2012 Sailing } \\
\text { Ships Q1" }\end{array}$ & 48 & $\begin{array}{l}\text { Simple Multiple } \\
\text { Choice }\end{array}$ & Quantity & Scientific & Employ & 59.49 & 511.7 \\
\hline $\begin{array}{l}\text { "MATH - P2012 Revolving } \\
\text { Door Q1" }\end{array}$ & 48 & $\begin{array}{l}\text { Constructed } \\
\text { Response Manual }\end{array}$ & $\begin{array}{l}\text { Space and } \\
\text { shape }\end{array}$ & Scientific & Employ & 57.67 & 512.3 \\
\hline $\begin{array}{l}\text { "MATH - P2012 Racing } \\
\text { Q2" }\end{array}$ & 16 & $\begin{array}{l}\text { Simple Multiple } \\
\text { Choice }\end{array}$ & $\begin{array}{l}\text { Uncertainty } \\
\text { and data }\end{array}$ & Societal & Interpret & 38.14 & 515.6 \\
\hline $\begin{array}{l}\text { "MATH - P2000 Pop } \\
\text { Pyramids Q4" }\end{array}$ & 64 & $\begin{array}{l}\text { Complex Multiple } \\
\text { Choice }\end{array}$ & $\begin{array}{l}\text { Change and } \\
\text { Relationships }\end{array}$ & Scientific & Interpret & 55.87 & 515.8 \\
\hline $\begin{array}{l}\text { "MATH - P2000 Pipelines } \\
\text { Q1" }\end{array}$ & 64 & $\begin{array}{l}\text { Complex Multiple } \\
\text { Choice }\end{array}$ & $\begin{array}{l}\text { Space and } \\
\text { Shape }\end{array}$ & Occupational & Employ & 51.46 & 521.6 \\
\hline $\begin{array}{l}\text { "MATH - P2003 Cash } \\
\text { Withdrawal Q1" }\end{array}$ & 64 & $\begin{array}{l}\text { Complex Multiple } \\
\text { Choice }\end{array}$ & Quantity & Societal & Formulate & 52.97 & 521.6 \\
\hline $\begin{array}{l}\text { "MATH - P2012 Chocolate } \\
\text { Q5" }\end{array}$ & 16 & $\begin{array}{l}\text { Constructed } \\
\text { Response Expert }\end{array}$ & $\begin{array}{l}\text { Uncertainty } \\
\text { and data }\end{array}$ & Occupational & Interpret & 42.76 & 524.6 \\
\hline $\begin{array}{l}\text { "MATH - P2000 Pop } \\
\text { Pyramids Q2" }\end{array}$ & 64 & $\begin{array}{l}\text { Constructed } \\
\text { Response Expert }\end{array}$ & $\begin{array}{l}\text { Change and } \\
\text { Relationships }\end{array}$ & Scientific & Employ & 61.57 & 529.1 \\
\hline $\begin{array}{l}\text { "MATH - P2012 Arches } \\
\text { Q1" }\end{array}$ & 48 & $\begin{array}{l}\text { Simple Multiple } \\
\text { Choice }\end{array}$ & $\begin{array}{l}\text { Change and } \\
\text { relationships }\end{array}$ & Occupational & Formulate & 50.02 & 531.1 \\
\hline $\begin{array}{l}\text { "MATH - P2012 } \\
\text { Employment Data Q4" }\end{array}$ & 64 & $\begin{array}{l}\text { Simple Multiple } \\
\text { Choice }\end{array}$ & $\begin{array}{l}\text { Uncertainty } \\
\text { and data }\end{array}$ & Societal & Formulate & 51.45 & 532.0 \\
\hline $\begin{array}{l}\text { "MATH - P2012 Flu Test } \\
\text { Q3" }\end{array}$ & 48 & $\begin{array}{l}\text { Constructed } \\
\text { Response Manual }\end{array}$ & $\begin{array}{l}\text { Uncertainty } \\
\text { and data }\end{array}$ & Scientific & Formulate & 51.80 & 536.0 \\
\hline $\begin{array}{l}\text { "MATH - P2012 Sailing } \\
\text { Ships Q3" }\end{array}$ & 48 & $\begin{array}{l}\text { Simple Multiple } \\
\text { Choice }\end{array}$ & $\begin{array}{l}\text { Space and } \\
\text { shape }\end{array}$ & Scientific & Employ & 49.79 & 538.5 \\
\hline $\begin{array}{l}\text { "MATH - P2003 Transport } \\
\text { Q1" }\end{array}$ & 64 & $\begin{array}{l}\text { Complex Multiple } \\
\text { Choice }\end{array}$ & $\begin{array}{l}\text { Uncertainty } \\
\text { and data }\end{array}$ & Personal & Interpret & 50.02 & 538.8 \\
\hline
\end{tabular}

1. Items administered in the 16 countries that opted for the easy booklet (Argentina, Brazil, Bulgaria, Chile, Colombia, Costa Rica, Jordan, Kazakhstan, Mexico, Peru, Romania, Serbia, Tunisia, United Arab Emirates, Uruguay and Viet Nam) are not analysed in this paper.

2. Only full credit

Source: OECD, PISA 2012 Database. 
Table A.1. List of mathematics items PISA 2012 [Part 3/4]

\begin{tabular}{|c|c|c|c|c|c|c|c|}
\hline Unit Name & $\begin{array}{l}\text { No. } \\
\text { countries' }\end{array}$ & Item Format & Content & Context & Process & $\begin{array}{c}\% \\
\text { correct }\end{array}$ & $\begin{array}{l}\text { PISA } \\
\text { scale }^{2}\end{array}$ \\
\hline "MATH - P2003 Chair Lift & 64 & Simple Multiple & Quantity & Societal & Formulate & 46.11 & 539.8 \\
\hline $\begin{array}{l}\text { "MATH - P2003 Chair Lift } \\
\text { Q2" }\end{array}$ & 64 & $\begin{array}{l}\text { Simple Multiple } \\
\text { Choice }\end{array}$ & $\begin{array}{l}\text { Uncertainty } \\
\text { and data }\end{array}$ & Societal & Formulate & 45.82 & 542.9 \\
\hline $\begin{array}{l}\text { "MATH - P2012 Tennis } \\
\text { Balls Q2" }\end{array}$ & 48 & $\begin{array}{l}\text { Constructed } \\
\text { Response Expert }\end{array}$ & Quantity & Occupational & Interpret & 50.05 & 543.8 \\
\hline $\begin{array}{l}\text { "MATH - P2012 Flu Test } \\
\text { Q2" }\end{array}$ & 48 & $\begin{array}{l}\text { Constructed } \\
\text { Response Expert }\end{array}$ & $\begin{array}{l}\text { Uncertainty } \\
\text { and data }\end{array}$ & Scientific & Interpret & 49.76 & 546.3 \\
\hline $\begin{array}{l}\text { "MATH - P2003 Diving } \\
\text { Q1" }\end{array}$ & 64 & $\begin{array}{l}\text { Constructed } \\
\text { Response Manual }\end{array}$ & Quantity & Societal & Employ & 51.08 & 546.6 \\
\hline $\begin{array}{l}\text { "MATH - P2003 Diving } \\
\text { Q2" }\end{array}$ & 64 & $\begin{array}{l}\text { Simple Multiple } \\
\text { Choice }\end{array}$ & $\begin{array}{l}\text { Uncertainty } \\
\text { and data }\end{array}$ & Societal & Interpret & 45.71 & 548.4 \\
\hline $\begin{array}{l}\text { "MATH - P2003 Stop the } \\
\text { Car Q1" }\end{array}$ & 64 & $\begin{array}{l}\text { Simple Multiple } \\
\text { Choice }\end{array}$ & $\begin{array}{l}\text { Change and } \\
\text { Relationships }\end{array}$ & Scientific & Interpret & 47.67 & 549.4 \\
\hline $\begin{array}{l}\text { "MATH - P2012 Wooden } \\
\text { Train Set Q1" }\end{array}$ & 16 & $\begin{array}{l}\text { Constructed } \\
\text { Response Manual }\end{array}$ & $\begin{array}{l}\text { Space and } \\
\text { shape }\end{array}$ & Personal & Employ & 30.21 & 552.6 \\
\hline $\begin{array}{l}\text { "MATH - P2012 Which } \\
\text { Car Q3" }\end{array}$ & 16 & $\begin{array}{l}\text { Constructed } \\
\text { Response Manual }\end{array}$ & Quantity & Personal & Employ & 25.56 & 552.6 \\
\hline $\begin{array}{l}\text { "MATH - P2003 Number } \\
\text { Check Q1" }\end{array}$ & 64 & $\begin{array}{l}\text { Complex Multiple } \\
\text { Choice }\end{array}$ & Quantity & Scientific & Employ & 45.07 & 561.1 \\
\hline $\begin{array}{l}\text { "MATH - P2012 } \\
\text { Revolving Door Q3" }\end{array}$ & 48 & $\begin{array}{l}\text { Simple Multiple } \\
\text { Choice }\end{array}$ & Quantity & Scientific & Formulate & 46.42 & 561.3 \\
\hline $\begin{array}{l}\text { "MATH - P2012 Zs Fan } \\
\text { Merchandise Q2" }\end{array}$ & 48 & $\begin{array}{l}\text { Constructed } \\
\text { Response Manual }\end{array}$ & Quantity & Personal & Formulate & 44.72 & 562.4 \\
\hline $\begin{array}{l}\text { "MATH - P2012 Bike } \\
\text { Rental Q4" }\end{array}$ & 64 & $\begin{array}{l}\text { Complex Multiple } \\
\text { Choice }\end{array}$ & $\begin{array}{l}\text { Change and } \\
\text { relationships }\end{array}$ & Personal & Employ & 40.44 & 568.7 \\
\hline $\begin{array}{l}\text { "MATH - P2012 Crazy } \\
\text { Ants Q2" }\end{array}$ & 64 & $\begin{array}{l}\text { Constructed } \\
\text { Response Expert }\end{array}$ & Quantity & Scientific & Employ & 42.12 & 571.4 \\
\hline $\begin{array}{l}\text { "MATH - P2012 Carbon } \\
\text { Tax Q1" }\end{array}$ & 64 & $\begin{array}{l}\text { Simple Multiple } \\
\text { Choice }\end{array}$ & $\begin{array}{l}\text { Uncertainty } \\
\text { and data }\end{array}$ & Societal & Employ & 40.18 & 575.6 \\
\hline $\begin{array}{l}\text { "MATH - P2012 } \\
\text { Apartment Purchase } \\
\text { Q1" }\end{array}$ & 48 & $\begin{array}{l}\text { Constructed } \\
\text { Response Expert }\end{array}$ & $\begin{array}{l}\text { Space and } \\
\text { shape }\end{array}$ & Personal & Formulate & 44.64 & 576.2 \\
\hline $\begin{array}{l}\text { "MATH - P2000 Bricks } \\
\text { Q1" }\end{array}$ & 64 & $\begin{array}{l}\text { Constructed } \\
\text { Response Auto- } \\
\text { coded }\end{array}$ & $\begin{array}{l}\text { Space and } \\
\text { Shape }\end{array}$ & Occupational & Formulate & 42.38 & 579.0 \\
\hline $\begin{array}{l}\text { "MATH - P2000 } \\
\text { Containers Q1" }\end{array}$ & & $\begin{array}{l}\text { Complex Multiple } \\
\text { Choice }\end{array}$ & $\begin{array}{l}\text { Change and } \\
\text { Relationships }\end{array}$ & Scientific & Formulate & 42.44 & 580.0 \\
\hline $\begin{array}{l}\text { "MATH - P2012 Roof } \\
\text { Truss Design Q3" }\end{array}$ & 64 & $\begin{array}{l}\text { Constructed } \\
\text { Response Expert }\end{array}$ & $\begin{array}{l}\text { Space and } \\
\text { shape }\end{array}$ & Occupational & Formulate & 32.55 & 584.7 \\
\hline $\begin{array}{l}\text { "MATH - P2003 Lotteries } \\
\text { Q1" }\end{array}$ & 64 & $\begin{array}{l}\text { Complex Multiple } \\
\text { Choice }\end{array}$ & $\begin{array}{l}\text { Uncertainty } \\
\text { and data }\end{array}$ & Societal & Interpret & 39.39 & 590.9 \\
\hline $\begin{array}{l}\text { "MATH - P2012 London } \\
\text { Eye Q1" }\end{array}$ & 16 & $\begin{array}{l}\text { Constructed } \\
\text { Response Manual }\end{array}$ & $\begin{array}{l}\text { Space and } \\
\text { shape }\end{array}$ & Societal & Employ & 15.96 & 592.3 \\
\hline $\begin{array}{l}\text { "MATH - P2003 Braille } \\
\text { Q2" }\end{array}$ & 64 & $\begin{array}{l}\text { Constructed } \\
\text { Response Manual }\end{array}$ & Quantity & Societal & Interpret & 38.26 & 592.7 \\
\hline $\begin{array}{l}\text { "MATH - P2012 Roof } \\
\text { Truss Design Q2" }\end{array}$ & 64 & $\begin{array}{l}\text { Complex Multiple } \\
\text { Choice }\end{array}$ & $\begin{array}{l}\text { Space and } \\
\text { shape }\end{array}$ & Occupational & Employ & 31.74 & 594.2 \\
\hline $\begin{array}{l}\text { "MATH - P2012 } \\
\text { Migration Q2" }\end{array}$ & 64 & $\begin{array}{l}\text { Constructed } \\
\text { Response Expert }\end{array}$ & $\begin{array}{l}\text { Uncertainty } \\
\text { and data }\end{array}$ & Societal & Interpret & 34.21 & 597.7 \\
\hline $\begin{array}{l}\text { "MATH - P2012 } \\
\text { Speeding Fines Q3" }\end{array}$ & 64 & $\begin{array}{l}\text { Constructed } \\
\text { Response Expert }\end{array}$ & $\begin{array}{l}\text { Change and } \\
\text { relationships }\end{array}$ & Societal & Interpret & 35.70 & 605.5 \\
\hline $\begin{array}{l}\text { "MATH - P2012 } \\
\text { Employment Data } \\
\text { Q2" }\end{array}$ & 64 & $\begin{array}{l}\text { Constructed } \\
\text { Response Manual }\end{array}$ & $\begin{array}{l}\text { Uncertainty } \\
\text { and data }\end{array}$ & Societal & Employ & 30.73 & 609.6 \\
\hline $\begin{array}{l}\text { "MATH - P2012 Climbing } \\
\text { Mount Fuji Q3" }\end{array}$ & 16 & $\begin{array}{l}\text { Constructed } \\
\text { Response Manual }\end{array}$ & Quantity & Societal & Employ & 11.58 & 610.0 \\
\hline $\begin{array}{l}\text { "MATH - P2012 Medicine } \\
\text { Doses Q2" }\end{array}$ & 48 & $\begin{array}{l}\text { Constructed } \\
\text { Response Expert }\end{array}$ & $\begin{array}{l}\text { Change and } \\
\text { relationships }\end{array}$ & Scientific & Employ & 33.56 & 614.9 \\
\hline
\end{tabular}

1. Items administered in the 16 countries that opted for the easy booklet (Argentina, Brazil, Bulgaria, Chile, Colombia, Costa Rica, Jordan, Kazakhstan, Mexico, Peru, Romania, Serbia, Tunisia, United Arab Emirates, Uruguay and Viet Nam) are not analysed in this paper.

2. Only full credit

Source: OECD, PISA 2012 Database. 
Table A.1. List of mathematics items PISA 2012 [Part 4/4]

\begin{tabular}{|c|c|c|c|c|c|c|c|}
\hline Unit Name & $\begin{array}{c}\text { No. } \\
\text { countries }\end{array}$ & Item Format & Content & Context & Process & $\begin{array}{c}\% \\
\text { correct }\end{array}$ & $\begin{array}{l}\text { PISA } \\
\text { scale }^{2}\end{array}$ \\
\hline "MATH - P2003 Carbon & 64 & Constructed & Quantity & Scientific & Employ & 28.02 & 621.2 \\
\hline "MATH - P2003 Carbon & 64 & Constructed & $\begin{array}{l}\text { Change and } \\
\text { Relationshins }\end{array}$ & Scientific & Employ & 28.45 & 622.5 \\
\hline $\begin{array}{l}\text { "MATH - P2012 Drip Rate } \\
\text { Q3" }\end{array}$ & 48 & Constructed & $\begin{array}{l}\text { Change and } \\
\text { relationships }\end{array}$ & Occupational & Employ & 25.70 & 631.7 \\
\hline $\begin{array}{l}\text { "MATH - P2012 Climbing } \\
\text { Mount Fuji Q2" }\end{array}$ & 16 & $\begin{array}{l}\text { Constructed } \\
\text { Response Expert }\end{array}$ & $\begin{array}{l}\text { Change and } \\
\text { relationships }\end{array}$ & Societal & Formulate & 14.25 & 641.6 \\
\hline $\begin{array}{l}\text { "MATH - P2003 Labels } \\
\text { Q1" }\end{array}$ & 64 & $\begin{array}{l}\text { Constructed } \\
\text { Response Auto- }\end{array}$ & $\begin{array}{l}\text { Uncertainty } \\
\text { and data }\end{array}$ & Occupational & Formulate & 29.18 & 643.6 \\
\hline $\begin{array}{l}\text { "MATH - P2012 Medicine } \\
\text { Doses Q4" }\end{array}$ & 48 & $\begin{array}{l}\text { Constructed } \\
\text { Response Expert }\end{array}$ & $\begin{array}{l}\text { Change and } \\
\text { relationships }\end{array}$ & Scientific & Employ & 26.35 & 644.1 \\
\hline $\begin{array}{l}\text { "MATH - P2003 Running } \\
\text { Tracks Q1" }\end{array}$ & 64 & $\begin{array}{l}\text { Constructed } \\
\text { Response Expert }\end{array}$ & $\begin{array}{l}\text { Space and } \\
\text { Shape }\end{array}$ & Societal & Employ & 25.62 & 644.5 \\
\hline $\begin{array}{l}\text { "MATH - P2003 The } \\
\text { Fence Q1" }\end{array}$ & 64 & $\begin{array}{l}\text { Constructed } \\
\text { Response Auto- } \\
\text { coded }\end{array}$ & $\begin{array}{l}\text { Space and } \\
\text { Shape }\end{array}$ & Societal & Formulate & 23.66 & 651.6 \\
\hline $\begin{array}{l}\text { "MATH - P2012 Drip Rate } \\
\text { Q1" }\end{array}$ & 48 & $\begin{array}{l}\text { Constructed } \\
\text { Response Expert }\end{array}$ & $\begin{array}{l}\text { Change and } \\
\text { relationships }\end{array}$ & Occupational & Employ & 22.23 & 657.7 \\
\hline $\begin{array}{l}\text { "MATH - P2012 Spacers } \\
\text { Q2" }\end{array}$ & 64 & $\begin{array}{l}\text { Constructed } \\
\text { Response Manual }\end{array}$ & $\begin{array}{l}\text { Space and } \\
\text { shape }\end{array}$ & Occupational & Formulate & 18.25 & 672.7 \\
\hline $\begin{array}{l}\text { "MATH - P2012 Wooden } \\
\text { Train Set Q3" }\end{array}$ & 16 & $\begin{array}{l}\text { Complex Multiple } \\
\text { Choice }\end{array}$ & $\begin{array}{l}\text { Space and } \\
\text { shape }\end{array}$ & Personal & Formulate & 7.03 & 675.2 \\
\hline $\begin{array}{l}\text { "MATH - P2012 Flu Test } \\
\text { Q4" }\end{array}$ & 48 & $\begin{array}{l}\text { Constructed } \\
\text { Response Expert }\end{array}$ & $\begin{array}{l}\text { Uncertainty } \\
\text { and data }\end{array}$ & Scientific & Formulate & 18.21 & 676.9 \\
\hline $\begin{array}{l}\text { "MATH - P2012 Part-Time } \\
\text { Work Q3" }\end{array}$ & 16 & $\begin{array}{l}\text { Constructed } \\
\text { Response Expert }\end{array}$ & Quantity & Occupational & Employ & 8.84 & 683.0 \\
\hline $\begin{array}{l}\text { "MATH - P2012 Garage } \\
\text { Q2" }\end{array}$ & 16 & $\begin{array}{l}\text { Constructed } \\
\text { Response Expert }\end{array}$ & $\begin{array}{l}\text { Space and } \\
\text { shape }\end{array}$ & Occupational & Employ & 2.66 & 687.3 \\
\hline $\begin{array}{l}\text { "MATH - P2003 Running } \\
\text { Tracks Q2" }\end{array}$ & 64 & $\begin{array}{l}\text { Constructed } \\
\text { Response Expert }\end{array}$ & $\begin{array}{l}\text { Space and } \\
\text { Shape }\end{array}$ & Societal & Formulate & 16.89 & 695.8 \\
\hline $\begin{array}{l}\text { "MATH - P2000 Pop } \\
\text { Pyramids Q3" }\end{array}$ & 64 & $\begin{array}{l}\text { Constructed } \\
\text { Response Expert }\end{array}$ & $\begin{array}{l}\text { Change and } \\
\text { Relationships }\end{array}$ & Scientific & Employ & 18.68 & 696.6 \\
\hline $\begin{array}{l}\text { "MATH - P2012 Helen } \\
\text { The Cyclist Q3" }\end{array}$ & 16 & $\begin{array}{l}\text { Constructed } \\
\text { Response Manual }\end{array}$ & $\begin{array}{l}\text { Change and } \\
\text { relationships }\end{array}$ & Personal & Employ & 5.75 & 696.6 \\
\hline $\begin{array}{l}\text { "MATH - P2003 The Third } \\
\text { Side Q1" }\end{array}$ & 64 & $\begin{array}{l}\text { Constructed } \\
\text { Response Expert }\end{array}$ & $\begin{array}{l}\text { Space and } \\
\text { Shape }\end{array}$ & Scientific & Employ & 12.20 & 698.6 \\
\hline $\begin{array}{l}\text { "MATH - P2012 } \\
\text { Wheelchair Basketball } \\
\text { Q2" }\end{array}$ & 64 & $\begin{array}{l}\text { Constructed } \\
\text { Response Expert }\end{array}$ & $\begin{array}{l}\text { Space and } \\
\text { shape }\end{array}$ & Personal & Formulate & 14.85 & 699.9 \\
\hline $\begin{array}{l}\text { "MATH - P2012 Migration } \\
\text { Q3" }\end{array}$ & 64 & $\begin{array}{l}\text { Constructed } \\
\text { Response Expert }\end{array}$ & $\begin{array}{l}\text { Uncertainty } \\
\text { and data }\end{array}$ & Societal & Employ & 11.98 & 701.3 \\
\hline $\begin{array}{l}\text { "MATH - P2012 Sailing } \\
\text { Ships Q4" }\end{array}$ & 48 & $\begin{array}{l}\text { Constructed } \\
\text { Response Expert }\end{array}$ & $\begin{array}{l}\text { Change and } \\
\text { relationships }\end{array}$ & Scientific & Formulate & 15.28 & 702.1 \\
\hline $\begin{array}{l}\text { "MATH - P2012 } \\
\text { Chocolate Q2" }\end{array}$ & 16 & $\begin{array}{l}\text { Constructed } \\
\text { Response Expert }\end{array}$ & $\begin{array}{l}\text { Change and } \\
\text { relationships }\end{array}$ & Occupational & Employ & 4.21 & 717.1 \\
\hline $\begin{array}{l}\text { "MATH - P2012 Spacers } \\
\text { Q3" }\end{array}$ & 64 & $\begin{array}{l}\text { Constructed } \\
\text { Response Expert }\end{array}$ & $\begin{array}{l}\text { Change and } \\
\text { relationships }\end{array}$ & Occupational & Formulate & 8.11 & 751.1 \\
\hline $\begin{array}{l}\text { "MATH - P2012 An } \\
\text { Advertising Column } \\
\text { Q1" }\end{array}$ & 64 & $\begin{array}{l}\text { Constructed } \\
\text { Response Manual }\end{array}$ & $\begin{array}{l}\text { Space and } \\
\text { shape }\end{array}$ & Personal & Formulate & 8.78 & 760.1 \\
\hline $\begin{array}{l}\text { "MATH - P2003 The } \\
\text { Thermometer Cricket } \\
\text { Q2" }\end{array}$ & 64 & $\begin{array}{l}\text { Constructed } \\
\text { Response Expert }\end{array}$ & $\begin{array}{l}\text { Change and } \\
\text { Relationships }\end{array}$ & Scientific & Formulate & 6.82 & 777.6 \\
\hline $\begin{array}{l}\text { "MATH - P2012 Arches } \\
\text { Q2" }\end{array}$ & 48 & $\begin{array}{l}\text { Constructed } \\
\text { Response Expert }\end{array}$ & $\begin{array}{l}\text { Space and } \\
\text { shape }\end{array}$ & Occupational & Formulate & 5.29 & 785.3 \\
\hline $\begin{array}{l}\text { "MATH - P2012 Revolving } \\
\text { Door Q2" }\end{array}$ & 48 & $\begin{array}{l}\text { Constructed } \\
\text { Response Expert }\end{array}$ & $\begin{array}{l}\text { Space and } \\
\text { shape }\end{array}$ & Scientific & Formulate & 3.47 & 840.3 \\
\hline
\end{tabular}

1. Items administered in the 16 countries that opted for the easy booklet (Argentina, Brazil, Bulgaria, Chile, Colombia, Costa Rica, Jordan, Kazakhstan, Mexico, Peru, Romania, Serbia, Tunisia, United Arab Emirates, Uruguay and Viet Nam) are not analysed in this paper.

2. Only full credit

Source: OECD, PISA 2012 Database. 


\section{ANNEX B. EXPLAINING CROSS-SUBJECT ANALYSIS WITH STUDENT FIXED-EFFECTS}

The main motivation for using the fixed-effect within-student estimator is the ability to control for timeinvariant heterogeneity at the student, school and teaching-staff levels that cannot be directly or easily observed or measured through questionnaires. This includes the unobserved "ability" of students, which might be potentially correlated with academic performance, family-related determinants of performance not asked in the PISA 2012 questionnaires, such as the number of siblings or the parenting style, and various school-level factors common to all the subjects assessed.

The relationship between student performance and teaching practices can be represented by the following regression model

$$
y_{i s c}=\alpha+\beta X_{i}+\gamma W_{s}+\delta Q_{s c}+\eta_{i}+\mu_{s}+\varepsilon_{i s c}
$$

where $y_{i s c}$ is the performance that student $i$ enrolled in school $s$ attained in subject $c$, the matrices $X_{i}$ and $W_{s}$ include family- and school-related determinants of student performance in the TALIS-PISA Link, respectively, $Q_{s c}$ describes the prevalence of the different teaching practices and other characteristics of the staff in school $s$ and subject $c ; \eta_{i}$ and $\mu_{s}$ include student- and family-related $(i)$ and school-level ( $\left.s\right)$ unobserved determinants of student performance, and $\varepsilon_{i s c}$ is a "classical" error term that satisfies the assumptions underlying the fixed-effects estimator (Arellano, 2003).

The fixed-effect within-student estimator identifies the effect of teaching practices on student performance (i.e. the parameters in vector $\delta$ ) by exploiting the differences in students' performance across the subjects assessed in PISA, and the differences in the reported use of teaching practices between teachers from different subjects. Let $Q_{s c}$ be decomposed into $Q_{1, s c}$ and $Q_{2 s c}$, with the first component indicating the differences in the teaching practices reported by teachers of subject $c$ in school $s$ compared to those reported by other teachers from the same school, and $Q_{2 s c}$ describing other relevant differences (for student outcomes) between teachers of subject $c$ in school $s$ and other teachers from the same school. The effect of interest is then estimated by Ordinary Least Squares using the following regression model:

$$
\left(y_{i s c}-\bar{y}_{i}\right)=\delta_{1}\left(Q_{1 s c}-\bar{Q}_{1}\right)+\delta_{2}\left(Q_{2 s c}-\bar{Q}_{2}\right)+\left(\varepsilon_{i s c}-\bar{\varepsilon}_{i}\right)
$$

where the average operates across the subjects being evaluated in PISA. The unobserved (to the analyst) student, family and school determinants of student performance cannot affect the estimated effects. 